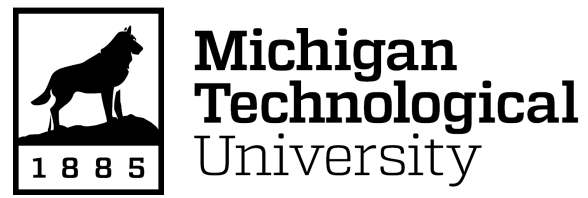

Michigan Technological University Digital Commons @ Michigan Tech

Dissertations, Master's Theses and Master's Reports

2016

\title{
AN EXPERIMENTAL INVESTIGATION OF LOW TEMPERATURE COMBUSTION REGIMES IN A LIGHT DUTY ENGINE
}

Kaushik Kannan

Michigan Technological University, kkannan@mtu.edu

Copyright 2016 Kaushik Kannan

\section{Recommended Citation}

Kannan, Kaushik, "AN EXPERIMENTAL INVESTIGATION OF LOW TEMPERATURE COMBUSTION REGIMES IN A LIGHT DUTY ENGINE", Open Access Master's Thesis, Michigan Technological University, 2016.

https://doi.org/10.37099/mtu.dc.etdr/176

Follow this and additional works at: https://digitalcommons.mtu.edu/etdr

Part of the Other Mechanical Engineering Commons 


\title{
AN EXPERIMENTAL INVESTIGATION OF LOW TEMPERATURE COMBUSTION REGIMES IN A LIGHT DUTY ENGINE
}

\author{
By \\ Kaushik Kannan
}

\begin{abstract}
A THESIS
Submitted in partial fulfillment of the requirements for the degree of MASTER OF SCIENCE

In Mechanical Engineering
\end{abstract}

MICHIGAN TECHNOLOGICAL UNIVERSITY

2016

(C) 2016 Kaushik Kannan 

This thesis has been approved in partial fulfillment of the requirements for the Degree of MASTER OF SCIENCE in Mechanical Engineering.

Department of Mechanical Engineering- Engineering Mechanics

\author{
Thesis Advisor: Dr. Mahdi Shahbakhti \\ Committee Member: Dr. Youngchul Ra \\ Committee Member: Dr. Scott Miers \\ Department Chair: Dr. William W. Predebon
}





\section{Dedication}

To my Parents, Prathibha, Mentors, Friends and Baby Elephant

Ambition is a dream with a V8 Engine. - Elvis Presley. 



\section{Contents}

List of Figures $\ldots \ldots \ldots \ldots \ldots \ldots \ldots \ldots \ldots \ldots \ldots \ldots$ xiii

List of Tables .................... xxiii

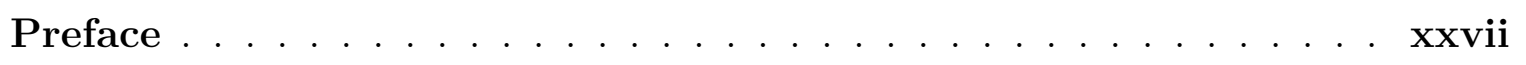

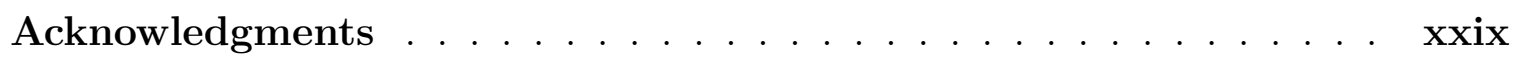

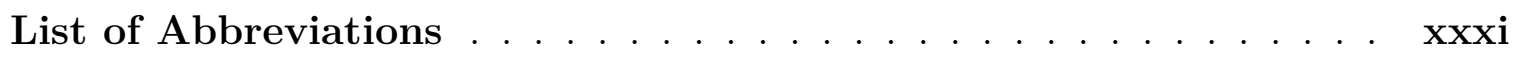

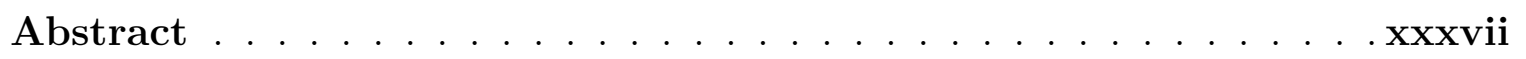

1 Introduction .......................... 1

1.1 The evolution of Low temperature Combustion (LTC) engines ... 3

1.2 Principle of Operation of LTC engines $\ldots \ldots \ldots$

1.3 Research Goals and Scope of Research . . . . . . . . . . 11

1.4 Organization of Thesis $\ldots \ldots \ldots \ldots \ldots \ldots \ldots$

2 Engine Instrumentation and Experimentation $\ldots \ldots \ldots$

2.1 Engine Setup and Specifications . . . . . . . . . . 15 
2.2 Port Fuel Injectors (PFI) Instrumentation, Calibration and Assembly 17

2.3 Supercharger control using dSpace . . . . . . . . . . . 25

2.4 Engine Analysis Parameters . . . . . . . . . . . . . . . 30

2.4.1 Engine Geometry ............... 30

2.4.2 Net Work and Mean effective pressure . . . . . . . . . 34

2.4.3 Polytropic Index . . . . . . . . . . . . . . . . . 36

2.4.4 Combustion Stability . . . . . . . . . . . 36

2.4.5 Heat Transfer Coefficient Correlation . . . . . . . . . . 38

2.4.6 Combustion Efficiency ............... 40

2.5 Filter Design for Pressure trace . . . . . . . . . . . . . 41

2.6 Uncertainty in Analysis . . . . . . . . . . . . . . . . 43

2.7 BMEP Parametrization . . . . . . . . . . . . . . . 48

2.8 Accounting for Supercharger losses . . . . . . . . . . . 49

2.9 SI Map for Baseline Comparison . . . . . . . . . . . . . . 52

3 Homogeneous Charge Compression Ignition (HCCI) . . . . . . 53

3.1 Parametrization of BMEP using Flynn-Chen Model for HCCI combustion regime ...................... 54

3.2 Operating Range . . . . . . . . . . . . . . . . . . . 56

3.3 Maps for ISFC, BSFC, Indicated Thermal Efficiency and Exhaust Gas Temperature ........................ 59

3.4 Optimized HCCI maps . . . . . . . . . . . . . . 68 
3.5 Effects of RON on HCCI combustion . . . . . . . . . . 75

3.6 Effects of Intake Air temperature on HCCI combustion . . . . . . 78

3.7 Effect of boost pressure on HCCI combustion . . . . . . . . . 82

4 Reactivity Controlled Compression Ignition (RCCI) . . . . . . 85

4.1 Parametrization of BMEP using Flynn-Chen Model for RCCI combustion regime ......................... 86

4.2 Operating Range . . . . . . . . . . . . . . . . 88

4.3 Maps for ISFC, BSFC, Indicated Thermal efficiency and Exhaust gas temperature ............................. 91

4.4 Optimized RCCI maps . . . . . . . . . . . . . . . 96

4.5 RCCI optimized maps with supercharger losses accounted . . . . . . 103

4.6 RCCI optimized maps with COV of IMEP less than 5 percent . . . 106

4.7 Effects of PR on RCCI combustion . . . . . . . . . . 108

4.8 Effects of Intake Air Temperature on RCCI Combustion . . . . . . 114

4.9 Effect of boost pressure on RCCI combustion . . . . . . . 118

5 Partially Premixed Compression Ignition (PPCI) . . . . . . 123

5.1 Parametrization of BMEP using Flynn-Chen Model for PPCI combustion regime ........................ 124

5.2 Operating Range Maps . . . . . . . . . . . . . . . . 126

5.3 Maps for ISFC, BSFC, Indicated Thermal Efficiency and Exhaust Gas Temperature........................ 128 
5.4 Optimized PPCI maps ................... 133

5.5 Effect of Intake Air Temperature on PPCI Combustion . . . . . . . 138

5.6 Effects of Boost pressure on PPCI combustion . . . . . . . . . . 144

5.7 Effect of SOI on PPCI combustion . . . . . . . . . 151

6 Summary and Conclusions . . . . . . . . . . . . . . 157

6.1 Conclusions ........................ 158

6.1.1 Operating range and performance maps . . . . . . . 158

6.1.2 Parametric Study on Combustion and Performance characteristics . . . . . . . . . . . . . . . . 162

6.2 Major Contribution towards the thesis . . . . . . . . . . . 164

6.3 Future Work . . . . . . . . . . . . . . . . . 166

References....................... 169

A Table of Data points for Experiments . . . . . . . . . 181

A.1 PPCI . . . . . . . . . . . . . . . . . . . . . 181

A.2 HCCI . . . . . . . . . . . . . . . . . . 192

A.3 RCCI . . . . . . . . . . . . . . . . . . 197

B MSc Publications ...................... 203

B.1 Conference Papers . . . . . . . . . . . . . . . . 203

B.2 Journal Paper . . . . . . . . . . . . . . . . 204 
C Program and Data File Summary ............. 205

D Letters of Permission . . . . . . . . . . . . . . 217 



\section{List of Figures}

1.1 Contour plots of soot, $N O_{x}, \mathrm{HC}$ and $\mathrm{CO}$ depicting the operating regions of several combustion regimes [1] (Letter of permission D.1) .

1.2 Comparison of diesel, Gasoline and HCCI engine [2] (Permission letter

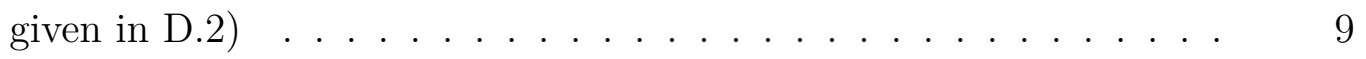

1.3 Thesis Organization . . . . . . . . . . . . . . . . 13

2.1 Schematic of the LTC engine setup $\ldots \ldots \ldots \ldots$

2.2 Experimental LTC Engine Setup $\ldots \ldots \ldots \ldots \ldots$

2.3 Port fuel injector assembly . . . . . . . . . . . . . . . 19

2.4 Triggered sub-system for PFI control $\ldots \ldots \ldots$

2.5 Monitoring Panel on dSPACE Control Desk for PFI Control . . . 20

2.6 Verification of dSPACE model for calculating injected fuel mass from using DI injectors .................... 21

2.7 Calibration and Verification of the PFI injectors for Iso-Octane fuel 23

2.8 Calibration and Verification of the PFI injectors for n-Heptane fuel 24

2.9 Supercharger VFD unit $\ldots \ldots \ldots \ldots \ldots \ldots \ldots$ 
2.10 Supercharger Frequency maps for IVO of a) -24.5 CAD bTDC and b)

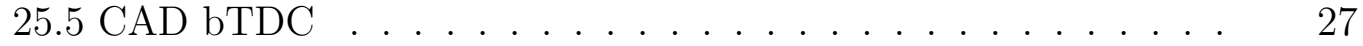

2.11 Simulink Model for Supercharger Control using dSpace . . . . . 28

2.12 Supercharger User Control panel on dSpace control desk . . . . . 29

2.13 Supercharger power consumed if assumed to be mounted on the engine 51

2.14 Supercharger performance map for Eaton M62 supercharger [3] . . 51

2.15 ISFC map for Spark Ignition (SI) mode . . . . . . . . . . . . . 52

3.1 Experimental FMEP vs Parameterized FMEP . . . . . . . . 55

3.2 HCCI IMEP and speed range . . . . . . . . . . . . . 58

3.3 HCCI IMEP and speed range for $40{ }^{\circ} \mathrm{C}$ intake air temperature and 120 $\mathrm{kPa}$ intake pressure ................. 59

3.4 HCCI ISFC map for $40{ }^{\circ} \mathrm{C}$ intake air temperature at naturally aspirated conditions ......................... 60

3.5 HCCI ISFC map for $40^{\circ} \mathrm{C}$ intake air temperature and $120 \mathrm{kPa}$ intake pressure ........................... 61

3.6 HCCI BSFC map for $40{ }^{\circ} \mathrm{C}$ intake air temperature at naturally aspirated conditions ................... 63

3.7 $\mathrm{HCCI} \mathrm{BSFC}$ map for $40{ }^{\circ} \mathrm{C}$ intake air temperature at $120 \mathrm{kPa}$ intake pressure .............................. 64

3.8 HCCI indicated thermal efficiency map for $40{ }^{\circ} \mathrm{C}$ intake air temperature at naturally aspirated conditions . . . . . . . . . . . 65 
3.9 HCCI Indicated thermal efficiency map for $40{ }^{\circ} \mathrm{C}$ intake air temperature and $120 \mathrm{kPa}$ intake pressure . . . . . . . . . . 66

$3.10 \mathrm{HCCI}$ exhaust gas temperature map for $40{ }^{\circ} \mathrm{C}$ intake air temperature and Naturally aspirated ................. 67

$3.11 \mathrm{HCCI}$ exhaust gas temperature map for $40{ }^{\circ} \mathrm{C}$ intake air temperature and $120 \mathrm{kPa}$ Boost Pressure . . . . . . . . . . . . . 68

3.12 HCCI ISFC map for all intake air temperatures and RONs at naturally aspirated conditions . . . . . . . . . . . . . . . . 69

3.13 HCCI ISFC map for all intake air temperatures and RONs and 120 $\mathrm{kPa}$ intake pressure . . . . . . . . . . . . . . . 70

3.14 HCCI BSFC map for all intake air temperatures and RONs at naturally aspirated conditions ................... 71

3.15 HCCI BSFC map for all intake air temperatures and RONs and 120 $\mathrm{kPa}$ intake pressure .................... 71

3.16 HCCI indicated thermal efficiency map for all intake air temperatures and RONs at naturally aspirated conditions . . . . . . . . . 772

3.17 HCCI indicated thermal efficiency map for all intake air temperatures and RONs and $120 \mathrm{kPa}$ intake pressure . . . . . . . . . . 73

3.18 HCCI exhaust temperature map for all intake air temperatures and RONs at naturally aspirated conditions . . . . . . . . . . 74 
3.19 HCCI exhaust temperature map for all intake air temperatures and RONs and $120 \mathrm{kPa}$ intake pressure .............. 74

3.20 a) Pressure and heat release rates for RON 0, 20 and 40 at $1000 \mathrm{rpm}$ and intake temperature of $100{ }^{\circ} \mathrm{C}$ and b) Combustion phasing parameters for HCCI combustion regime . . . . . . . . . . . . . . . [77

3.21 Effects of the RON on a) IMEP, b) Indicated thermal efficiency and c) Combustion efficiency for HCCI combustion regime . . . . . . . 778

3.22 Effects of the intake air temperature on 1. IMEP, 2. Indicated thermal efficiency and 3. Combustion efficiency for HCCI combustion regime

3.23 a) Pressure and heat release rates for intake air temperatures 40, 60, 80 and $100{ }^{\circ} \mathrm{C}$ at $1000 \mathrm{rpm}$ and RON of 20 and b) Effects of the intake air temperature on combustion characteristics (CA10 CA50, CA90 and Burn Duration) for HCCI combustion regime . . . . . . . . 81

3.24 Pressure and heat release rates for intake pressures $100 \mathrm{kPa}, 120 \mathrm{kPa}$ and $140 \mathrm{kPa}$ at $1000 \mathrm{rpm}$ and $\mathrm{RON} 40 \ldots \ldots$

3.25 Effects of intake pressure on combustion characteristics (CA10 CA50, CA90 and Burn Duration) for HCCI combustion regime . . . . . 84

3.26 Effects of the boost pressure on (a) IMEP, (b) Indicated thermal efficiency and (c) Combustion efficiency for HCCI combustion regime . 84

4.1 Experimental FMEP vs Parameterized FMEP . . . . . . . . . . 87 
4.2 RCCI IMEP and speed range for $40{ }^{\circ} \mathrm{C}$ intake air temperature and boost pressure of $140 \mathrm{kPa} \ldots \ldots$. . . . . . . . . . . 89

4.3 RCCI IMEP and speed range for $60{ }^{\circ} \mathrm{C}$ intake air temperature and boost pressure of $140 \mathrm{kPa} \ldots \ldots$. . . . . . . . . . . 90

4.4 RCCI ISFC map for three PRs at $40{ }^{\circ} \mathrm{C}$ intake air temperature and intake pressure of $140 \mathrm{kPa} \ldots \ldots \ldots \ldots$

4.5 RCCI BSFC map for three PRs at $40{ }^{\circ} \mathrm{C}$ intake air temperature and $140 \mathrm{kPa}$ intake pressure . . . . . . . . . . . . . 93

4.6 RCCI Indicated thermal efficiency map for three PRs at $40{ }^{\circ} \mathrm{C}$ intake air temperature and $140 \mathrm{kPa}$ intake pressure . . . . . . . . 94

4.7 RCCI Exhaust gas temperature map for three PRs at $40{ }^{\circ} \mathrm{C}$ intake air temperature and $140 \mathrm{kPa}$ boost pressure . . . . . . . . . 95

4.8 RCCI ISFC optimized map for all intake air temperatures and PRs for naturally aspirated conditions . . . . . . . . . . . . 97

4.9 RCCI ISFC optimized map for all intake air temperatures and PRs at $140 \mathrm{kPa}$ boost pressure . . . . . . . . . . . . . . . . . 98

4.10 RCCI BSFC optimized map for all intake air temperatures and PRs at naturally aspirated conditions . . . . . . . . . . . . .

4.11 RCCI BSFC optimized map for all intake air temperatures and PRs at $140 \mathrm{kPa}$ intake pressure . . . . . . . . . . . . . 
4.12 RCCI indicated thermal efficiency optimized map for all intake air temperatures and PRs at naturally aspirated conditions . . . . . . 101

4.13 RCCI indicated thermal efficiency optimized map for all intake air temperatures and PRs at $140 \mathrm{kPa}$ intake pressure . . . . . . . . 101

4.14 RCCI exhaust temperature optimized map for all intake air temperatures and PRs at naturally aspirated conditions . . . . . . . 102

4.15 HCCI exhaust temperature optimized map for all intake air temperatures and PRs at $140 \mathrm{kPa}$ intake pressure . . . . . . . . . . 103

4.16 Optimized ISFC map for RCCI combustion regime with supercharger losses accounted for . . . . . . . . . . . . . . 105

4.17 Optimized $\eta_{t h, i n d}$ map for RCCI combustion regime with supercharger losses accounted for . . . . . . . . . . . . . . 105

4.18 ISFC optimized map for RCCI combustion regime for COV of IMEP less than $5 \%$ at naturally aspirated conditions . . . . . . . . 106

4.19 Indicated thermal efficiency optimized map for RCCI combustion regime for COV of IMEP less than 5\% at naturally aspirated conditions .......................... 107

4.20 ISFC optimized map for RCCI combustion regime for COV of IMEP less than $5 \%$ and boosted conditions . . . . . . . . . . 107

4.21 Indicated thermal efficiency optimized map for RCCI combustion regime for COV of IMEP less than 5\% and boosted conditions . . . 108 
4.22 Pressure and heat release rates for PR 20, 40 and 60 for operating conditions listed in Table $4.4 \ldots \ldots$. . . . . . . . . . . 111

4.23 Heat release rate characteristics for RCCI combustion . . . . . . . 112

4.24 Effects of PR on combustion characteristics (CA10 CA50, CA90 and Burn Duration) for RCCI combustion regime . . . . . . . . . . 112

4.25 Effects of PR on (a) IMEP, (b) Indicated thermal efficiency and (c) Combustion efficiency for RCCI combustion regime . . . . . . . . 113

4.26 Pressure and heat release rates for PR 20 for operating conditions listed in Table $4.5 \ldots \ldots \ldots \ldots$. . . . . . . . . . . . . . 116

4.27 Effect of intake air temperature on combustion characteristics (CA10 CA50, CA90 and Burn Duration) for RCCI combustion regime . . . 117

4.28 Effects of $T_{\text {intake }}$ on (a) IMEP, (b) Indicated thermal efficiency and (c) Combustion efficiency for RCCI combustion regime . . . . . . . . 118

4.29 Pressure and heat release rates for PR 20 for operating conditions listed in Table $4.6 \ldots \ldots \ldots \ldots$. . . . . . . . . . . . . . . . . . . . . .

4.30 Effects of intake pressure on combustion characteristics (CA10 CA50, CA90 and Burn Duration) for RCCI combustion regime . . . . . . 121

4.31 Effects of intake pressure on (a) IMEP, (b) Indicated Thermal efficiency and (c) Combustion efficiency for RCCI combustion regime . . . . 121

5.1 Experimental FMEP vs Parameterized FMEP . . . . . . . . . 125 
5.2 PPCI IMEP and speed range for $40^{\circ} \mathrm{C}$ intake air temperature at naturally aspirated conditions ................ 127

5.3 PPCI IMEP and speed range for $80^{\circ} \mathrm{C}$ intake air temperature at naturally aspirated conditions ................ 128

5.4 PPCI ISFC map for $40^{\circ} \mathrm{C}$ intake air temperature at naturally aspirated conditions ....................... 130

5.5 PPCI BSFC map for $40{ }^{\circ} \mathrm{C}$ intake air temperature at naturally aspirated conditions ...................... 131

5.6 PPCI indicated thermal efficiency map for $40^{\circ} \mathrm{C}$ intake air temperature at naturally aspirated conditions . . . . . . . . . . . 132

5.7 PPCI exhaust gas temperature map for $40{ }^{\circ} \mathrm{C}$ intake air temperature at naturally aspirated conditions . . . . . . . . . . . 133

5.8 PPCI ISFC optimized map for all intake air temperatures and RONs at naturally aspirated conditions . . . . . . . . . . 134

5.9 PPCI BSFC optimized map for all intake air temperatures and RONs at naturally aspirated . . . . . . . . . . . . 135

5.10 PPCI indicated thermal efficiency optimized map for all intake air temperatures and RONs at naturally aspirated conditions . . . . . . .

5.11 PPCI exhaust temperature optimized map for all intake air temperatures and RONs at naturally aspirated conditions . . . . . . . 137 
5.12 Effect of intake air temperature on PPCI in-cylinder pressure at a lambda of $2 \ldots \ldots \ldots \ldots \ldots$

5.13 Effect of intake air temperature on the PPCI heat release rate at a lambda of $2 \ldots \ldots \ldots$. . . . . . . . . . . . . . . . . . . . .

5.14 Effect of Intake temperature on IMEP and BMEP at a lambda of 2

5.15 Effect of intake temperature on indicated thermal efficiency at a lambda of $2 \ldots \ldots \ldots \ldots$. . . . . . . . . . . . . . . . . . . . .

5.16 Effect of intake temperature on combustion phasing at a lambda of $2 \quad 143$

5.17 Effect of boost pressure on IMEP in the PPCI regime . . . . . . . . 145

5.18 Variation of cylinder pressure versus crank angle at different intake manifold pressures at constant fuel energy $749 \mathrm{~J}$ in the PPCI regime

5.19 Variation of heat release rate versus crank angle at different intake manifold pressures at constant fuel energy $749 \mathrm{~J}$ in the PPCI combustion regime . . . . . . . . . . . . . . . . . . . . . . 148

5.20 Variation of indicated thermal efficiency with lambda at different intake manifold pressures in PPCI combustion regime . . . . . . . . . 149

5.21 Effect of intake manifold pressure on CA50 at different lambda values in PPCI combustion regime . . . . . . . . . . . . 150

5.22 Effects of SOI on in-cylinder pressure in PPCI combustion regime . 153

5.23 Effects of SOI on heat release rate in PPCI combustion regime . . . 154

5.24 Effects of SOI on CA10, CA50 and CA90 in PPCI combustion regime 155 
D.1 Copyright permission for the Figure 1.1 . . . . . . . . . 217

D.2 Copyright permission for the Figure $1.2 \ldots \ldots \ldots$ 


\section{List of Tables}

2.1 Engine Specifications . . . . . . . . . . . . . . 17

2.2 Port Fuel Injector (Bosch EV14) Specifications . . . . . . . . . . 18

2.3 Uncertainties involved in Measurement of independent parameters during experimentation ................. 44

2.4 Range of Uncertainties involved in estimation of parameters ... 45

2.5 Uncertainties of calculated variables with respect to independent parameters ........................ 46

2.6 Test parameters . . . . . . . . . . . . . . . . . . . . . . . 47

2.7 Mean and Standard deviation for repeatability (three trials) . . 4 47

3.1 Operating Parameters for HCCI Combustion Mode . . . . . . . 54

3.2 Error in estimation of FMEP $\ldots \ldots \ldots \ldots \ldots$

3.3 Coefficients for the Flynn- Chen Model . . . . . . . . . 56

3.4 Operating conditions used for the experiments to study the effect of RON on HCCI combustion . . . . . . . . . . 76

3.5 Operating conditions used for the experiments to study the effect of intake air temperature on HCCI combustion . . . . . . . 80 
3.6 Operating conditions used for the experiments to study the effect of Boost pressure on HCCI combustion . . . . . . . . . . 83

4.1 Operating Parameters for RCCI Combustion mode . . . . . . . 86

4.2 Error in estimation of FMEP . . . . . . . . . . . . . . 87

4.3 Coefficients for the Flynn- Chen Model . . . . . . . . . . . . . . 88

4.4 Operating conditions used for the experiments to study the effect of PR on RCCI combustion . . . . . . . . . . . . . . . 109

4.5 Operating conditions used for the experiments to study the effect of PR on RCCI combustion ................ 114

4.6 Operating conditions used for the experiments to study the effect of boost pressure on RCCI combustion . . . . . . . . . . . . . . 119

5.1 Operating Parameters for PPCI Combustion Mode . . . . . . 124

5.2 Error in estimation of FMEP . . . . . . . . . . . . 125

5.3 Coefficients for the Flynn- Chen Model . . . . . . . . . . . . 126

5.4 Operating conditions used for the experiments to study the effect of intake air temperature on PPCI combustion . . . . . . . . . 138

5.5 Operating conditions used for the experiments to study the effect of intake pressure on PPCI combustion . . . . . . . . . . . . 144

5.6 Operating conditions used for the experiments to study the effect of SOI on PPCI combustion . . . . . . . . . . . . 151 
A.1 Steady State Tests-Optimized . . . . . . . . . . . . . . 182

A.2 Steady State Tests- $T_{\text {intake }}=40^{\circ} \mathrm{C} \ldots \ldots$. . . . . . . . 184

A.3 Steady State Tests- $T_{\text {intake }}=60^{\circ} \mathrm{C} \ldots \ldots$ 186

A.4 Steady State Tests- $T_{\text {intake }}=80^{\circ} \mathrm{C} \ldots \ldots \ldots$

A.5 Steady State Tests- $T_{\text {intake }}=100^{\circ} \mathrm{C} \ldots \ldots$. . . . . . . 190

A.6 Steady State Tests-Optimized at naturally aspirated conditions . . . 193

A.7 Steady State Tests-Optimized at Boosted conditions . . . . . . . . 195

A.8 Steady State Tests-Boosted-Optimized . . . . . . . . . . 198

C.1 Experimental data files . . . . . . . . . . . . . . . 205

C.2 Experimental data files organized in excel . . . . . . . . . 206

C.3 Origin Project files . . . . . . . . . . . . . . . 206

C.4 DSPACE Raw Data for all experiments . . . . . . . . . . . 207

C.5 Labview Raw Data for all experiments . . . . . . . . . . . . 208

C.6 ACAP Raw Data for all experiments . . . . . . . . . . . . 209

C.7 Matlab Scripts for post processing the data . . . . . . . . . 210

C.8 Figure files included in this thesis . . . . . . . . . . 211

C.9 Figure files included in this thesis (Contd.) . . . . . . . . . 212

C.10 Figure files included in this thesis (Contd.) . . . . . . . . . . . 213

C.11 Visio Figure files in this thesis . . . . . . . . . . . . 214

C.12 Project files for testing and data acquisition . . . . . . . 215 



\section{Preface}

A small portion of this thesis are based on one journal paper [4] and one conference paper [5]. The contribution of the author of this thesis and the contributions of the co-authors for each of the papers are as follows:

Contribution for Chapter 2 [4]: Engine setup, data collection, analysis of experimental data and writing the section for experimental setup have been done by the author of this thesis, K. Kannan. The artificial neural network (ANN) model (not included in this thesis) and validation of the model have been done by Dr. B. Bahri. Dr. M. Shahbakhti and Dr. A. A. Aziz provided technical comments and manuscript editing during the course of this paper.

Contribution for Chapter 5 [5]: Engine setup, data collection and analysis of experimental data have been done by Dr. S. Polat and the author of this thesis, K. Kannan. The author of this thesis is also responsible for the write up for the abstract, introduction and experimental setup sections for this paper. The figures and write up for the effect of boost pressure on PPCI combustion and performance characteristics have been done by Dr. S. Polat and Dr. A. Uyumaz. Valuable technical comments and manuscript editing have been done by Dr. M. Shahbakhti and H. S. Yucesu. 



\section{Acknowledgments}

With great pleasure, I take this opportunity to express my gratitude to the many people who have helped or supported this work.

First, I wish to thank my advisor Dr. Mahdi Shahbakhti for giving me this opportunity to be a part of his research team at MTU. I am extremely grateful to him for believing in my abilities and shaping this thesis to "perfection". I would also like to thank Dr. Scott Miers and Dr. Youngchul Ra for being a part of my thesis defense committee.

I would like to thank the EML group for assisting me in completing my tasks. I would like to thank Seyfi, Mehran and Hamit for helping me understand the research ethics and for providing valuable technical advice. I would also like to appreciate Jayant, Nithin and Jayadev for helping me in developing the experimental test cell and conducting experiments. I truly appreciate your hard work, it would have never been possible without your efforts.

I would like to thank Paul, Jeremy, Chris and Steve for their advice, knowledge and patience for helping me understand several tasks of my projects. I highly appreciate Akshat, Karan, Nithin and Jayant for helping me editing my draft. 
Last but not the least, I would like to thank my parents for providing me with this opportunity to pursue my MS degree in the US. I also thank my parents and sister for their love and for being a pillar of support during all stages of my life. Special thanks to Aishwarya for being such a huge motivation in my life. I appreciate the encouragement I have received from Rakesh, Dheeraj, Vijay and Akshay through all these years. My friends Avinash, Ram, Roshini, Muralee and Kavitha have played an instrumental part of this journey. I thank you for the good times. 


\title{
List of Abbreviations
}

\author{
Acronyms \\ aBDC \\ After Bottom Dead Center \\ $\operatorname{aTDC}$ \\ After Top Dead Center \\ $\mathrm{BDC}$ \\ Bottom Dead Center \\ CAD \\ Crank Angle Degree \\ CAI \\ Controlled Auto-Ignition \\ CA50 \\ Crank Angle for $50 \%$ of the cumulative heat release rate \\ CI \\ Compression Ignition \\ $\mathrm{CO}$ \\ Carbon Monoxide \\ DI \\ Direct Injection \\ EGR \\ Exhaust Gas Recirculation \\ EOC \\ End of Combustion \\ EPA \\ Environmental Protection Agency \\ EVC \\ Exhaust Valve Closing \\ EVO \\ Exhaust Valve Opening \\ exh \\ Exhaust \\ GDI \\ Gasoline Direct Injection \\ GDICI \\ Gasoline Direct Injection Compression Ignition
}

xxxi 


\begin{tabular}{|c|c|}
\hline HCCI & Homogenous Charge Compression Ignition \\
\hline $\mathrm{HEV}$ & Hybrid Electric Vehicle \\
\hline HTR & High Temperature Region \\
\hline HTHR & High Temperature Heat Release \\
\hline ICE & Internal Combustion Engine \\
\hline IMEP & Indicated Mean Effective Pressure \\
\hline ISFC & Indicated Specific Fuel Consumption \\
\hline IVC & Intake Valve Closing \\
\hline IVO & Intake Valve Opening \\
\hline LTC & Low Temperature Combustion \\
\hline MABX & Micro Auto Box \\
\hline MAP & Manifold Absolute Pressure \\
\hline$N O_{x}$ & Nitrogen Oxides \\
\hline RON & Research Octane Number \\
\hline PPCI & Partially Premixed Compression Ignition \\
\hline PFI & Port Fuel Injection \\
\hline PI & Proportional Integral \\
\hline PID & Proportional Integral Derivative \\
\hline PM & Particulate Matter \\
\hline PPM & Parts Per Million \\
\hline PR & Premixed Ratio \\
\hline
\end{tabular}




$\begin{array}{ll}\text { PRF } & \text { Primary Reference Fuel } \\ \text { RCCI } & \text { Reactivity Controlled Compression Ignition } \\ \text { RMSE } & \text { Root Mean Square Error } \\ \text { rpm } & \text { Revolution per Minute } \\ \text { SI } & \text { Spark Ignition } \\ \text { SOC } & \text { Start of Combustion } \\ \text { SOI } & \text { Start of Injection } \\ \text { STD } & \text { Standard Deviation } \\ \text { TDC } & \text { Top Dead Center } \\ \text { THC } & \text { Total Hydrocarbon } \\ \text { UDDS } & \text { Urban Dynamometer Driving Schedule } \\ \text { uHC } & \text { Unburned Hydrocarbon } \\ \text { VFD } & \text { Variable Frequency Drive } \\ \text { VVA } & \text { Variable Valve Actuation }\end{array}$

\section{Symbols}

A

AFR

BSFC

$B M E P$

$\bar{C}_{v}$

$C_{p}$
Area $\left(m^{2}\right)$

Air Fuel Ratio (-)

Brake Specific Fuel Consumption $\left(\frac{g}{k W \cdot h}\right)$

Brake Mean Effective Pressure (kPa)

Average Constant-volume Specific Heat Capacity $\left(\frac{k J}{k g . K}\right)$

Constant Pressure Specific Heat Capacity $\left(\frac{k J}{k g \cdot K}\right)$ 


\begin{tabular}{|c|c|}
\hline CA50 & Crank Angle for $50 \%$ CHRR (CADaTDC) \\
\hline $\mathrm{COV}$ & Coefficienct of Variation (\%) \\
\hline E & Total Energy $(\mathrm{kJ})$ \\
\hline EGR & Exhaust Gas Recirculation Fraction (-) \\
\hline$\eta$ & Efficiency (\%) \\
\hline$F$ & Force $(\mathrm{N})$ \\
\hline$F M E P$ & Friction Mean Effective Pressure (kPa) \\
\hline h & Convective Heat Transfer Coefficient $\left(\frac{W}{m^{2} K}\right)$ \\
\hline IMEP & Indicated Mean Effective Pressure $(\mathrm{kPa})$ \\
\hline ISFC & Indicated Specific Fuel Consumption $\left(\frac{g}{k W \cdot h}\right)$ \\
\hline$\lambda$ & AFR over Stoichiometric AFR (-) \\
\hline LHV & Low Heating Value $(\mathrm{kJ} / \mathrm{kg})$ \\
\hline $\mathrm{m}$ & Mass (g) \\
\hline LPP & Location of Peak Pressure (CAD aTDC) \\
\hline MPRR & Maximum Pressure Rise Rate (bar/CAD) \\
\hline$\dot{m}$ & Mass Flow Rate $(\mathrm{kg} / \mathrm{s})$ or $(\mathrm{g} / \mathrm{s})$ \\
\hline $\mathrm{N}$ & Engine Speed (rpm) \\
\hline$N O_{x}$ & Nitrogen Oxides Concentration (ppm) \\
\hline $\mathrm{n}$ & Ratio of Specific Heat Capacities (-) \\
\hline$n_{c}$ & Compression Polytropic Index (-) \\
\hline$\omega$ & Rotational Speed $\left(\frac{\mathrm{rad}}{\mathrm{s}}\right)$ \\
\hline
\end{tabular}




$\begin{array}{ll}\text { RON } & \text { Research Octane Number }(-) \\ \mathrm{P} & \text { Power }(\mathrm{kW}) \\ \mathrm{T} & \text { Temperature }\left({ }^{\circ} \mathrm{C} / \mathrm{K}\right) \\ \mathrm{W} & \text { Work }(\mathrm{J}) \\ \text { subscripts } & \\ \text { th } & \text { Thermal } \\ \text { ind } & \text { Indicated } \\ \text { exh } & \text { Exhaust } \\ \text { comb } & \text { Combustion }\end{array}$





\section{Abstract}

A continuous investigation on the improvement of internal combustion engines is necessary due to the stringent emission and fuel economy regulations. Low Temperature Combustion (LTC) is a promising field of research since it can simultaneously reduce $N O_{x}$ and soot while attaining high thermal efficiencies in automotive engines. A thorough study of several LTC regimes is necessary to understand the quantitative comparison and the extent of feasibility of these regimes functioning on an automotive engine. This thesis concentrates on an experimental investigation of three different LTC modes namely Homogeneously Charged Compression Ignition (HCCI), Partially Premixed Compression Ignition (PPCI) and Reactivity Controlled Compression Ignition (RCCI) on a 2.0-liter 4-cylinder gasoline engine.

A detailed experimental study of the LTC regimes with over 2,500 data points on a GM 2.0 L Ecotec engine is performed to study the relationship among the engine variables, combustion and performance characteristics. The operating range extension of the engine for lean limit and load limit while functioning in each combustion mode is discussed through operating region maps. Performance metric maps for indicated specific fuel consumption (ISFC), brake specific fuel consumption (BSFC), thermal efficiency and exhaust temperature are developed and discussed. The optimized maps

are developed for each LTC regime considering the best ISFC at each speed-load 
condition. Moreover, the behavior of the engine for each combustion mode is investigated and discussed through the trends observed for combustion phasing (CA10, CA50, CA90 and BD) and performance metrics (IMEP, indicated thermal efficiency, combustion efficiency).

The results show that the RCCI combustion mode offers the best indicated thermal efficiency of $47 \%$ among the three LTC modes. The Start of Injection (SOI) of nheptane is found as a dominant factor in order to determine the optimal combustion phasing. The results of a comparative study indicate that HCCI is more suitable for running the engine at low loads, PPCI for low-mid loads and RCCI for mid-high loads. 


\section{Chapter 1}

\section{Introduction}

Over the past two decades, the demand for highly fuel efficient vehicles has increased significantly, owing to the constantly changing emission standards and environmental concerns. New engine technologies are being explored to enhance thermal efficiency and minimize fuel consumption in engines. Automotive manufacturers are trying to comply with emission standards which are designed by environmental legislators and also provide low fuel consumption and high performance engines for customers. Therefore, many experimental and numerical studies were carried out by researchers on these issues. The studies have focused on improving combustion efficiency of internal combustion engines, reduction in emissions and use of alternative fuels [6, 7, 8. 
Figure 1.1 represents the soot and $N O_{x}$ regions for different combustion modes as a plot of local equivalence ratio vs local temperature. It can be seen that the lower equivalence ratio results in higher $N O_{x}$ while higher equivalence ratios lead to soot formation. The challenge that researchers currently face is to reduce the soot and $N O_{x}$ emissions, simultaneously. In order to accomplish this, a number of combustion regimes have been explored. $N O_{x}$ formation occurs at temperatures higher than $2000 \mathrm{~K}$. Therefore, with a decrease in in-cylinder temperatures and avoiding rich local zones, the problem of soot and $N O_{x}$ emissions could be eliminated to a fair extent.
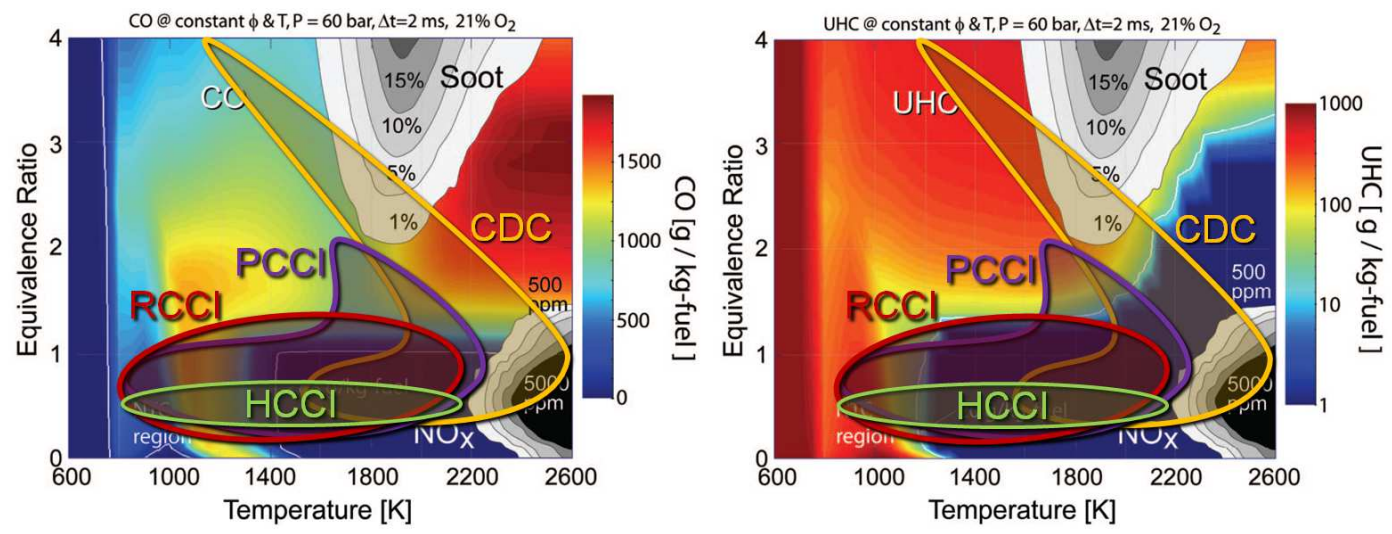

Figure 1.1: Contour plots of soot, $N O_{x}, \mathrm{HC}$ and $\mathrm{CO}$ depicting the operating regions of several combustion regimes [1] (Letter of permission D.1]

Low temperature combustion techniques such as HCCI, PPCI and RCCI have proven to be promising alternatives to the conventional Spark ignition and diesel combustion engines beacause of their ability to reduce the in-cylinder local temperatures and the rich zones simultaneously. In all the three LTC modes, the injection of fuel is either 
in the port or early during compression stroke in the cylinder. This results in the fuel being premixed, hence avoiding the local rich zones in the cylinder. Moreover, RCCI combustion can be accomplished with split injections over a time period in a cycle, which results in better homogeneity of the air-fuel mixture [9]. Considering this factor, it is of prime importance to reduce the need for aftertreatment systems, while achieving high engine efficiencies.

This chapter describes the evolution of LTC engines explaining their evolution, background, advantages and challenges. It also outlines the operating principle of HCCI engines. Moreover, the research goals and scope of the study are introduced.

\subsection{The evolution of Low temperature Combus- tion (LTC) engines}

Spark ignition (gasoline) engines are one of the commonly used IC engines in commercial automobiles these days. Spark ignition engines do not use very high compression ratio due to knock limit and therefore the thermal efficiency is lower in these engines. Also in the spark ignition engines, speed and load conditions are controlled by throttling fresh cylinder charge which results in throttling loss. Cylinder charge in spark ignition engines is homogenous because fuel and air are mixing in intake port. Com-

bustion phenomena in spark ignition engines encompass flame propagation which is 
initiated by the spark plug. Since fuel and air are taken into the cylinder together, the fuel sticks on the cylinder wall and piston cavity. Consequently, oxidation is not fully done on these surface and unburned hydrocarbon (HC) emissions are high in spark ignition engines. [6] Compression ignition (diesel) engines are another type of internal combustion engines that are used widely nowadays. High compression ratio is used in these engines which result in high thermal efficiency. There are no throttling losses due to the fact that fuel is sprayed directly into the cylinder. Adverse aspect of compression ignition engines is heterogeneous cylinder charge which is caused by subsequent fuel addition to air inside the cylinder. Nitrogen oxides (NOx) and soot (PM) emissions are high in diesel engines. [7]

Homogeneous charge compression-ignition engines have advantages of spark ignition engines as well as benefits of compression ignition engines. The homogeneous airfuel mixture is taken into the cylinder without throttling losses. This homogeneous mixture undergoes simultaneous self-ignition throughout the cylinder without the flame propagation while being compressed by piston. Thus the combustion efficiency is higher and the heat transfer losses are lower due to shorter combustion duration. Also thermal efficiency is high because of high compression ratio implementation in these engines. Considering these characteristics we can conclude that HCCI engines provide high thermal efficiency while emitting very low levels of NOx and PM [6, 7, 8. However, HCCI engines suffer from some problems and commercial use of these engines needs resolution of these weak points which are related to ignition timing and 
the combustion rate control. These two problems are difficult to overcome. First, there is no mechanism for ignition timing control similar to spark in spark ignition engines or injection timing in direct injection engines. Second, chemical reaction's dependence on the fuel properties is more dominant in HCCI engines than spark ignition and diesel engines. HCCI engines face with issues such as misfire at low load and knocks at high load. Therefore, HCCI engines have a limited operating range [8]. Recently, many studies have been carried out about the potential control methods as intake air heating [10, 11], variable compression ratio [12, 13], variable valve timing [14, 15] and EGR system [16, 17], etc. Most of studies have focused on the effects of physical and chemical properties of different alternative fuels to control HCCI combustion [6, 18, 19]. In these studies, the important results were obtained about control of the HCCI combustion process. However, satisfactory result was not gained at high-load operation of HCCI engines due to lack of a direct method to control combustion phasing. Another way to overcome the disadvantages of HCCI engines is application of dual mode engine as $\mathrm{HCCI}$ /SI engine. A dual-mode HCCI/SI engine is equipped with variable valve timing and ignition system, that can operate in HCCI mode at low and medium load, while operates in SI mode at high load when necessary. In contrast, transition between modes is not acceptably stable especially from SI mode to HCCI mode. It is necessary to make further improvements on controlling strategies in order to eliminate between cycle to cycle variations. Generally, HCCI and SI operation are combined for obtaining the best performance in double-mode 
engine [20, 21].

In order to overcome the difficulty of combustion phasing control in HCCI, an alternative LTC mode called Partially Premixed Compression Ignition (PPCI) was introduced in 2005 [22, 23]. Unlike HCCI, the fuel was premixed in a fuel tank (in a desired ratio based on the RON) and was injected directly into the engine cylinder using direct injection. The tests were performed on a boosted Diesel engine with high EGR rates. This type of combustion is more suitable for high octane fuels, since the high volatility of gasoline enabled better mixing of the fuel and air after injection. In this study, a significantly lower fuel consumption, NOx and PM were observed. Extensive research has been conducted in order to understand the dynamics and combustion characteristics of PPCI combustion [5, 24]. An experimental and numerical investigation was performed on a light duty diesel engine to identify the characteristics of GDICI combustion. A parametric study was performed to analyze the feasibility of full load operation of the engine. It was observed that low-emission engine concepts could be extended to high octane high speed engine operation. Owing to the high volatility and octane number of gasoline, there was a significant reduction in the combustion temperatures and ultra-low NOx was achieved, while the ISFC was about $180 \mathrm{~g} / \mathrm{kW}$-h. It was also observed that the injection pressure had to be optimized in order to obtain an optimized operating map for a given load. It was observed that the maps were highly sensitive to EGR rate, boost pressure and intake air temperature. Moreover, increasing the intake air temperature and reducing the EGR rate had 
very comparable effects on the operating map region [24]. The effects of boost pressure was investigated on PPCI combustion in an early direct injection HCCI engine through experimental methods. It was observed that intake manifold pressure had a significant effect on the operating range extension of the engine. The in-cylinder pressure increased and the combustion was advanced with boosting. Moreover, the best indicated thermal efficiency was obtained when the engine was run at a combustion phasing slightly after TDC. The peak thermal efficiency obtained was about 40 $\%$, which is very much comparable to that of diesel engines. Moreover, higher engine loads could be achieved with higher boost pressures and the engine load boundary was extended significantly [5]. Partial fuel stratification is an approach that has been studied extensively ever since its inception. It has been observed that the autoignition knocking tendency could be reduced with PPCI [25, 26]. With this reduction in knock intensity, the combustion phasing control became much easier. As a result of this, higher thermal efficiencies could be attained at higher loads [27]. When partial fuel stratification was compounded with the introduction of reactivity of equivalence ratio stratification, it was possible to further precisely control the combustion phasing and the gradient of heat release [28]. The knock intensity was further reduced at mid-high load condition. This technique has been termed as reactivity controlled compression ignition (RCCI). It is a dual fuel combustion strategy that uses a higher reactivity fuel to be injected directly into the cylinder and the low reactive fuel to be injected in the intake manifold. It has been observed that with RCCI, the engine 
operation region could be extended to high load condition, while attaining thermal efficiencies close to the conventional diesel combustion (CDC). The experiments were performed with pump gas 87 octane fuel as the low reactive fuel and ultra-low sulfur diesel as the high reactive fuel. While the MPRR was significantly reduced, indicating acceptable operating region without knock, the EPA 2010 standards for NOx and soot was also met [29]. With RCCI combustion, the gross thermal efficiencies could be escalated to $60 \%$, with simultaneous reduction in friction and pumping losses. Using an engine with a compression ratio of 18.6:1, a $50 \%$ reduction in heat transfer losses and combustion losses were obtained. Moreover, the NOx and PM levels were near-zero. This shows that thermodynamic conditions and combustion parameters need to be optimized in order to extend the lean limit operation and higher thermal efficiencies at all test points. Moreover, improvement in supercharger efficiencies, low temperature of the exhaust and reduction in friction losses play a key role in attaining high gross efficiencies [30].

\subsection{Principle of Operation of LTC engines}

HCCI combustion has been an interesting field of research due to its ability to attain ultra low $N O_{x}$ and near zero PM emissions. This can be achieved by firstly obtaining a homogeneous air-fuel mixture and then providing sufficient heat for the mixture to auto-ignite at the end of compression stroke. Achieving these tasks can prove to be 
challenging. [31]

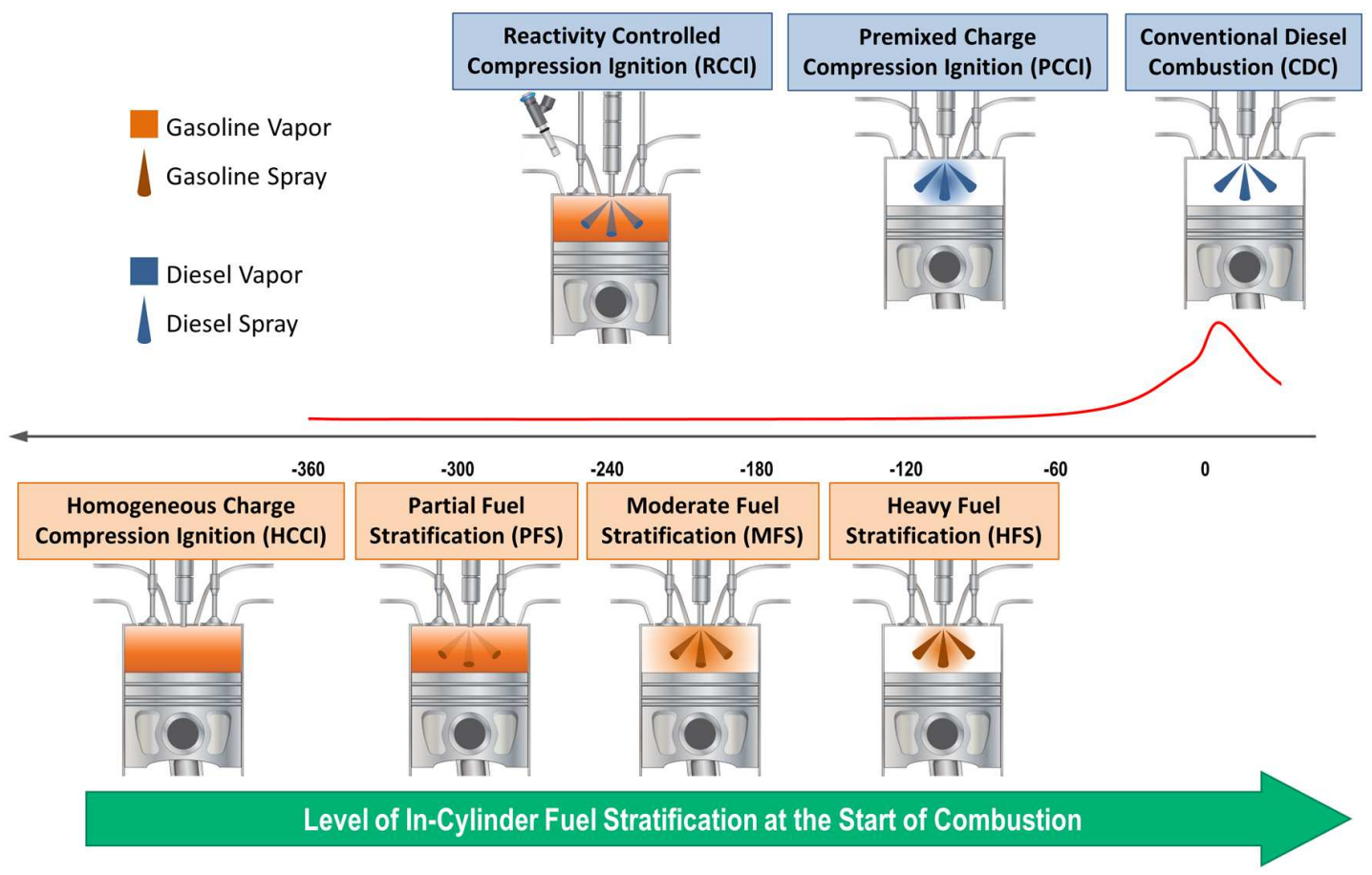

Figure 1.2: Comparison of diesel, Gasoline and HCCI engine [2] (Permission letter given in D.2

If complete homogeneity is obtained for a mixture, there is a rise in temperature and pressure of the mixture during compression. This leads to auto-ignition of the mixture. However, this differs from a typical diesel CI. In case of HCCI the autoignition does not occur at a certain place in the cylinder, but simultaneously across the combustion chamber. Contrary to SI combustion, there is no high temperature flame front in HCCI during the auto-ignition of the mixture. This leads to reduced in-cylinder gas temperatures and lean mixtures, thereby reducing the $N O_{x}$ formation to near-zero levels. Moreover, due to the absence of local rich zones in the cylinder, the soot emissions is also simultaneously reduced. [32] [33]. In a HCCI engine, the 
fuel and air are premixed in the intake port, while in case of PPCI the mixture preparation happens in the cylinder, similar to Gasoline direct injection. The airfuel mixture is compressed during the compression stroke and combustion is attained by auto-ignition of the mixture at the end of compression. In order to auto ignite the mixture at the end of compression stroke, the gas temperature at the start of compression has to be higher. This can be achieved by either pre-heating the intake air or by trapping residuals in the cylinder. As a result of this, the chemical reactions become more faster and catalyze the combustion process of the mixture. [34]

Although the start of main heat release usually occurs when the temperature reaches a value of $1050-1100 \mathrm{~K}$ for gasoline or less than $800 \mathrm{~K}$ for diesel, many hydrocarbon components in gasoline and diesel undergo low temperature oxidation reactions accompanied by a heat release that can account for up to $10 \%$ of the total energy released. The heat release rate and combustion characteristics of HCCI combustion depends on several factors such as the chemical kinetics of the fuel used, dilution strategies used and the temperature-pressure history of the mixture during compression. 34

While high efficiencies and ultra-low $N O_{x}$ can be obtained using HCCI, it is limited to low loads and there is no direct means to control combustion phasing [35]. In case of RCCI, two fuels with different reactivities are used. The lower reactive fuel (typically iso-octane) is injected in the port and the higher reactive fuel (typically 
n-heptane) is injected late directly in to the cylinder. The heat release for RCCI occurs in three stages: the cool flame, the PRF burn and the late burn. The first stage reaction occurs due to the n-heptane injection which corresponds to the cool flame. The first stage of HTHR occurs due to the PRF burn, where n-heptane and the entrained iso-octane combust resulting in a heat release. The final stage of heat release occurs due to the late burn of the lower reactive fuel i.e iso-octane. The changing fuel ratio results in the change of shape and the magnitude of heat release [36]. This is discussed elaborately in Chapter 4.

\subsection{Research Goals and Scope of Research}

Low temperature combustion is a promising alternative to conventional SI and CI engines, given the high gross efficiencies, while affirming to the EPA emission standards. However, the operating region for both the lean limit operation and load limit operation for all major LTC regimes on a same engine is not thoroughly discussed in literature. This research is one of its kind, given the fact that all three combustion modes: HCCI, PPCI and RCCI could be run on the same engine. Therefore, the thesis focuses on operating region extension for all three LTC modes, by adopting different techniques. The range of operation for each mode is individually studied and explained. The operating region maps for the load and speed are created. In order to understand the performance characteristics of the engine, maps for BSFC, 
ISFC and net indicated thermal efficiency are developed. Moreover, it is important to understand the effect of operating conditions on the performance and combustion characteristics of the engine. Parameters such as engine speed, fuel-air equivalence ratio, intake air temperature, boost pressure, research octane number (RON) and fuel rail pressure were varied independently, one at a time, keeping other parameters constant. A parametric study was performed on the engine for each LTC mode independently under steady state conditions. Blends of n-Heptane and iso-Octane are used as the fuels. Since they are primary reference fuels and have an octane rating of 0 and 100, respectively, they are very similar to the octane rating of conventional diesel and gasoline, respectively. In the thesis, the term Research Octane Number (RON) is used for PPCI and HCCI combustion modes. However, the term premixed ratio $(\mathrm{PR})$, the ratio of premixed fuel (iso-octane) to the total energy supplied, is used for RCCI mode. The ultimate goal of the project is to understand and evaluate thoroughly the operating region characteristics of each of the three combustion modes and parametric studies to understand the effect of operating conditions on the performance and combustion characteristics of the engine.

\subsection{Organization of Thesis}

This thesis is organized into six different chapters as represented in Figure 1.3. Chapter 1 gives an overview of background, evolution and principle of operation of LTC 
engines. The research goals and scope of the thesis are discussed. Chapter 2 gives an overview of the experimental setup, instrumentation and calibration of the com-

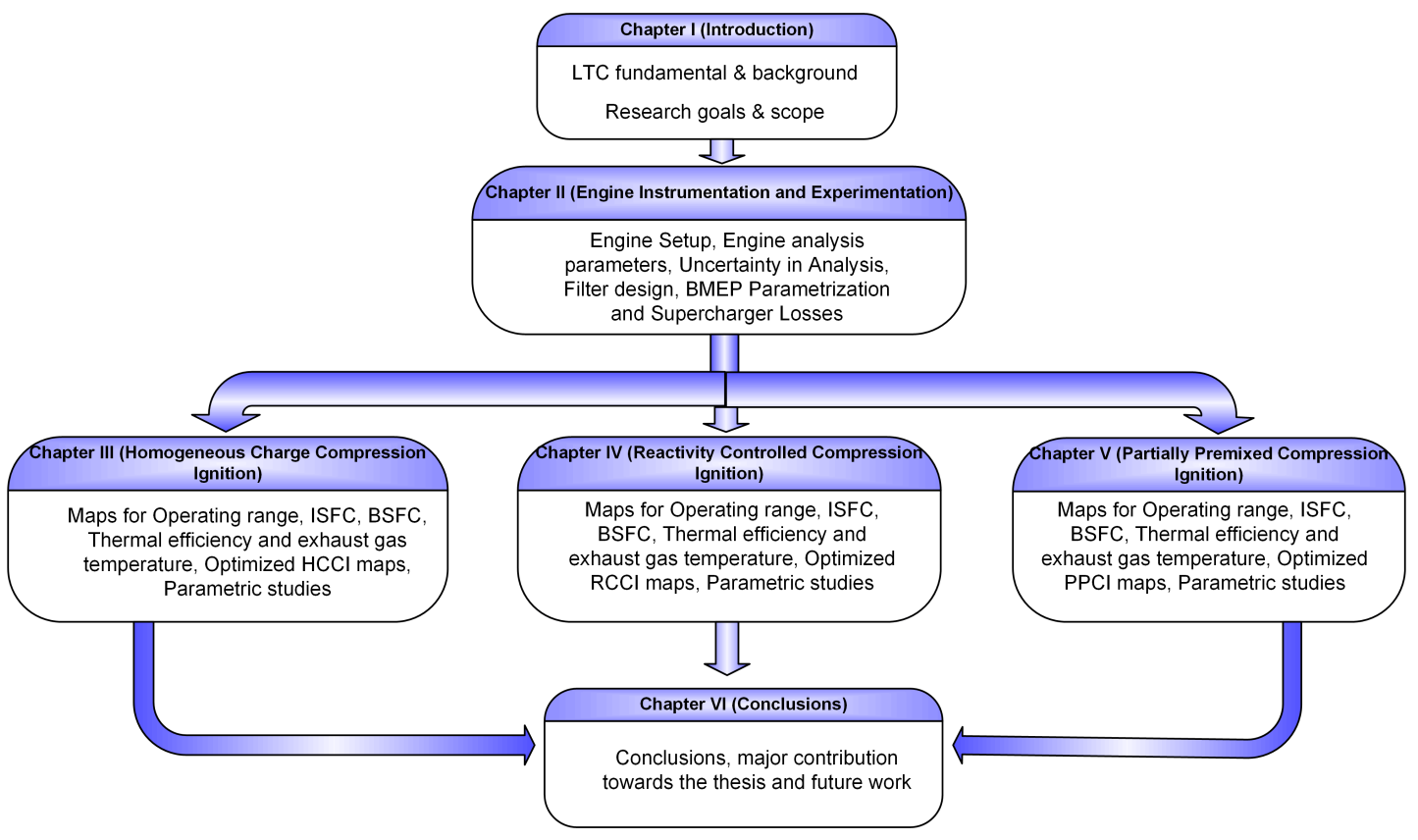

Figure 1.3: Thesis Organization

ponents involved. The calculations involved in the calculation of the engine analysis parameters are elaborated. Further, an uncertainty analysis of the dependent and independent parameters is discussed. Chapters 3, 4 and 5 discuss the results for three different combustion modes HCCI, RCCI and PPCI, respectively. In these three chapters, maps for operating regions, ISFC, BSFC, exhaust gas temperature and thermal efficiency were discussed. Moreover, optimized maps for each of these parameters were also developed. A parametric study of the effect of intake air temperature, boost pressure, RON and SOI were conducted and discussed. Finally, chapter 6 summarizes the results and significant contribution towards the thesis. It also provides 
recommendations for the future research based on the results from this thesis. 


\section{Chapter 2}

\section{Engine Instrumentation and}

\section{Experimentation}

An experimental GDI engine was modified and instrumented to run in several LTC

modes including HCCI, PPCI and RCCI. This chapter elaborates the contributions made to the instrumentation of the engine from this thesis.

\subsection{Engine Setup and Specifications}

Figure 2.1 shows the schematic of the experimental setup of the engine used for running tests in LTC modes. A GM 2.0 L 4-stroke, 4-cylinder Gasoline Direct Injection 
Ecotec engine was used for this purpose. The specifications of the engine is shown in Table 2.1.

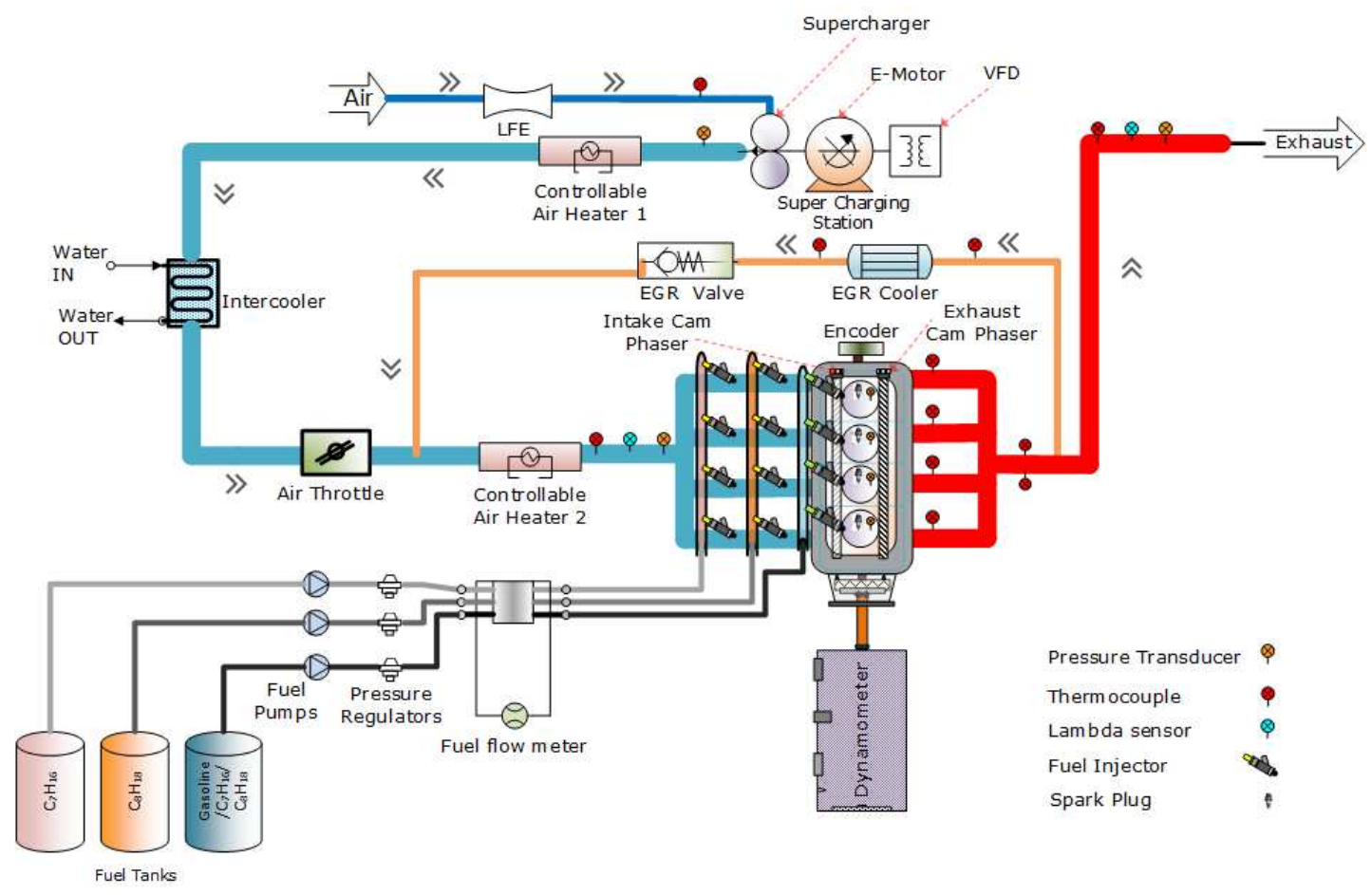

Figure 2.1: Schematic of the LTC engine setup

The turbocharger was disabled. Instead, an Eaton M62 supercharger driven by an external 20 hp e-motor was used. The e-motor was controlled remotely with a GS34040 Variable Frequency Drive (VFD) unit and dSpace MicroAutoBox. An external fuel pump was used to supply fuel at 3 bar pressure to the Port Fuel injectors. Two air heaters between the supercharging station and the intake manifold were used to preheat the intake air to the desired temperature. A 460 hp GE AC Dynamometer was used to control the speed and load of the engine. The mass flow rate of intake air was measured using Merriam MDT500 air flow measurement system [4]. The LTC 
experimental setup is shown in Figure 2.2. More information with respect to the instrumentation of the engine can be obtained from the previous works [37, 38, 39]

Table 2.1

Engine Specifications

\begin{tabular}{|c|c|}
\hline Engine Type & 4 stroke, Gasoline \\
\hline Number of Cylinders & 4 \\
\hline Cylinder volume & $1998 \mathrm{cc}$ \\
\hline Bore & $86 \mathrm{~mm}$ \\
\hline Stroke & $86 \mathrm{~mm}$ \\
\hline Compression ratio & $9.2: 1$ \\
\hline Max engine power & $164 @ 5300(\mathrm{~kW} / \mathrm{rpm})$ \\
\hline Max engine torque & $353 @ 2400(\mathrm{Nm} / \mathrm{rpm})$ \\
\hline Diameter of intake valves & $35.17 \mathrm{~mm}$ \\
\hline Firing order & $1-3-4-2$ \\
\hline IVO & $25.5 /-24.5(\mathrm{CAD}$ bTDC) \\
\hline IVC & $2 /-48(\mathrm{CAD} \mathrm{bBDC})$ \\
\hline EVO & $36 /-14(\mathrm{CAD}$ bBDC) \\
\hline EVC & $22 /-28(\mathrm{CAD}$ bTDC) \\
\hline Valve lift & $10.3 \mathrm{~mm}$ \\
\hline
\end{tabular}

\subsection{Port Fuel Injectors (PFI) Instrumentation, Calibration and Assembly}

Eight Bosch EV14 port fuel injectors were used for the engine. The EV14 specifications are given in Table 2.2 


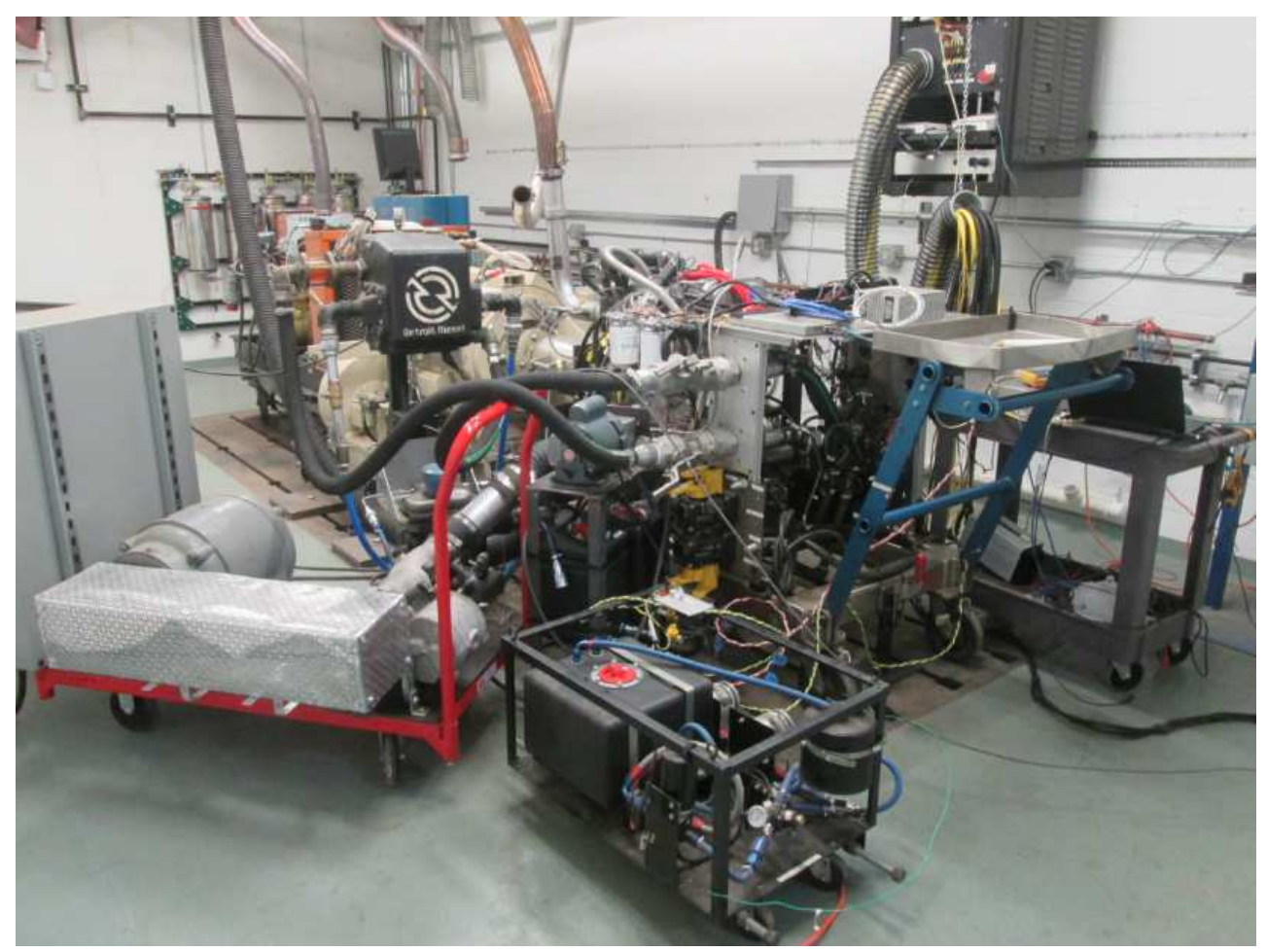

Figure 2.2: Experimental LTC Engine Setup

Table 2.2

Port Fuel Injector (Bosch EV14) Specifications

\begin{tabular}{|c|c|}
\hline Part No. & 0280158116 \\
\hline \hline Flow rate $/ \mathrm{min}$ & $237 \mathrm{~g} / \mathrm{min}$ \\
\hline Type & $\mathrm{E}$ \\
\hline Housing & $\mathrm{L}$ \\
\hline Resistance & $12 \mathrm{ohm}$ \\
\hline Tilt angle & $22^{\circ}$ \\
\hline
\end{tabular}

Two Fuel Rails with four injectors were mounted on an interface which was then mounted on the intake manifold of the engine. Figure 2.3 shows the PFI assembly on the engine setup.

The port fuel injectors were controlled using a low side driver unit from Rapid Pro. 


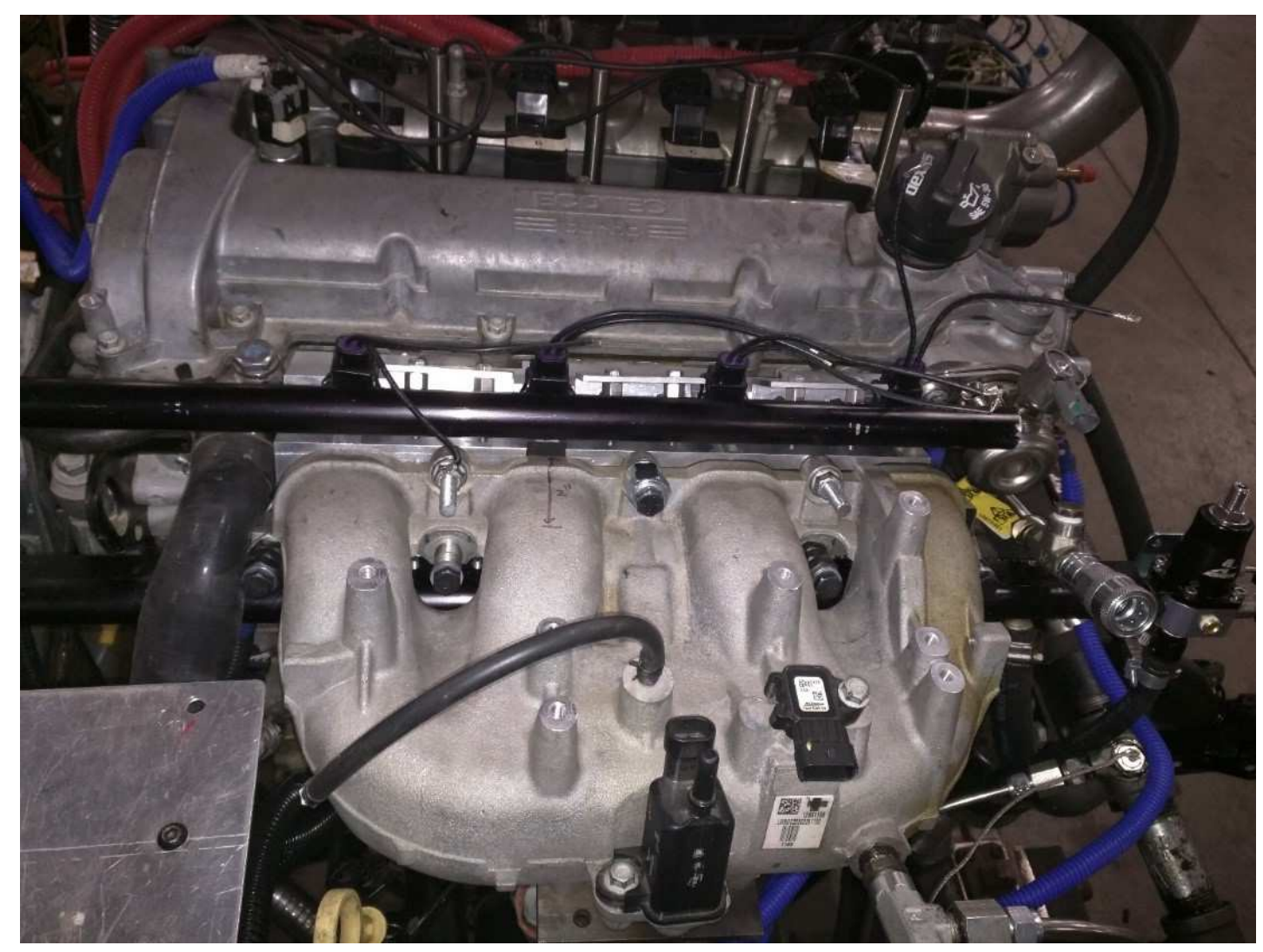

Figure 2.3: Port fuel injector assembly

A model as shown in Figure 2.4 was developed in Simulink for Injectors actuation and control. The injector control blocks resided in a sub-system triggered by an angle interrupt. In order to update the injection pulse pattern at run time, the angle value of the interrupt was set lower than the smallest angle value of the new injection pulse pattern. Figure 2.5 represents the display panel for the injectors control. The RON, injection start angle and the fuel mass are the inputs to the model. On the basis of this, the required pulse width is calculated for injectors on rail 1 (x1) and rail $2(\mathrm{x} 2)$. a1, a2, b1 and b2 are the calibration factors for rails 1 and 2 . 


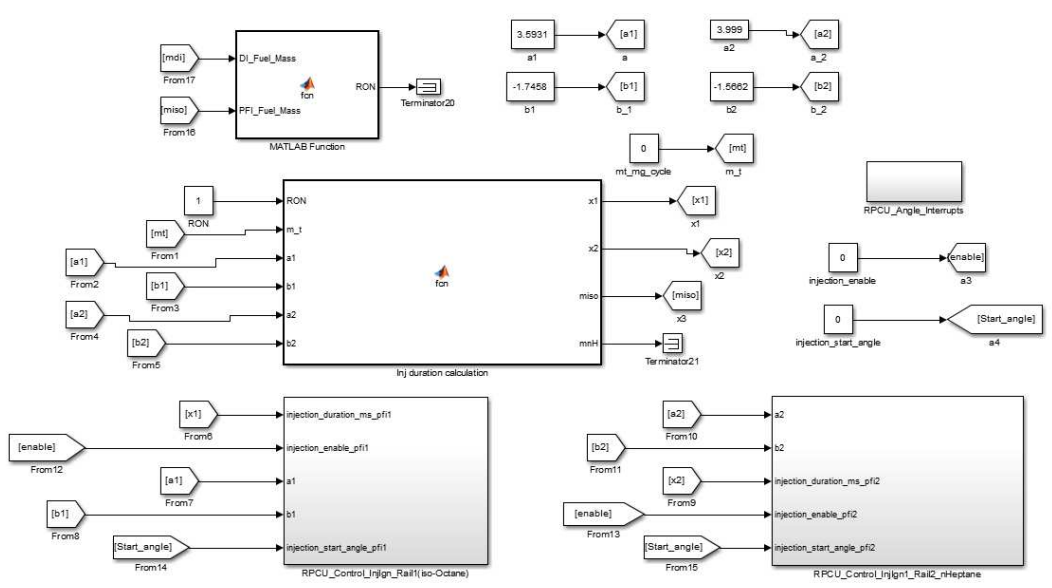

Figure 2.4: Triggered sub-system for PFI control

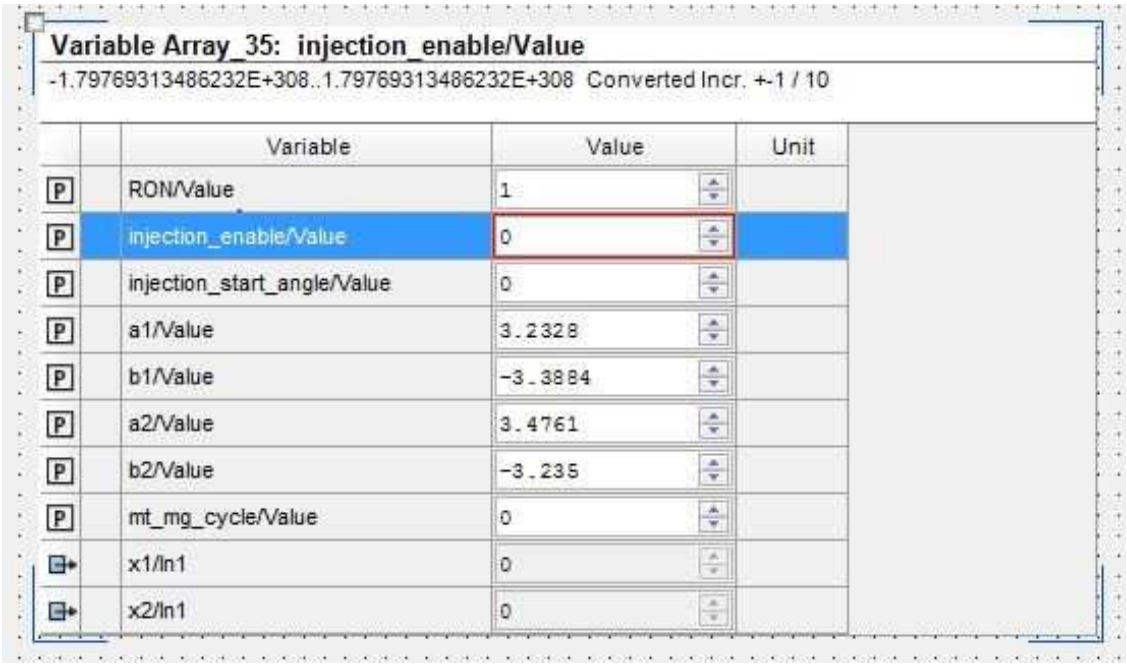

Figure 2.5: Monitoring Panel on dSPACE Control Desk for PFI Control

Low Temperature Combustion engines have the flexibility of being operated with different fuel combinations. For the experiments, iso-octane and n-heptane were blended volumetrically in different proportions so as to attain the desired research octane number $(\mathrm{RON})$. As discussed in this section, the engine is equipped with two PFI rails with four injectors on each rail. The injectors on Rail 1 inject n-heptane while 
injectors on Rail 2 inject iso-octane. The percentage of the injected isooctane and nheptane determines the RON of the fuel. RON number can be regulated by changing the injection durations of the injectors. Therefore, there arises the need to estimate the amount of fuel injected for a given injection duration. This requires the calibration of the PFI injectors for different fuel types because each fuel has a different density value. Micro Motion 1500 transmitter and CMF050 flow sensor were used for the calibration of the PFI injectors. Injected fuel mass was measured via Prolink III software. Prior to the calibration of PFI injectors, the accuracy of the new fuel flow meter was tested using DI injectors which were previously calibrated. Figure 2.6 illustrates the verification result for DI injectors. The average error was determined to be $0.27 \mathrm{mg} /$ cycle that corresponds $1 \%$.

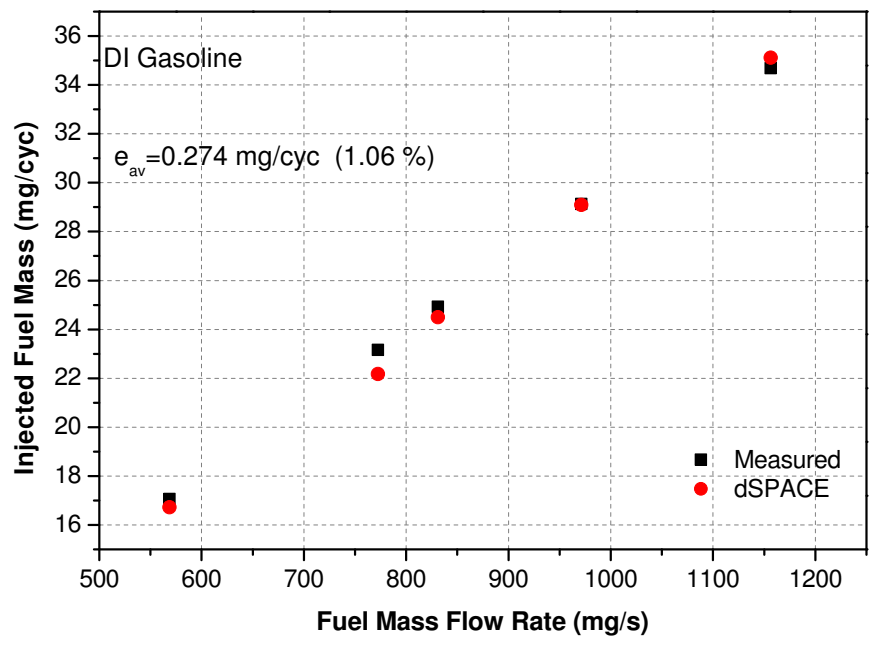

Figure 2.6: Verification of dSPACE model for calculating injected fuel mass from using DI injectors 
Figure 2.7(a) illustrates the calibration of the PFI injectors for iso-octane fuel. In order to calibrate the injectors, one of the rail lines was connected to the fuel tank which contained iso-octane. The engine was run at $1000 \mathrm{rpm}$ and injection durations were changed between $3 \mathrm{~ms}$ and $11 \mathrm{~ms}$. The mass of fuel injected was measured for two minutes for every injection duration value. The gain and offset values were then determined and a polynomial was fitted as shown in Figure 2.7(a). Figure 2.7(b) illustrates the verification of the calibration of PFI injectors for iso-octane fuel. For mass flow rate of fuel greater than $100 \mathrm{mg} / \mathrm{s}$, an average error of $0.05 \mathrm{mg} /$ cycle was obtained. It was observed that the error increased significantly below $100 \mathrm{mg} / \mathrm{s}$. This can be attributed to the non-linear characteristics of the injector at very low Fuel flow rates. However, for practical applications, the minimum injection duration will be greater than $3 \mathrm{~ms}$. Therefore, this calibration factors hold good. The PFI injectors were also calibrated for n-heptane fuel and the same procedure was followed. Figure $22.8(\mathrm{a})$ and Figure 2.8(b) show the calibration and verification of the calibration for n-heptane, respectively. 


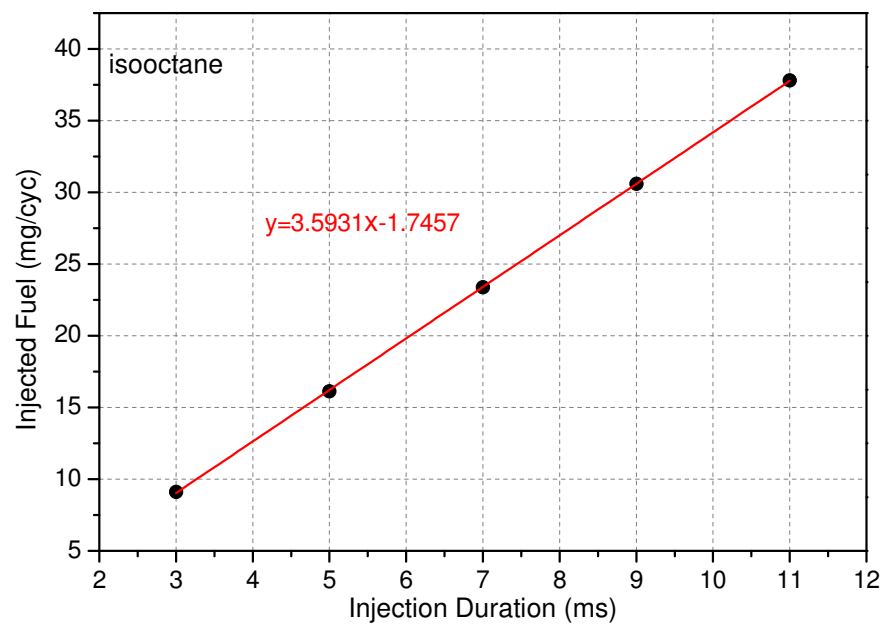

(a) Calibration

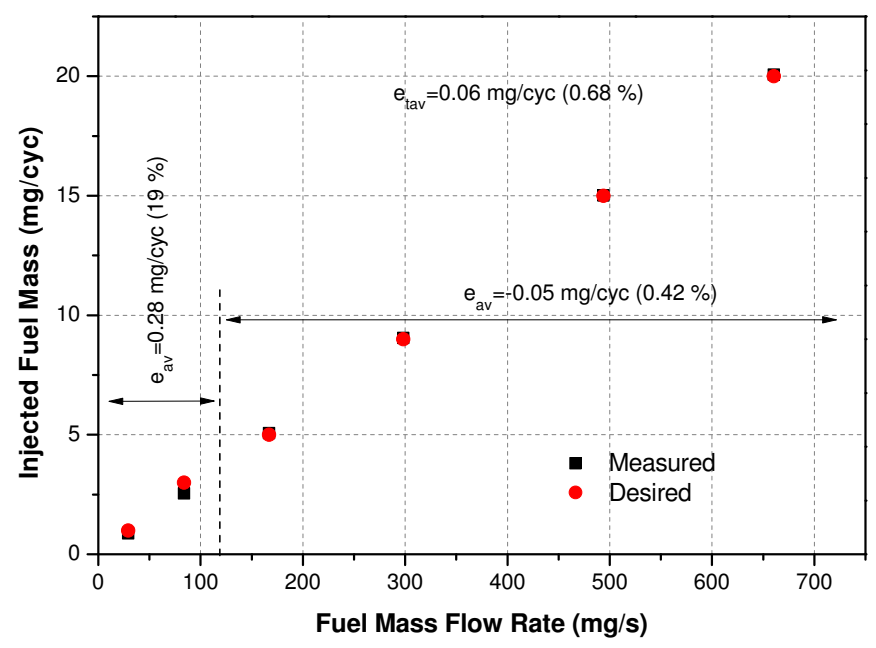

(b) Verification

Figure 2.7: Calibration and Verification of the PFI injectors for Iso-Octane fuel 


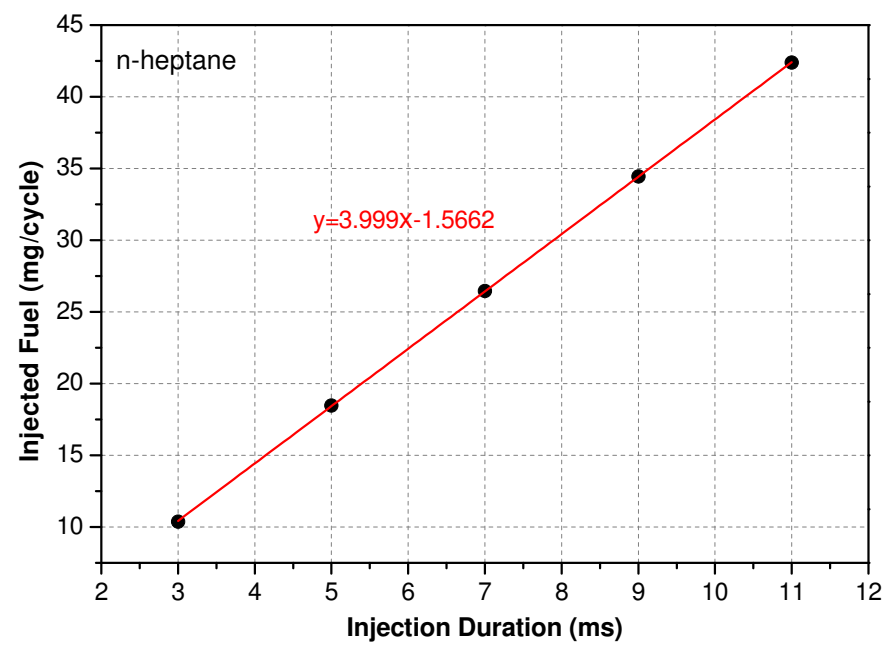

(a) Calibration

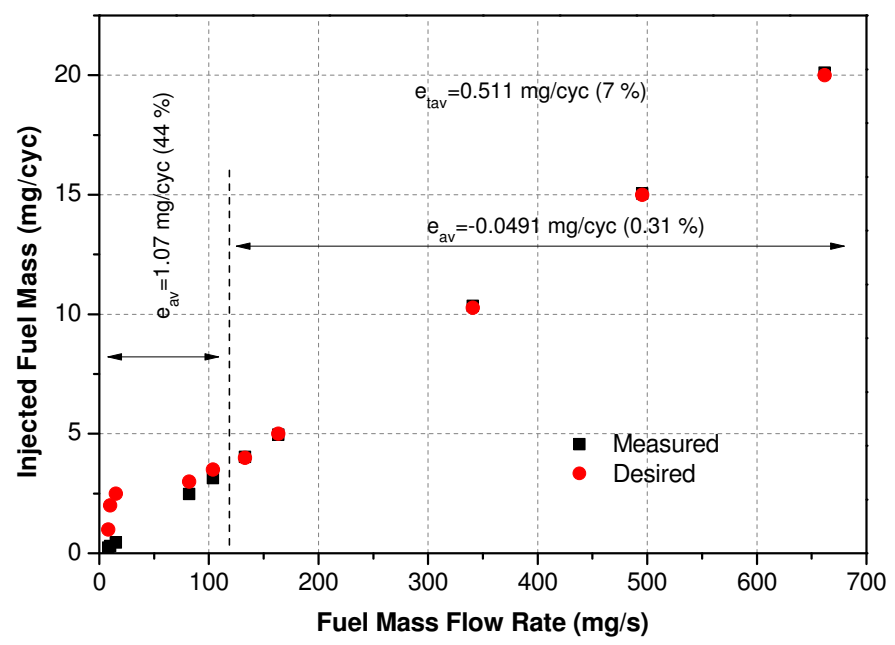

(b) Verification

Figure 2.8: Calibration and Verification of the PFI injectors for n-Heptane fuel 


\subsection{Supercharger control using dSpace}

The supercharger can either be controlled manually using the VFD unit or remotely by supplying an analog voltage between 0-10 V. The former method requires the user to manually change the frequency of the e-motor to attain the desired boost pressure. Supercharger VFD unit runs with a voltage range of 0-10 V. The user changes the frequency of the VFD unit and the VFD controller decides the voltage that needs to be supplied to run the e-motor at a given speed. The correlation between the terminal voltage and the operating frequency of the e-motor is given in Equation (2.1).

$$
V=\frac{\nu}{f_{\text {sys }}} f_{o}
$$

Where $\mathrm{V}$ is the terminal voltage, $f_{\text {sys }}$ is the operation frequency of the system and $f_{o}$ is the actual operating frequency of the e-motor.

The manual speed setting method is not time efficient and user friendly. Moreover, it is not applicable when the engine needs to be tested for transient conditions. Therefore, the latter method was developed and the supercharger was controlled and monitored using dSpace MicroAutoBox (MABX). MABX can supply analog voltage in the range of 0-4.75 V. Therefore, a voltage multiplier circuit was designed in order 
to amplify the voltage from $0-4.75 \mathrm{~V}$ to $0-9.5 \mathrm{~V}$. A schematic of the VFD with the phase monitor relay is depicted in Figure 2.9

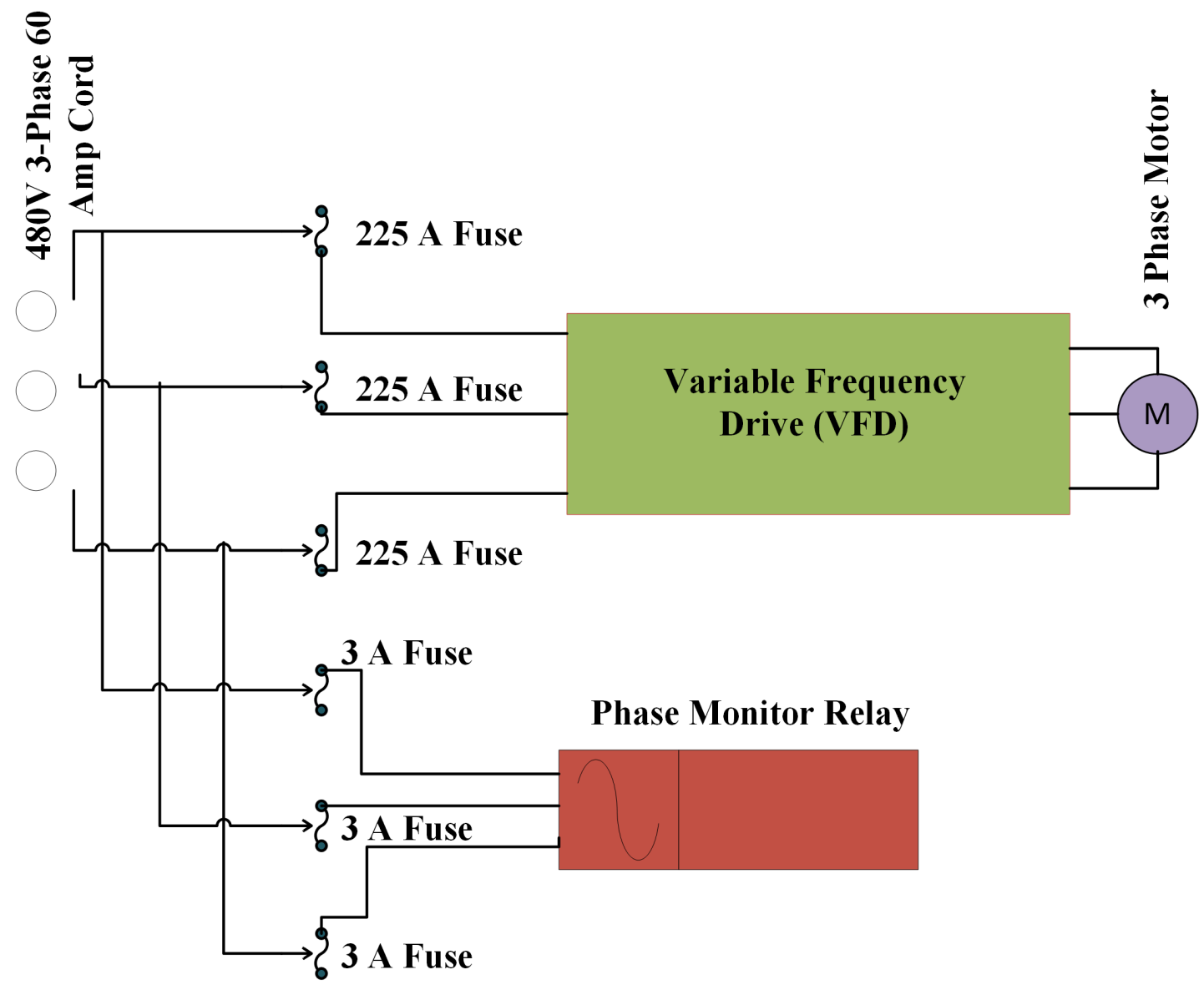

Figure 2.9: Supercharger VFD unit

In order to determine the required terminal voltage for a given boost pressure, two frequency maps with engine speed as a function of boost pressure were developed by operating the supercharger manually. These maps were then used as a lookup table in the Matlab Simulink model. Frequency maps were obtained for intake valve opening (IVO) of -24.5 and 25.5 CAD bTDC. Figure 2.10 illustrate the frequency maps for 
-24.5 and 25.5 CAD IVO bTDC.

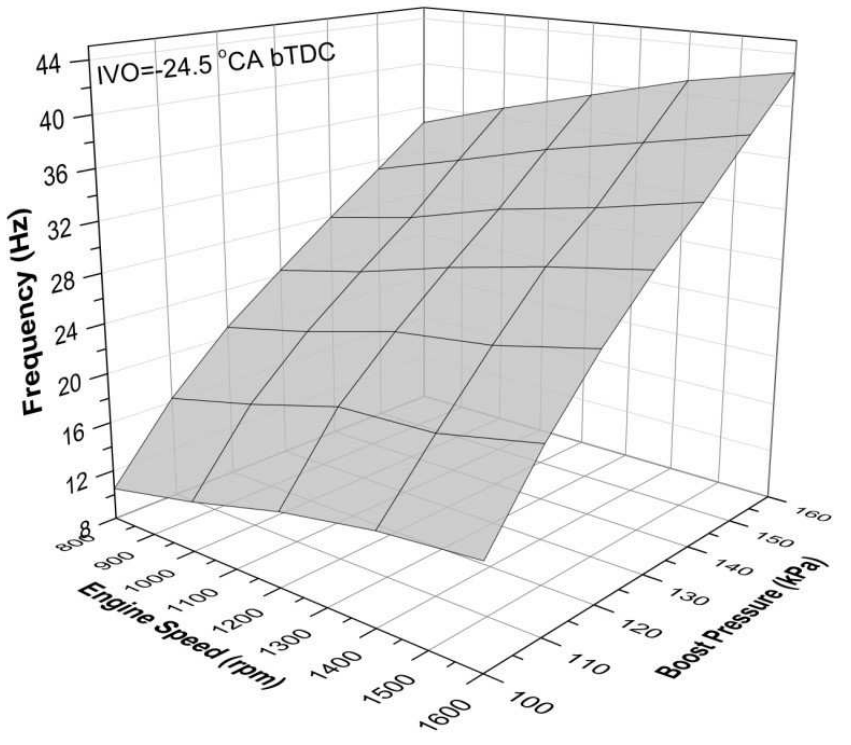

(a) $\mathrm{IVO}=-24.5 \mathrm{CAD}$ bTDC

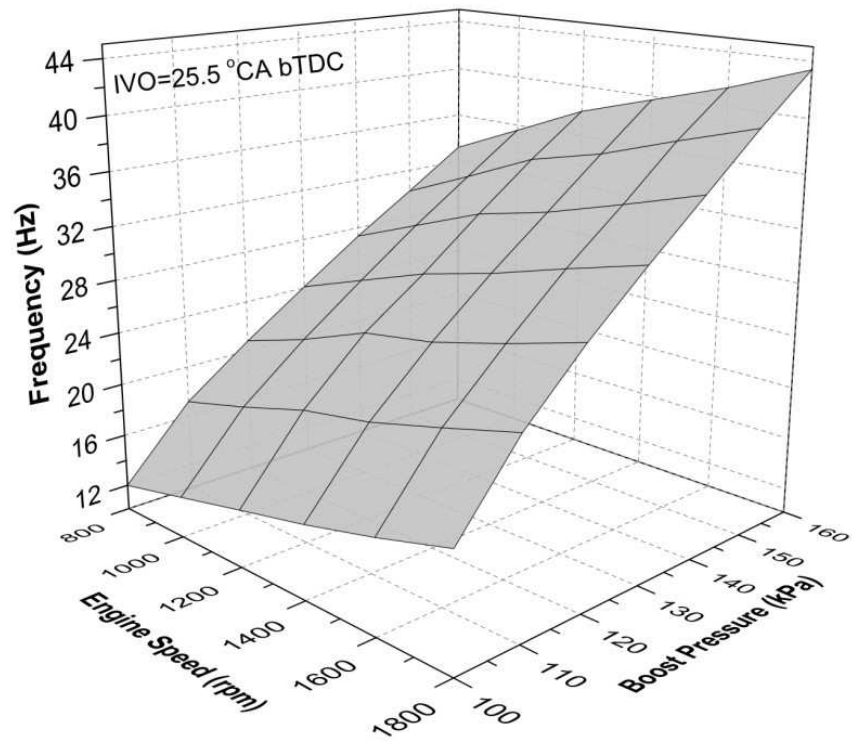

(b) $\mathrm{IVO}=25.5 \mathrm{CAD}$ bTDC

Figure 2.10: Supercharger Frequency maps for IVO of a) -24.5 CAD bTDC and b) 25.5 CAD bTDC 
Figure 2.11 shows the Matlab Simulink model developed for the MABX to supply the necessary terminal voltage to the VFD. The required frequency is determined from the look-up table. The desired manifold pressure is commanded by the user via dSpace control desk interface. Figure 2.12 shows the screenshot of the supercharger user control panel on the control desk interface. The model gets the instantaneous engine speed from the crank position sensor and frequency was determined from the look-up table. Determined frequency is converted to the voltage value by means of desired gain2 in the model. MicroAutoBox supplies the voltage in terms of duty cycle (in the range of 0-1). Therefore, the calculated voltage is converted to the duty cycle level via desired gain 3 in the model.

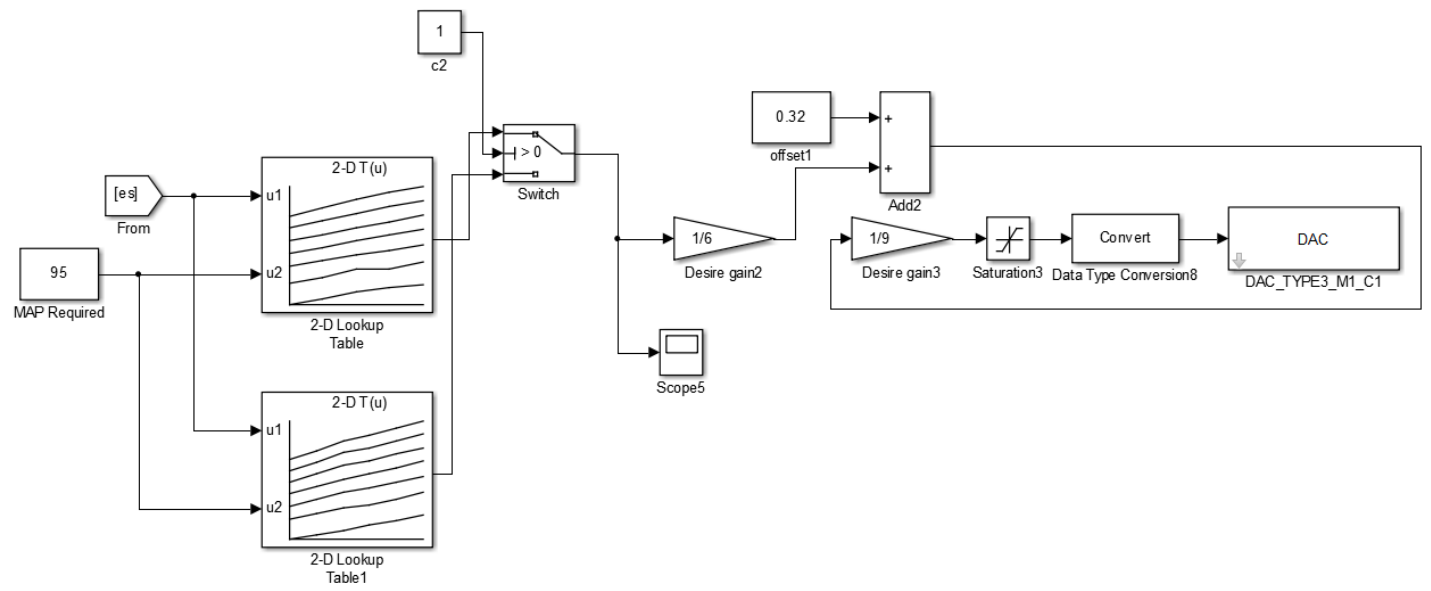

Figure 2.11: Simulink Model for Supercharger Control using dSpace

The Supercharger Control using dSpace has a mean error of $1.2 \mathrm{kPa}$ between the set desired manifold pressure and the output boost pressure. This difference resulted from the variable resistance of the electrical circuitry between the VFD and MABX. 
In order to compensate for the decrease in voltage, an average offset value of $0.32 \mathrm{~V}$ was used. Although there is a slight difference between the desired and actual values of MAP, the error was less than $1 \%$.

\section{MAP: Switch/Threshold}

$-1.79769313486232 \mathrm{E}+308.1 .79769313486232 \mathrm{E}+308$ Converted Incr. $+-1 / 10$

\begin{tabular}{|c|c|c|c|}
\hline & Variable & Value & Unit \\
\hline 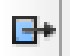 & Saturation3/Out1 & $0.18292462445 \ldots \frac{4}{\frac{1}{r}}$ & \\
\hline $\mathbf{P}$ & Saturation3/UpperLimit & $\stackrel{4}{\div}$ & \\
\hline P & Saturation3/LowerLimit & $\stackrel{4}{\square}$ & \\
\hline$\Xi$ & Scope $4 / \ln 1$ & $110.557892707 \ldots \frac{\hat{A}}{\frac{1}{4}}$ & \\
\hline$P$ & MAP Required/Value & $\div$ & \\
\hline P & Desire gain2/Gain & $0.16666666666 \ldots$ & \\
\hline$\Xi$ & Desire gain $2 /$ Out 1 & $1.32632162012 \ldots \frac{4}{\frac{1}{r}}$ & \\
\hline 田 & Scope5/ln1 & $7.95792972074 \ldots . \frac{4}{\frac{1}{r}}$ & \\
\hline$P$ & Switch/Threshold & 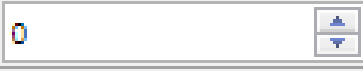 & \\
\hline$\Xi$ & Switch/Out1 & $7.95792972074 \ldots$ 会 & \\
\hline
\end{tabular}

Figure 2.12: Supercharger User Control panel on dSpace control desk 


\subsection{Engine Analysis Parameters}

A MATLAB code was developed for the combustion analysis. Data from dSpace, LabVIEW and ACAP were synchronized on a time basis and were used as the input to the code. The outputs of the code were the averaged in-cylinder pressure trace, average brake mean effective pressure, average intake manifold absolute pressure, piston displacement relative to the crank angle, instantaneous cylinder volume, stroke volume, combustion chamber volume, volumetric efficiency, lambda, equivalence ratio, maximum pressure rise rate (MPRR), gross work, indicted mean effective pressure (IMEP), Coefficient of Variance (COV) of indicated mean effective pressure, expansion and compression polytropic index, in-cylinder temperature prediction, heat transfer, heat release rate, cumulative heat release rate, CA10, CA50, CA90, fuel mass burn fraction, combustion duration, thermal efficiency, combustion efficiency, effective power, effective torque, effective specific fuel consumption, indicated power, indicated torque, indicated specific fuel consumption and mechanical efficiency.

\subsubsection{Engine Geometry}

Cylinder volume and first derivative of cylinder volume must be computed versus crank angle in order to calculate net work, heat release rate, indicate mean effective 
pressure, amount of heat transfer and some engine performance parameters.

The displacement volume, combustion chamber volume and the total cylinder volume were computed using Equations 2.2, 2.3 and 2.4, respectively.

$$
\begin{gathered}
V_{s}=\pi \frac{D^{2}}{4} H \\
V_{c}=\frac{V_{s}}{C R-1} \\
V_{\text {total }}=V_{s}+V_{c}
\end{gathered}
$$

Where $V_{s}$ is the displacement volume $\left(m^{3}\right), V_{c}$ is the combustion chamber volume $\left(m^{3}\right), V_{\text {total }}$ is the cylinder volume $\left(m^{3}\right), \mathrm{D}$ is the cylinder bore $(\mathrm{m}), \mathrm{H}$ is the stroke length $(\mathrm{m})$ and $\mathrm{CR}$ is the compression ratio.

The instantaneous piston displacement can be calculated using Equation 2.5.

$$
S=L+r-r \cos \theta-L \cos \beta
$$


The term $\cos \theta$ can be expressed in terms of crank angle $\theta$ as shown in the set of equations below [40].

$$
L \sin \beta=r \sin \theta
$$

$$
\sin \beta=\frac{r}{L} \sin \theta
$$

$$
\sin ^{2} \beta+\cos ^{2} \beta=1
$$

$$
\cos \beta=\sqrt{1-\sin ^{2} \beta}
$$

$$
\cos \beta=\sqrt{1-\left(\frac{r}{L} \sin \theta\right)^{2}}
$$

From Equation 2.5 and 2.10, the following correlation for piston displacement is obtained [40]. 


$$
\begin{aligned}
& S(\theta)=L+r-r \cos \theta-L \sqrt{1-\left(\frac{r}{L} \sin \theta\right)^{2}} \\
& S(\theta)=r(1-\cos \theta)+\frac{1}{\lambda}-\sqrt{\frac{1}{(\lambda)^{2}}-\sin ^{2} \theta}
\end{aligned}
$$

Where $\mathrm{L}$ is the connecting rod length $(\mathrm{m}), \mathrm{r}$ is the diameter of the crankshaft $(\mathrm{m}), \lambda$ is the ratio of diameter of the crankshaft to the connecting rod length, $\theta$ is the angle of the crank shaft (deg), and $\mathrm{S}(\theta)$ is the instantaneous displacement of the piston with respect to the crankshaft angle (rad).

The instantaneous cylinder volume with respect to the crank angle is given in Equation 2.13 ,

$$
V=V_{c}+\pi \frac{D^{2}}{4} S(\theta)
$$

The first derivative of instantaneous cylinder volume is given in Equation 2.14.

$$
\frac{d V}{d \theta}=\pi \frac{D^{2}}{4} r\left(\sin \theta+\frac{\cos \theta \sin \theta}{\left.\sqrt{\left(\frac{1}{\lambda^{2}}-\sin ^{2} \theta\right)}\right)}\right.
$$




\subsubsection{Net Work and Mean effective pressure}

The work and indicated mean effective pressure (IMEP) can be calculated for each cycle using in-cylinder pressure data. IMEP values can be used in determining the engine efficiency since IMEP values are independent of the cylinder volume, cylinder number and engine speed.

Pressure data for the gas in the cylinder over operating cycle of the engine can be used to calculate the work transfer from gas to the piston. The cylinder pressure and corresponding cylinder volume throughout the engine cycle can be shown on a P-V diagram. The indicated work per cycle is obtained by the area under the curve on the PV diagram.

$$
W=\oint P d V
$$

Where, $\mathrm{W}$ is work (Joule), $\mathrm{P}$ is cylinder pressure $(\mathrm{Pa})$ and $\mathrm{dV}$ is displaced volume $\left(m^{3}\right)$. There are two ways of defining the work done per cycle. Gross indicated work per cycle $W_{\text {gross }}$; work delivered to the piston over the compression and expansion stroke only. Net indicated work per cycle $W_{\text {net }}$; work delivered to the piston over the entire four stroke cycle. $W_{\text {gross }}=($ area $\mathrm{A}+\operatorname{area} \mathrm{B})$ and $W_{\text {net }}=(\operatorname{area} \mathrm{A}+\operatorname{area} \mathrm{C})$ 
- $(\operatorname{area} B+\operatorname{area} C)=(\operatorname{area} A-\operatorname{area} B)$, where each of these areas is regarded as a positive quantity. Area $\mathrm{B}+$ area $\mathrm{C}=$ work transfer between the piston and the cylinder gases during the inlet and exhaust strokes and is called the pumping work $\left(W_{\text {pump }}\right)$. In case of naturally aspirated engines, the pumping work transfer will be to the cylinder gases because the pressure during the inlet stroke is less than the pressure during the exhaust stroke [41]. The pumping work transfer will be from the cylinder gases to the piston if the exhaust stroke pressure is lower than the intake pressure, which is normally the case with highly loaded turbocharged engines. Net work is equal to area $\mathrm{A}$ - area B.

$$
\begin{gathered}
W_{\text {net }}=W_{\text {gross }}-W_{\text {pump }} \\
I M E P_{\text {gross }}=\frac{W_{\text {gross }}}{V_{k}} \\
I M E P_{\text {net }}=\frac{W_{\text {net }}}{V_{k}}
\end{gathered}
$$




\subsubsection{Polytropic Index}

The polytropic index remains constant during the compression and expansion process but it changes during the combustion process. Start and end of combustion can be determined through keen observation of polytropic index. The polytropic index during compression and expansion stroke can be expressed as follows:

$$
P V^{n_{c}}=C
$$

$$
n_{c} P V^{n_{c}-1} d V+d P V^{n_{c}}=0
$$

$$
n_{c}=-\frac{V d P}{P d V}
$$

\subsubsection{Combustion Stability}

Combustion stability is defined in terms of Coefficient of Variation of the Net IMEP. Compared to traditional S.I. engines, the initiation of HCCI combustion and the 
following heat release process are controlled by the chemical reaction rates, which depend on the temperature, pressure and mixture properties including fuel composition, air/fuel ratio and EGR rate. Numerous factors that influence the mode and extent of cycle-to-cycle variation have been identified. These include fluctuations in the following parameters and factors: (1) intake temperature and pressure; (2) intake air/fuel ratio or fuel flow rate; (3) coolant and lubrication oil temperatures; (4)the presence of diluents as a result of either external or internal EGR; (5) thermal and mixture composition stratification as results of in-homogeneity; (6) the intensity of intake charge motion and bulk turbulence; (7) the completeness of combustion in the preceding cycle; and (8) fuel mixing system and homogeneous mixture formation strategies [16], [42].

The $C O V_{I M E P}$ is calculated by:

$$
C O V_{\text {imep }}(\%)=\frac{\sigma_{\text {imep }}}{\mu_{\text {imep }}} x 100
$$

where $\sigma_{i m e p}$ is the standard deviation of IMEP and $\mu_{i m e p}$ is the mean in IMEP. 


\subsubsection{Heat Transfer Coefficient Correlation}

The heat losses account towards approximately $10-15 \%$ of the energy which is transferred to the cylinder as a result of ignition of fuel during the combustion [40]. Force and net work which is applied over the piston decrease due to heat loss from the piston, piston ring crevices, combustion chamber surfaces and cylinder walls. So, thermal efficiency and engine performance are influenced by heat transfer. Heat flux drops to the negative and heat is transferred from cylinder walls to the charge mixture as the temperature of the cylinder charge mixture is lower than the temperature of

cylinder walls. Heat flux rises to the highest level and heat is transferred from charge mixture to the cylinder during combustion especially at maximum cylinder pressure and temperatures [31, 32, 33].

According to Newton's law of cooling, heat transfer to the cylinder walls can be calculated as follows [40]:

$$
\begin{gathered}
\frac{d Q_{h t}}{d \theta}=\frac{1}{6 n} h_{g} A\left(T_{g}-T_{w}\right) \\
A=\frac{V}{A_{p}} \pi D+2 A_{p}
\end{gathered}
$$




$$
A_{p}=\frac{\pi D^{2}}{4}
$$

Where, $\frac{d Q_{h t}}{d \theta}$ is instant heat transfer versus crank angle $(\mathrm{J} / \mathrm{deg}), \mathrm{n}$ is engine speed $(\mathrm{RPM}), h_{g}$ is the instantaneous convection heat transfer coefficient, $\mathrm{W} /\left(m^{2} \mathrm{~K}\right), T_{g}$ is instantaneous in-cylinder mean gas temperature versus crank angle degree $(\mathrm{K}), T_{w}$ is cylinder wall temperature $(\mathrm{K}), A$ is heat transfer surface area versus crank angle $\left(m^{2}\right), V$ is instantaneous cylinder volume versus crank angle $\left(m^{3}\right), D$ is cylinder bore (m) and $A_{p}$ is piston crown area $\left(m^{2}\right)$

$h_{g}$ (Convection heat transfer coefficient) is dependent on cylinder bore, cylinder volume, in-cylinder pressure, in-cylinder gas temperature and mean in-cylinder gas velocity. A correlation was obtained by Woschni for the calculation of the convection heat transfer coefficient as defined in Equation 2.26 and it was used commonly in the internal combustion engines [40, 42, 43].

$$
h_{g}=3.26 D^{-0.2} T_{g}^{-0.55} P^{0.8} w^{0.8}
$$

Where, $\mathrm{D}$ is the cylinder bore $(\mathrm{m}), \mathrm{P}$ is the in cylinder pressure $(\mathrm{kPa})$ and $\mathrm{w}$ is the mean gas velocity $(\mathrm{m} / \mathrm{s})$.

However, in case of low temperature combustion modes, the heat release in cylinder 
occurs faster than conventional engines like SI and CI and the combustion duration is shorter. Therefore, in LTC engines, heat transfer ratio is less than that in conventional engines. For this reason, Chang at al [44] suggested a modified Woschini model for HCCI engines and a new correlation for LTC engines was developed. Therefore, Equation (2.27) and (2.28) are used for the calculation of heat transfer coefficient.

$$
\begin{gathered}
h_{g}=\alpha_{\text {scaling }} L^{-0.2} T_{g}^{-0.73} P^{0.8} \nu_{\text {tuned }}^{0.8} \\
\nu_{\text {tuned }}=c_{1} S_{p}+\frac{\frac{c_{2}}{6} V_{d} T_{r}}{P_{r} V_{r}}\left(P-P_{\text {motored }}\right)
\end{gathered}
$$

In the equation used, $T_{g}$ is calculated based on the ideal gas law over the closed cycle (compression and expansion).

\subsubsection{Combustion Efficiency}

Combustion efficiency is calculated by the proportion of the total released energy to the total energy delivered to the cylinder between the start and end of combustion [42. The start of combustion of charge mixture can be determined via the second derivative of cylinder pressure value which rises from negative to positive values. 
Similarly, the end of combustion can be determined via second derivative of cylinder pressure value closest to the zero. Fuel delivered to the cylinder in a cycle must be determined in order to find combustion efficiency. The combustion efficiency is calculated based on the equation given below [42].

$$
\eta_{\text {combustion }}=\int_{t_{\text {start }}}^{t_{\text {end }}} \frac{\frac{d Q_{\text {in }}}{d \theta} d \theta}{m_{f} Q_{L H V_{\text {fuel }}}}
$$

where $m_{f}$ is the mass of fuel, $Q_{L H V_{f u e l}}$ is the heating value of the fuel and $d Q_{i n}$ is the cumulative heat release rate.

\subsection{Filter Design for Pressure trace}

There are four steps involved in the analysis of In-cylinder pressure: level correction, angle referencing, cycle averaging and filtering. This chapter stresses on the last two steps. There are different types of filters that can be used for reducing the effect of noise and interference on the signal. Two common types of filters are Infinite impulse response (IIR) and Finite Impulse Response (FIR) filters. The latter is based on linear phase characteristics of a system, whereas the former is used for systems which are nonlinear. 
In this study, different filters were studied and the most efficient one in terms of noise elimination was used for the In-cylinder pressure analysis. Initially, a center weighted moving average filter was proposed for post processing of the pressure data. However, it was observed that a moving average filter may not eliminate duct resonances properly. Moreover, sharp pressure fluctuations were also distorted. It was also observed that the sampling interval played an important role in determining the smoothing capability of the filter. Payri et. al. [45] suggested that this smoothing method was not frequency sensitive since the sharp heat release peaks were smoothed and hence not recommended. There are a wide range of IIR filters such as Butterworth filter, Chebyshev filter, Bessel filter etc. Among all these filters, Butterworth has the flattest passband and poor roll off rate. Chebyshev filter has a steeper roll off and more pass band ripple than a Butterworth filter. Since the filtering was done offline, the order of the filter had to be chosen in such a way that the roll-off is not very steep as a faster roll-off in the frequency domain corresponds to a slower response rate in the time domain.

In order to determine the filter cut-off frequency, spectral analysis of the pressure trace was performed. With the use of a MATLAB script, a Fast Fourier Transform (FFT) was performed on the pressure trace and the power spectral density of the cylinder pressure signal was obtained. Based on the power spectral density of the trace, the filter cut off frequency was determined. A low pass Butterworth filter was used to filter the pressure trace. The filter cutoff frequency was varied based on the 
operating conditions and the cut-off frequency for each set of data.

\subsection{Uncertainty in Analysis}

Uncertainty analysis refers to the process of estimating the impact that uncertainties in measurement have on the estimated parameters. This provides the experimentalist a rational way of evaluating the significance of the derived and independent parameters on each other. In order to understand the uncertainties involved in measurement, an uncertainty analysis is performed on the experimental data. As already discussed in this chapter, most of the thermodynamic parameters are evaluated from the in-cylinder pressure trace. Some of these properties are MPRR, heat release rate, combustion phasing, Burn Duration, IMEP and thermodynamic efficiencies. To evaluate these parameters, the geometry of the engine and the thermodynamic properties at different states of the cycle are taken as the inputs. The calculated parameter Y can be expressed as a function of one or more independent variables.

$$
Y=f\left(X_{1}, X_{2}, \ldots . X_{i}\right)
$$

Using the Uncertainty analysis, the uncertainties involved in each of the measured variables that propagate into the value of the calculated quantity can be estimated. 
Assuming the individual measurements to be uncorrelated and random, the uncertainty in the calculated quantity can be determined using the Root sum of Squares (RSS) method. This method for determining the uncertainty propagation is described in NIST Technical Note 1297 (Taylor B.N and Kuyatt).

$$
U_{Y}=\sqrt{\sum\left(\frac{\partial Y}{\partial X_{i}}\right)^{2} U_{x}^{2}}
$$

A list of independent parameters used for calculation and post processing is given in Table 2.3 ,

Table 2.3

Uncertainties involved in Measurement of independent parameters during experimentation

\begin{tabular}{|l|l|l|}
\hline \multicolumn{1}{|c|}{ Parameter } & \multicolumn{1}{c|}{ Value } & Uncertainty $( \pm)$ \\
\hline Pin-cylinder & $2500-6000(\mathrm{kPa})$ & $1(\%)$ \\
\hline Crank angle & $0-720(\mathrm{deg})$ & $1(\mathrm{deg})$ \\
\hline$T_{\text {intake }}$ & $40-60-80-100\left({ }^{\circ} \mathrm{C}\right)$ & $2 \%$ \\
\hline Lambda & $1-5.4$ & 0.05 \\
\hline Mass flow rate of intake air & $8.1-66.7(\mathrm{~g} / \mathrm{s})$ & $0.72 \%$ \\
\hline Mass flow rate of supply fuel & $7.4-48(\mathrm{mg} / \mathrm{cycle})$ & $0.1 \%$ \\
\hline Manifold absolute pressure & $95-140 \mathrm{kPa}$ & $0.5 \%$ \\
\hline Coolant temperature & $60-80\left({ }^{\circ} \mathrm{C}\right)$ & $2 \%$ \\
\hline Engine mounted oil temperature & $70-90\left({ }^{\circ} \mathrm{C}\right)$ & $2 \%$ \\
\hline$T_{\text {exhaust }}$ & $215-450\left({ }^{\circ} \mathrm{C}\right)$ & $2 \%$ \\
\hline
\end{tabular}

As explained in Table 2.4, the range of uncertainties can be obtained for the range 
Table 2.4

Range of Uncertainties involved in estimation of parameters

\begin{tabular}{|l|l|l|}
\hline \multicolumn{1}{|c|}{ Parameter } & Range of Values & Range of Uncertainty $( \pm)$ \\
\hline \hline Burn Duration $(\mathrm{CAD})$ & $3-31$ & 1 \\
\hline CA50 $(\mathrm{CAD}$ aTDC) & $-8-15$ & 1 \\
\hline ISFC $(\mathrm{g} / \mathrm{kWh})$ & $110-325$ & $1.2-6.4$ \\
\hline BSFC $(\mathrm{g} / \mathrm{kWh})$ & $130-380$ & $2.4-14.5$ \\
\hline IMEP $(\mathrm{kPa})$ & $280-1300$ & $0.5-15.5$ \\
\hline$\eta_{\text {ind }, \text { th }}(\%)$ & $25.5-47.9$ & $0.21-2.32$ \\
\hline$\eta_{\text {comb }}(\%)$ & $75.3-95.8$ & $0.6-2.2$ \\
\hline
\end{tabular}

of parameters listed in the table, using the procedure discussed earlier in the section. All error bars for this thesis are calculated using the same procedure and lie in the range of values listed in the table.

Table 2.5 summarizes the uncertainties involved in calculation of the combustion and performance parameters with respect to the independent parameters. 


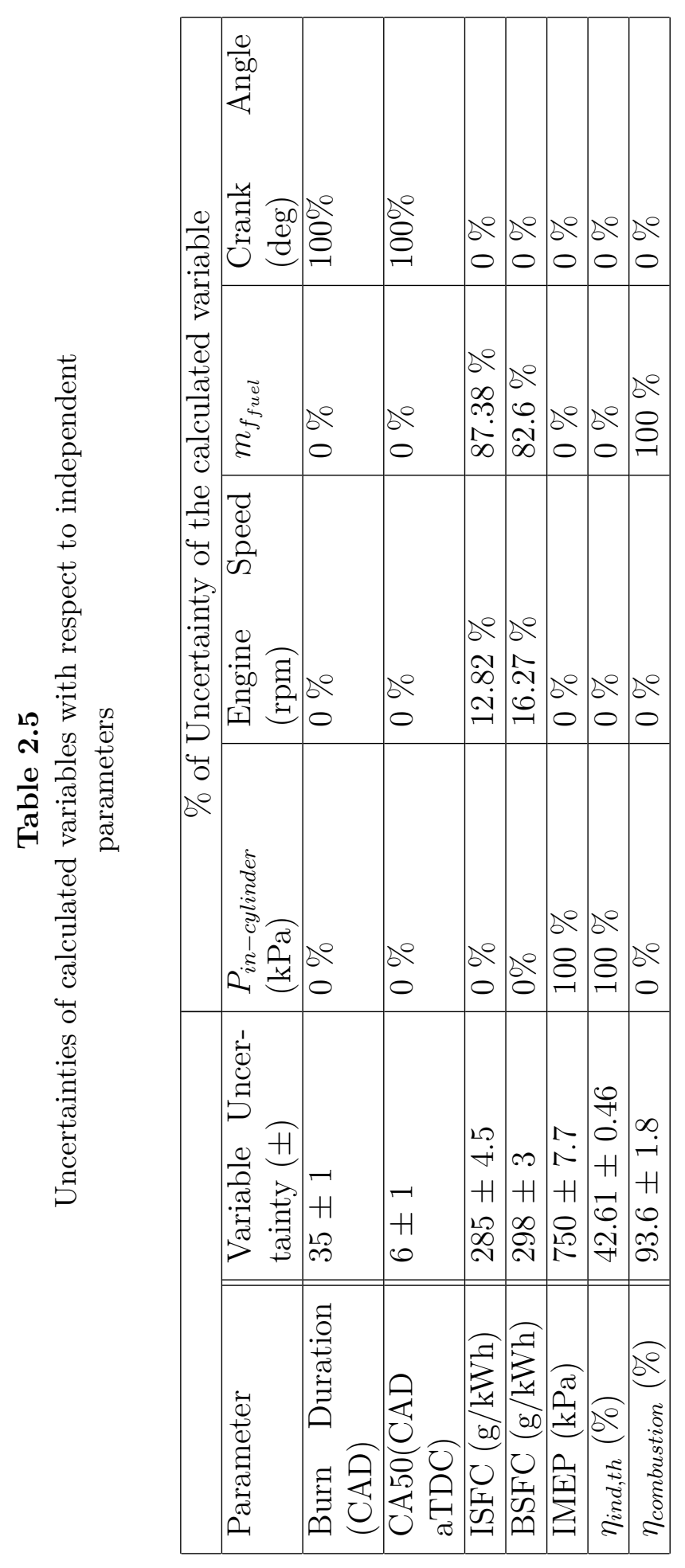


To build confidence in collected data, a repeatability of test was conducted. The tests were performed at three different time stamps in order to calculate the error in calculated variables while keeping all controlled parameters constant. The operating conditions for the tests are described in Table 2.6. The mean and standard deviation for the test points are given in Table 2.7

Table 2.6

Test parameters

\begin{tabular}{|l|l|}
\hline \multicolumn{1}{|c|}{ Parameter } & Value/Description \\
\hline \hline Combustion Mode $(-)$ & RCCI \\
\hline Engine Speed (RPM) & 1000 \\
\hline Boost Pressure (kPa) & 120 \\
\hline Intake Air Temperature $\left({ }^{\circ} \mathrm{C}\right)$ & 40 \\
\hline Fuel Mass (mg/cycle) & 15 \\
\hline SOI (deg bTDC) & 33 \\
\hline IVO (deg bTDC) & 25.5 \\
\hline EVC (deg bTDC) & 22 \\
\hline Fuel Premixed Ratio (PR) (-) & 20 \\
\hline
\end{tabular}

Table 2.7

Mean and Standard deviation for repeatability (three trials)

\begin{tabular}{|l|l|l|}
\hline \multicolumn{1}{|c|}{ Parameter } & Mean & Std Dev \\
\hline \hline Intake Air Temperature $\left({ }^{\circ} \mathrm{C}\right)$ & 40.6 & 0.5 \\
\hline Boost Pressure $(\mathrm{kPa})$ & 121.5 & 1.3 \\
\hline CA50 $(\mathrm{CAD}$ aTDC) & 7 & 1 \\
\hline ISFC $(\mathrm{g} / \mathrm{kWh})$ & 224.7 & 3.2 \\
\hline IMEP $(\mathrm{kPa})$ & 527.3 & 2.5 \\
\hline$\lambda(-)$ & 2.34 & 0.2 \\
\hline
\end{tabular}




\section{7 $\quad$ BMEP Parametrization}

Even though the brake torque from the engine dynamometer was calculated using ACAP combustion analyzer, there was significant noise in the signal captured, as a result of which the mechanical efficiency of a large number of tests were lesser than expected. However, the exhaust temperature measurement corroborated the speculation, since it was seen that all engine cylinders were firing at the time of data acquisition. As a result of this, the measured values of the brake parameters were not credible. Thus, there arises the need for developing friction models to estimate the brake parameters.

Simple models can be used to estimate the FMEP, making use of a few independent variables, typically one related to the engine load and the other related to the engine speed, in order to separately account for the energy dissipated by friction due to the mass of fuel burned and the losses due to the speed. The Chen and Flynn model is one of the widely used friction model for the estimation of FMEP [46]. It is based on the following equation:

$$
F M E P=A+B P_{\max }+C n+D n^{2}
$$


As shown, this equation accounts for the engine speed (n) effect through constants C and $\mathrm{D}$, while the load effect is represented by the maximum in cylinder pressure $\left(P_{\max }\right)$ through constant B. In order to be more precise in the estimation of FMEP, a higher order polynomial was developed and the load factor was accounted for, introducing the second and third power of $P_{\max }[46]$.

$$
F M E P=A+B P_{\max }+C P_{\max }^{2}+D P_{\max }^{3}+E n+F n^{2}
$$

The friction model was parameterized separately for each combustion mode and the corresponding coefficients were used for the estimation of FMEP and BMEP for the respective combustion regime in this thesis.

\subsection{Accounting for Supercharger losses}

Superchargers are usually mounted on the engine and draw power from the engine crankshaft. Thereby, a part of the power output from the engine is utilized for driving the supercharger. However, for the current setup, the supercharger is driven by an external E-motor which consumes electrical energy. The energy used in driving the supercharger needs to be accounted for. Therefore, based on an assumption that the supercharger is mounted on the engine, with a supercharger efficiency of 0.62 [47], 
the power consumed by the supercharger is calculated. The Eaton M62 supercharger used for this setup is capable of running at speeds upto 14,000 rpm. However, for the experiments performed, the full capacity of the supercharger was not utilized. The experiments were run at a boost pressure limit of 1.6 bar and speeds less than 3200 rpm. This corresponds to an inlet volume flow of less than $250 \mathrm{~m}^{3} / \mathrm{hr}$. Given the limited operating region, a well defined supercharger efficiency could not be estimated based on Figure 2.14. Therefore, based on the operating region of the map, an average value of 0.62 was assumed to be constant for all supercharger speeds.

$$
P_{\text {consumed }}=m_{f_{\text {air }}} P_{\text {boost }} \eta_{\text {supercharger }}
$$

The power consumed by the supercharger for a boost pressure of 1.2 bar and 1.4 bar were calculated for a speed range of 800 to $3200 \mathrm{rpm}$ as depicted in Figure 2.13 


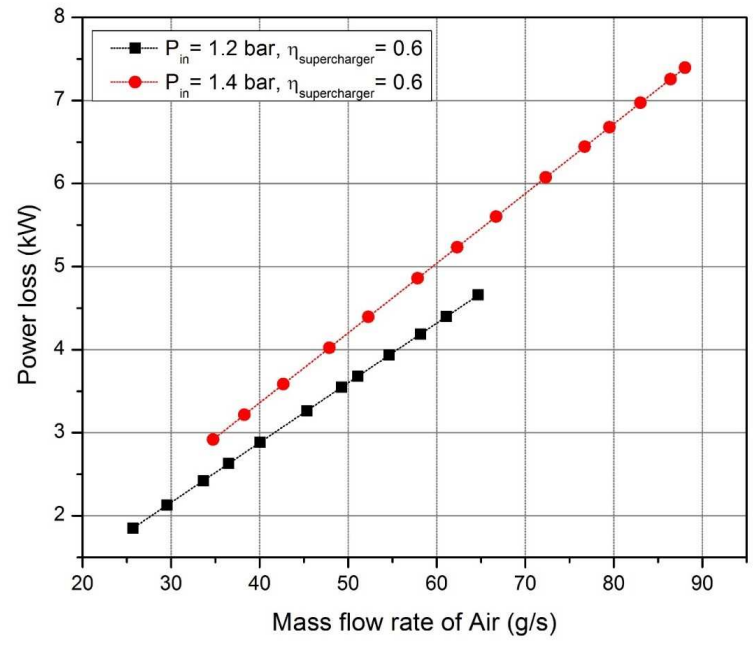

Figure 2.13: Supercharger power consumed if assumed to be mounted on the engine

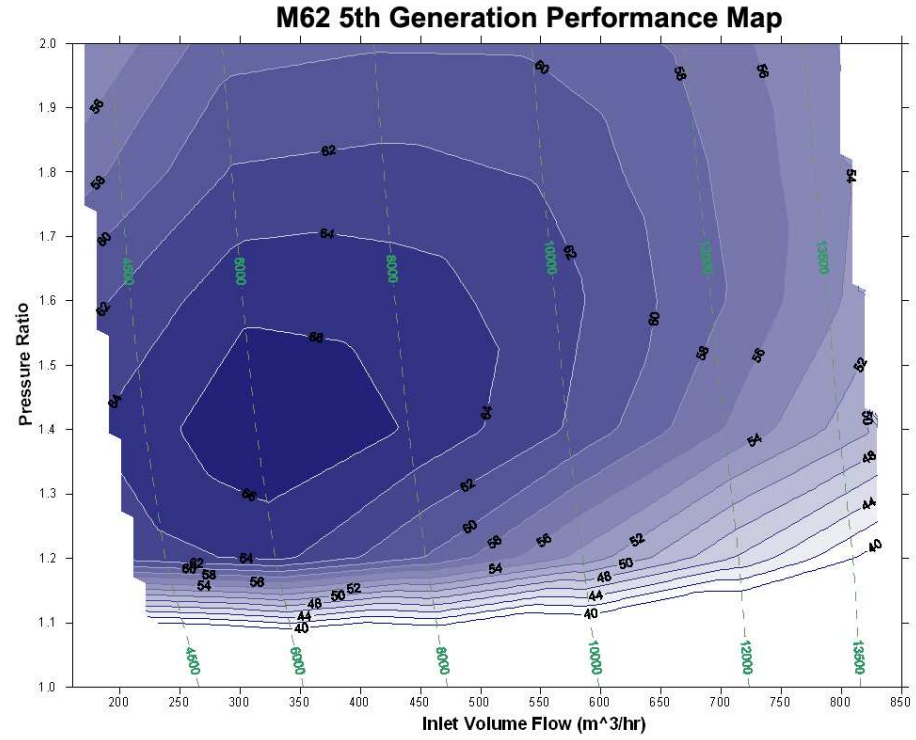

Figure 2.14: Supercharger performance map for Eaton M62 supercharger [3] 


\subsection{SI Map for Baseline Comparison}

There is a need to quantify the improvement in fuel consumption and thermal efficiency of the LTC modes on a relative basis. In order to carry out this task, a spark ignition (SI) map was developed for the engine as a baseline comparison, as shown in Figure 2.15. It can be observed that the engine speed is in the range of 1000-4000 rpm and the engine load is in the range of $370-860 \mathrm{kPa}$ IMEP. The best ISFC of $180 \mathrm{~g} / \mathrm{kWh}$ was obtained at an engine speed of $3000 \mathrm{rpm}$ and engine load of $390 \mathrm{kPa}$ IMEP.

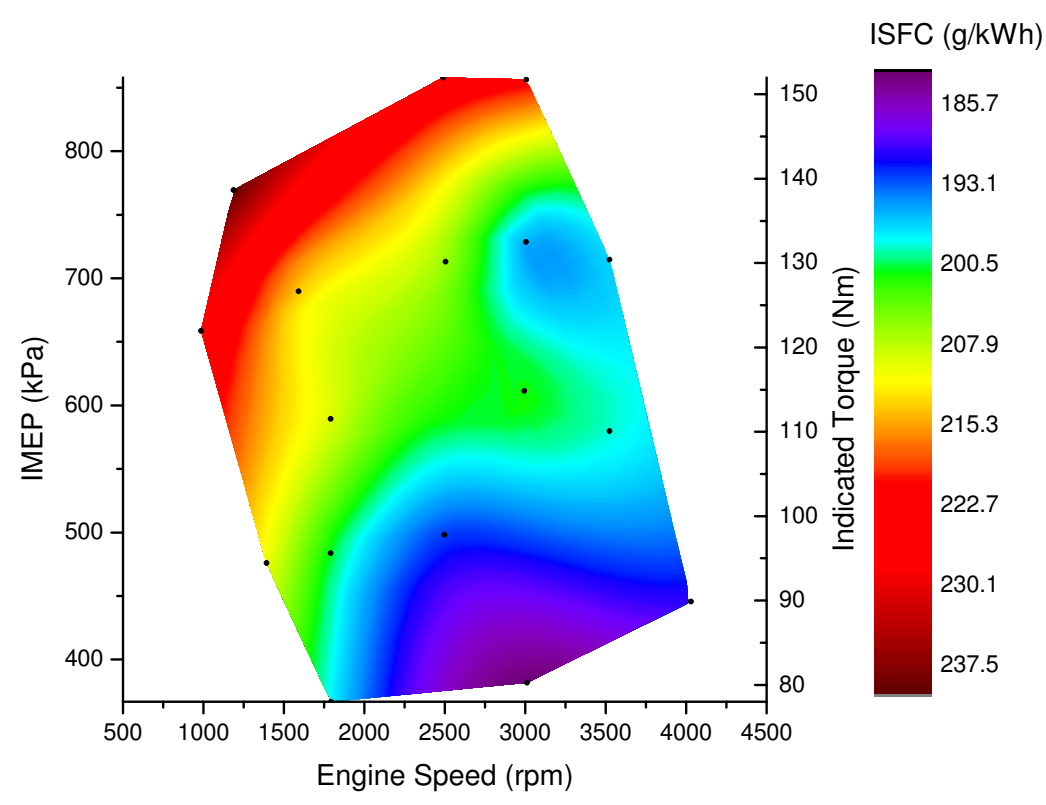

Figure 2.15: ISFC map for Spark Ignition (SI) mode 


\section{Chapter 3}

\section{Homogeneous Charge Compression Ignition (HCCI)}

In this chapter a discussion for the effect of operating parameters on HCCI combustion is presented and maps were developed to determine the operating region for the HCCI combustion regime. The engine was tested in HCCI combustion mode in order to determine the operating region of the engine. Operating parameters such as intake air temperature, boost pressure, engine speed, Research Octane number (RON) of fuel and equivalence ratio were varied. The data was acquired using dSpace, ACAP combustion analyzer and LabVIEW. The acquired data was post processed using a Matlab script developed for this purpose. All indicated parameters were calculated from the mean pressure trace over 100 engine cycles and crank angle (in deg). In 
order to estimate the brake parameters, the Flynn-Chen Friction Model was used to parametrize the FMEP and thereby the brake parameters were calculated. Using the post processed variables, maps for BSFC, exhaust gas temperature, IMEP and BMEP were created. The range of operating parameters are given in Table 3.1 .

Table 3.1

Operating Parameters for HCCI Combustion Mode

\begin{tabular}{|l|l|}
\hline \multicolumn{1}{|c|}{ Parameter } & Operating Conditions \\
\hline Intake Air Temperature & $40-60-80-100\left({ }^{\circ} \mathrm{C}\right)$ \\
\hline Manifold Pressure & $95-120-140(\mathrm{kPa})$ \\
\hline Engine Speed & $800: 200: 2400(\mathrm{rpm})$ \\
\hline RON of Fuel & $0-20-40(-)$ \\
\hline Lambda & $1.8-3.8(-)$ \\
\hline
\end{tabular}

\subsection{Parametrization of BMEP using Flynn-Chen}

\section{Model for HCCI combustion regime}

As shown in the Figure 3.1, a plot of experimental FMEP vs parameterized FMEP for HCCI combustion regime is depicted. It can be seen that the FMEP could be estimated within an error of $14 \%$. 


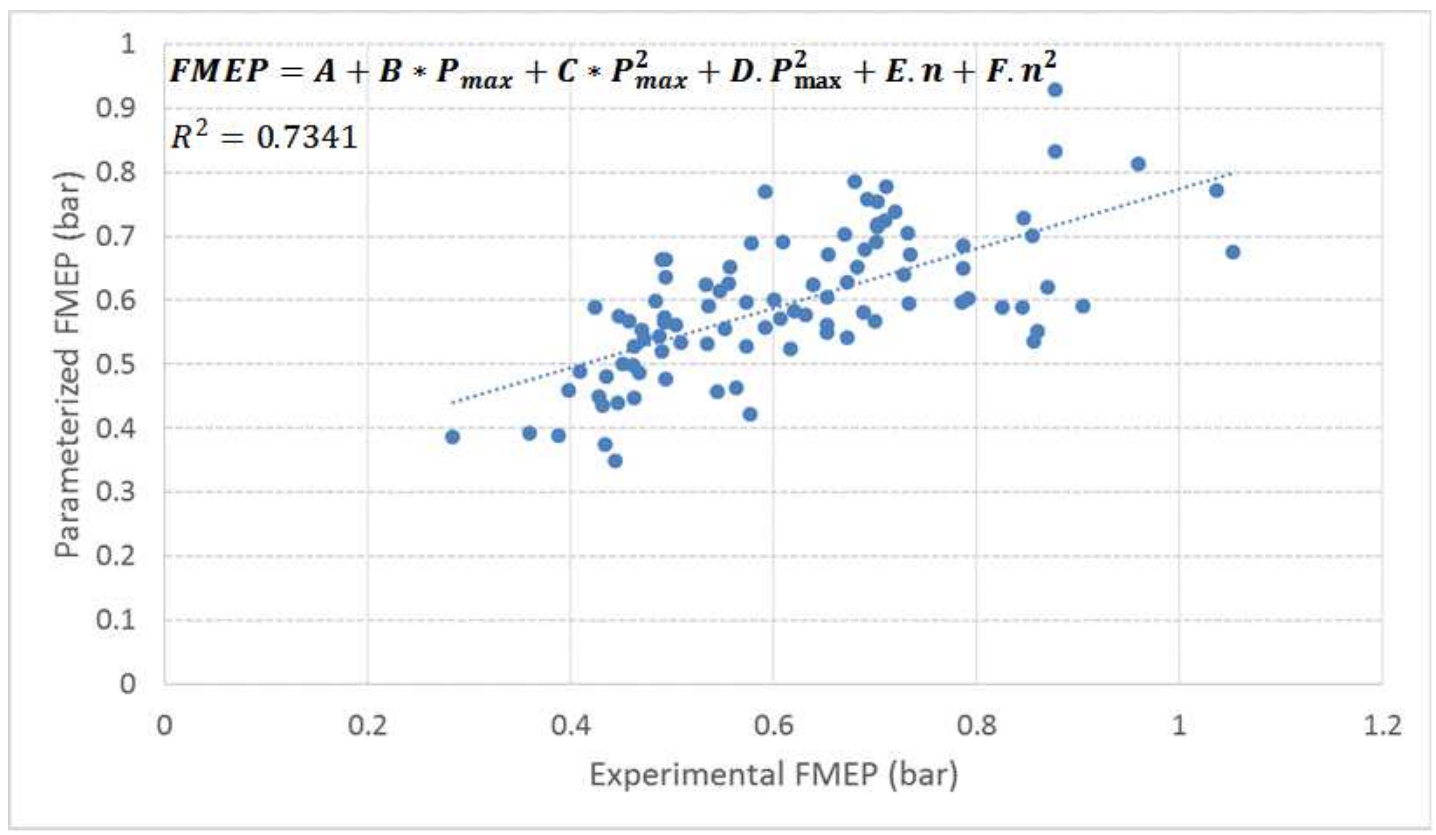

Figure 3.1: Experimental FMEP vs Parameterized FMEP

Table 3.2

Error in estimation of FMEP

\begin{tabular}{|l|l|}
\hline \multicolumn{1}{|c|}{ Model } & Chen-Flynn with $P_{\max }^{2}$ and $P_{\max }^{3}$ \\
\hline Mean relative error & $14 \%$ \\
\hline Max relative error & $37 \%$ \\
\hline Max absolute error & 0.75 bar \\
\hline
\end{tabular}

Based on the parametrized model for FMEP, the constants obtained for the equation are given in Table 3.3 
Table 3.3

Coefficients for the Flynn- Chen Model

\begin{tabular}{|l|l|}
\hline Coefficient & \multicolumn{1}{|c|}{ Value } \\
\hline A & -0.3052 \\
\hline B & 0.0604 \\
\hline C & -0.0016 \\
\hline D & $1.1159 \mathrm{E}-5$ \\
\hline E & -0.1159 \\
\hline F & 0.0316 \\
\hline
\end{tabular}

\subsection{Operating Range}

The operating range maps for HCCI combustion regime at three different operating conditions are shown in Figures 3.2 and 3.3 . Figure 3.2 (a) shows the operating range for RON 0, 20 and 40 at an intake temperature of $40{ }^{\circ} \mathrm{C}$ at naturally aspirated conditions. The results are in good agreement with some HCCI studies [48, 49], in which the operating range for a given octane number reduces with higher engine speeds. It is also apparent that the operating range changes significantly with change in RON. The operating range for RON 0 occurs at a leaner equivalence ratio as compared to RONs 20 and 40. Higher RON reflects a lower reactivity, requires relatively richer mixture to initiate the combustion. The mixtures with lower lambda values have higher energy content. Therefore, the engine load can be increased. However, the control of the SOC is very difficult at higher RONs especially at lower intake air 
temperatures. Studies have shown that HCCI engines operate well at part loads [4]. The pressure oscillations are larger at higher engine loads due to the high MPRR and HRR characteristics. Moreover, due to the rich fuel-air mixture at higher engine loads, the auto ignition is due to the locally rich zones in the cylinder. However, there is a higher knock intensity in these cases. Therefore, the homogeneous air-fuel mixture could be diluted with trapped residuals and reduce the gradient of the heat release rate. On the contrary, the compression and combustion temperatures and pressures are lower. In this case, dilution using residual gases can lead to unstable combustion and result in a misfire. The HCCI operating range is limited due to this characteristic of HCCI engines at high engine loads and speeds [50]. As illustrated in Figure 3.2 and Figure 3.3 , it is evident that there is a marked difference in the operating range for HCCI at an increased intake temperature and boost pressure. Higher intake temperatures and boost pressures result in enabling HCCI operation over a wider equivalence ratio and a larger speed range. This is mainly attributed to the mixture composition at IVC. With an increase in intake temperature and boost pressure, the density of the air decreases. This results in an increase in the mass flow rate of air being inducted into the cylinder, thereby making the mixture much leaner. 


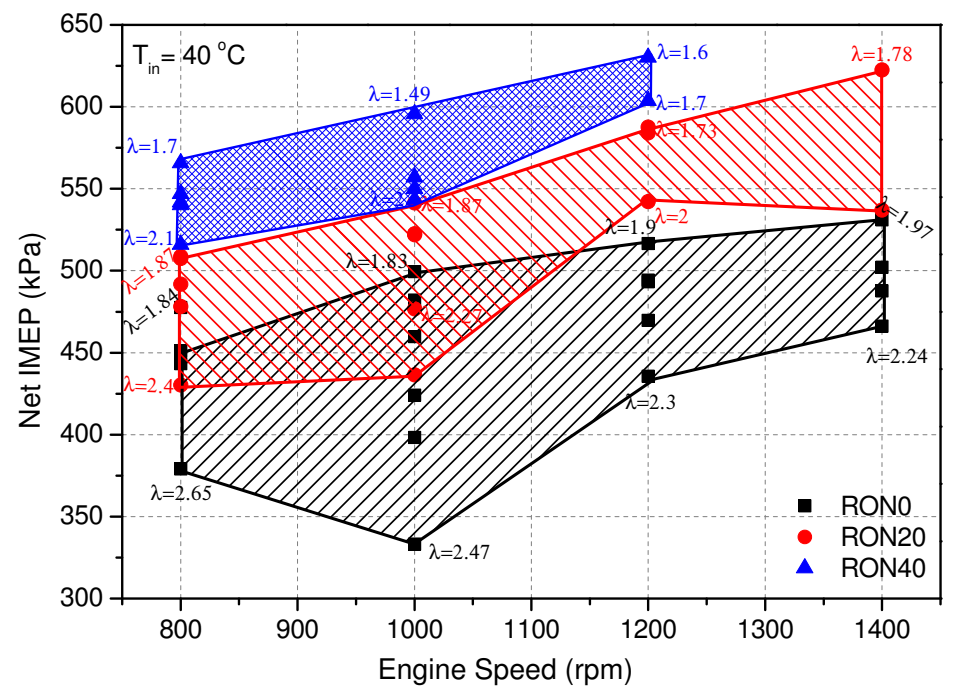

(a) $40{ }^{\circ} \mathrm{C}$ intake air temperature and naturally aspirated

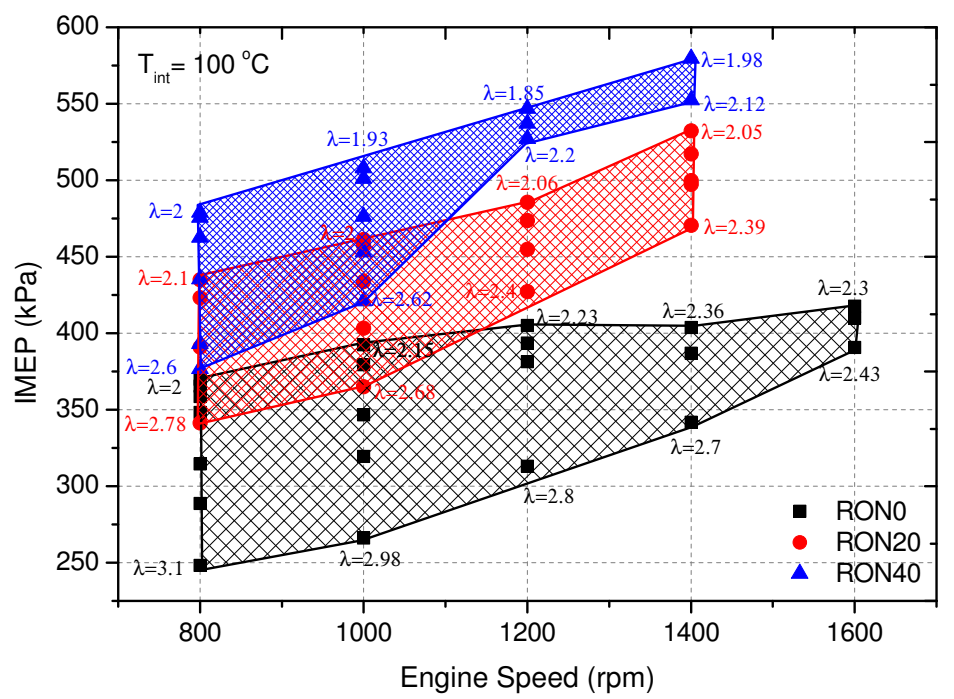

(b) $100{ }^{\circ} \mathrm{C}$ intake air temperature and naturally aspirated

Figure 3.2: HCCI IMEP and speed range 


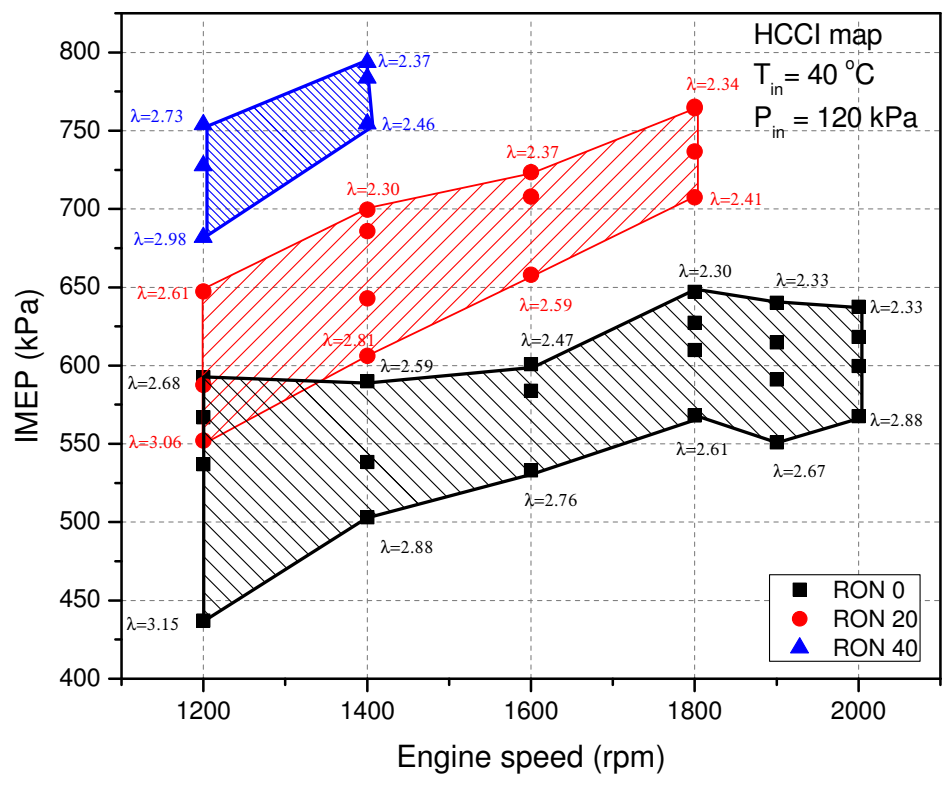

Figure 3.3: HCCI IMEP and speed range for $40{ }^{\circ} \mathrm{C}$ intake air temperature and $120 \mathrm{kPa}$ intake pressure

\subsection{Maps for ISFC, BSFC, Indicated Thermal Ef- ficiency and Exhaust Gas Temperature}

ISFC is an indicator as to how efficient the engine is, in utilizing the fuel supplied to do useful work, without accounting for the friction losses [51]. Figure 3.4 shows the ISFC map for HCCI combustion regime for RON 0, 20 and 40 at an intake air temperature of $40{ }^{\circ} \mathrm{C}$ and naturally aspirated conditions. It can be observed that the minimum ISFC is at the low loads for RON 40 with a value of $205 \mathrm{~g} / \mathrm{kWh}$. The trend 
shows that the ISFC improves with higher RON, where the combustion pressures and the heat release rates are lower [52]. The low ISFC at these points is a result of the combustion phasing being optimized where the compression work is minimized and expansion work is maximized [53].
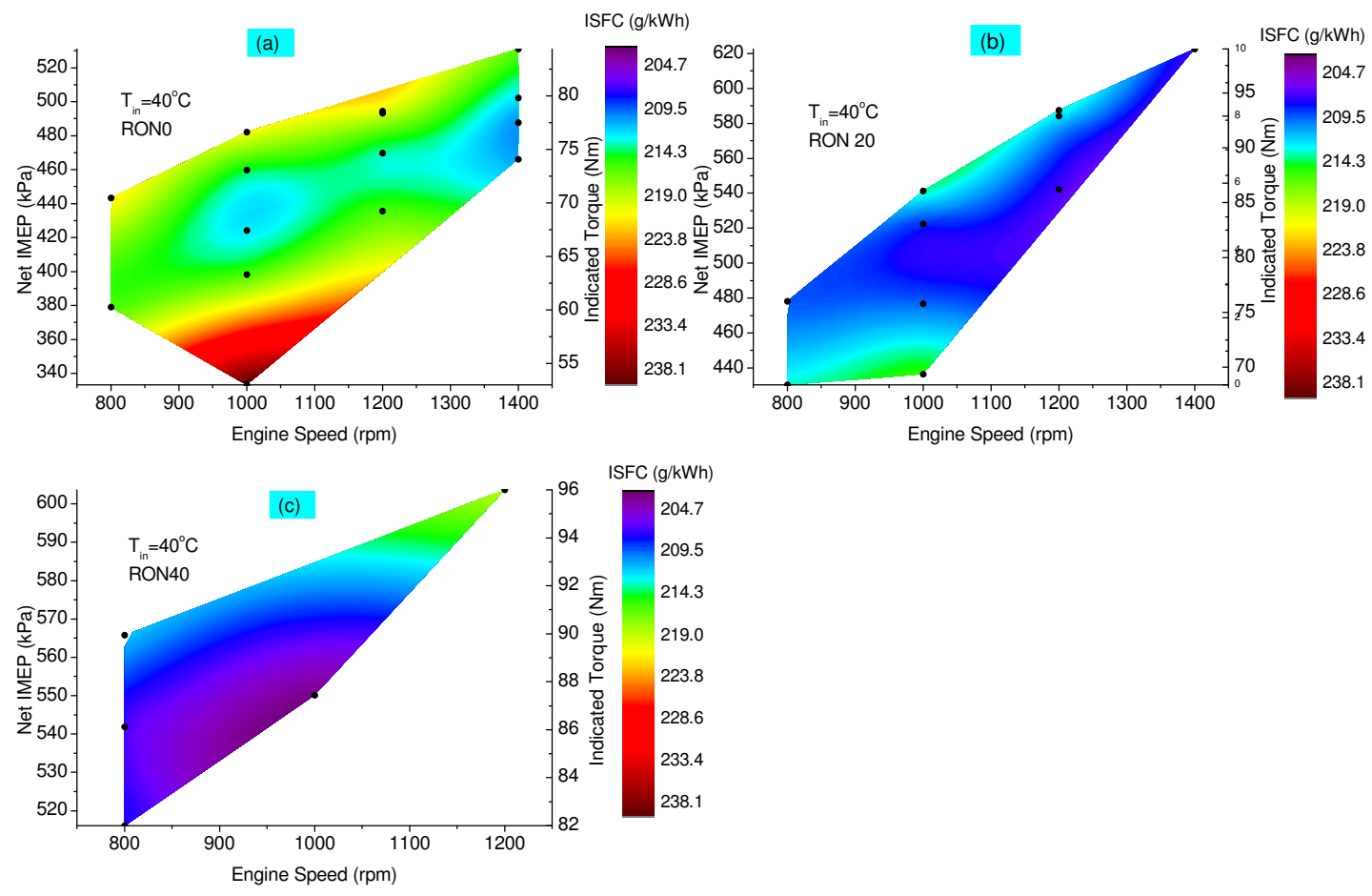

Figure 3.4: HCCI ISFC map for $40{ }^{\circ} \mathrm{C}$ intake air temperature at naturally aspirated conditions 

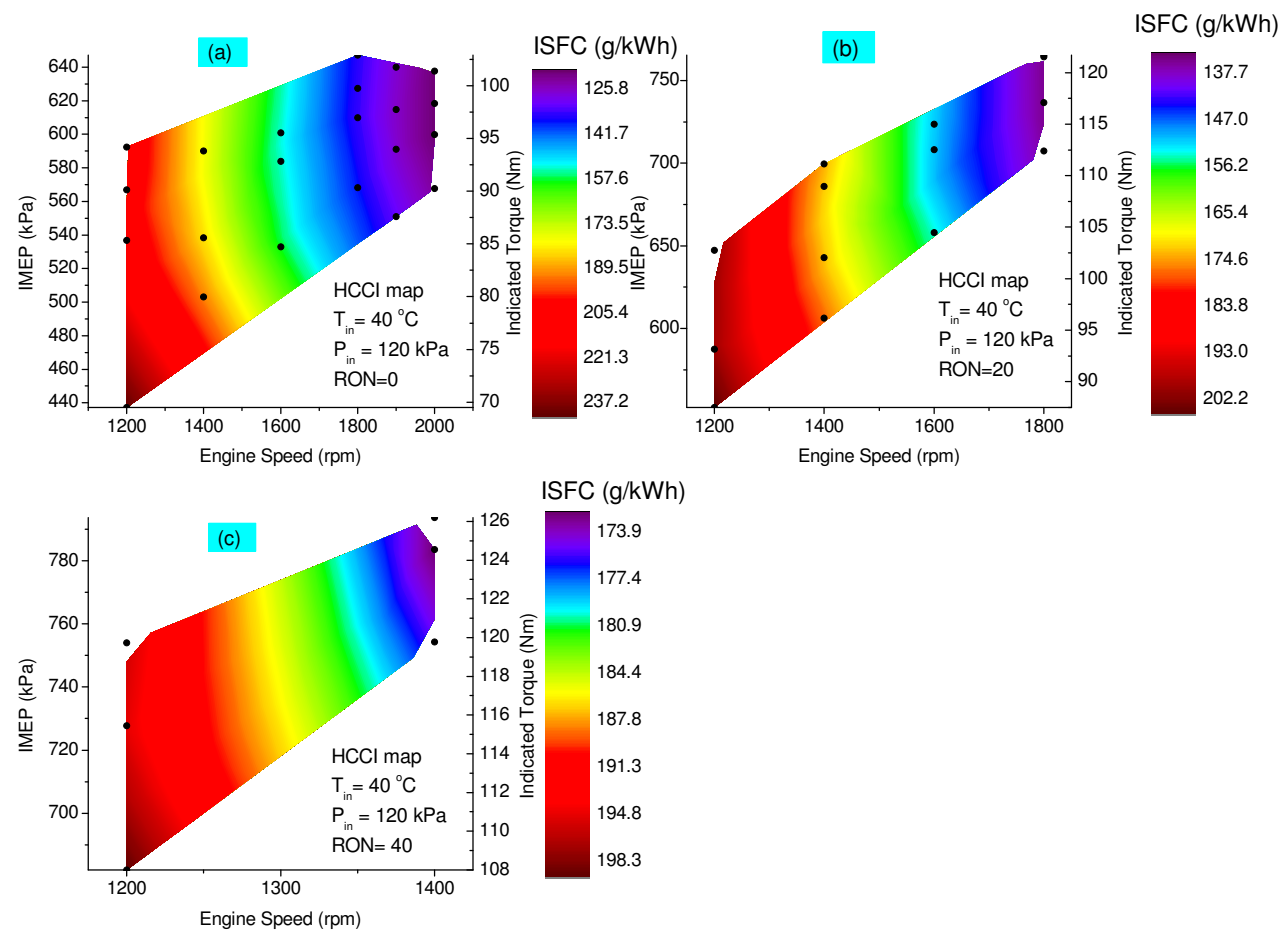

Figure 3.5: HCCI ISFC map for $40{ }^{\circ} \mathrm{C}$ intake air temperature and $120 \mathrm{kPa}$ intake pressure

Brake specific fuel consumption (BSFC) maps are shown in Figure 3.6 for RON 0, RON 20 and RON 40 at an intake temperature of $40{ }^{\circ} \mathrm{C}$. When all the intake air temperatures and RONs are taken into consideration, it is seen that the load range of the HCCI engine is between about 50-100 Nm which is ideal for an LTC engine. BSFC maps are very important to understand the most efficient operation ranges of the HCCI engine. HCCI engines can be looked upon as range extenders for hybrid 
electrical vehicles in near future [54]. Total efficiency of a hybrid vehicle can be increased by operating the HCCI engine at the most efficient point. Therefore, BSFC, thermal efficiency, CA50 and similar maps have importance to determine an efficient operation range. As seen in the figures, the lowest BSFC is obtained as $210 \mathrm{~g} / \mathrm{kWh}$ with RON 0. Fuels having high reactivity allow leaner HCCI operation as it is mentioned above. As a result of this lower BSFC values are obtained. Increased intake air temperature causes a decrease in volumetric efficiency of the engine at naturally aspirated operations. Therefore, BSFC increases at higher intake air temperatures. When HCCI operation is observed at boosted conditions, it can be observed that the BSFC improves with an increase in engine speed. The best BSFC is obtained at high speeds and high loads for all three RONs, as shown in Figure 3.7. The pumping losses increase with boosting and reduce significantly with an increase in engine speed [40]. Moreover, the combustion duration is longer for lower engine speeds [55], which tends to have a negative effect on BSFC. However, with an increase in engine speed, the shorter combustion duration and a lower pumping losses results in an improvement in BSFC. 

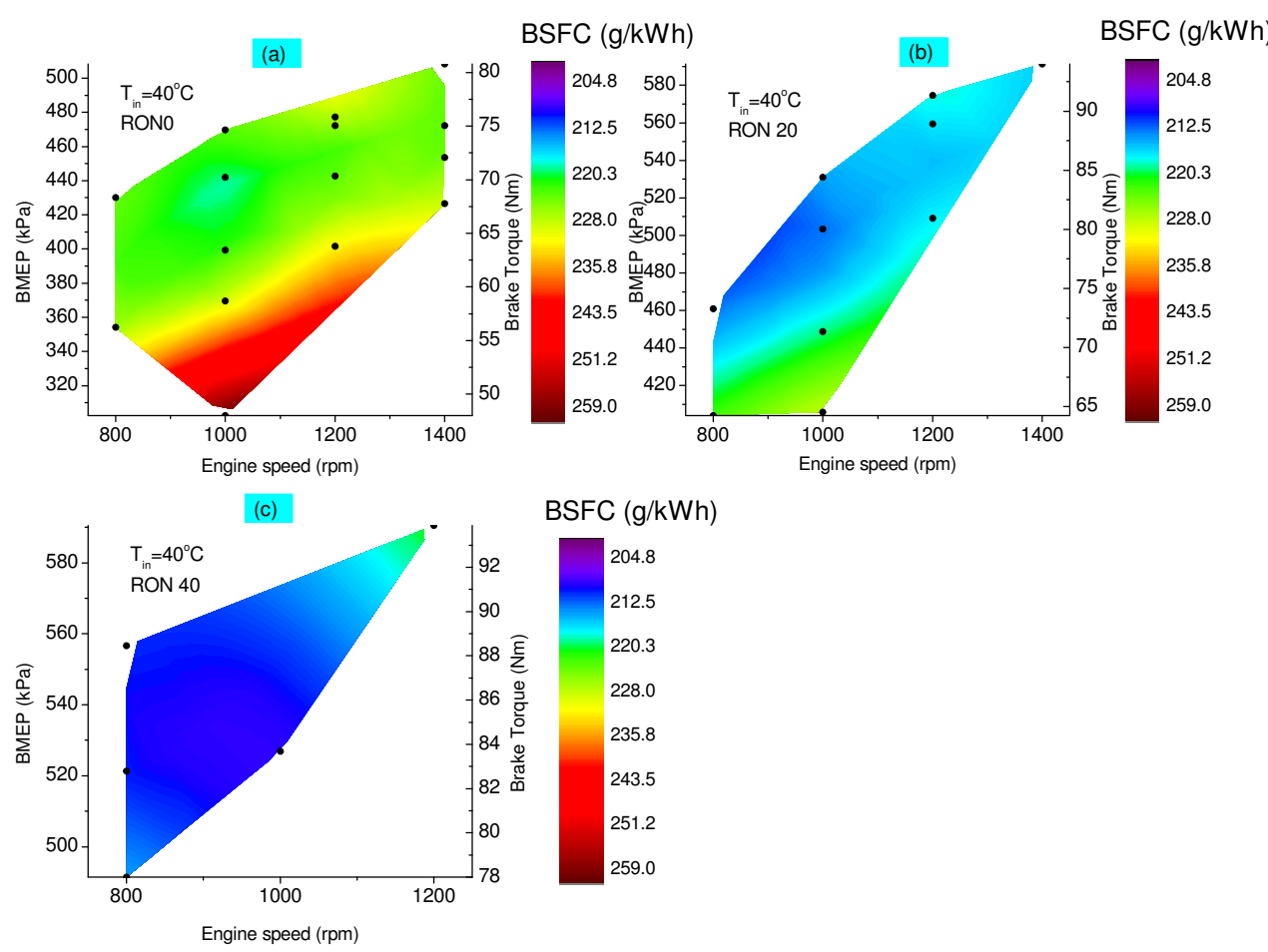

Figure 3.6: $\mathrm{HCCI}$ BSFC map for $40{ }^{\circ} \mathrm{C}$ intake air temperature at naturally aspirated conditions 


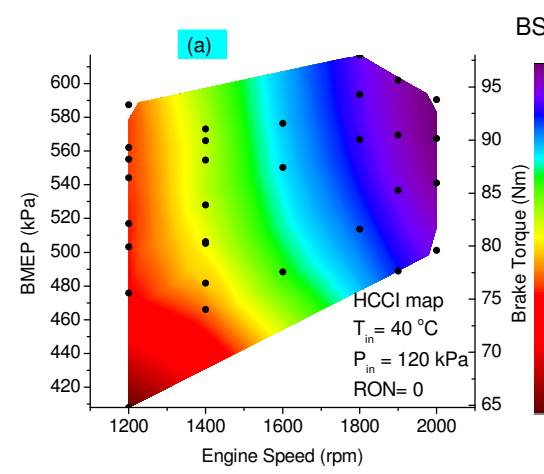

BSFC $(g / k W h)$
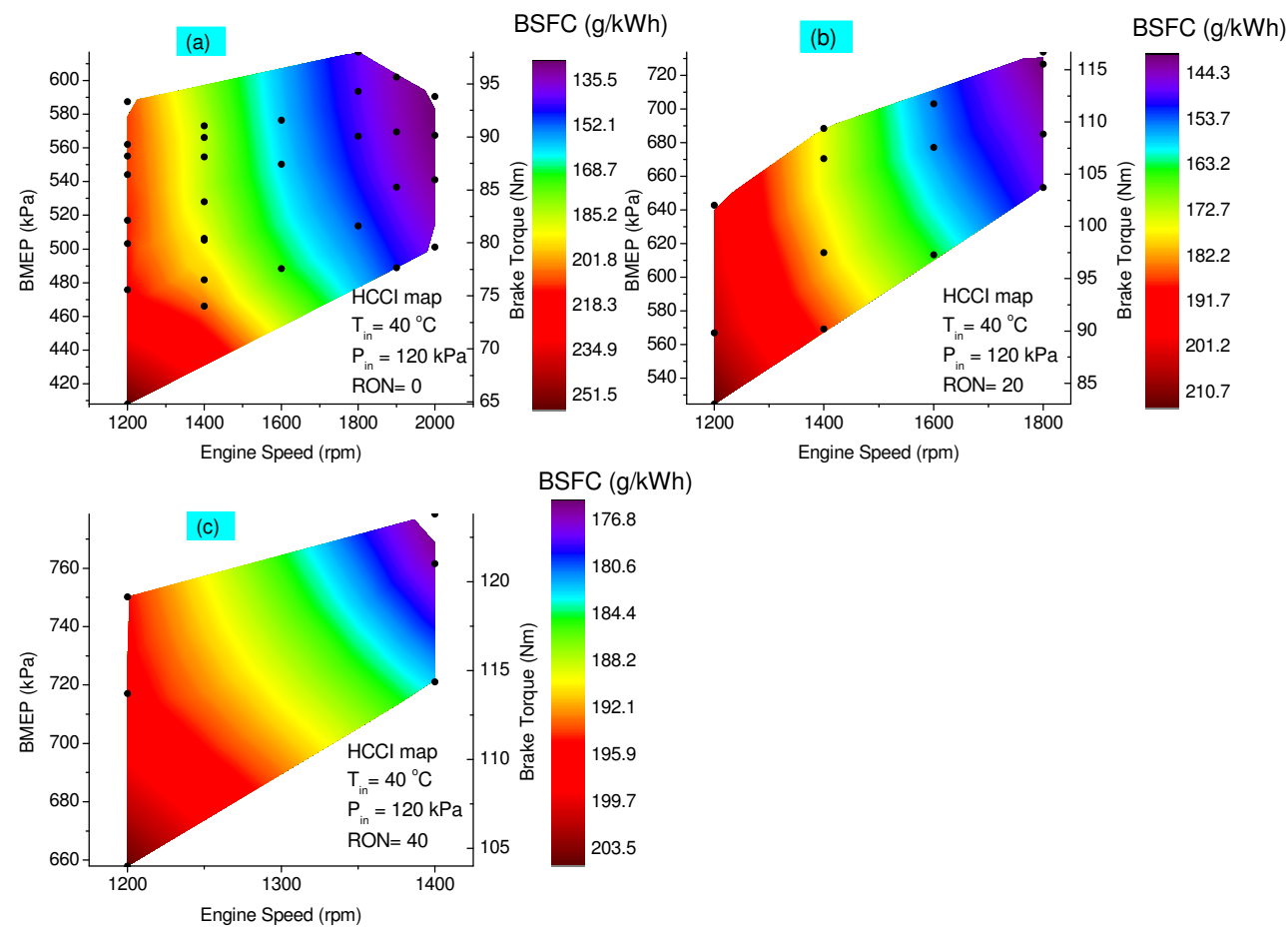

Figure 3.7: HCCI BSFC map for $40{ }^{\circ} \mathrm{C}$ intake air temperature at $120 \mathrm{kPa}$ intake pressure

The indicated thermal efficiency map for HCCI at the same operating conditions is illustrated is Figure 3.8. It can be seen that the map is in accordance with the ISFC map. The best thermal efficiency is achieved at the lowest ISFC regions. The present data shows that combustion phasing has a significant effect on HCCI efficiency. All the best thermal efficiency regions were attained at a combustion phasing of 5-8 ${ }^{\circ}$ TDC [40]. A maximum thermal efficiency of $40 \%$ was obtained at mid load conditions for all three RONs at $40{ }^{\circ} \mathrm{C}$. This is mainly because of reduced heat transfer losses due 
to lower compression and combustion temperatures [56]. Moreover, the combustion phasing was optimal, which enabled better mixing of the air-fuel mixture at mid load conditions. The range of thermal efficiencies for the given operating conditions were $33-40 \%$.

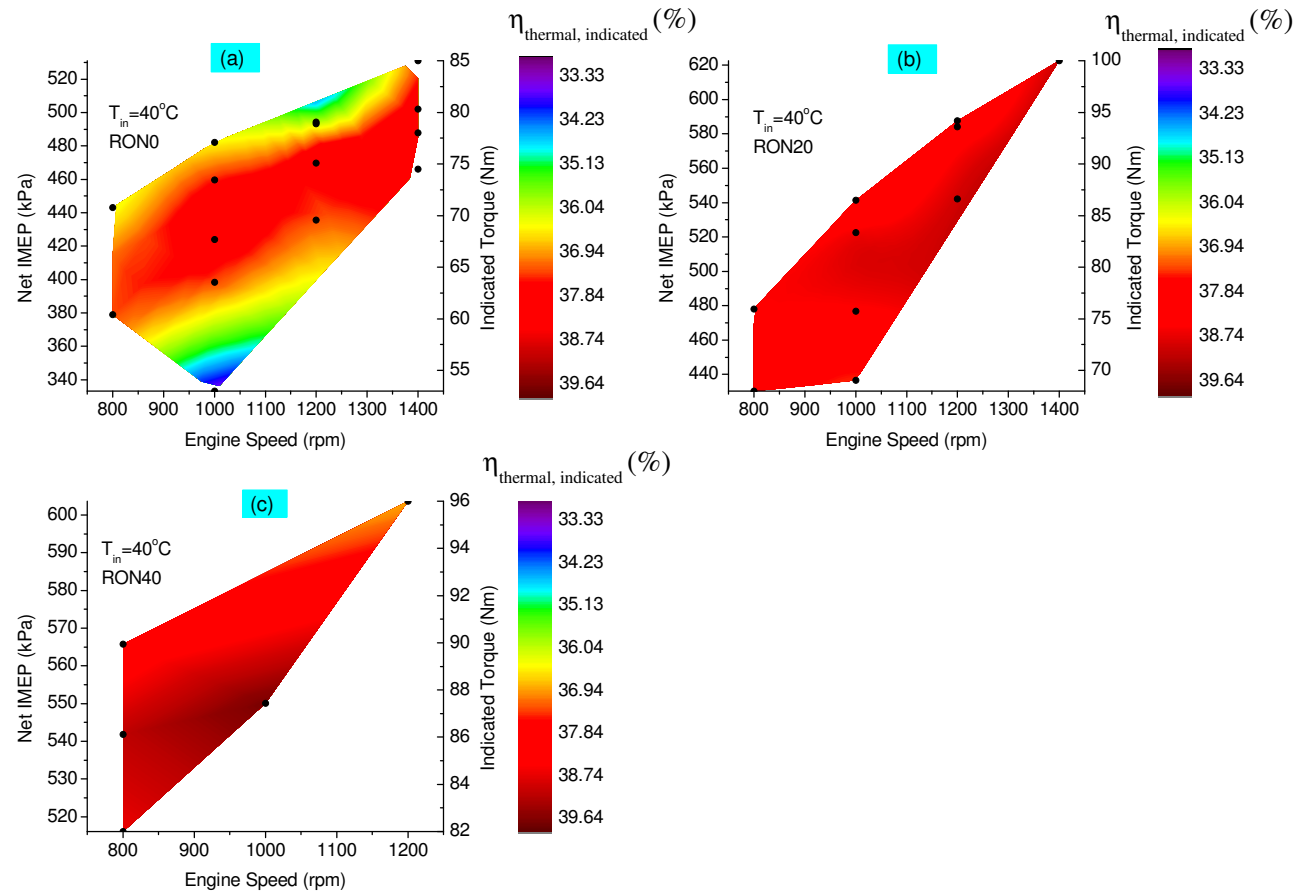

Figure 3.8: HCCI indicated thermal efficiency map for $40{ }^{\circ} \mathrm{C}$ intake air temperature at naturally aspirated conditions

HCCI holds the advantage of achieving ultra-low NOx and PM, with a relatively low SFC as compared to SI/CI combustion regimes. However, higher $\mathrm{HC}$ and $\mathrm{CO}$ 


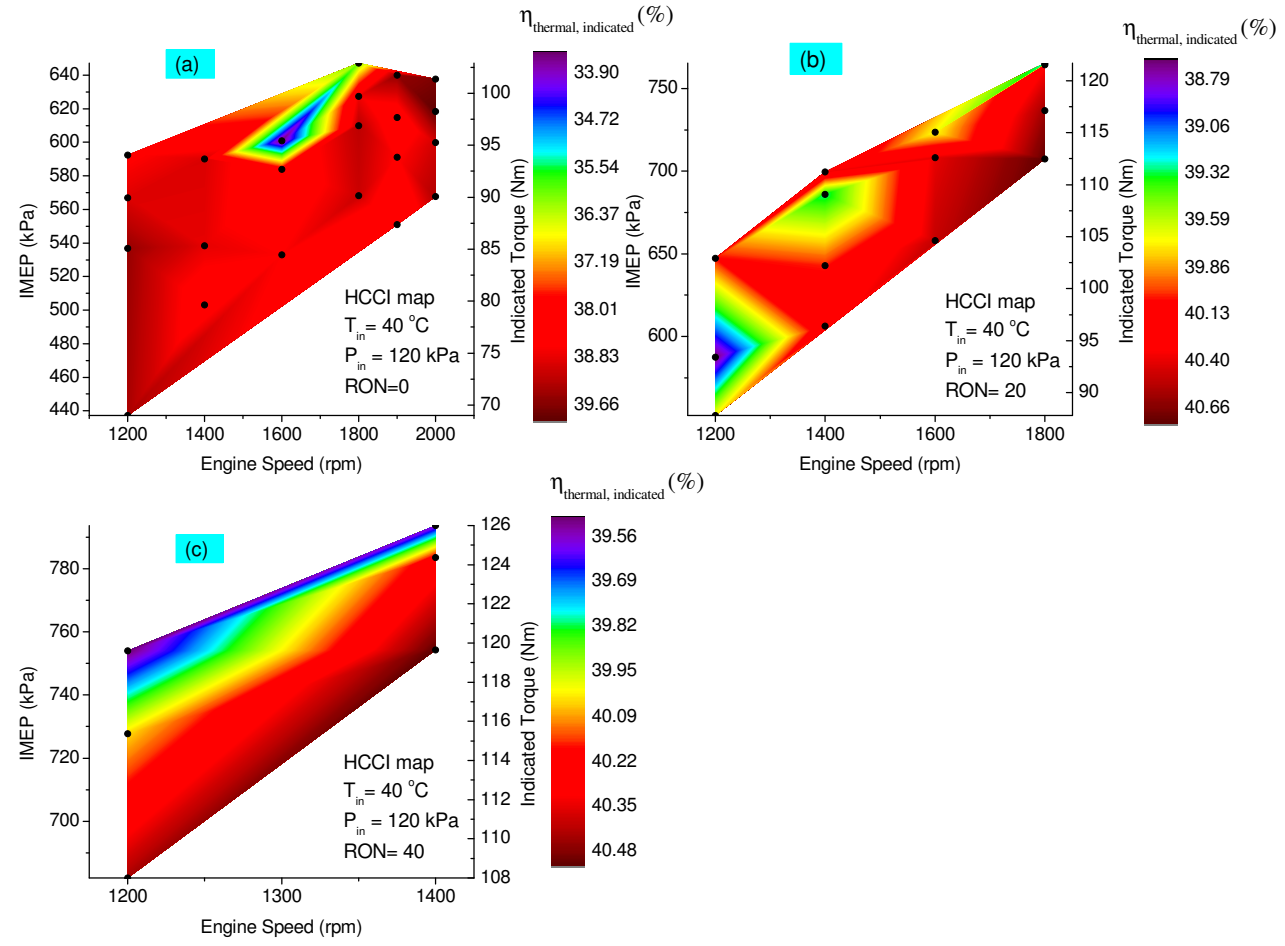

Figure 3.9: HCCI Indicated thermal efficiency map for $40{ }^{\circ} \mathrm{C}$ intake air temperature and $120 \mathrm{kPa}$ intake pressure

emissions is a major challenge for HCCI engines. Moreover, the lower exhaust temperatures in HCCI is a limiting factor in constraining the operating range of the engine [57. because high exhaust gas temperature is required to achieve high efficiency of the oxidation catalysts. The catalysts can reach conversion efficiencies of around 95 $\%$ for $\mathrm{HC}$ and $\mathrm{CO}$, as long as the catalyst light off temperatures are in the range of 250- $300{ }^{\circ} \mathrm{C}$ [40, 58, 59]. As seen in Figure 3.11 for naturally aspirated conditions at $T_{\text {intake }}$ of $40{ }^{\circ} \mathrm{C}$, the exhaust gas temperature range is between $223 \hat{a} \mathrm{~A} S ̧ 400{ }^{\circ} \mathrm{C}$ over the entire speed and load range. This is an acceptable range for the catalytic converter 
to function properly. Moreover, with this range of temperatures, if the turbocharger is used to extend operating range for high loads, there would be sufficient energy to drive the turbo [58]. The exhaust temperature range for boosted conditions is shown in Figure 3.10 for the entire range of speeds and loads. It can be seen that the exhaust temperature increased with an increase in load and speed for both naturally aspirated and boosted conditions. The range of temperatures is $230{ }^{\circ} \mathrm{C}$ to $410{ }^{\circ} \mathrm{C}$, which is equivalent to the temperatures attained in SI combustion for low and mid loads. The energy, if extracted from the exhaust gas using a waste heat recovery system, could be used to heat the intake air, thereby eliminating the need of electrical energy to drive the intake air heater.
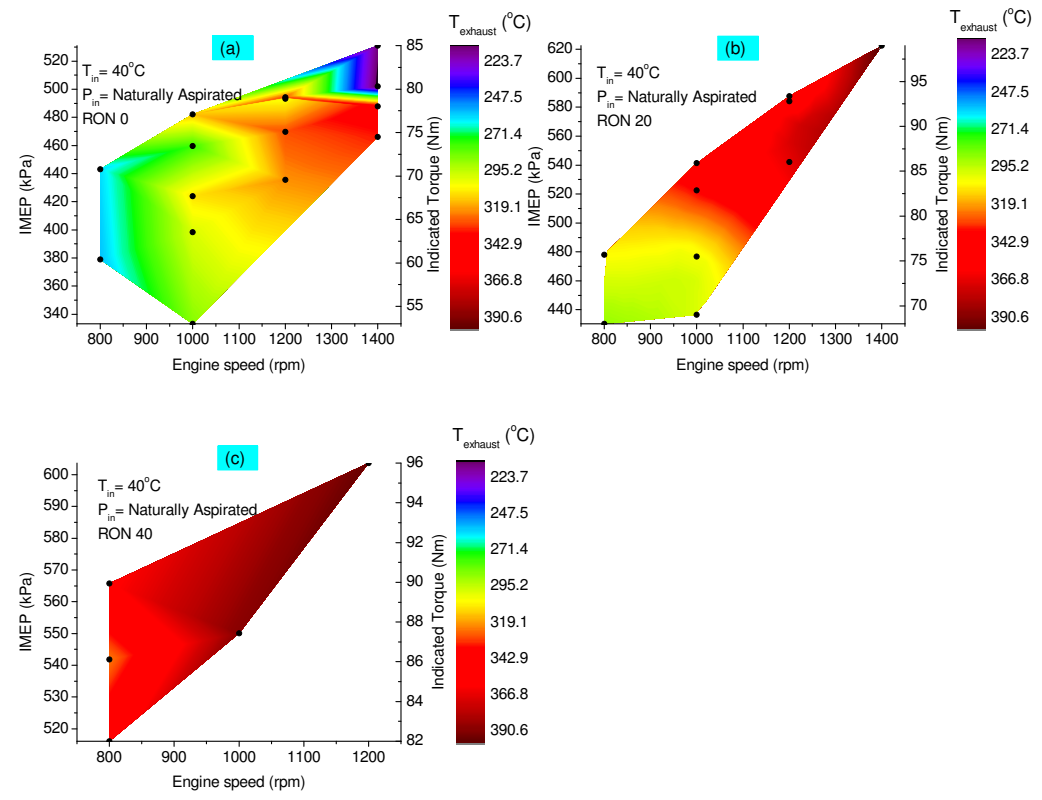

Figure 3.10: HCCI exhaust gas temperature map for $40{ }^{\circ} \mathrm{C}$ intake air temperature and Naturally aspirated 

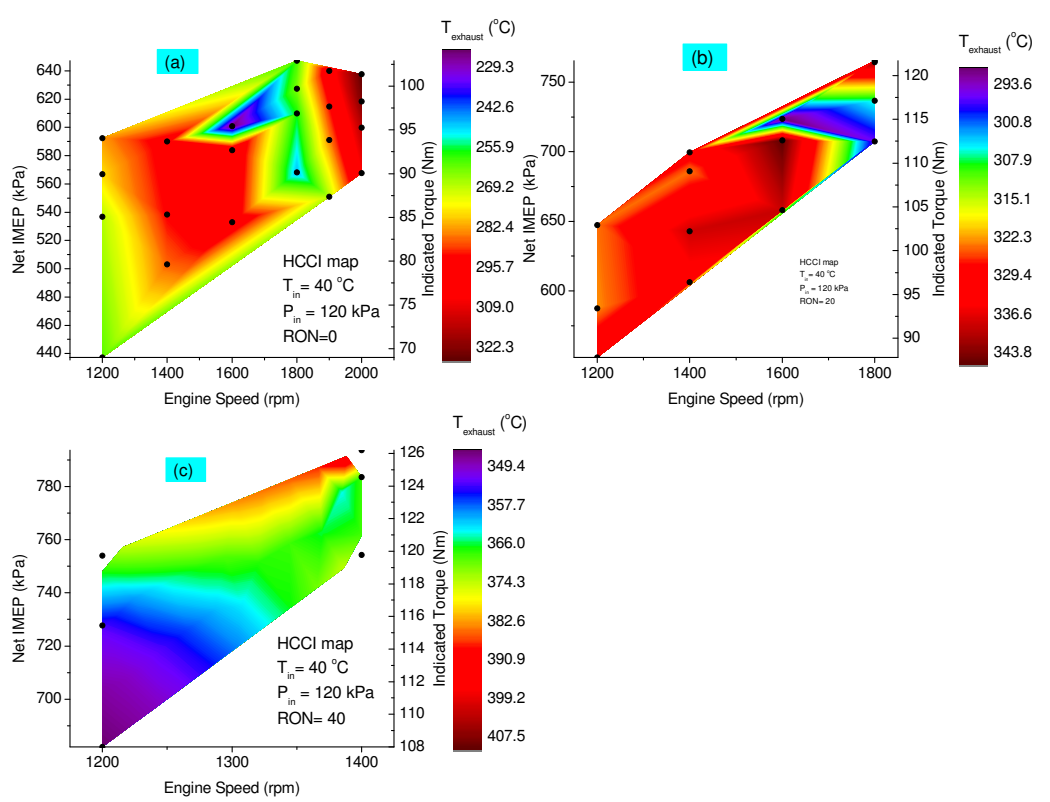

Figure 3.11: HCCI exhaust gas temperature map for $40{ }^{\circ} \mathrm{C}$ intake air temperature and $120 \mathrm{kPa}$ Boost Pressure

\subsection{Optimized HCCI maps}

HCCI tests were carried out for 900 data points over a wide range of operating conditions (Intake air temperature, Boost pressure, RON, Engine speed and equivalence ratio). An optimized map for best ISFC at each speed-load condition was developed and other maps for BSFC, thermal efficiency and exhaust temperature were derived from the optimized data set. The optimized maps were created separately for naturally aspirated and boosted conditions. The data points considered for developing 
these maps are given in Appendix A.2. ISFC maps for intake pressures of $100 \mathrm{kPa}$ and $120 \mathrm{kPa}$ are illustrated in Figures 3.12 and 3.13 , respectively. While it can be seen that equivalence ratio has a significant effect on the ISFC for naturally aspirated conditions, engine speed takes over predominance for boosted conditions. ISFC increases with a drop in IMEP and indicated torque since the mixture becomes leaner. As a result of this, the oxygen dilution is higher and thereby decreasing combustion temperatures. The best ISFC achieved was $200 \mathrm{~g} / \mathrm{kWh}$ and $110 \mathrm{~g} / \mathrm{kWh}$ for naturally aspirated and boosted conditions, respectively. The speed range and load range improved considerably for a boost pressure of $120 \mathrm{kPa}$ as compared to those for 100 $\mathrm{kPa}$.

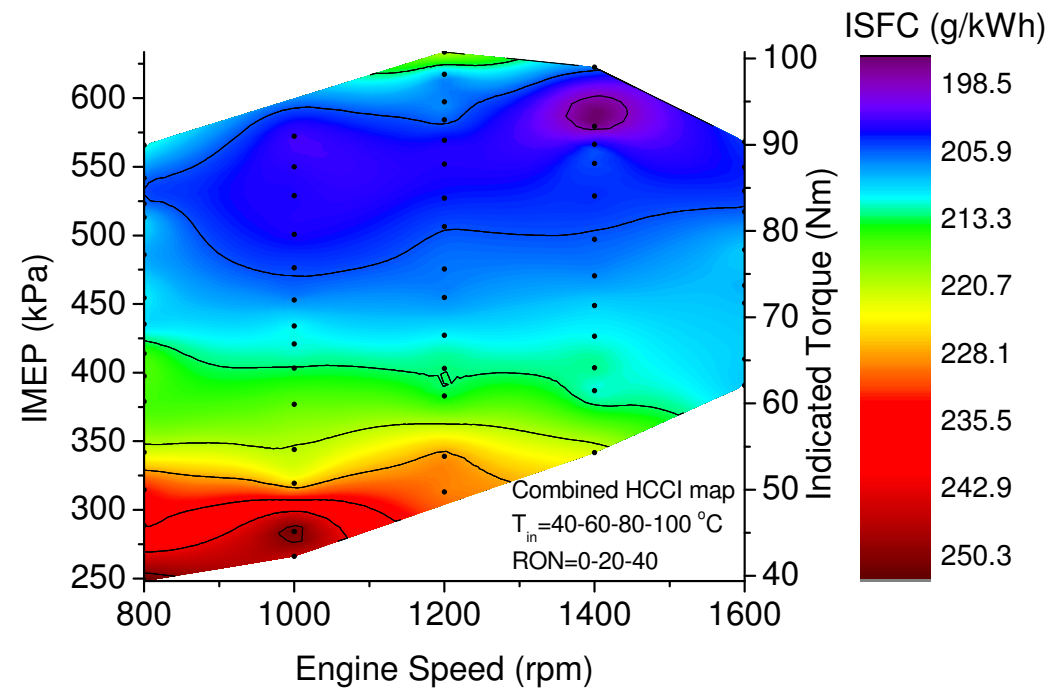

Figure 3.12: HCCI ISFC map for all intake air temperatures and RONs at naturally aspirated conditions

BSFC maps for boost pressures of $100 \mathrm{kPa}$ and $120 \mathrm{kPa}$ are illustrated in Figures 3.14 


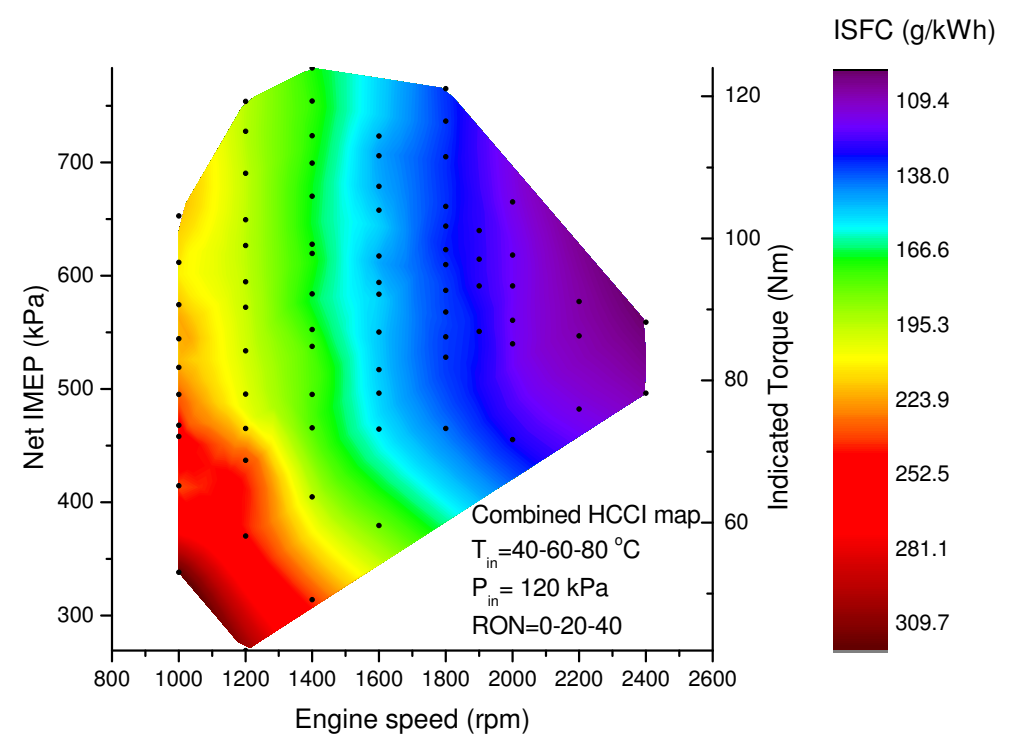

Figure 3.13: HCCI ISFC map for all intake air temperatures and RONs and $120 \mathrm{kPa}$ intake pressure

and 3.15 , respectively. It can be seen that the trends are very similar to that of ISFC maps. It can be seen that BMEP decreased with decrease in equivalence ratio. The sweet spot for BSFC (210 g/kWh) for $100 \mathrm{kPa}$ was obtained at $1400 \mathrm{rpm}$ engine speed and $88 \mathrm{Nm}$ brake torque. For $120 \mathrm{kPa}$ boost pressure, the best BSFC of $130 \mathrm{~g} / \mathrm{kWh}$ was obtained at maximum engine speed of $2400 \mathrm{rpm}$ and $80 \mathrm{Nm}$ brake torque. At high engine speeds, the engine seems to run at a higher combustion efficiency typically above $92 \%$. This is a result of better fuel-air mixing and higher homogeneity of the mixture [60]. However, at low engine speeds and low loads, the BSFC increases due to the unburned fuel at the exhaust, which approximately corresponds to $80-90 \%$ of combustion efficiency. 


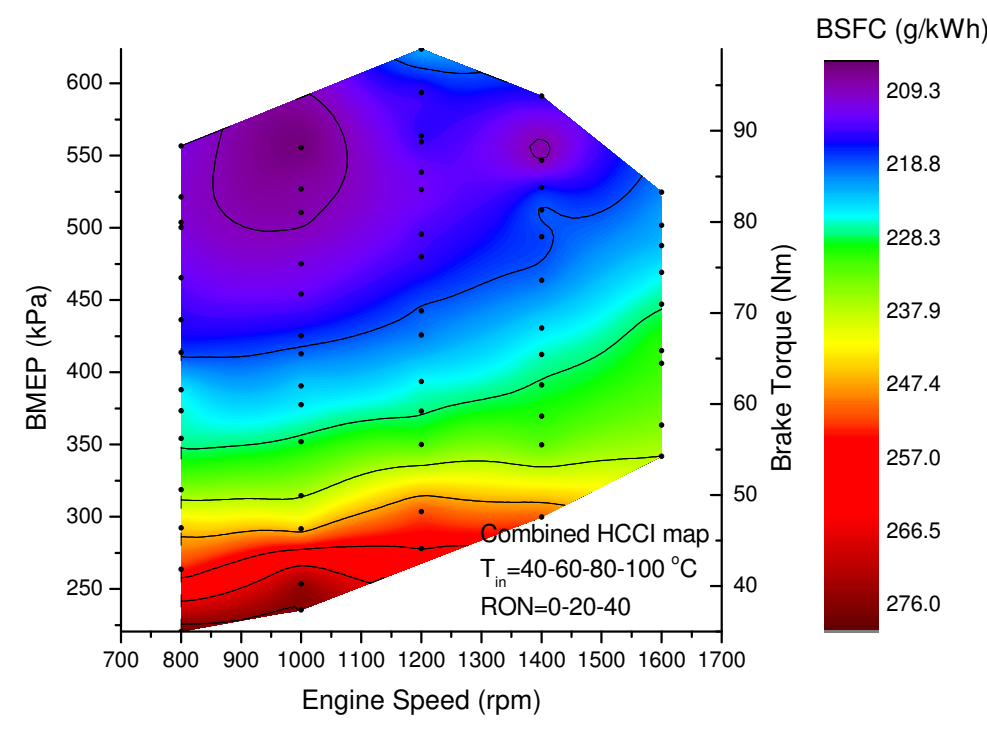

Figure 3.14: HCCI BSFC map for all intake air temperatures and RONs at naturally aspirated conditions

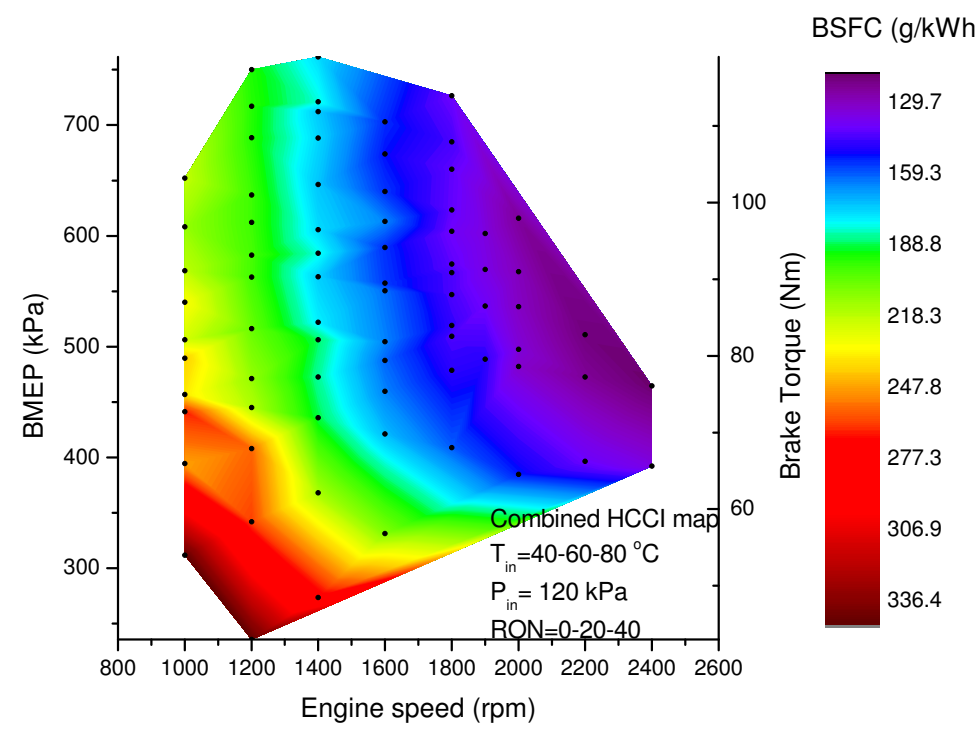

Figure 3.15: HCCI BSFC map for all intake air temperatures and RONs and $120 \mathrm{kPa}$ intake pressure 
The $\eta_{t, \text { ind }}$ maps for $100 \mathrm{kPa}$ and $120 \mathrm{kPa}$ boost pressure are illustrated in Fig 3.16 and 3.17, respectively. It can be observed that the net indicated thermal efficiency improved with an increase in boost pressure. With an increase in operating range in terms of load and speed, a boost pressure of $120 \mathrm{kPa}$ yielded a peak indicated thermal efficiency of $46 \%$ while $100 \mathrm{kPa}$ intake pressure had a peak thermal efficiency of 41\%. Moreover, with an increase in equivalence ratio, the thermal efficiency increased for both intake pressures. With richer mixture the compression and combustion temperatures are significantly higher and therefore the combustion efficiencies are higher [56]. The data shows that for better thermal efficiencies, the combustion efficiencies should be higher than $91 \%$ to prevent this from having a deteriorating effect on thermal efficiency.

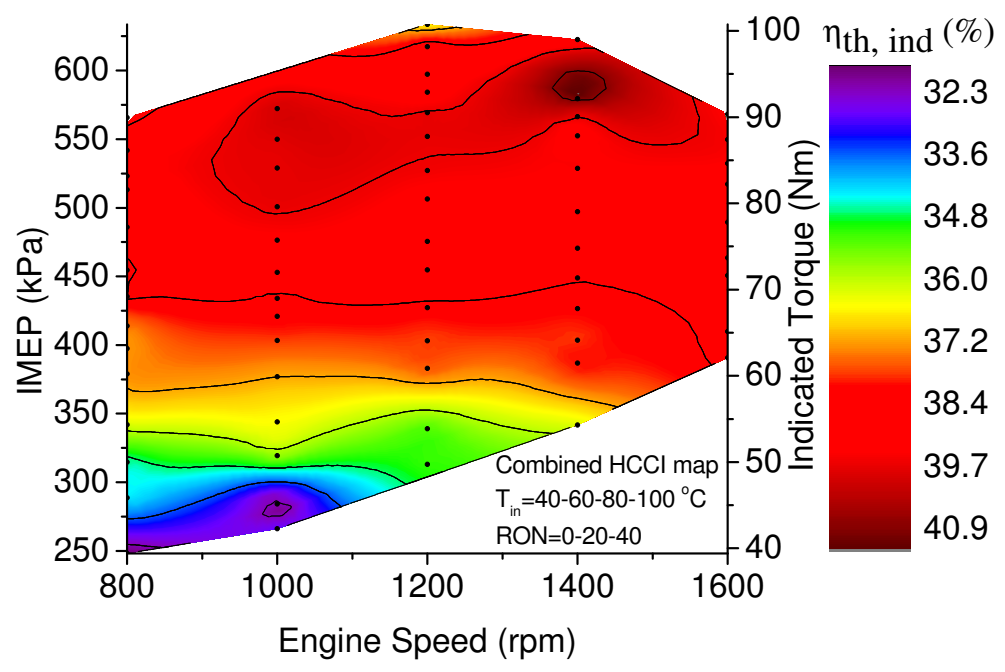

Figure 3.16: HCCI indicated thermal efficiency map for all intake air temperatures and RONs at naturally aspirated conditions 


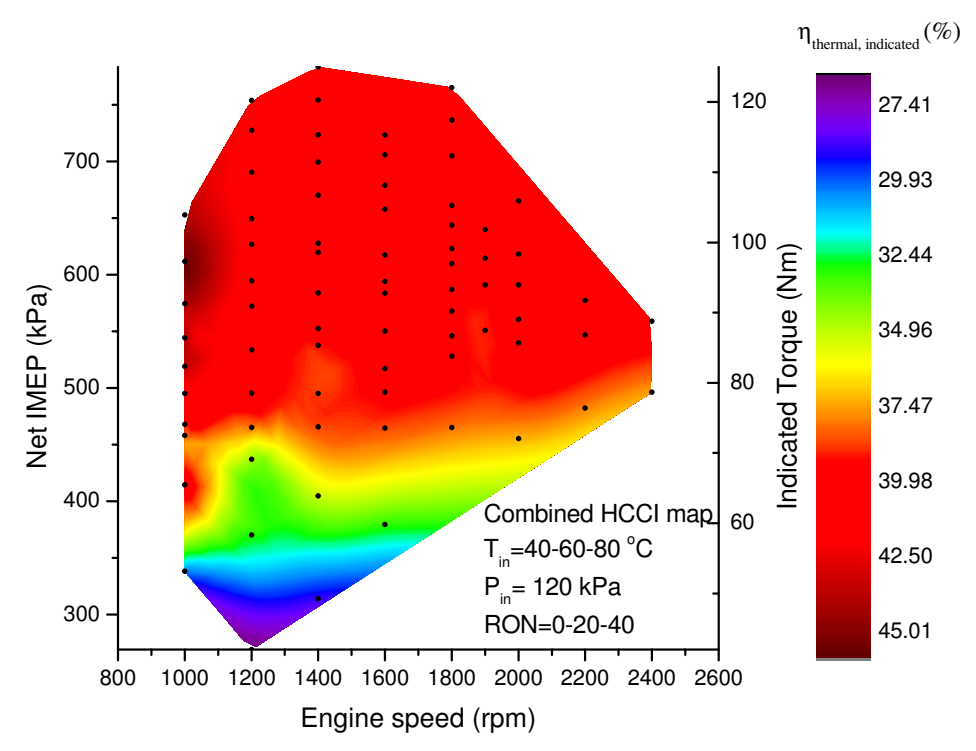

Figure 3.17: HCCI indicated thermal efficiency map for all intake air temperatures and RONs and $120 \mathrm{kPa}$ intake pressure

The optimized exhaust temperature map for naturally aspirated and boosted conditions is illustrated in Figures 3.18 and 3.19. A total of 250 data points were considered to develop the optimized maps and it can be observed from the Appendix A2 that over $75 \%$ of the data points have an exhaust temperature greater than $250{ }^{\circ} \mathrm{C}$, which implies that the $\mathrm{HC}$ and $\mathrm{CO}$ after treatment could be accomplished with a good conversion efficiency of the catalytic converter. It can be observed that the exhaust temperature increases with an increase in engine speed and load due to increase in compression and combustion temperatures. However, at low loads and low speeds, the low $T_{\text {exhaust }}$ could limit the practical operation of HCCI engines. But this can be overcome by retarding the combustion phasing for these data points after TDC, thereby compromising on the thermal efficiency of the engine [56]. 


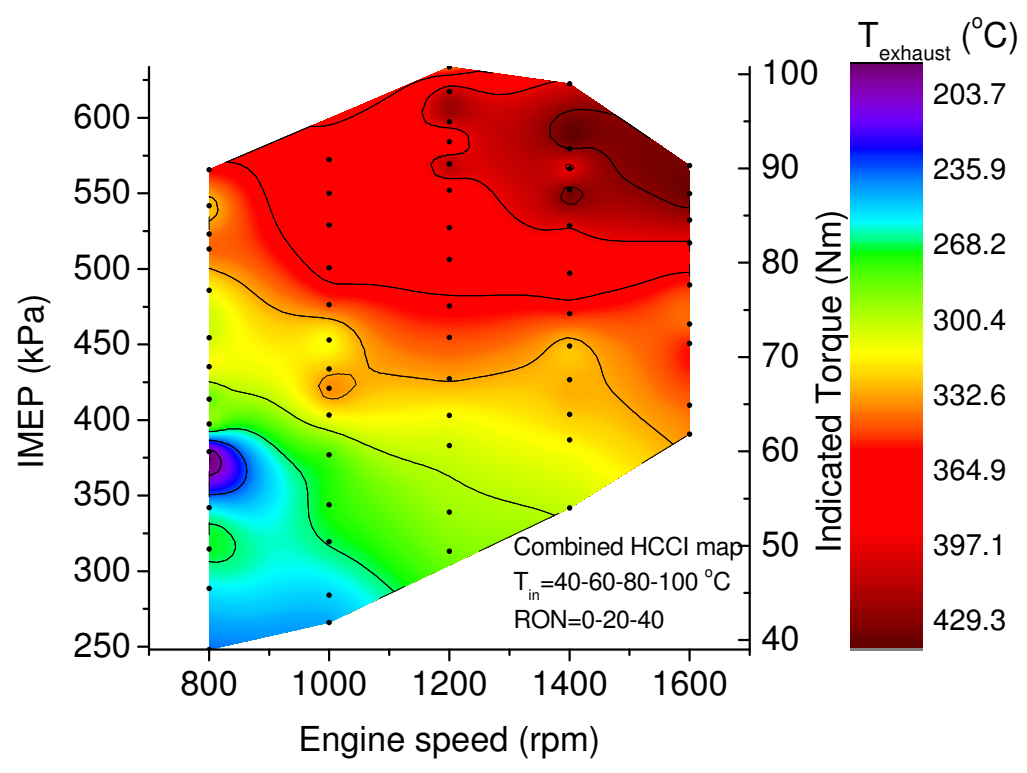

Figure 3.18: HCCI exhaust temperature map for all intake air temperatures and RONs at naturally aspirated conditions

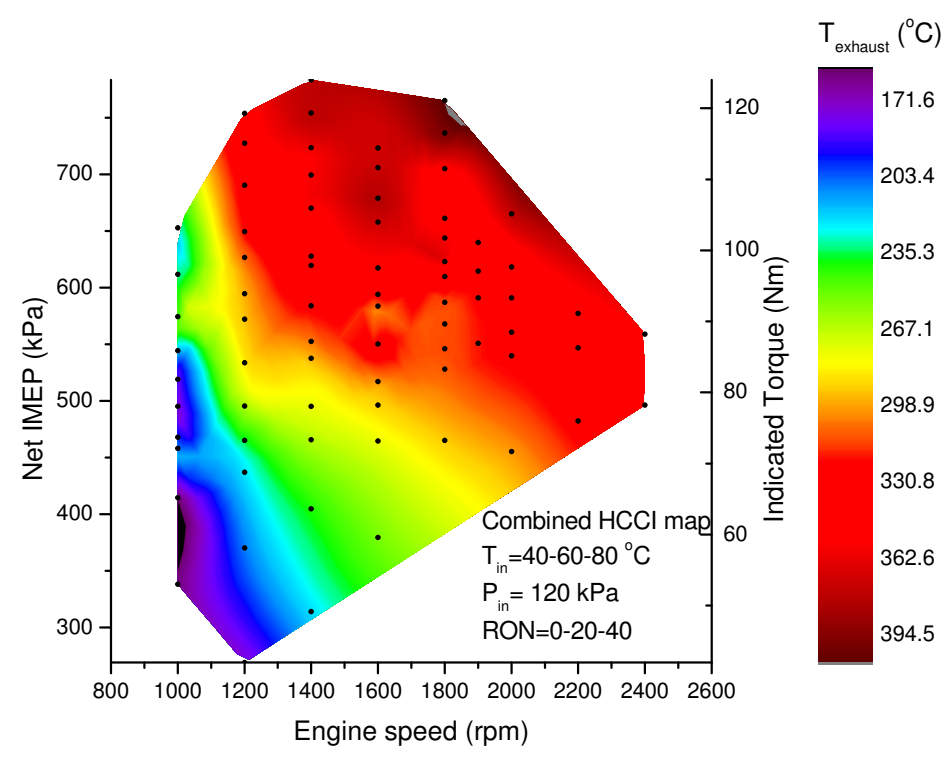

Figure 3.19: HCCI exhaust temperature map for all intake air temperatures and RONs and $120 \mathrm{kPa}$ intake pressure 


\subsection{Effects of RON on HCCI combustion}

Pressure and heat release rate traces for different RONs at $1000 \mathrm{rpm}$ engine speed and intake air temperature of $100{ }^{\circ} \mathrm{C}$ are seen in Figure 3.20. Lambda value is around 2.4 for each RON. Combustion characteristics of different RONs in HCCI mode such as CA10, CA50, CA90 and CA10-90 are also seen in Figure 3.21. As it can be seen from pressure trace, heat release rate trace and CA10 values, the SOC is advanced with lower RONs. The reactivity of the fuel decreases with an increase in RON. Higher reactivity enables earlier SOC. This property of the fuel can be useful at low intake air temperatures and lower engine loads. However, at the high intake air temperatures and higher engine loads, the control of SOC and combustion phasing becomes challenging. CA50 is around $-6 \mathrm{CAD}$ aTDC for RON0 that results in a lower thermal efficiency. Typically, the combustion phasing must be 8-10 CAD aTDC in order to achieve the best thermal efficiency [40]. This can be attributed to the fact that the heat transfer losses are minimal at the optimal combustion phasing, thereby leading to better thermal efficiencies [60]. It can be seen in Fig 3.21 that as the CA50 approaches close to $8 \mathrm{CAD}$ aTDC, the thermal efficiency increases. The combustion phasing retards as the RON increased because SOC is retarded for RON20 and RON40 compared to RONO. 
Table 3.4

Operating conditions used for the experiments to study the effect of RON on HCCI combustion

\begin{tabular}{|l|l|}
\hline \multicolumn{1}{|c|}{ Test Parameters } & Value/ Desciption \\
\hline Engine Speed & $1000(\mathrm{rpm})$ \\
\hline Injection Pressure & $3.5(\mathrm{bar})$ \\
\hline Injection Starting Angle & $450(\mathrm{deg}$ bTDC) \\
\hline Fuel Type & RON 0 -20- 40 \\
\hline IVO & $25.5(\mathrm{deg}$ bTDC $)$ \\
\hline EVC & $22(\mathrm{deg}$ bTDC $)$ \\
\hline Throttle Body Position & $100(\%)$ \\
\hline Intake Air Temperature & $100\left({ }^{\circ} \mathrm{C}\right)$ \\
\hline Lambda & 2.4 \\
\hline
\end{tabular}




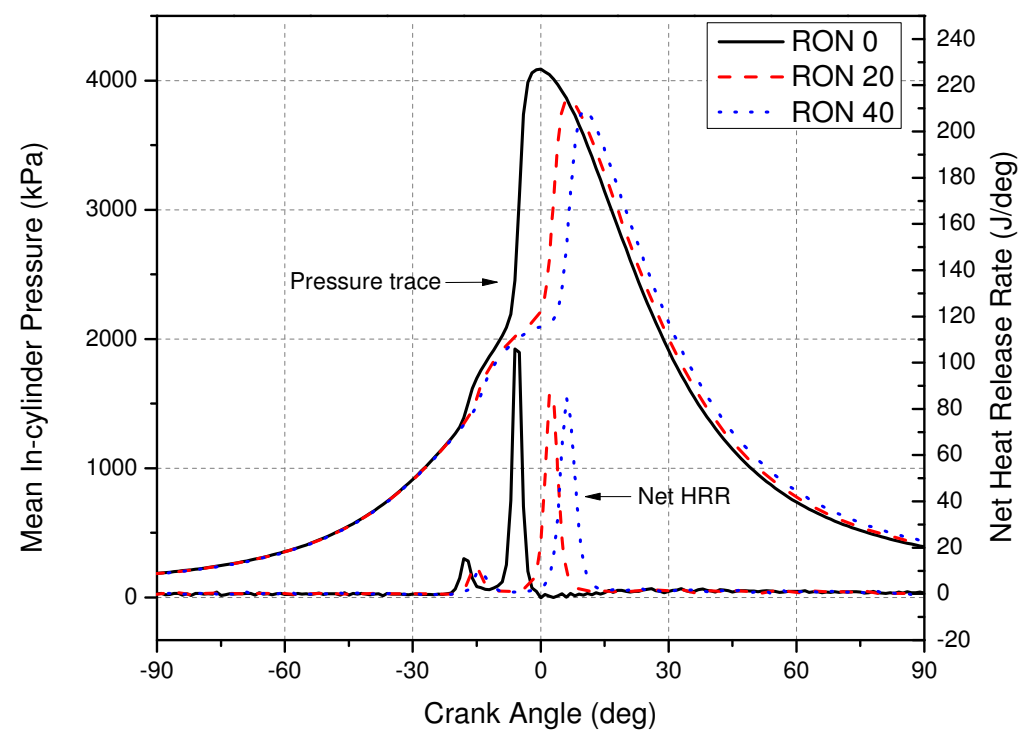

(a) Pressure and heat release rate

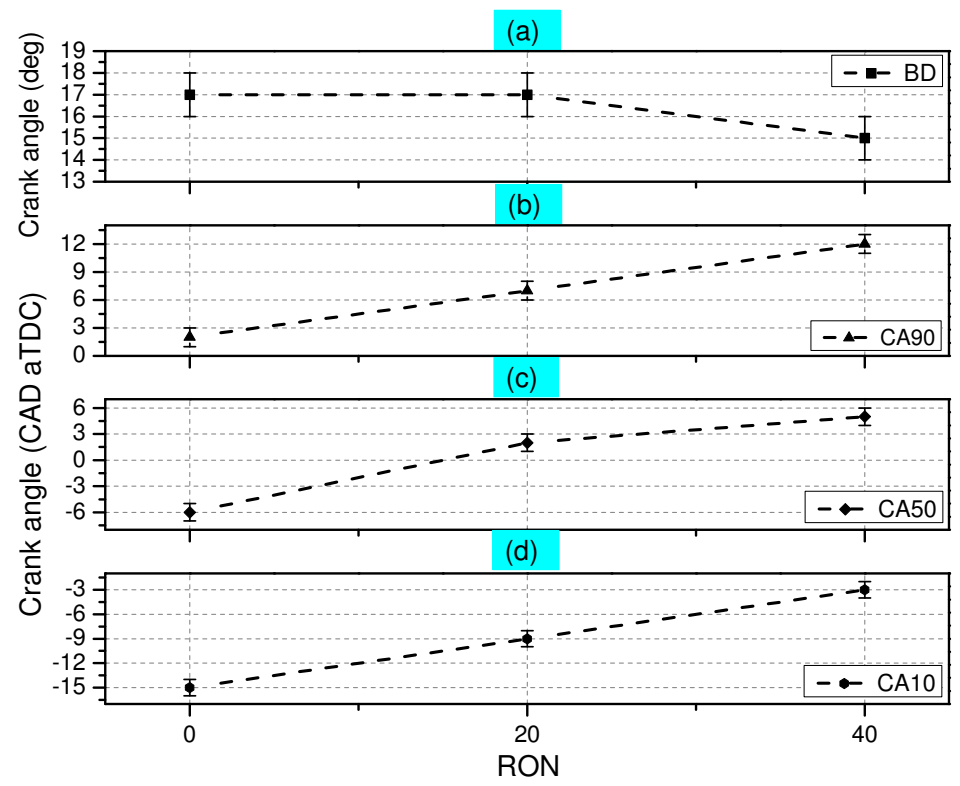

(b) Combustion phasing characteristics

Figure 3.20: a) Pressure and heat release rates for RON 0, 20 and 40 at $1000 \mathrm{rpm}$ and intake temperature of $100{ }^{\circ} \mathrm{C}$ and b) Combustion phasing parameters for HCCI combustion regime 
(a)

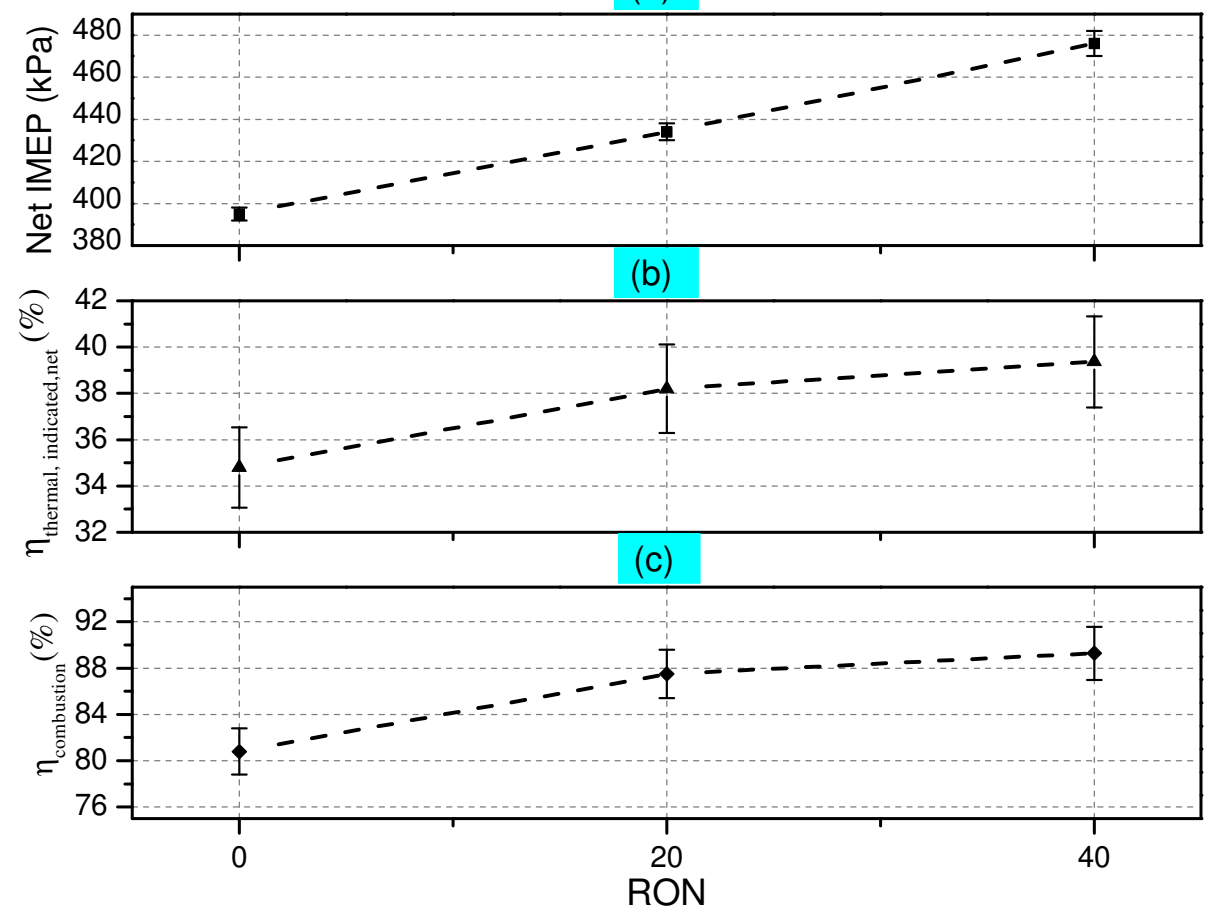

Figure 3.21: Effects of the RON on a) IMEP, b) Indicated thermal efficiency and c) Combustion efficiency for HCCI combustion regime

\subsection{Effects of Intake Air temperature on HCCI}

\section{combustion}

Pressure and heat release rate traces for different intake air temperatures at 1000 rpm engine speed are seen in Figure 3.23(a). Lambda value is around 2.3 for each temperature. Combustion characteristics of different intake air temperatures in HCCI 
mode such as CA10, CA50, CA90 and CA10-90 are also seen in Figure 3.23(b). The range of values for $T_{\text {intake }}$ and lambda were chosen based on the acceptable operating region for HCCI combustion with MPRR less than 8 bar/CAD and COV less than 10 $\%$ 61. HCCI combustion became unstable with leaner equivalence ratios because of misfiring at lower engine speeds and high loads. Moreover, higher MPRR at higher $T_{\text {intake }}$ and richer equivalence ratios resulted in higher knock intensities. The increase of $T_{\text {intake }}$ improves the auto-ignition characteristics of the mixture in the cylinder. The SOC is advanced at higher intake air temperature as seen in Figure 3.23(b) due to the increased temperature of compression. Furthermore, with an increase in $T_{\text {intake }}$, the chemical reactions between $\mathrm{HC}$ and oxygen molecules in side the cylinder was accelerated. As a result of this, the Burn Duration (BD) values decreased with an increase in $T_{\text {intake }}$. From Figure 3.22 and 3.23 , it can be seen that the best thermal efficiency is obtained at a combustion phasing of 6 CAD aTDC. The thermal efficiency is lower at other temperatures for which the IMEP values are relatively lower due to the change in fuel energy inducted in the cylinder. As a result of this, the ratio of specific heat of the charge gases decrease due to the higher compression temperatures [56]. 
Table 3.5

Operating conditions used for the experiments to study the effect of intake air temperature on HCCI combustion

\begin{tabular}{|l|l|}
\hline \multicolumn{1}{|c|}{ Test Parameters } & Value/ Desciption \\
\hline Engine Speed & $1000(\mathrm{rpm})$ \\
\hline Injection Pressure & $3.5(\mathrm{bar})$ \\
\hline Injection Starting Angle & $450(\mathrm{deg}$ bTDC) \\
\hline Fuel Type & RON 20 \\
\hline IVO & $25.5(\mathrm{deg}$ bTDC $)$ \\
\hline EVC & $22(\mathrm{deg} \mathrm{bTDC})$ \\
\hline Throttle Body Position & $100(\%)$ \\
\hline Intake Air Temperature & $40,60,80,100\left({ }^{\circ} \mathrm{C}\right)$ \\
\hline Lambda & 2.2 \\
\hline
\end{tabular}

(a)

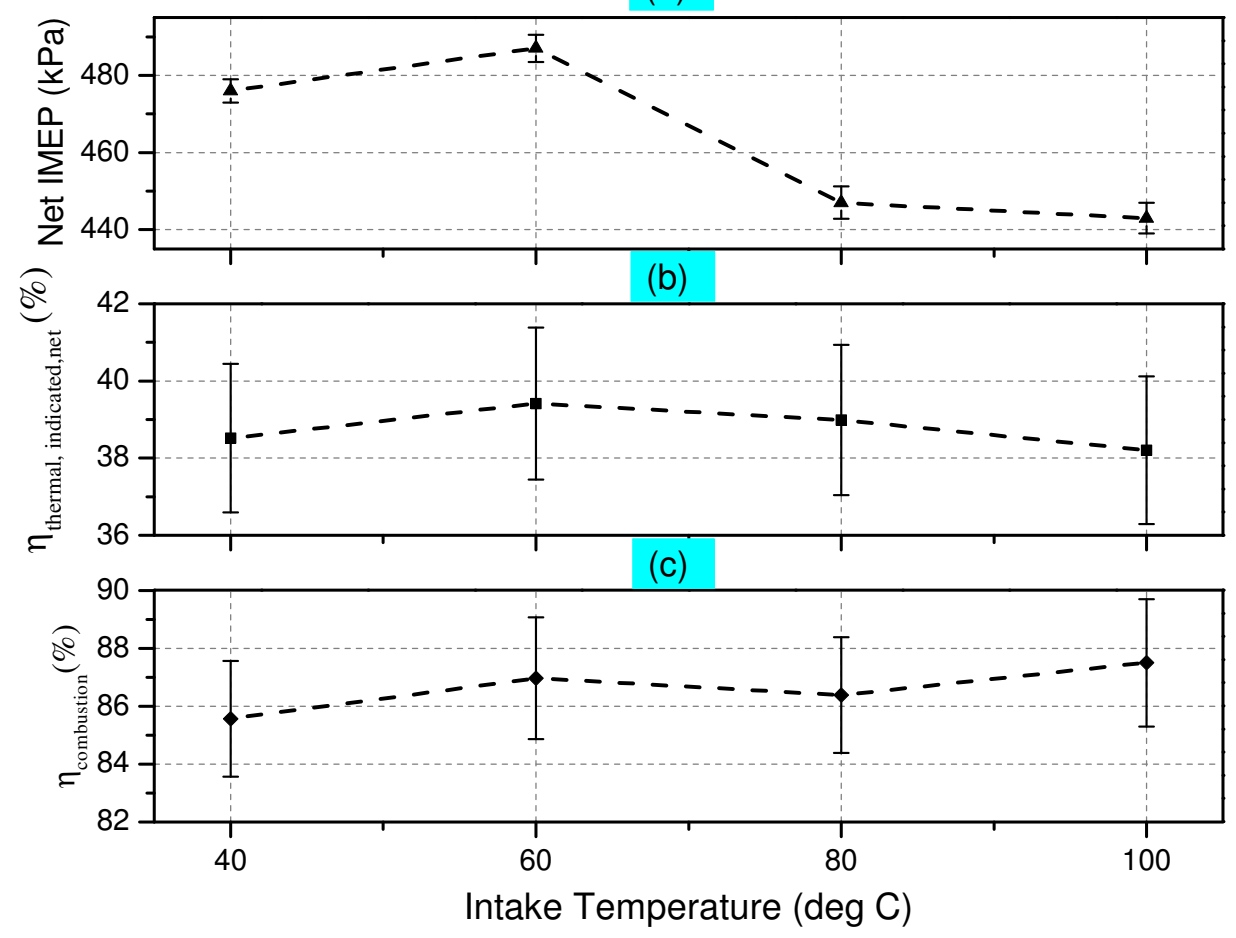

Figure 3.22: Effects of the intake air temperature on 1. IMEP, 2. Indicated thermal efficiency and 3. Combustion efficiency for HCCI combustion regime 


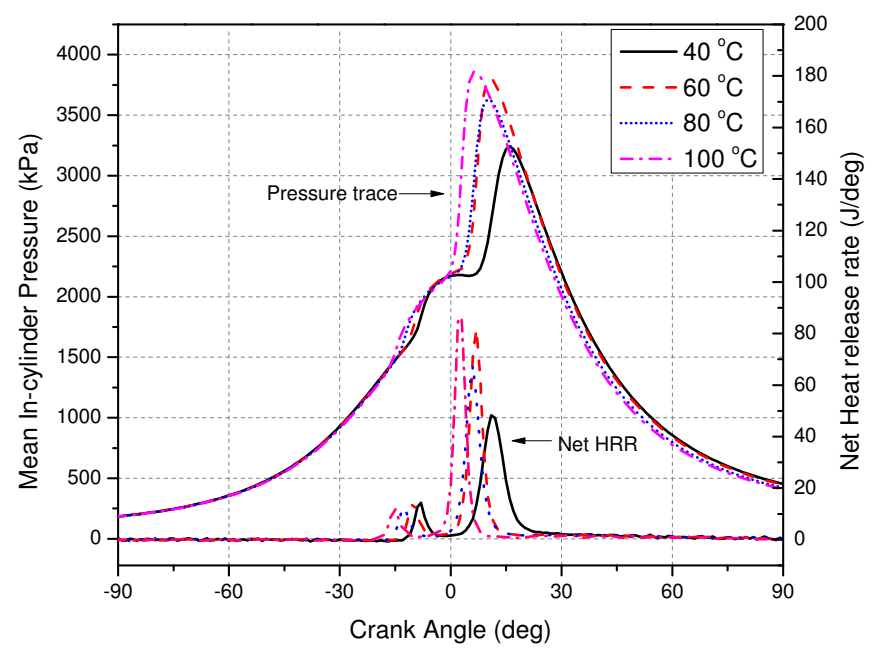

(a) Pressure and heat release rate curve

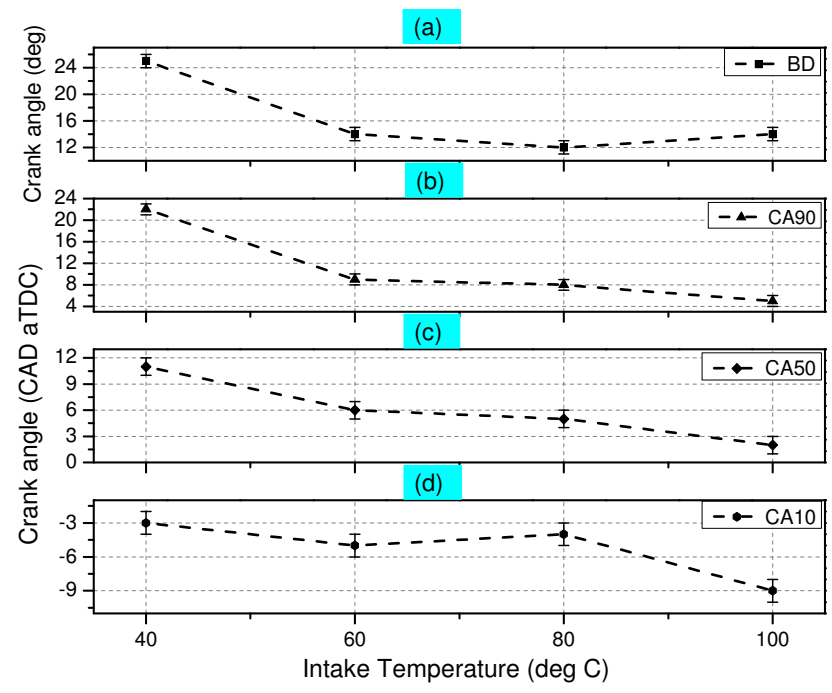

(b) Combustion characteristics

Figure 3.23: a) Pressure and heat release rates for intake air temperatures $40,60,80$ and $100{ }^{\circ} \mathrm{C}$ at $1000 \mathrm{rpm}$ and RON of 20 and b) Effects of the intake air temperature on combustion characteristics (CA10 CA50, CA90 and Burn Duration) for HCCI combustion regime 


\subsection{Effect of boost pressure on HCCI combustion}

Pressure and heat release rate traces for different intake boost pressures at $1000 \mathrm{rpm}$ engine speed and intake air temperature of $40{ }^{\circ} \mathrm{C}$ are seen in Figure 3.24. Lambda value is around 2.2 for each intake pressure. Combustion characteristics of different boost pressures in HCCI mode such as CA10, CA50, CA90 and BD are also seen in Figure 3.25. As seen through Figure 3.24, the peak pressure of combustion increases with an increase in boost pressure. This is due to the increase in the effective charge energy being induced into the cylinder owing to the increase in the air flow rate. In order to maintain the same lambda, the fuel quantity increases. As a result of this, the IMEP also increases with an increase in boost pressure. However, the thermal efficiency and the combustion efficiency decreases. The drop in efficiencies is due to the CA50 being too advanced bTDC. For the same lambda, with an increase in boost pressure, the CA50 tends to get advanced since the start of combustion is advanced with higher pressures at IVC. 
Table 3.6

Operating conditions used for the experiments to study the effect of Boost pressure on HCCI combustion

\begin{tabular}{|l|l|}
\hline \multicolumn{1}{|c|}{ Test Parameters } & \multicolumn{1}{c|}{ Value/ Unit } \\
\hline Engine Speed & $1000(\mathrm{rpm})$ \\
\hline Injection Pressure & $3.5(\mathrm{bar})$ \\
\hline Injection Starting Angle & $450(\mathrm{deg}$ bTDC $)$ \\
\hline Fuel Type & RON 40 \\
\hline IVO & $25.5(\mathrm{deg}$ bTDC $)$ \\
\hline EVC & $22(\mathrm{deg}$ bTDC $)$ \\
\hline Throttle Body Position & $100(\%)$ \\
\hline Intake Air Temperature & $40\left({ }^{\circ} \mathrm{C}\right)$ \\
\hline Lambda & 2.2 \\
\hline Boost Pressure & $100,120,140(\mathrm{kPa})$ \\
\hline
\end{tabular}

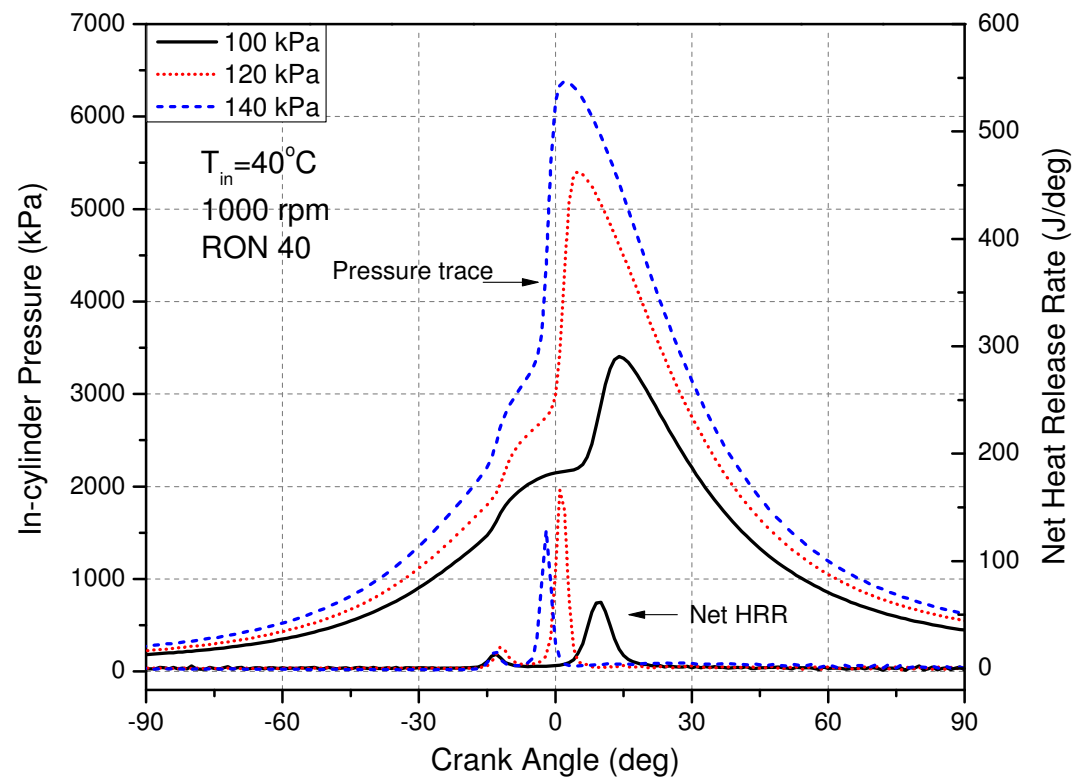

Figure 3.24: Pressure and heat release rates for intake pressures $100 \mathrm{kPa}$, $120 \mathrm{kPa}$ and $140 \mathrm{kPa}$ at $1000 \mathrm{rpm}$ and $\mathrm{RON} 40$ 


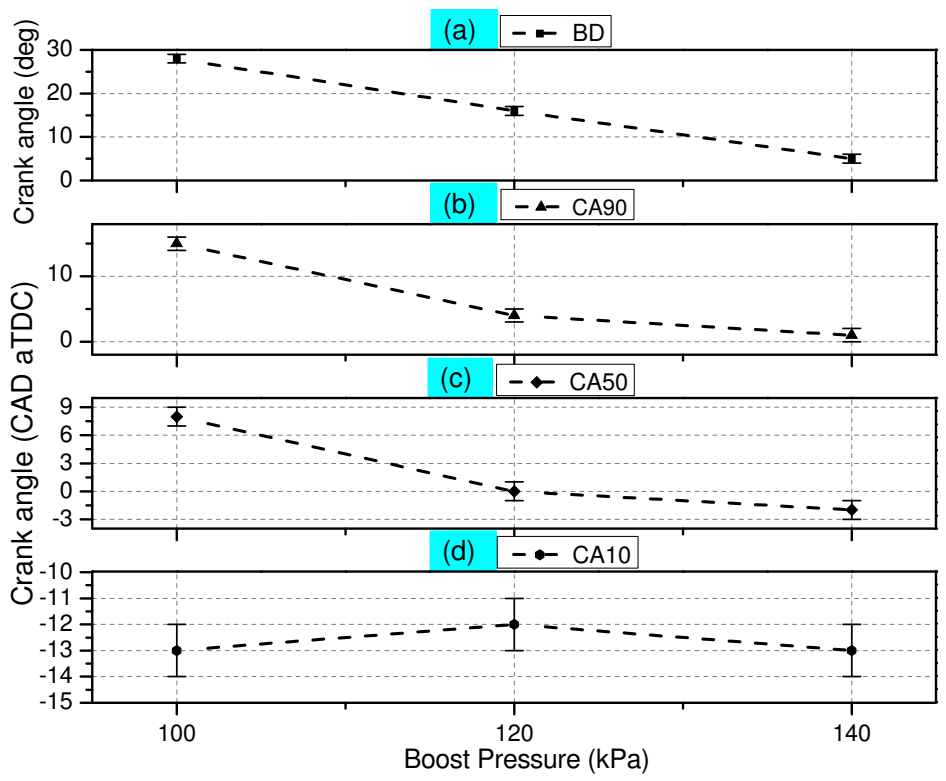

Figure 3.25: Effects of intake pressure on combustion characteristics (CA10 CA50, CA90 and Burn Duration) for HCCI combustion regime

(a)
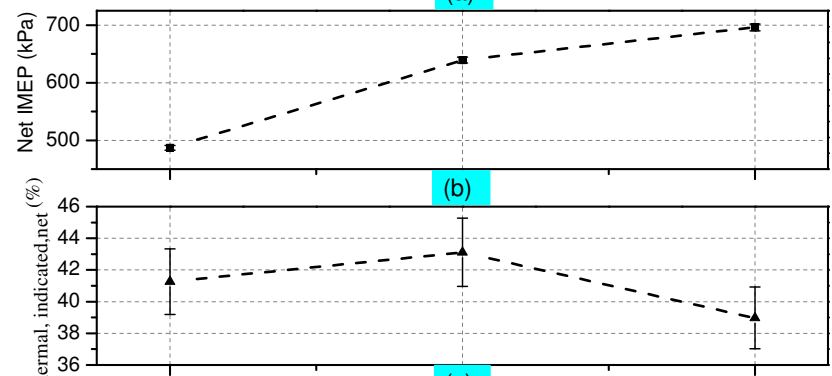

(c)

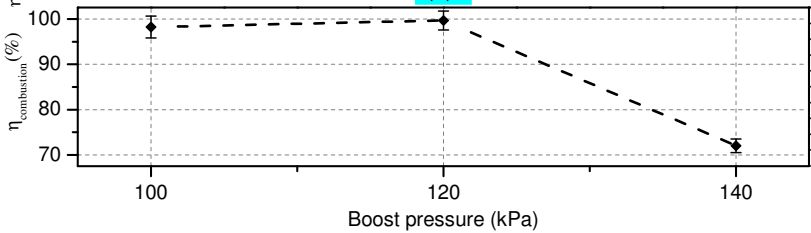

Figure 3.26: Effects of the boost pressure on (a) IMEP, (b) Indicated thermal efficiency and (c) Combustion efficiency for HCCI combustion regime 


\section{Chapter 4}

\section{Reactivity Controlled Compression Ignition (RCCI)}

This chapter presents an overview of the Reactivity Controlled Compression Ignition (RCCI) combustion regime. RCCI has an advantage over other LTC combustion regimes in that the combustion phasing can be controlled by the start of injection of the fuel injected directly into the cylinder. Moreover, the fuel reactivity can be modified based on the engine speed and load allowing a much stable low temperature combustion for low load applications [62]. This chapter explores the engine maps for efficiency and combustion for three different premixed ratios 20, 40 and 60 for RCCI combustion regime over a range of speed and load conditions. The maps are based on constraints with all data points over 8 bar/CAD of MPRR and $10 \% C O V_{I M E P}$ 
[61] are eliminated. The operating conditions for the tests are represented in Table

4.1 .

Table 4.1

Operating Parameters for RCCI Combustion mode

\begin{tabular}{|l|l|}
\hline \multicolumn{1}{|c|}{ Parameter } & Operating Conditions \\
\hline Intake Air temperature & $40,60,80\left({ }^{\circ} \mathrm{C}\right)$ \\
\hline Manifold Pressure & $120,140(\mathrm{kPa})$ \\
\hline Engine Speed & $800: 200: 3200(\mathrm{rpm})$ \\
\hline PR of Fuel & $20,40,60(-)$ \\
\hline Lambda & $1.0-4.2(-)$ \\
\hline
\end{tabular}

\subsection{Parametrization of BMEP using Flynn-Chen Model for RCCI combustion regime}

Figure4.1 compares the experimental FMEP vs parameterized FMEP for RCCI combustion regime. It can be seen that the FMEP can be estimated within an error of $14 \%$. 


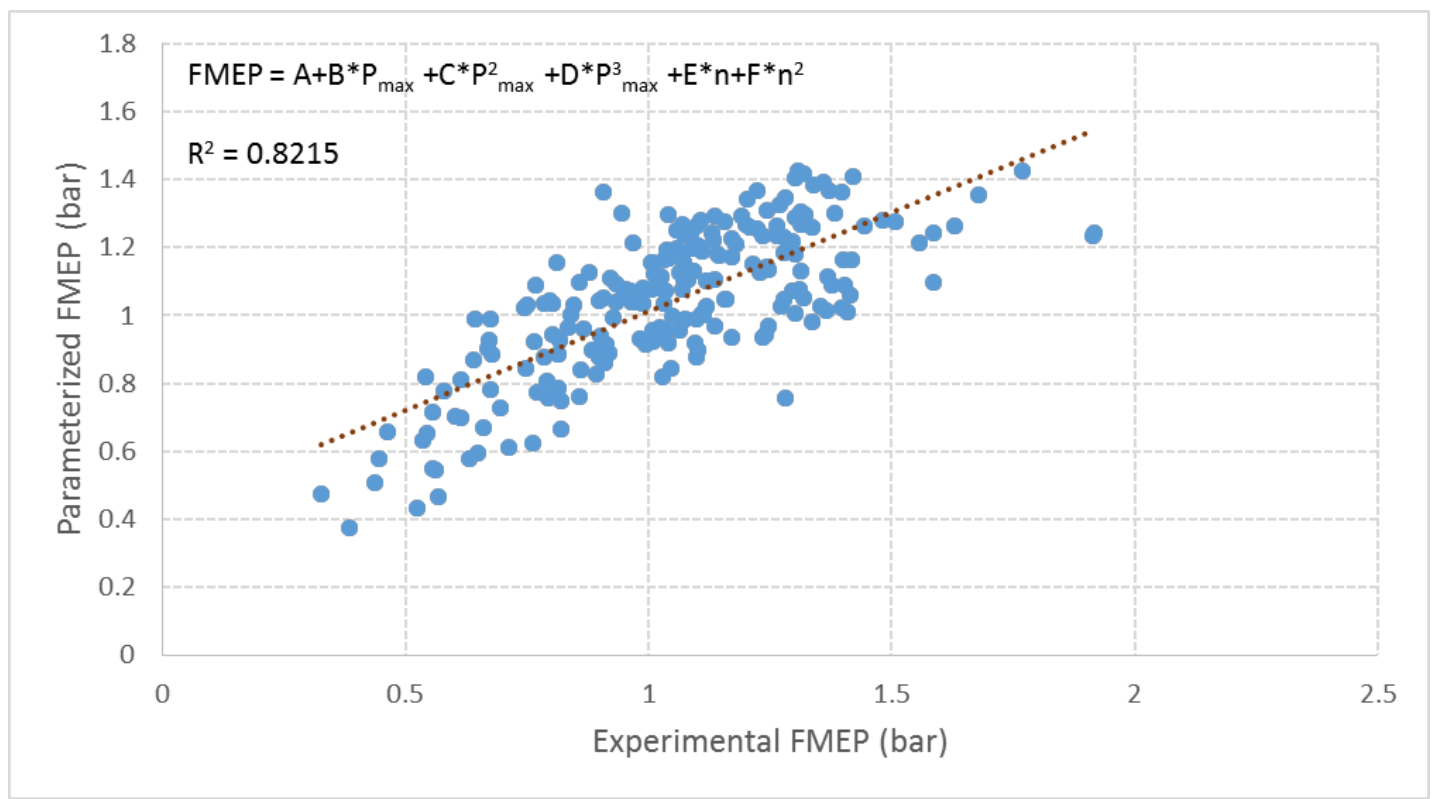

Figure 4.1: Experimental FMEP vs Parameterized FMEP

Table 4.2

Error in estimation of FMEP

\begin{tabular}{|l|l|}
\hline \multicolumn{1}{|c|}{ Model } & Chen-Flynn with $P_{\max }^{2}$ and $P_{\max }^{3}$ \\
\hline Mean relative error & $14 \%$ \\
\hline Max relative error & $41 \%$ \\
\hline Max absolute error & $0.7 \mathrm{bar}$ \\
\hline
\end{tabular}


Table 4.3

Coefficients for the Flynn- Chen Model

\begin{tabular}{|l|l|}
\hline Coefficient & Value \\
\hline A & -2.9371 \\
\hline B & 0.0016 \\
\hline C & -0.002 \\
\hline D & $9.19 \mathrm{E}-6$ \\
\hline E & 0.0806 \\
\hline F & -0.0042 \\
\hline
\end{tabular}

Based on the parametrized model for FMEP, the constants obtained for the ChenFlynn model are given in Table 4.3 .

\section{$4.2 \quad$ Operating Range}

RCCI operation over a range of engine speeds and loads was achieved based on a systematic procedure followed to run the tests. The injection pressure for both the DI and the PFI rails were held constant at 100 bar and 3 bar, respectively. The SOI timing was advanced with increase in engine speed. All tests were performed by monitoring the CA50 online and trying to maintain a constant combustion phasing of 5-8 deg aTDC. Figure 4.2 shows the operating range map in terms of equivalence ratio, engine speed and load limits for $T_{\text {intake }}$ of $40{ }^{\circ} \mathrm{C}$ and boost pressure of $140 \mathrm{kPa}$. The operating map shows that the speed range for RCCI mode gets narrower with an 
increase in PR. This is mainly because the reactive fuel quantity (n-heptane) reduces with an increase in PR. Therefore, the combustion becomes unstable at speeds higher than $1400 \mathrm{rpm}$ for PR 60. It can also be seen that the engine could be run much leaner for a lambda of 5.21 at PR 20 as compared to 4.41 at PR 60. The lean limit for lower PR is much higher because of the combustion stability with the high reactive fuel dominance.

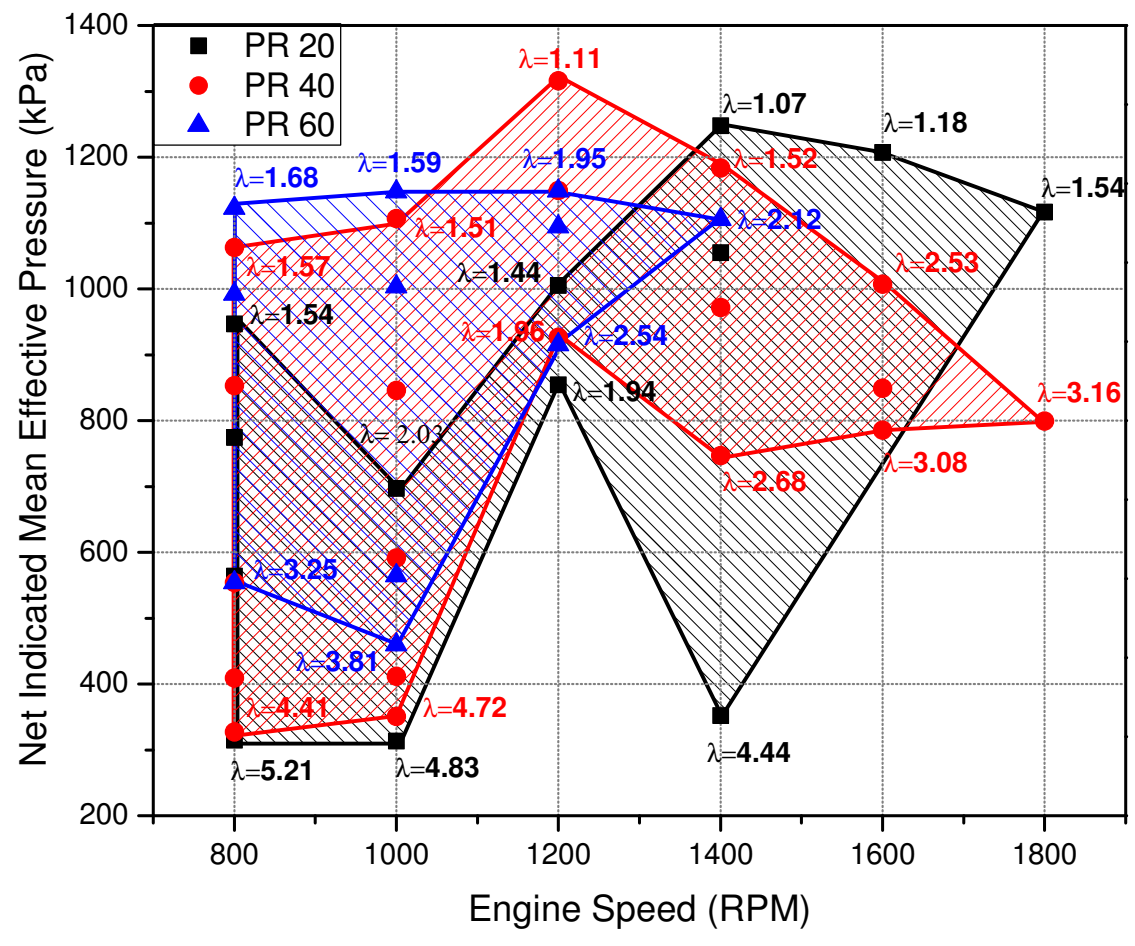

Figure 4.2: $\mathrm{RCCI}$ IMEP and speed range for $40{ }^{\circ} \mathrm{C}$ intake air temperature and boost pressure of $140 \mathrm{kPa}$

Figure 4.3 represents the operating range map for an intake temperature of $60{ }^{\circ} \mathrm{C}$ 
and an intake pressure of $140 \mathrm{kPa}$. It can be observed that the lean limit for PR 20 is pushed further to a lambda value of 6.27 at $800 \mathrm{rpm}$. This is mainly due to the increased temperature of the intake charge at IVC. Moreover, the speed range for all three PRs is improved with an increase in intake temperature.

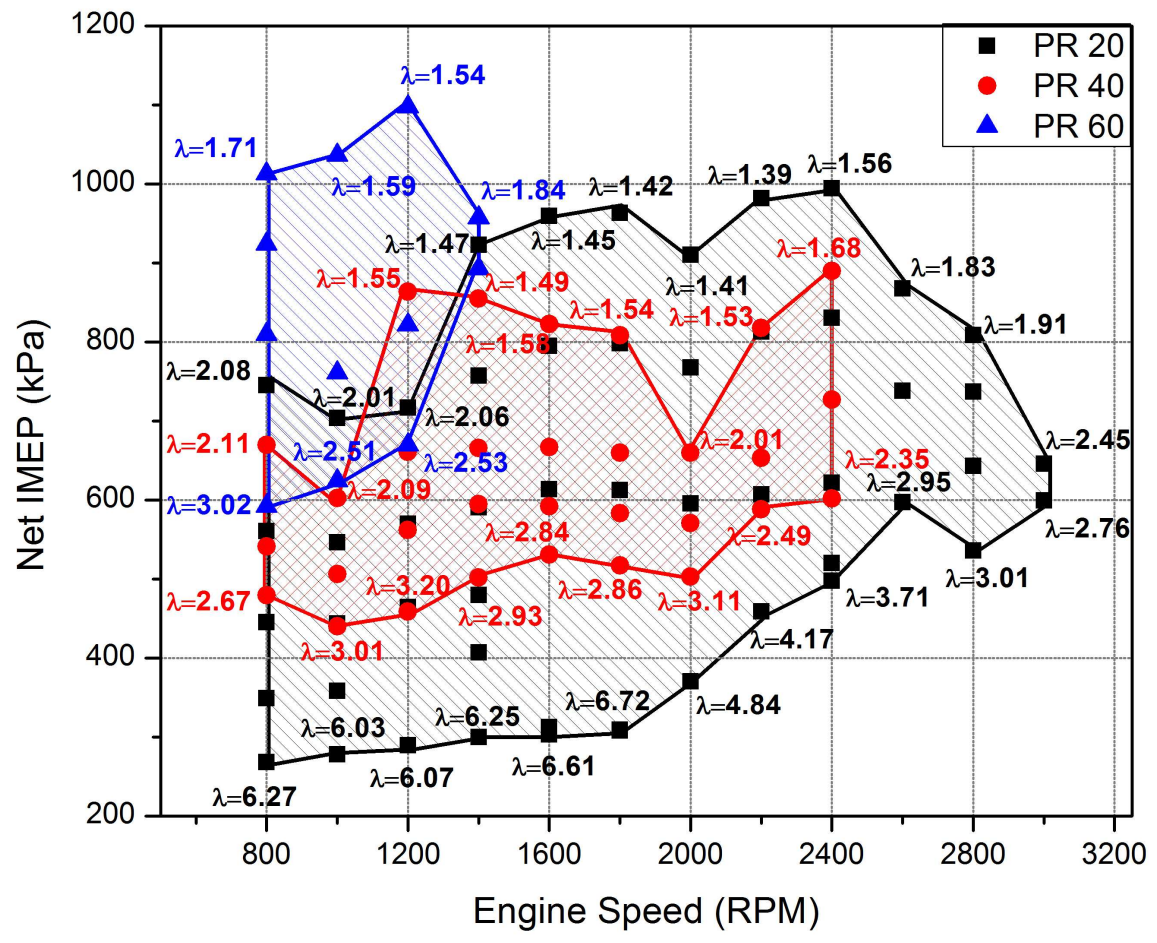

Figure 4.3: RCCI IMEP and speed range for $60{ }^{\circ} \mathrm{C}$ intake air temperature and boost pressure of $140 \mathrm{kPa}$ 


\subsection{Maps for ISFC, BSFC, Indicated Thermal ef- ficiency and Exhaust gas temperature}

The ISFC maps for RCCI mode at $T_{\text {intake }}$ of $40{ }^{\circ} \mathrm{C}$ and $P_{\text {intake }}$ of $140 \mathrm{kPa}$ for all three PRs are shown in Figure 4.4. It can be seen that the best ISFC points shift towards higher load conditions at an engine speed of $1400 \mathrm{rpm}$ with an increase in PR of the fuel blends. Lower load performance for PR 20 is diesel like and the ISFC improves with load. It is also observed that the ISFC values are higher at low loads and low speeds for PR 60. This is due to the fact that the combustion efficiency drops at low loads and low speeds due to the ultra-lean air-fuel mixture. This results in a decreased combustion temperature and thereby increasing the unburnt fuel at the exhaust. 

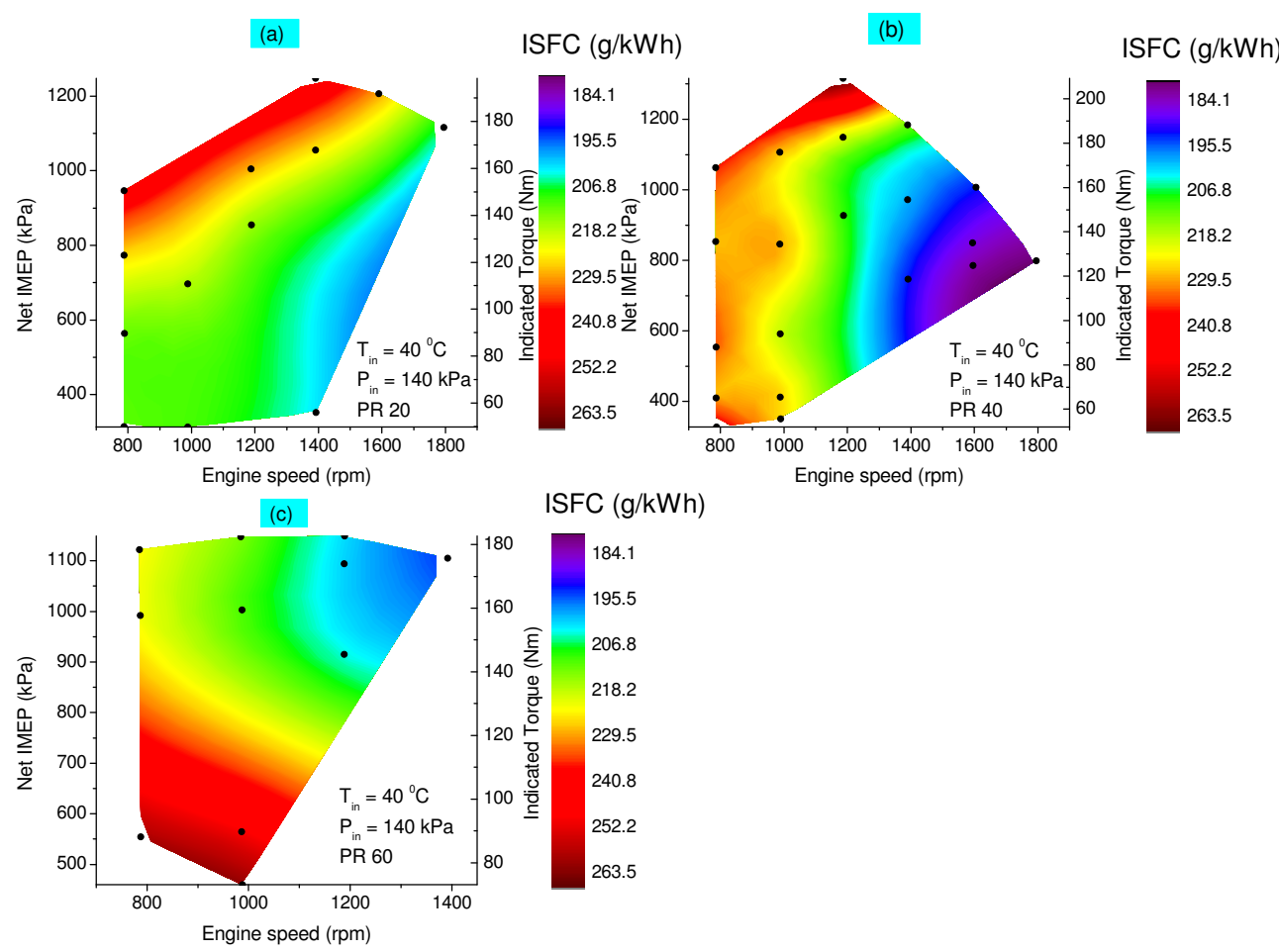

Figure 4.4: RCCI ISFC map for three PRs at $40{ }^{\circ} \mathrm{C}$ intake air temperature and intake pressure of $140 \mathrm{kPa}$

The BSFC maps were parameterized from the Flynn- Chen model and are represented in Figure 4.5 for the same operating conditions. The combustion efficiency was relatively lower at $75 \%$ for low loads and low engine speeds, as a result of which an increase in BSFC is observed for all three PRs. The range of BSFC was 230-325 $\mathrm{g} / \mathrm{kWh}$ with the best BSFC occurring at high speeds and high loads for all PRs. It can be seen that the BMEP increases with increase in fuel energy content per cycle. 


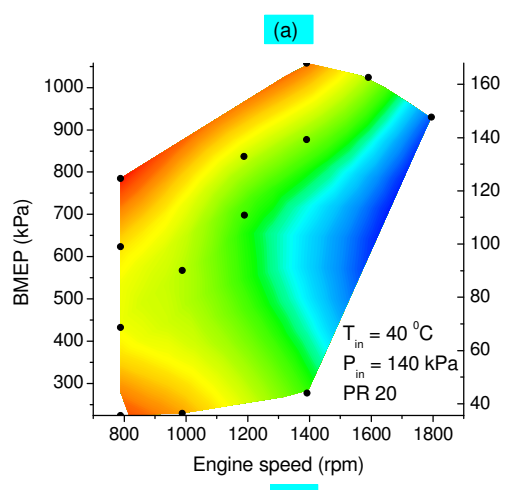

BSFC (g/kWh)

(b)

231.9

245.3

258.7

272.1

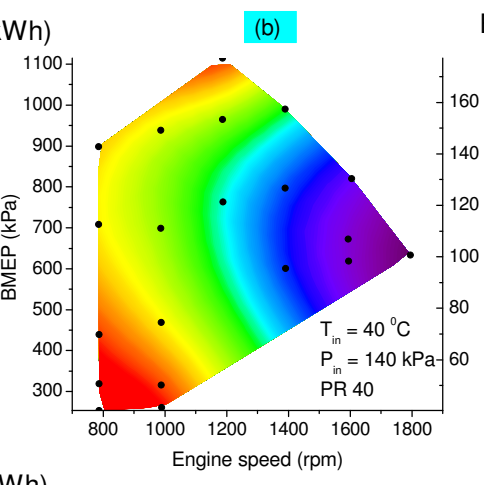

BSFC $(g / k W h)$

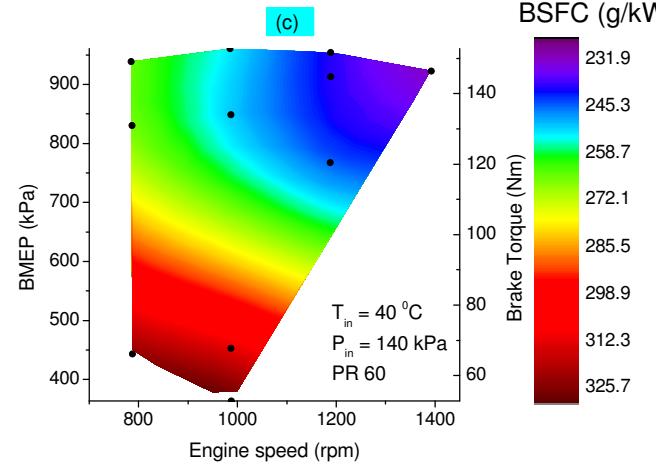

Figure 4.5: RCCI BSFC map for three PRs at $40{ }^{\circ} \mathrm{C}$ intake air temperature and $140 \mathrm{kPa}$ intake pressure

Figure 4.6 shows a comparison of indicated thermal efficiencies for the RCCI mode for the same operating conditions. It can be seen that the thermal efficiency improves with load. The maximum thermal efficiency for this map was $45 \%$ at $1800 \mathrm{rpm}$ and $120 \mathrm{Nm}$ load for PR 40, which is $5 \%$ better than the $\eta_{t h, i n d}$ for PR 20 at the same speed-load condition. The compression ratio of the engine, pumping losses and specific heat ratio play crucial roles in determining the thermal efficiency [32]. For $1800 \mathrm{rpm}$ and $120 \mathrm{kPa}$ for $\mathrm{PR}$ 40, the heat transfer losses are significantly reduced 
due to high engine speed. Thereby, the ratio of specific heat is higher with a lower in-cylinder temperature. This results in better combustion efficiency and thereby increasing the thermal efficiency.
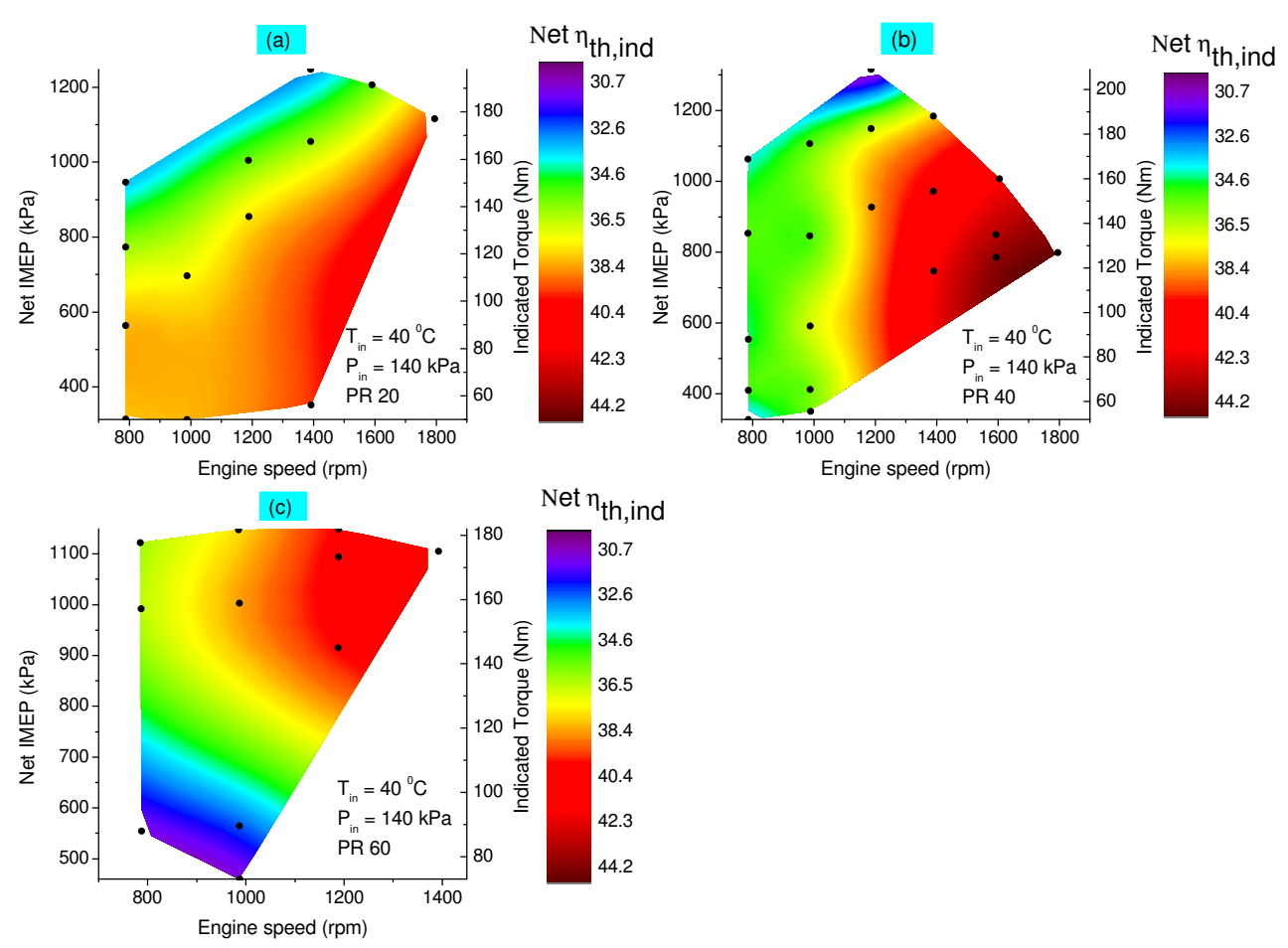

Figure 4.6: RCCI Indicated thermal efficiency map for three PRs at $40{ }^{\circ} \mathrm{C}$ intake air temperature and $140 \mathrm{kPa}$ intake pressure

For RCCI combustion regime, the exhaust temperature map is shown in Figure 4.7 .

It can be seen that at lower loads and lower speeds, $T_{\text {exhaust }}$ is less than $200{ }^{\circ} \mathrm{C}$, which implies less capability to reach to catalyst light off temperatures and poses a challenge with respect to the functioning of the oxidation catalysts. However, it can be seen 
that the temperatures increase as high as $570{ }^{\circ} \mathrm{C}$ at higher speeds and loads. This is the typical temperature at which most SI engines work, at mid- high load conditions. For PR 20, at loads higher than $80 \mathrm{Nm}$ for all engine speeds, the $T_{\text {exhaust }}$ is higher than the catalyst light off temperature of the oxidation catalyst. The $T_{\text {exhaust }}$ range is much wider as compared to that in the HCCI combustion regime.

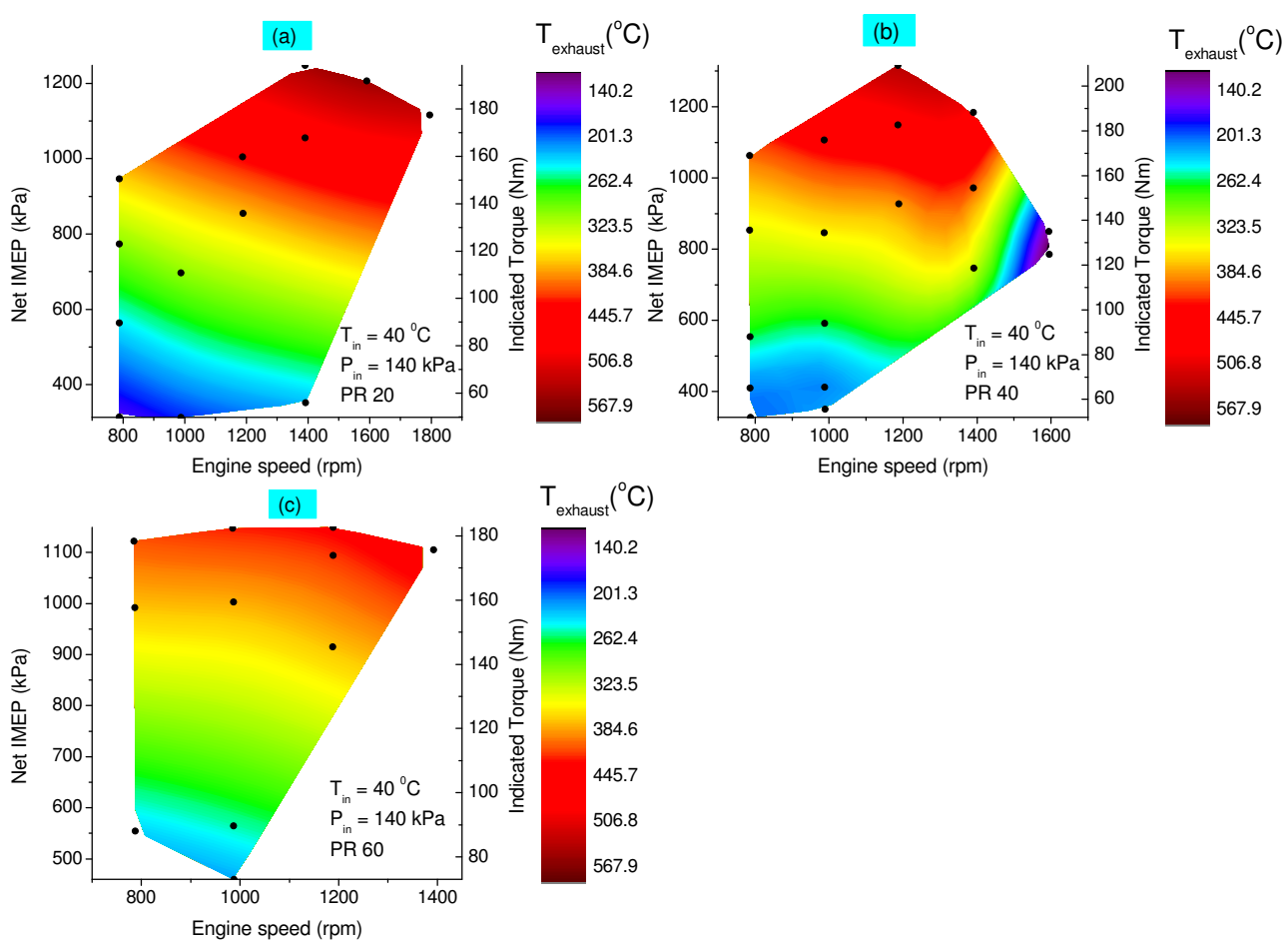

Figure 4.7: RCCI Exhaust gas temperature map for three PRs at $40{ }^{\circ} \mathrm{C}$ intake air temperature and $140 \mathrm{kPa}$ boost pressure 


\subsection{Optimized RCCI maps}

The data points for RCCI combustion regime were optimized by considering data points with best ISFC at each speed-load condition. Maps for BSFC, $\eta_{t h, i n d}$ and $T_{\text {exh }}$ were evaluated for the same optimized set of data points. Figures 4.8 and 4.9 represent the optimized RCCI map for ISFC for naturally aspirated and boosted conditions, respectively. It is evident that the speed and load range could be extended with boosting. In order to obtain the best ISFC for Naturally aspirated conditions, the engine should be run within the load range of 70-120 Nm, where an ISFC of 180 g/kWh was obtained. At $1400 \mathrm{rpm}$ and $100 \mathrm{Nm}$ indicated torque, the lowest ISFC of $175 \mathrm{~g} / \mathrm{kWh}$ was obtained. This data point was run with a combustion phasing of 7 CAD aTDC and had the best indicated thermal efficiency of $46 \%$. The start of injection was varied to keep the combustion phasing between 5-8 CAD aTDC. Moreover, the mass of fuel unburnt was less than $3 \%$ for this data point. This shows that both combustion efficiency and combustion phasing play a crucial role in attaining the optimal ISFC at a given speed-load condition. For boosted conditions, the speed range was extended to $3400 \mathrm{rpm}$, while the load range was extended to $210 \mathrm{Nm}$ indicated torque. With this range expansion, the best ISFC was shifted to higher engine speeds and loads as compared to the ISFC map for naturally aspirated conditions. At $140 \mathrm{kPa}$ intake pressure, $2400 \mathrm{rpm}$ engine speed and $80 \mathrm{Nm}$ indicated torque, an ISFC of $176 \mathrm{~g} / \mathrm{kWh}$ was obtained. It can be seen that the SOI was advanced 
to $65 \mathrm{CAD}$ bTDC for this operating condition, in order to maintain a CA50 of 10 CAD aTDC. Moreover, the engine was run at a PR of 60 . Thereby, with lower incylinder temperatures and a two stage HTHR, the combustion was complete with a combustion efficiency of $98 \%$. With such an optimized set of operating conditions, the thermal efficiencies and henceforth the ISFC seemed to improve considerably.

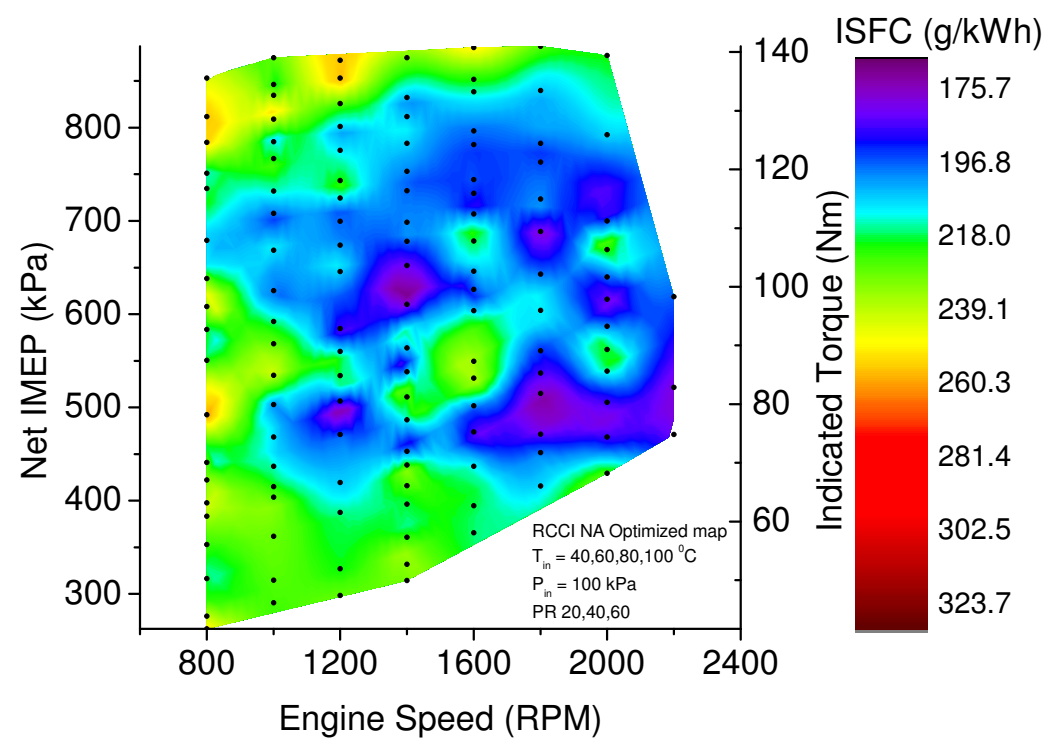

Figure 4.8: RCCI ISFC optimized map for all intake air temperatures and PRs for naturally aspirated conditions 


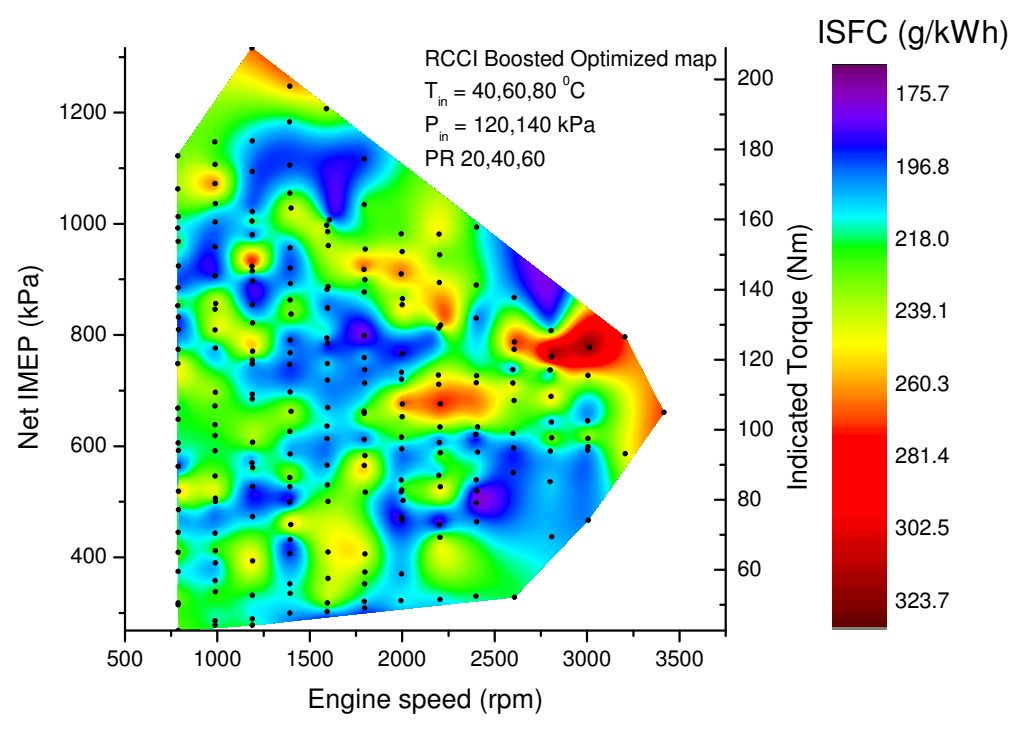

Figure 4.9: RCCI ISFC optimized map for all intake air temperatures and PRs at $140 \mathrm{kPa}$ boost pressure

The BSFC maps as a function of engine speed and load are shown in Figures 4.10 and 4.11 for naturally aspirated and boosted conditions, respectively. It can be seen that with boosted conditions for the lower speeds, the engine could be run at lower loads as compared to naturally aspirated. This correlates to the lower equivalence ratio at boosted conditions, due to the increased density of the air inducted into the cylinder, making the mixture oxygen-rich and thereby leaner. However, the combustion efficiencies at these points were relatively lower, thereby justifying the higher values of BSFC. 


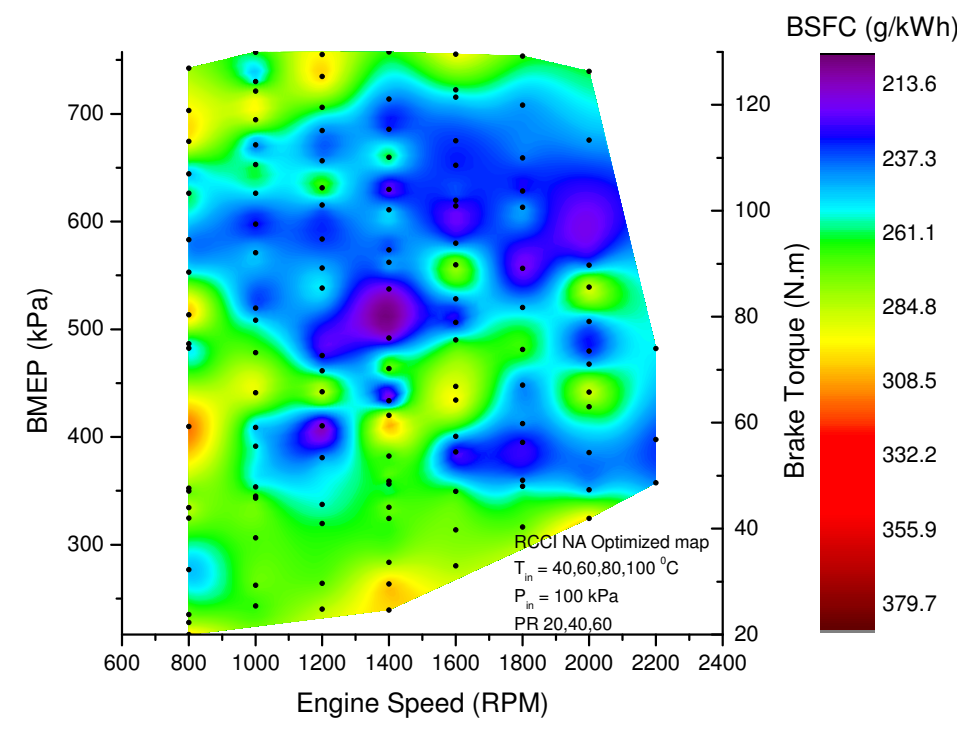

Figure 4.10: RCCI BSFC optimized map for all intake air temperatures and PRs at naturally aspirated conditions

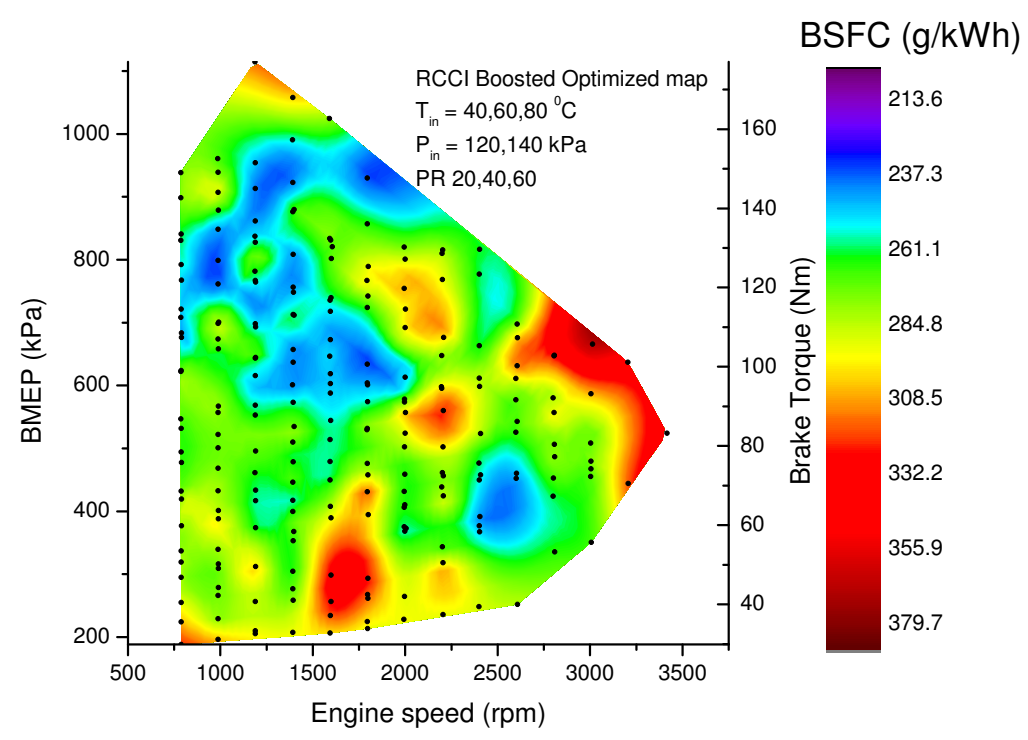

Figure 4.11: RCCI BSFC optimized map for all intake air temperatures and PRs at $140 \mathrm{kPa}$ intake pressure 
The most significant observation for RCCI combustion regime is the higher $\eta_{t h, i n d}$ at a wide range of speed-load conditions. This can be observed in Figures 4.12 and 4.13 for naturally aspirated and boosted conditions, respectively. The $\eta_{t h, i n d}$ is quite high for high speed-load conditions. The lower equivalence ratio at low speeds and lowest loads comes with the price of decreased stability and efficiency. The start of injection pays a crucial role in determining the combustion phasing. As seen through the data, it is advisable to keep the combustion phasing not greater than 10 CAD aTDC. The combustion efficiencies tend to drop beyond this point. At low speeds such as 800 rpm, the Start of injection is 18 CAD bTDC, which is too late. However, this is the optimal SOI for which the desirable combustion phasing could be achieved. The low thermal efficiency at low speeds could be because of insufficient time for the n-heptane and iso-octane to mix, thereby leading to unburnt fuel over $15 \%$ in the exhaust. 


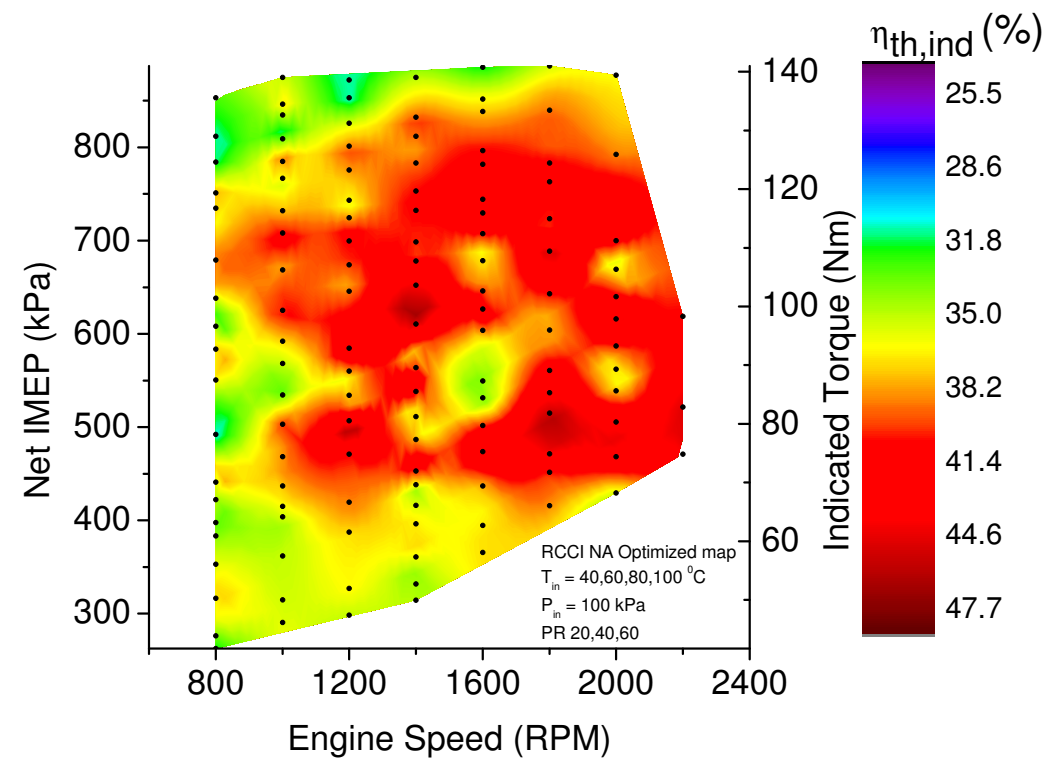

Figure 4.12: RCCI indicated thermal efficiency optimized map for all intake air temperatures and PRs at naturally aspirated conditions

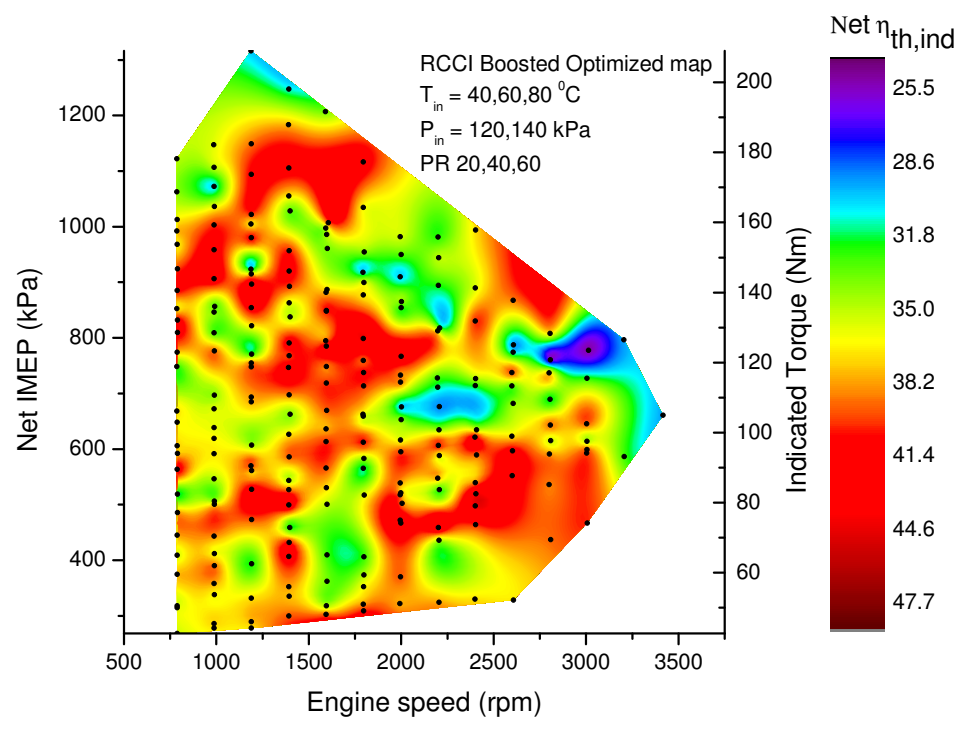

Figure 4.13: RCCI indicated thermal efficiency optimized map for all intake air temperatures and PRs at $140 \mathrm{kPa}$ intake pressure 
The optimized exhaust temperature maps for naturally aspirated and boosted conditions are illustrated in Figures 4.14 and 4.15 , respectively. The lower and upper limits for the temperatures are $190{ }^{\circ} \mathrm{C}$ and $720{ }^{\circ} \mathrm{C}$, respectively. With an increase in engine speed and load, the $T_{\text {exhaust }}$ increases. At loads higher than $70 \mathrm{Nm}$ and all engine speeds, the exhaust energy can be recovered to either run the turbocharger or to develop a waste heat recovery system to heat the intake air.

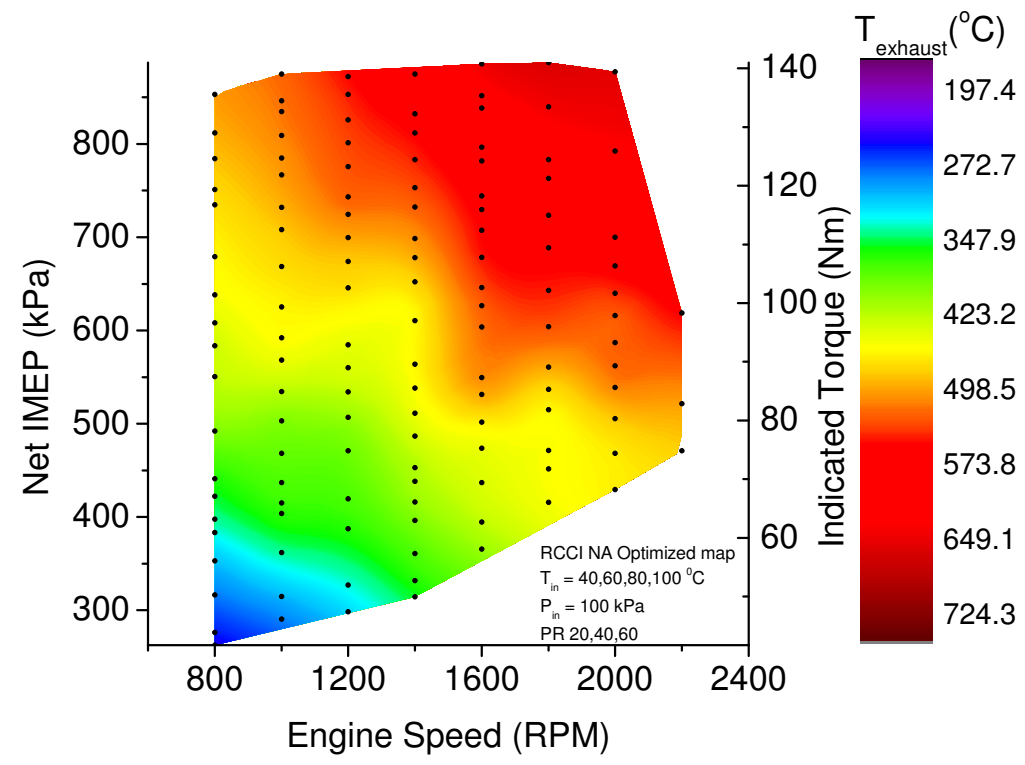

Figure 4.14: RCCI exhaust temperature optimized map for all intake air temperatures and PRs at naturally aspirated conditions 


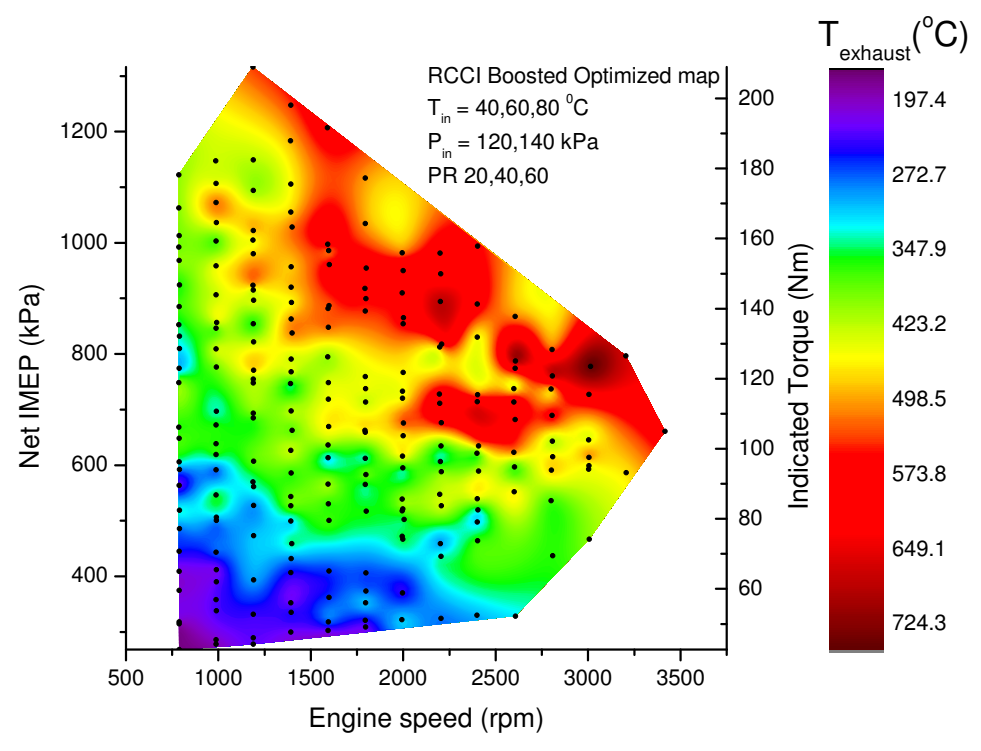

Figure 4.15: HCCI exhaust temperature optimized map for all intake air temperatures and PRs at $140 \mathrm{kPa}$ intake pressure

\subsection{RCCI optimized maps with supercharger}

\section{losses accounted}

The RCCI tests for boosted conditions were performed using an e-supercharger, which was driven by an electric motor. This energy consumed by the supercharger was unaccounted for, in the maps represented in Section 4.3. This section provides an overview of the change in the performance parameters, fuel consumption assuming the supercharger was mounted on the engine and drawing power from the engine 
crankshaft. The supercharger efficiency was considered constant with a value of 0.6 [37. The power consumed at each engine speed and boost pressure is illustrated in Section 2.8. Based on these values the Net Power from the engine was calculated by deducting the losses from the supercharger. Figure 4.16 represents the optimized ISFC map with the supercharger losses accounted for. It can be seen that the best ISFC point shifted from 175 to $225 \mathrm{~g} / \mathrm{kWh}$ after accounting for the losses. Moreover, given that the engine power output is lower at low engine speeds, the best ISFC for a given engine speed occurs at low power and the ISFC values increase at higher loads. Therefore it can be seen that the ISFC values increased roughly by $30 \%$ after the losses were accounted for. Moreover, the peak thermal efficiency dropped from $47 \%$ to $37 \%$, which is approximately a $10 \%$ reduction. This provides a good incentive to use RCCI exhaust energy (in Figures 4.14 and 4.15 for turbocharging the engine instead of using a supercharger. 


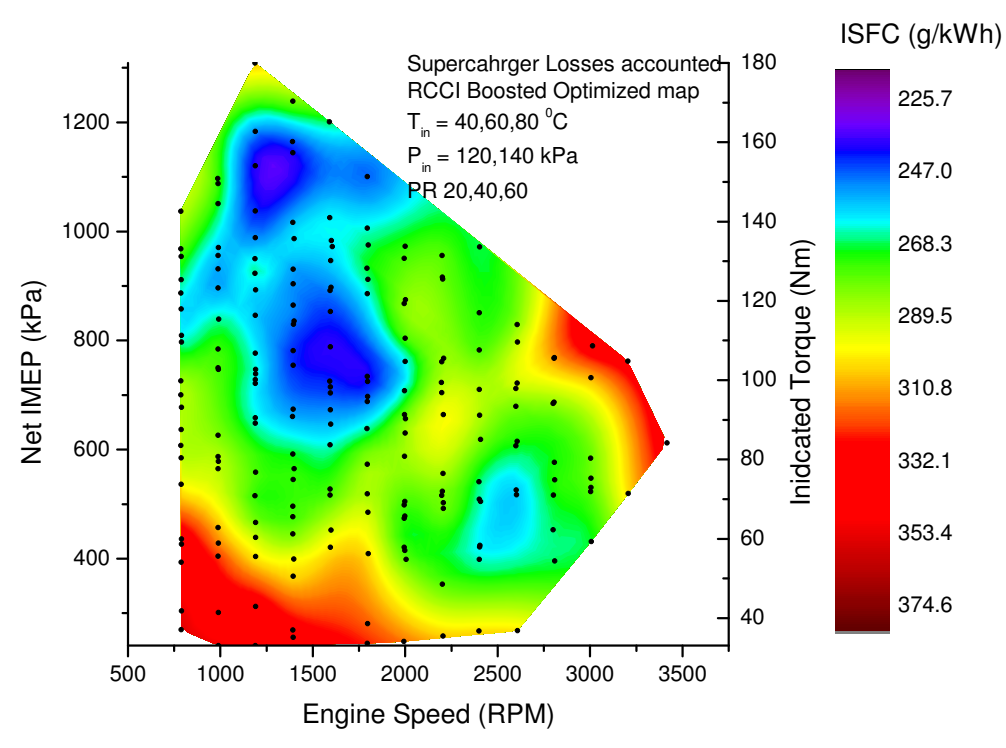

Figure 4.16: Optimized ISFC map for RCCI combustion regime with supercharger losses accounted for

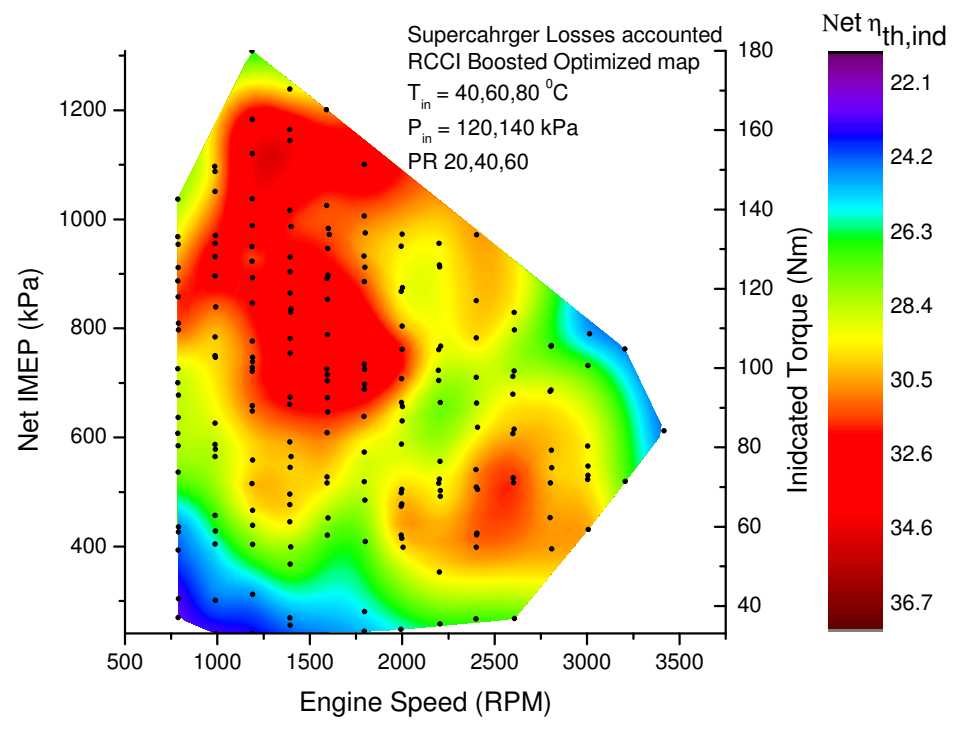

Figure 4.17: Optimized $\eta_{t h, i n d}$ map for RCCI combustion regime with supercharger losses accounted for 


\subsection{RCCI optimized maps with COV of IMEP less}

\section{than 5 percent}

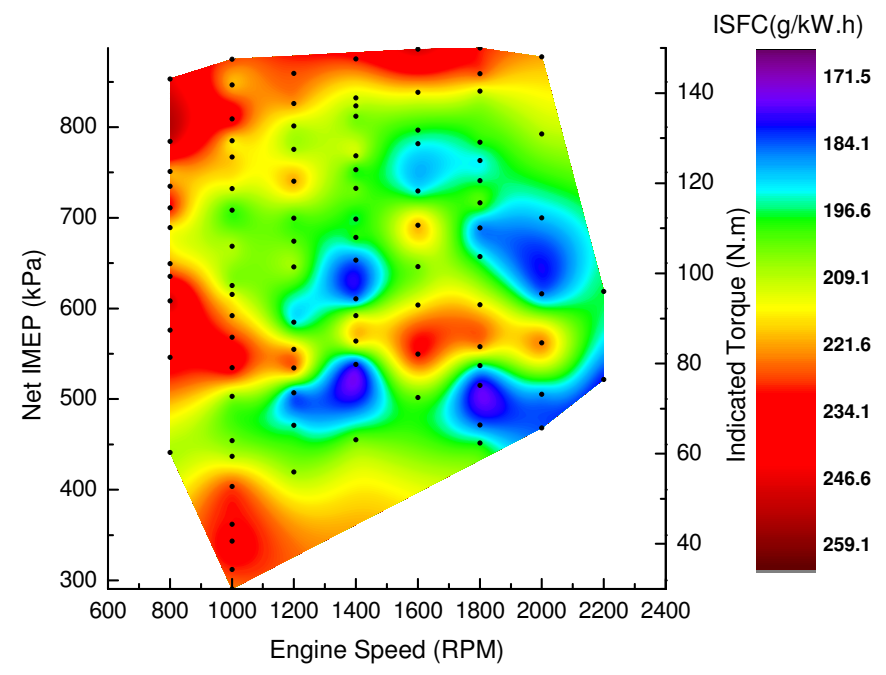

Figure 4.18: ISFC optimized map for RCCI combustion regime for COV of IMEP less than $5 \%$ at naturally aspirated conditions 


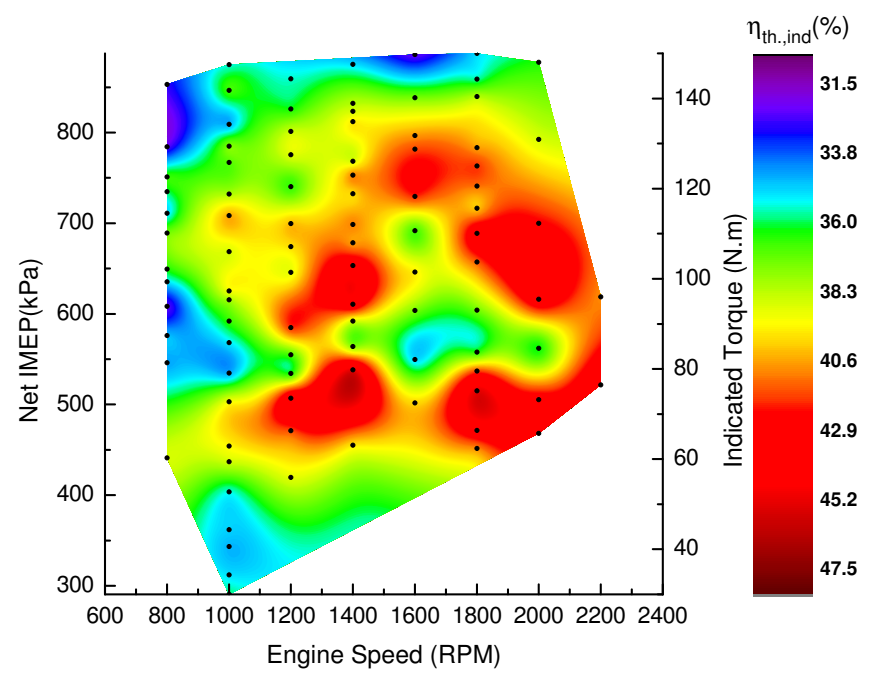

Figure 4.19: Indicated thermal efficiency optimized map for RCCI combustion regime for COV of IMEP less than $5 \%$ at naturally aspirated conditions

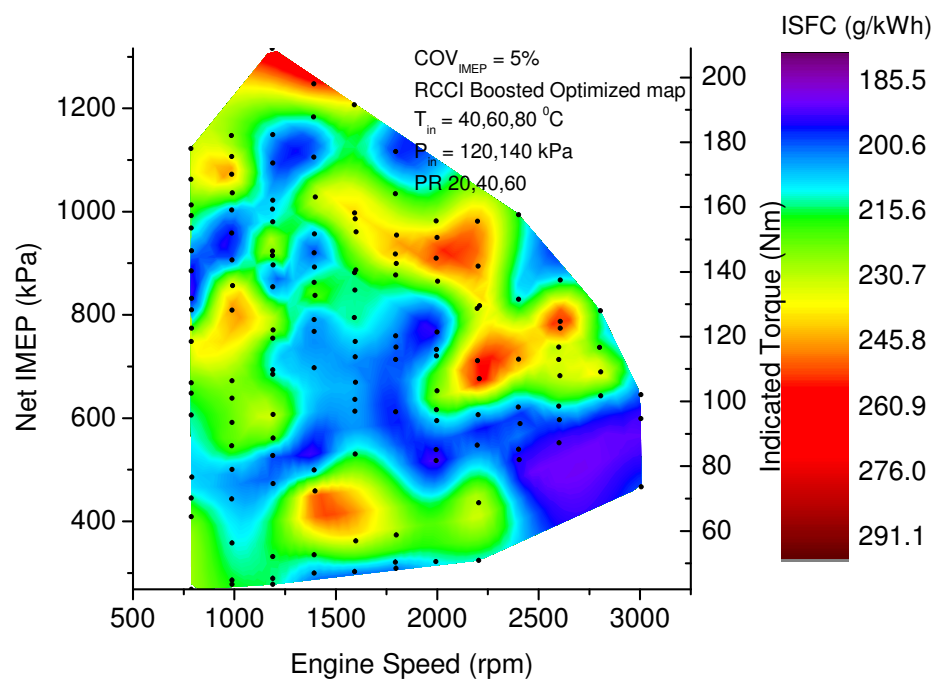

Figure 4.20: ISFC optimized map for RCCI combustion regime for COV of IMEP less than $5 \%$ and boosted conditions 


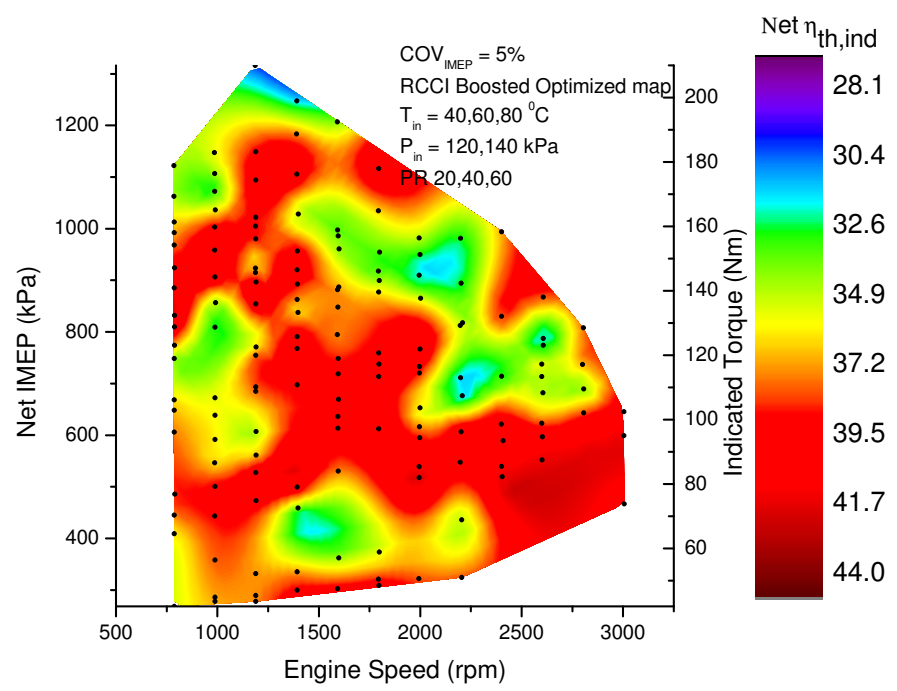

Figure 4.21: Indicated thermal efficiency optimized map for RCCI combustion regime for COV of IMEP less than $5 \%$ and boosted conditions

\subsection{Effects of PR on RCCI combustion}

This section discusses the effect of premixed ratio $(\mathrm{PR})$ on the combustion characteristics and performance metrics of RCCI combustion regime, with premixed ratios of 20, 40 and 60 . The start of injection was held constant at 25 CAD bTDC and the tests were performed at the constant total fuel energy. The operating conditions for performing these tests are given in Table 4.4 . 
Table 4.4

Operating conditions used for the experiments to study the effect of $\mathrm{PR}$ on RCCI combustion

\begin{tabular}{|l|l|}
\hline \multicolumn{1}{|c|}{ Test Parameters } & \multicolumn{1}{c|}{ Value/ Unit } \\
\hline Engine Speed & $1000(\mathrm{rpm})$ \\
\hline Injection Pressure & $100(\mathrm{bar})$ \\
\hline SOI & $25(\mathrm{deg}$ bTDC $)$ \\
\hline Fuel Type & PR $20,40,60$ \\
\hline IVO & $25.5(\mathrm{deg}$ bTDC $)$ \\
\hline EVC & $22(\mathrm{deg}$ bTDC $)$ \\
\hline Throttle Body Position & $100(\%)$ \\
\hline Intake Air Temperature & $60\left({ }^{\circ} \mathrm{C}\right)$ \\
\hline Fuel Mass & $18(\mathrm{mg} / \mathrm{cycle})$ \\
\hline Intake Pressure & $120(\mathrm{kPa})$ \\
\hline
\end{tabular}

Figure 4.22 illustrates the pressure trace and heat release rate curves for the three PRs used. It can be observed that the peak in-cylinder pressure decreases with an increase in PR. Moreover, the location of peak pressure (LPP) gets retarded too. The heat release rate curve shows that there is a significant charge cooling at the time when n-heptane is injected into the cylinder at $25 \mathrm{CAD}$ bTDC. With n-heptane being the more reactive fuel, with an increase in PR, the reactivity of mixture decreases resulting in the combustion phasing to be retarded as illustrated in Figure 4.22 and Figure 4.24. It can be seen that the CA50 changes from 10 to $15 \mathrm{CAD}$ aTDC as the PR is increased from 20 to 60 . Further owing to the reduced reactivity of fuel at higher PR, the burn duration (BD) also increases indicating that the combustion rate is slower as compared to lower PRs. 
An interesting observation from the heat release rate curve is that for PR 60 , there appears to be a two-stage high temperature heat release (HTHR), as shown in Figure 4.23. This can be attributed to the fact that the injection timing was too retarded bTDC. Iso-octane being injected much earlier in the port at 450 CAD bTDC, gets sufficient time to mix homogeneously with air and a part of it is consumed shortly after n-heptane is injected directly into the cylinder. The high pressure and temperature at TDC catalyzes this process resulting in the combustion of the mixture for the first stage of HTR. The remaining iso-octane is expected to get consumed after the TDC. Therefor the first stage heat release is mainly trigerred due to n-heptane being injected late in the cylinder. The first stage heat release triggers the the remainder mixture to burn and thereby resulting in the second stage HTR [63]. 


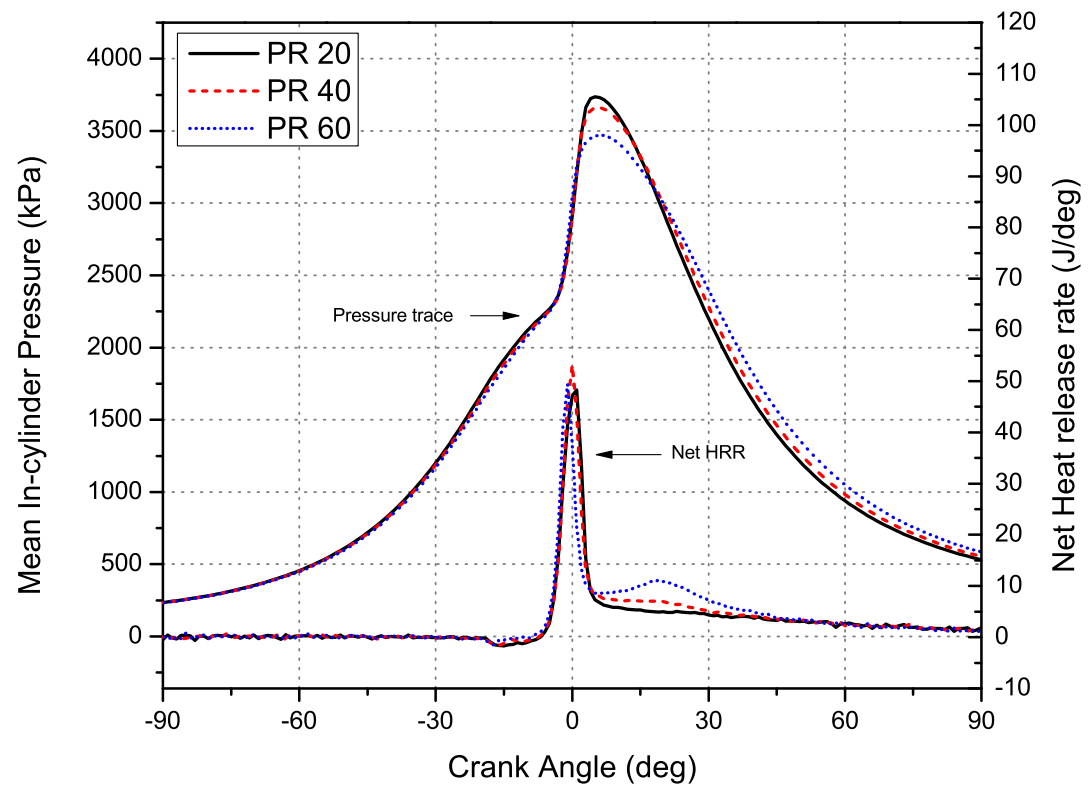

Figure 4.22: Pressure and heat release rates for PR 20, 40 and 60 for operating conditions listed in Table 4.4 


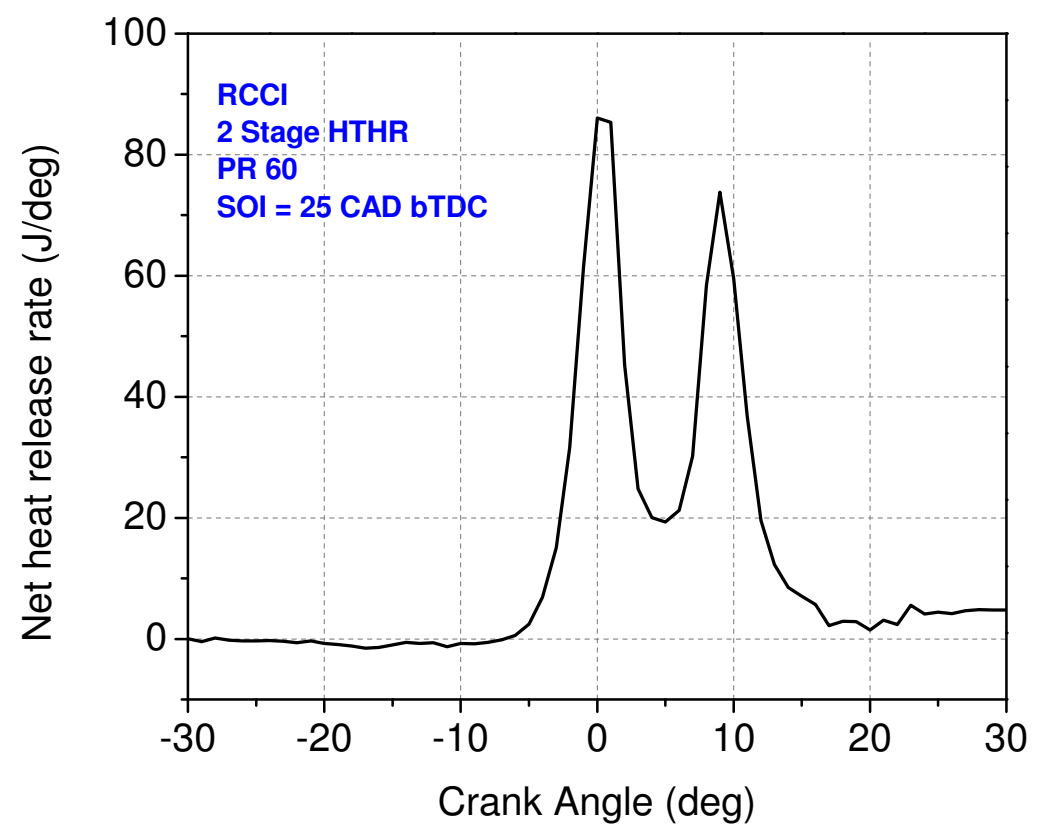

Figure 4.23: Heat release rate characteristics for RCCI combustion

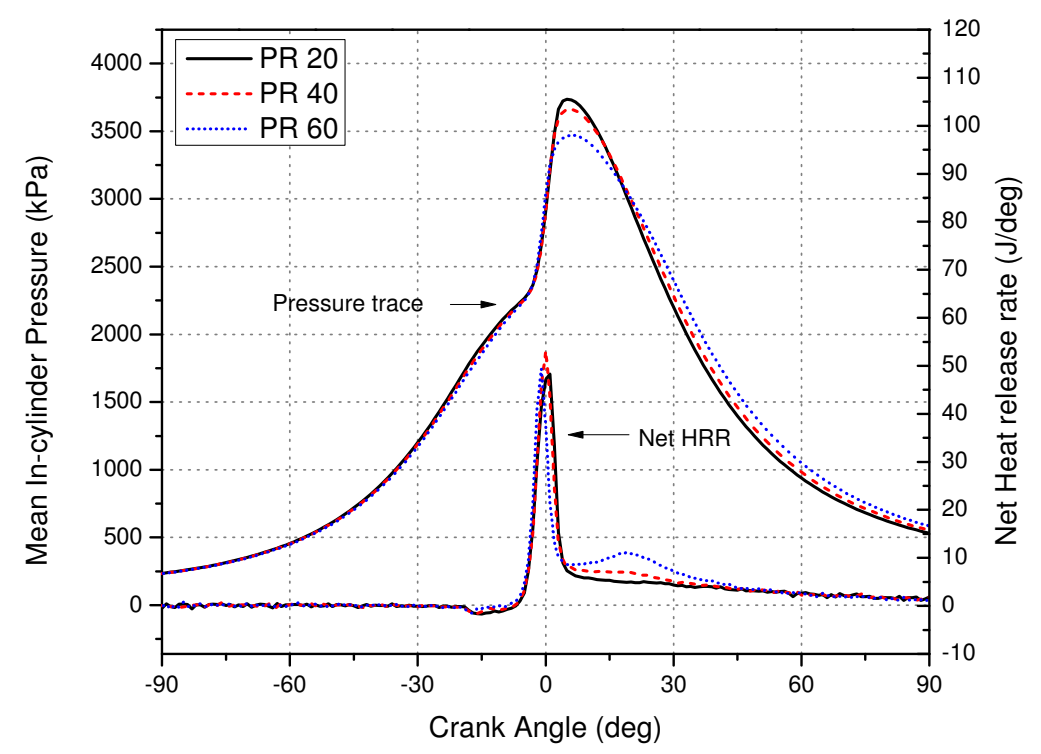

Figure 4.24: Effects of PR on combustion characteristics (CA10 CA50, CA90 and Burn Duration) for RCCI combustion regime 
Figure 4.25 illustrates the effect of PR on the performance metrics. Owing to the increase in the effective area under the curve for the HRR, IMEP increases from $460 \mathrm{kPa}$ to $545 \mathrm{kPa}$ for PR 20 and 60, respectively. Moreover, the indicated thermal efficiency increases with increase in PR because the in-cylinder temperature and pressure are lower for higher PRs due to the two-stage HTHR for PR 60. At lower PR, the indicated thermal efficiency is $29 \%$ which is significantly low. This is due to the incompleteness of combustion [64], as the combustion efficiency is $69 \%$ for PR20. The combustion efficiency lies in the range of $69 \%$ to $80 \%$, indicating that with higher PR and the two stage HTHR, the completeness of combustion is much higher as compared to that in lower PRs.

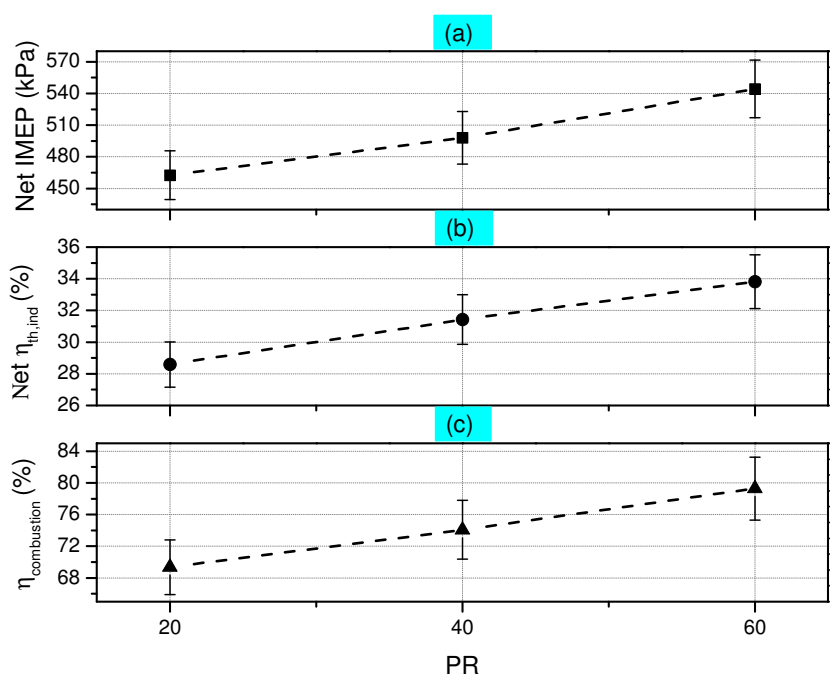

Figure 4.25: Effects of PR on (a) IMEP, (b) Indicated thermal efficiency and (c) Combustion efficiency for RCCI combustion regime 


\subsection{Effects of Intake Air Temperature on RCCI}

\section{Combustion}

This section discusses the effect of intake air temperature on RCCI combustion and performance metrics. Four different temperatures 40, 60, 80 and $100{ }^{\circ} \mathrm{C}$ are used. The operating conditions for these tests are given in Table 4.5 .

Table 4.5

Operating conditions used for the experiments to study the effect of PR on RCCI combustion

\begin{tabular}{|l|l|}
\hline \multicolumn{1}{|c|}{ Test Parameters } & \multicolumn{1}{c|}{ Value/ Unit } \\
\hline Engine Speed & $1000(\mathrm{rpm})$ \\
\hline Injection Pressure & $100(\mathrm{bar})$ \\
\hline SOI & $25(\mathrm{deg}$ bTDC $)$ \\
\hline Fuel Type & PR 20 \\
\hline IVO & $25.5(\mathrm{deg}$ bTDC $)$ \\
\hline EVC & $22(\mathrm{deg}$ bTDC $)$ \\
\hline Throttle Body Position & $100(\%)$ \\
\hline Intake Air Temperature & $40,60,80,100\left({ }^{\circ} \mathrm{C}\right)$ \\
\hline Fuel Mass & $18(\mathrm{mg} / \mathrm{cycle})$ \\
\hline Intake Pressure & $120(\mathrm{kPa})$ \\
\hline
\end{tabular}

The effect of intake temperature on the in-cylidner pressure and the Net HRR is shown in Figure 4.26. The maximum in-cylinder pressure increases with an increase in intake temperature. Further, the LPP is also advanced with an increase in $T_{\text {intake }}$. 
Heating the intake air increases the charge temperature that is inducted into the cylinder. The reaction rate of the fuel molecules are higher at higher temperatures. Beyond a temperature of $80{ }^{\circ} \mathrm{C}$, knocking was observed and the MPRR was higher than 8 bar/CAD.

As seen through Figures 4.26 and 4.27 , the start of combustion (CA10) is advanced with an increase in $T_{\text {intake }}$. Owing to the higher charge temperatures, the mixture starts to combust earlier at higher $T_{\text {intake }}$. However, it can be observed that the CA50 is $10 \mathrm{CAD}$ aTDC for $T_{\text {intake }}$ of $40{ }^{\circ} \mathrm{C}$, but with higher temperatures up to $100{ }^{\circ} \mathrm{C}$, the CA50 remains constant at $8 \mathrm{CAD}$ aTDC. This shows that $T_{\text {intake }}$ has a negligible effect on CA50, which could probably be better quantified if a higher resolution crank angle encoder was used. 


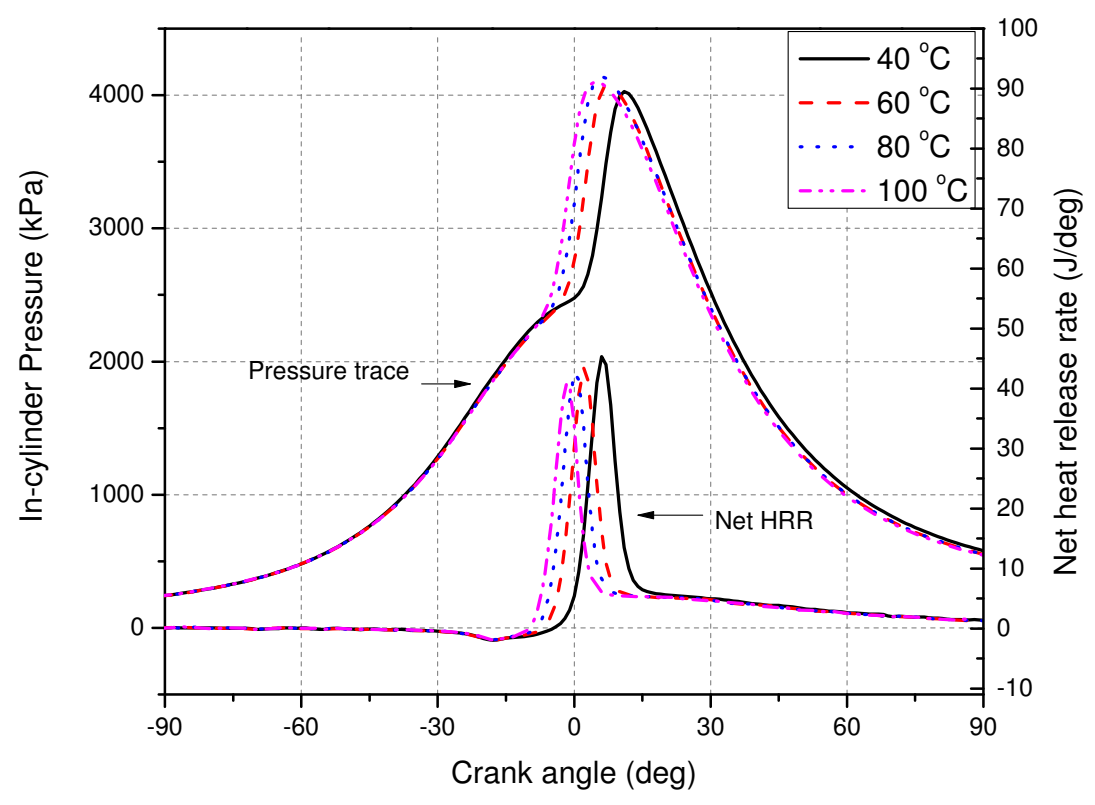

Figure 4.26: Pressure and heat release rates for PR 20 for operating conditions listed in Table 4.5 


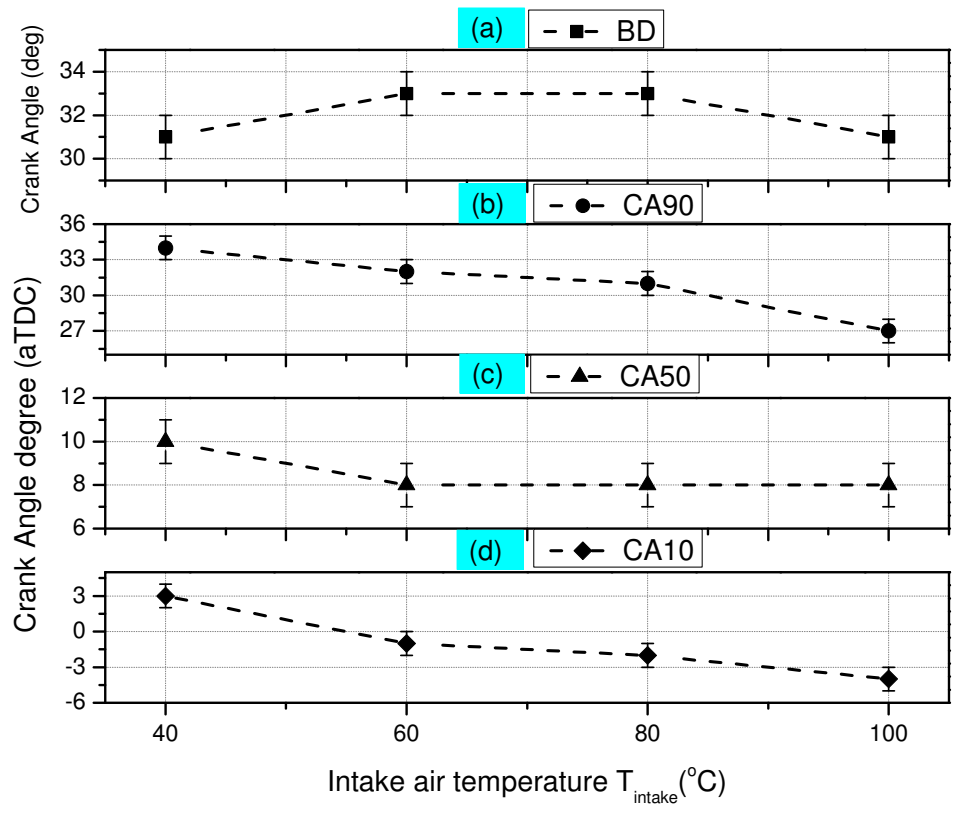

Figure 4.27: Effect of intake air temperature on combustion characteristics (CA10 CA50, CA90 and Burn Duration) for RCCI combustion regime

Figure 4.28 shows the effect of $T_{\text {intake }}$ on the performance metrics of RCCI combustion. The net IMEP and indicated thermal efficiency reduce with an increase in $T_{\text {intake }}$, because of the higher in-cylinder temperatures at higher $T_{\text {intake }}$. The ratio of specific heats is reduced, decreasing the polytropic expansion coefficient and thereby the expansion work [46]. As seen in Figure 4.29, the combustion efficiency lies in the range of $72 \%$ to $75 \%$ for all $T_{\text {intake }}$ values. 

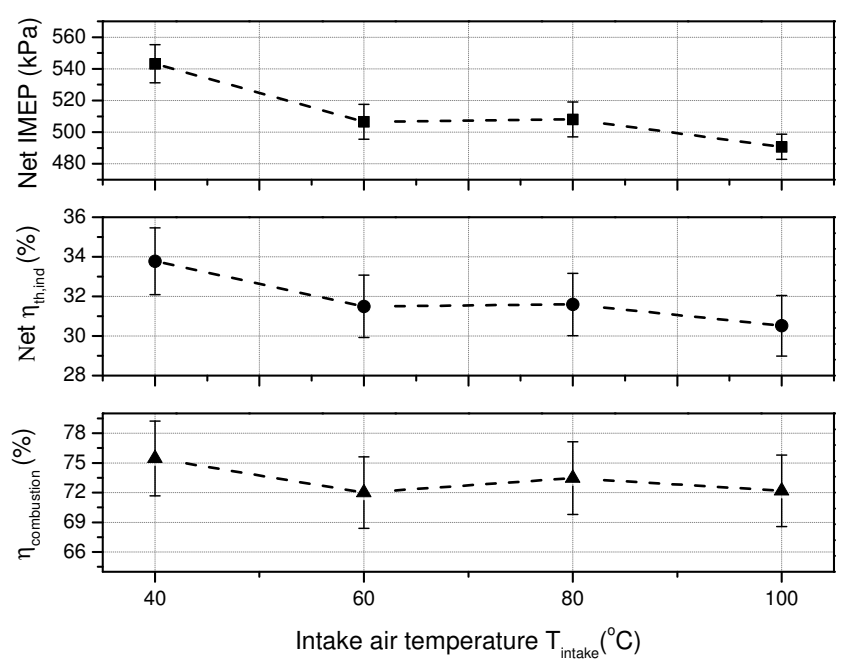

Figure 4.28: Effects of $T_{\text {intake }}$ on (a) IMEP, (b) Indicated thermal efficiency and (c) Combustion efficiency for RCCI combustion regime

\subsection{Effect of boost pressure on RCCI combustion}

An investigation of the experimental results was conducted to study the effect of boost pressure on RCCI combustion, with the boost pressure varying from $100 \mathrm{kPa}$ to $140 \mathrm{kPa}$. All experiments were performed at a constant fuel quantity and constant SOI as represented in Table 4.6 . 
Table 4.6

Operating conditions used for the experiments to study the effect of boost pressure on RCCI combustion

\begin{tabular}{|l|l|}
\hline \multicolumn{1}{|c|}{ Test Parameters } & \multicolumn{1}{c|}{ Value/ Unit } \\
\hline Engine Speed & $1000(\mathrm{rpm})$ \\
\hline Injection Pressure & $100(\mathrm{bar})$ \\
\hline SOI & $25(\mathrm{deg}$ bTDC $)$ \\
\hline Fuel Type & PR 20 \\
\hline IVO & $25.5(\mathrm{deg}$ bTDC $)$ \\
\hline EVC & $22(\mathrm{deg}$ bTDC $)$ \\
\hline Throttle Body Position & $100(\%)$ \\
\hline Intake Air Temperature & $60\left({ }^{\circ} \mathrm{C}\right)$ \\
\hline Fuel Mass & $15(\mathrm{mg} / \mathrm{cycle})$ \\
\hline Intake Pressure & $100,110,120,130,140(\mathrm{kPa})$ \\
\hline
\end{tabular}

Figure 4.29 shows the effect of boost pressure on the in-cylinder pressure and heat release rate. It can be noted that the in-cylinder pressure increases with an increase in boost pressure and the LPP becomes more advanced towards TDC. The pressure and temperature at the end of compression stroke increases with an increase in boost pressure. The volume of air inducted increases with increase in boost pressure. This results in more charge energy being combusted in the cylinder.

As seen in Figures 4.29 and 4.30 , the start of combustion (CA10) gets advanced significantly with increase in boost pressure. The combustion rates are faster at higher boost pressures due to stratification of the charge [32]. The thermal efficiency and net IMEP do not change significantly because the CA50 is obtained in the range of 8-12 CAD aTDC. The combustion efficiency lies between 75\% to 80\% between 100 
$\mathrm{kPa}$ and $140 \mathrm{kPa}$ boost pressures.

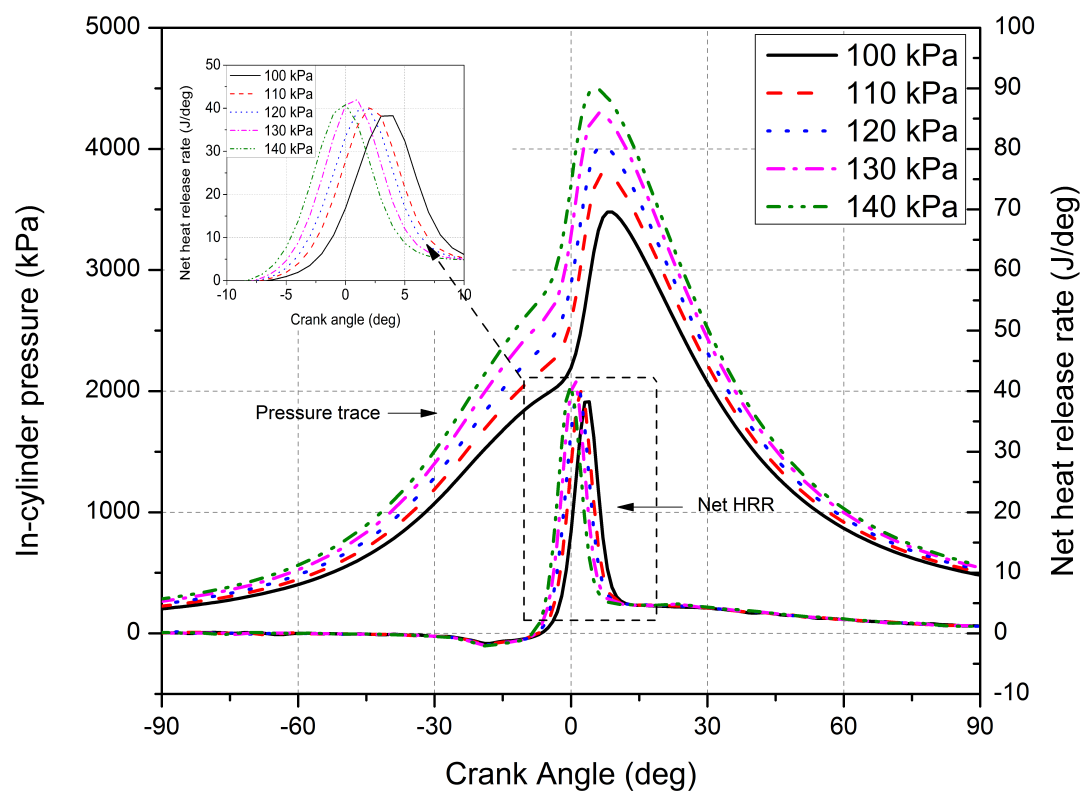

Figure 4.29: Pressure and heat release rates for PR 20 for operating conditions listed in Table 4.6 


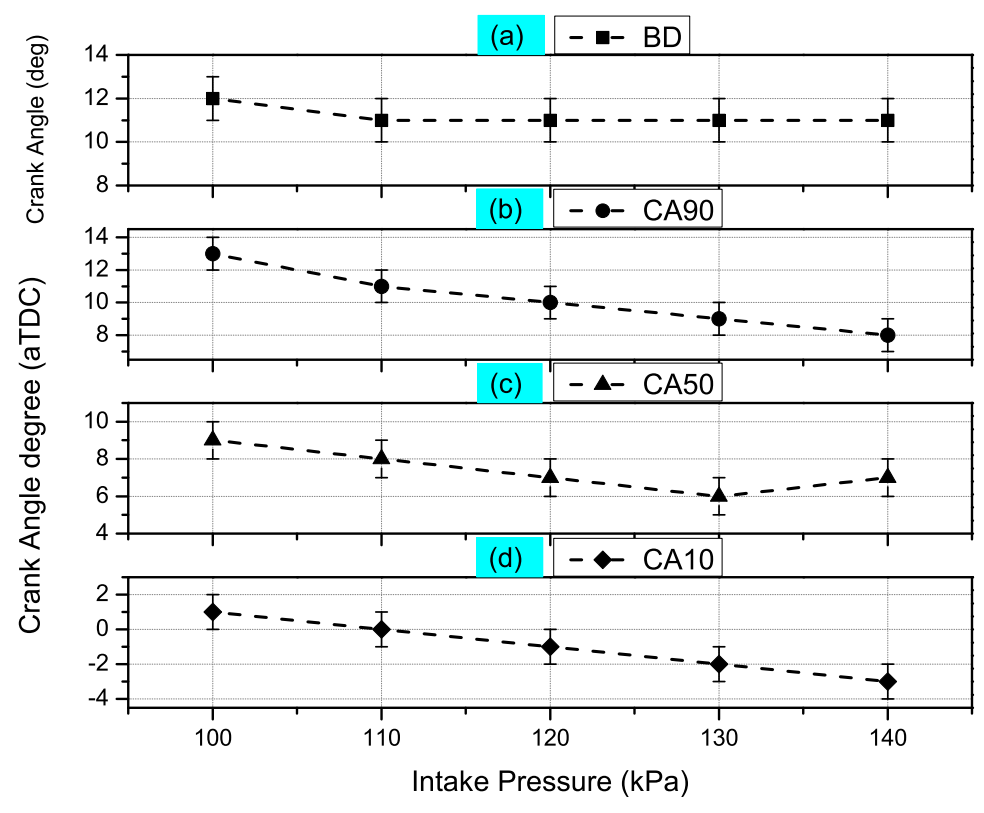

Figure 4.30: Effects of intake pressure on combustion characteristics (CA10 CA50, CA90 and Burn Duration) for RCCI combustion regime
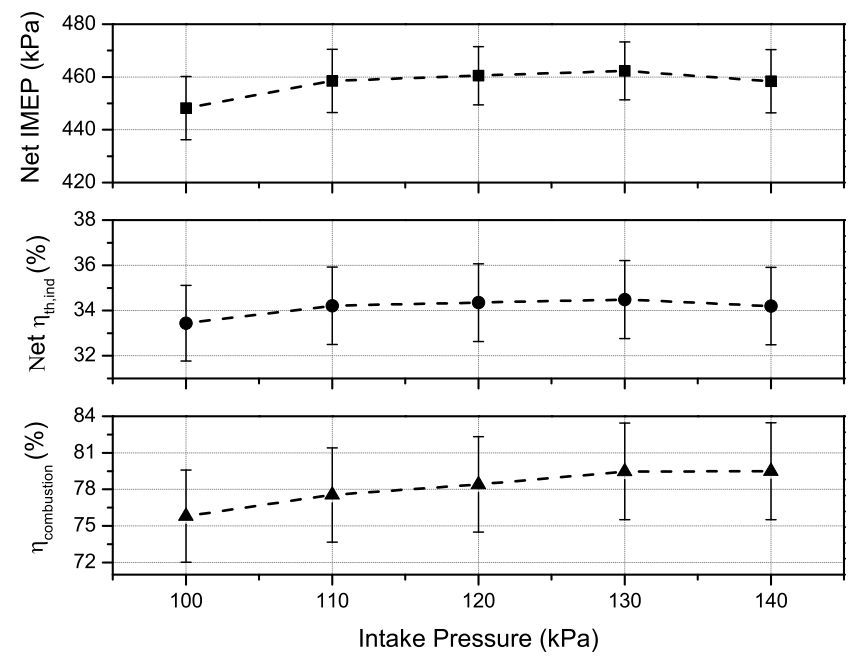

Figure 4.31: Effects of intake pressure on (a) IMEP, (b) Indicated Thermal efficiency and (c) Combustion efficiency for RCCI combustion regime 



\section{Chapter 5}

\section{Partially Premixed Compression}

\section{Ignition (PPCI)}

This chapter presents an investigation of the effect of various operating conditions on Partially Premixed Compression Ignition (PPCI) combustion mode. Engine maps were created to study the combustion and performance characteristics and the operating range of the engine running in PPCI combustion mode was determined. PPCI, also termed as early injection HCCI, aims to integrate the benefits of HCCI while improving the controllability of combustion phasing [51]. The ignition delay in PPCI is much longer than a CDI combustion regime but shorter than HCCI. The direct injection of the fuel into the cylinder can be used to control the combustion phasing [65. The engine was tested in PPCI combustion mode in order to determine the 
operating region of the engine. Operating parameters such as intake air temperature, boost pressure, engine speed, Research Octane number (RON) of fuel and equivalence ratio were varied. BSFC, exhaust gas temperature, ISFC and BSFC maps were created. The range of operating parameters are given in Table 5.1 .

Table 5.1

Operating Parameters for PPCI Combustion Mode

\begin{tabular}{|l|l|}
\hline \multicolumn{1}{|c|}{ Parameter } & Operating Conditions \\
\hline Intake Air Temperature & $40,60,80,100\left({ }^{\circ} \mathrm{C}\right)$ \\
\hline Manifold Pressure & $95(\mathrm{kPa})$ \\
\hline Engine Speed & $800: 200: 1800(\mathrm{rpm})$ \\
\hline RON of fuel & $0,20,40(-)$ \\
\hline Lambda & $1.4-5.6(-)$ \\
\hline
\end{tabular}

\subsection{Parametrization of BMEP using Flynn-Chen}

\section{Model for PPCI combustion regime}

A plot of experimental FMEP vs parameterized FMEP based on Chen-Flynn model is shown in Figure5.1 for PPCI combustion regime indicating that the FMEP can be estimated with a relative error of $6 \%$. 


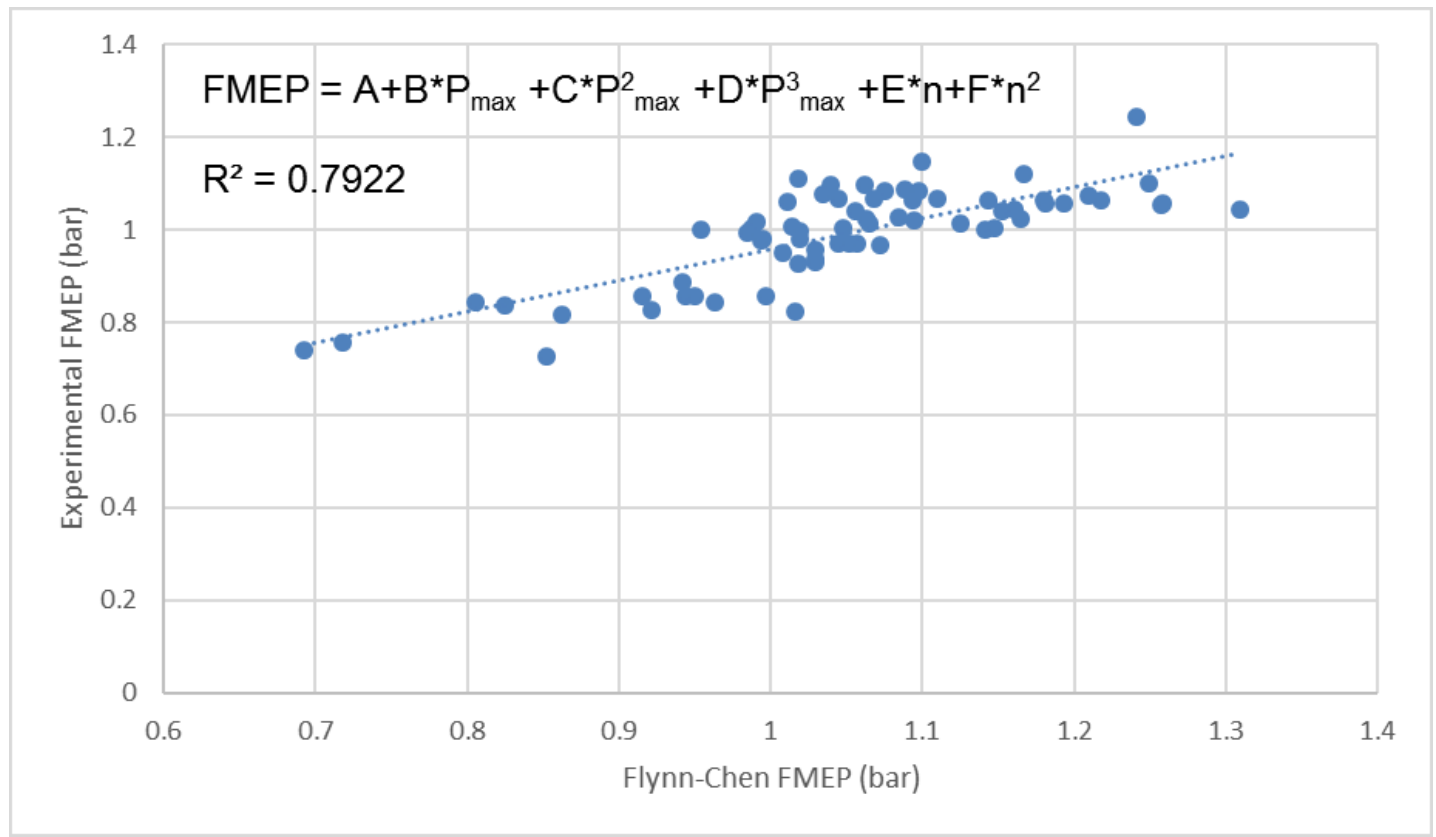

Figure 5.1: Experimental FMEP vs Parameterized FMEP

\section{Table 5.2}

Error in estimation of FMEP

\begin{tabular}{|l|l|}
\hline \multicolumn{1}{|c|}{ Model } & Chen-Flynn with $P_{\max }^{2}$ and $P_{\max }^{3}$ \\
\hline Mean relative error & $6 \%$ \\
\hline Max relative error & $16 \%$ \\
\hline Max absolute error & $0.17 \mathrm{bar}$ \\
\hline
\end{tabular}


Table 5.3

Coefficients for the Flynn- Chen Model

\begin{tabular}{|l|l|}
\hline Coefficient & \multicolumn{1}{|c|}{ Value } \\
\hline A & -2.088 \\
\hline B & 0.2483 \\
\hline C & -0.0058 \\
\hline D & $4.778 \mathrm{E}-5$ \\
\hline E & -0.4747 \\
\hline F & 0.0841 \\
\hline
\end{tabular}

Based on the parametrized model for FMEP, the constants obtained for the ChenFlynn model are given in Table 5.3 .

\subsection{Operating Range Maps}

The operating range maps for three fuel compositions RON 0, 20 and 40 for two different intake air temperatures $40{ }^{\circ} \mathrm{C}$ and $80{ }^{\circ} \mathrm{C}$ are illustrated in Figure 5.2 and 5.3. respectively. At $T_{\text {intake }}$ of $40{ }^{\circ} \mathrm{C}$ for the high octane fuel RON 40, the lean limit is $550 \mathrm{kPa}$ at $800 \mathrm{rpm}$ while it is $450 \mathrm{kPa}$ at $800 \mathrm{rpm}$ and $80{ }^{\circ} \mathrm{C}$. It can be seen that the engine could be run at a very lean equivalence ratio at higher temperatures, thereby improving the operating range enabling the load limit to be pushed towards much leaner operating conditions. For both intake air temperatures, the range of engine speed is much larger for lower octane fuels RON 0 as compared to RON 40. However, 
owing to the lower octane rating of RON 0, the upper limit of load was limited due to the knocking tendency of the fuel. Therefore, RON 0 was the best choice to run the engine at low load conditions, whereas RON 40 was efficient in running the engine at low-mid load conditions. Moreover, the speed range for all the fuels was limited due to the lower compression ratio of 9.2:1 being used for the engine.

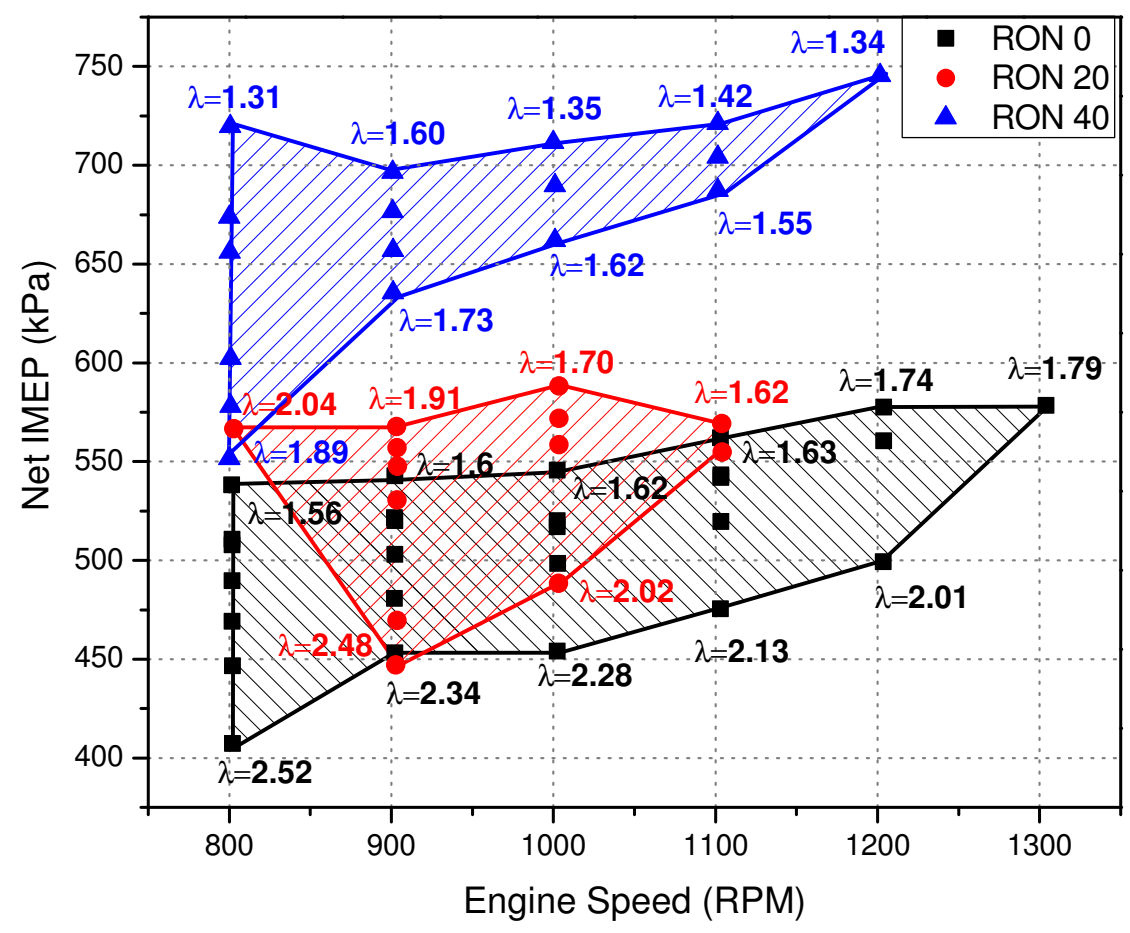

Figure 5.2: PPCI IMEP and speed range for $40{ }^{\circ} \mathrm{C}$ intake air temperature at naturally aspirated conditions 


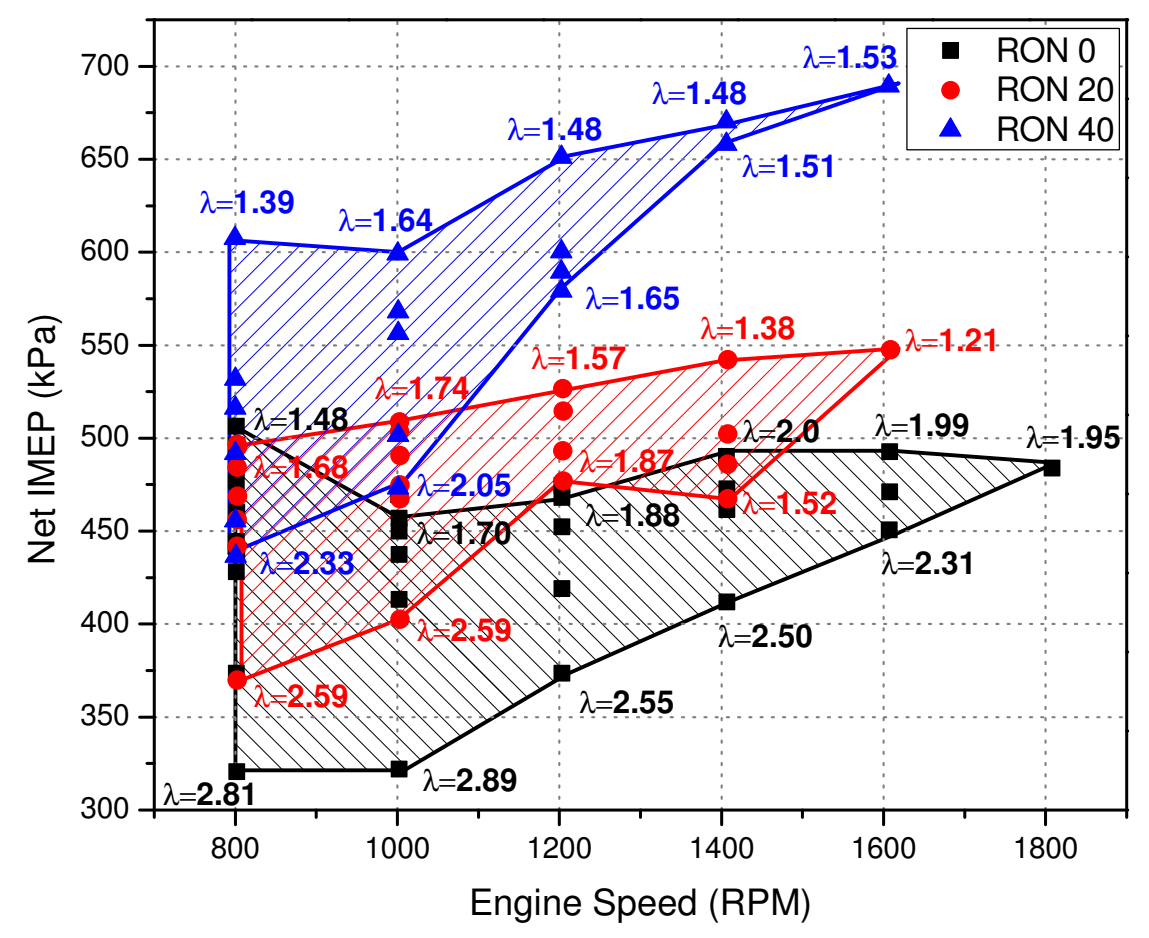

Figure 5.3: PPCI IMEP and speed range for $80{ }^{\circ} \mathrm{C}$ intake air temperature at naturally aspirated conditions

\subsection{Maps for ISFC, BSFC, Indicated Thermal Ef- ficiency and Exhaust Gas Temperature}

The operating range maps are critical in evaluating the engine's performance in terms of brake and indicated specific fuel consumption (SFC), load and thermal efficiency. It gives a good indication of the regions in which the engine would run efficiently. Figure 
5.4 represents the ISFC map for PPCI combustion mode at an intake temperature of $40{ }^{\circ} \mathrm{C}$ for three different fuel compositions RON 0, 20 and 40 . It can be observed that the best ISFC is obtained at low loads at each engine speed. This can be attributed to the lean operation of the engine due to better fuel atomization. The fuel is injected directly into the cylinder and results in higher value of gamma thereby lowering in-cylinder combustion temperatures [46]. The heat transfer losses are significantly reduced. As compared to the ISFC map for HCCI for the same intake temperature of $40{ }^{\circ} \mathrm{C}$, it can be observed that at $800 \mathrm{rpm}$ and $1000 \mathrm{rpm}$, the engine could be run at higher loads in case of PPCI. Because of the lower compression temperature of the gases in case of PPCI, it leads to higher charge density thereby enabling higher amount of fuel to be inducted [32]. Thereby, the engine could be run at much richer mixtures within an acceptable MPRR of within 8 bar/CAD, avoiding knock. 

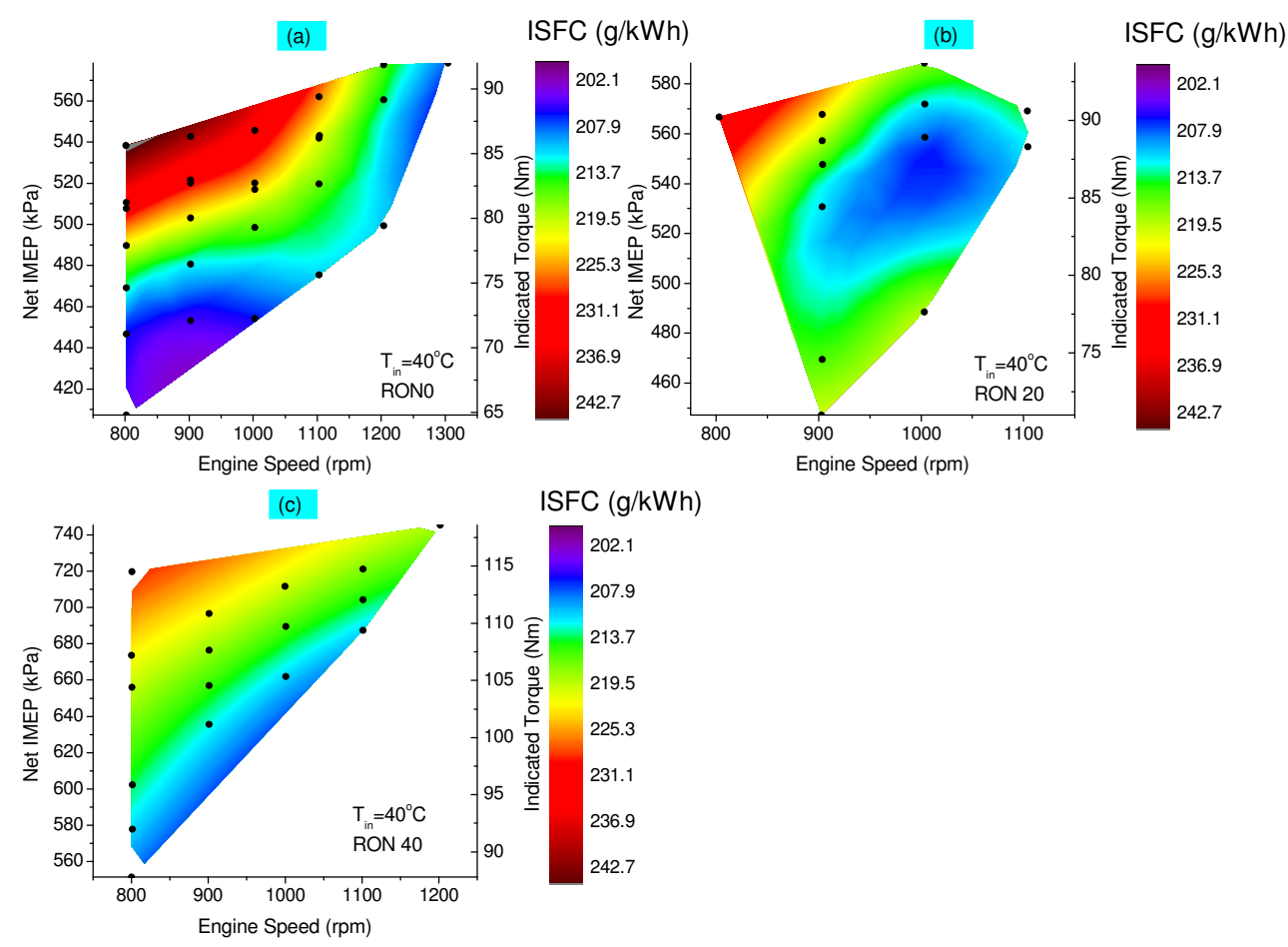

Figure 5.4: PPCI ISFC map for $40{ }^{\circ} \mathrm{C}$ intake air temperature at naturally aspirated conditions

The BSFC map for PPCI combustion regime at $T_{\text {intake }}$ of $40{ }^{\circ} \mathrm{C}$ is shown in Figure 5.5. The sweet spot for BSFC of $250 \mathrm{~g} / \mathrm{kWh}$ is obtained at a load of $72 \mathrm{Nm}$ and 1000 rpm for RON 20. It can be seen that BSFC increases considerably at lower engine speeds and high loads. This is mainly due to the friction losses, which are higher at higher engine speeds. The friction losses increase with an increase in engine speed [40]. 

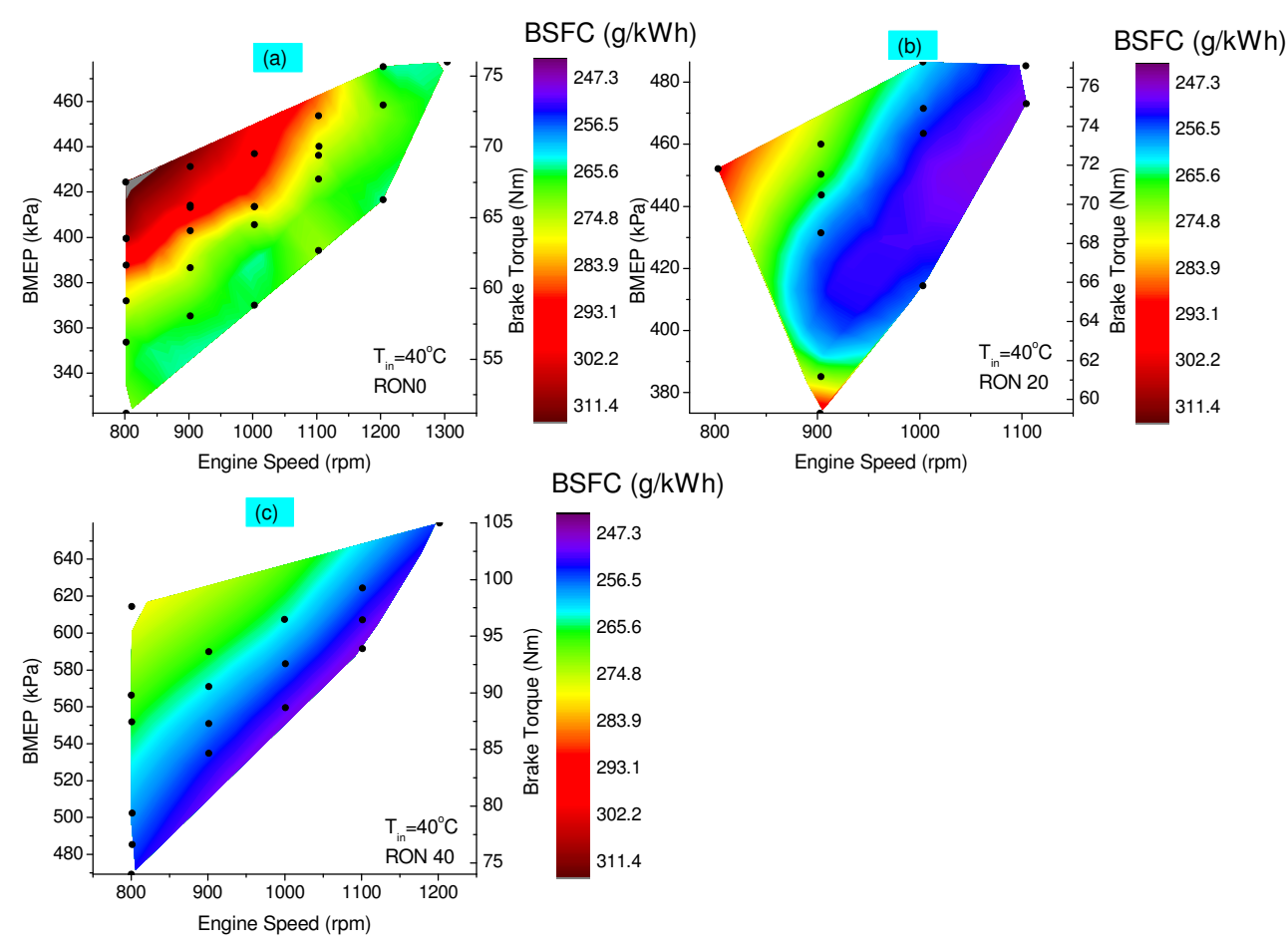

Figure 5.5: PPCI BSFC map for $40{ }^{\circ} \mathrm{C}$ intake air temperature at naturally aspirated conditions

Figure 5.6 represents the net indicated thermal efficiency maps for three RONs 0 , 20 and 40 for an intake temperature of $40{ }^{\circ} \mathrm{C}$ at naturally aspirated conditions. A maximum TEF of $42 \%$ is obtained for an indicated torque of $70 \mathrm{Nm}$ and $800 \mathrm{rpm}$ engine speed. It can also be seen that the best thermal efficiency is attained at lower loads for all speeds. This is a typical characteristic of PPCI combustion mode, which works efficiently at low loads. 


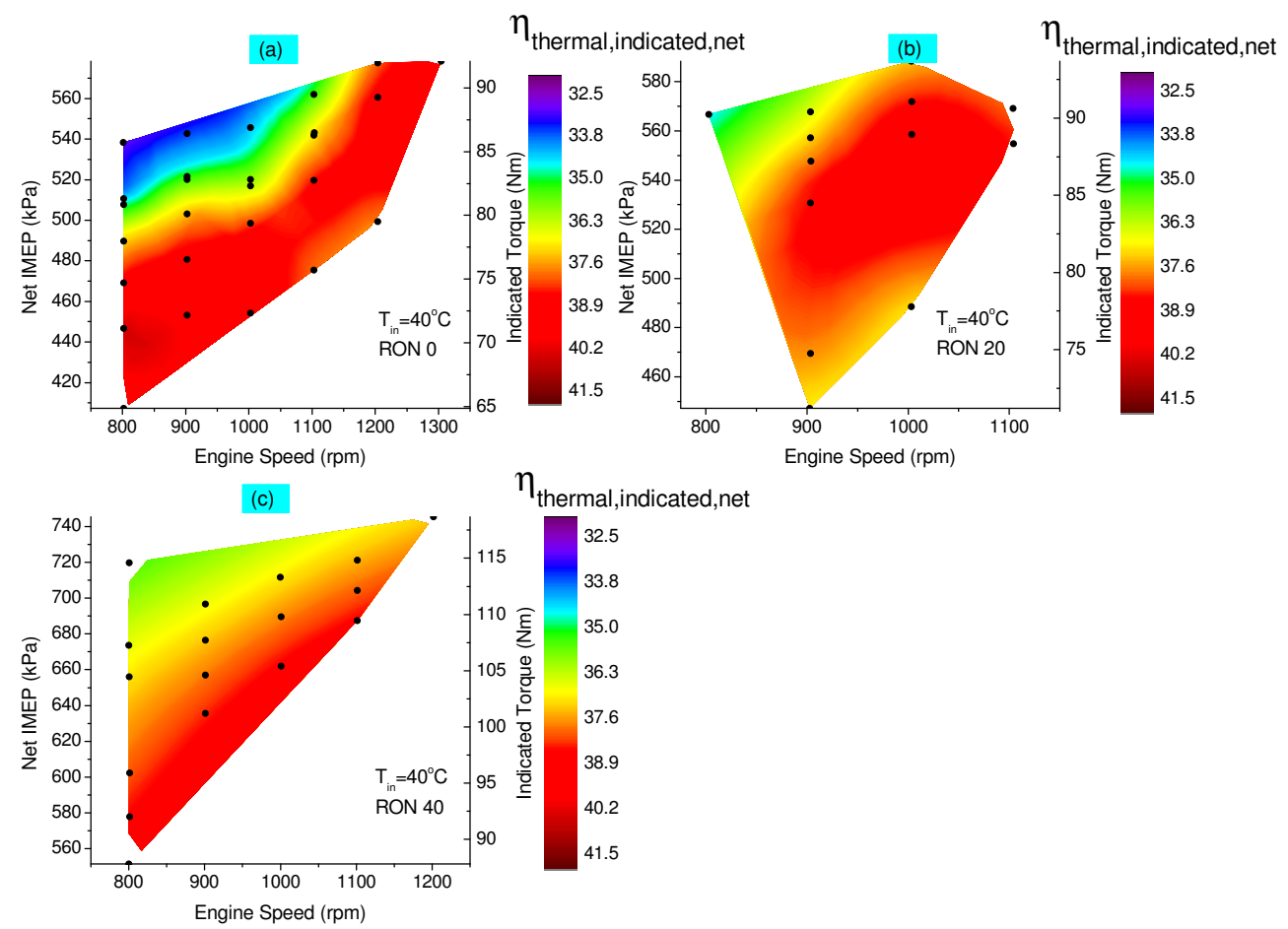

Figure 5.6: PPCI indicated thermal efficiency map for $40{ }^{\circ} \mathrm{C}$ intake air temperature at naturally aspirated conditions

Figure 5.7 shows the $T_{\text {exhaust }}$ map for PPCI combustion regime at $T_{\text {intake }}$ of $40{ }^{\circ} \mathrm{C}$. It can be seen that the exhaust temperatures have been maintained over $300{ }^{\circ} \mathrm{C}$ for even the lowest loads and speeds. This implies that the oxidation catalyst would function with a good conversion efficiency in order to break down the $\mathrm{HC}$ and $\mathrm{CO}$ molecules, since the catalyst light-off temperature is about $250{ }^{\circ} \mathrm{C}$ and the exhaust temperatures are way above it over the entire range of speeds and loads. 


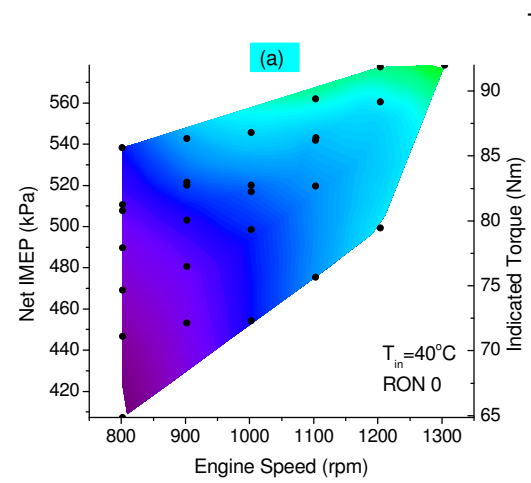

$\mathrm{T}_{\text {exhaust }}\left({ }^{\circ} \mathrm{C}\right)$
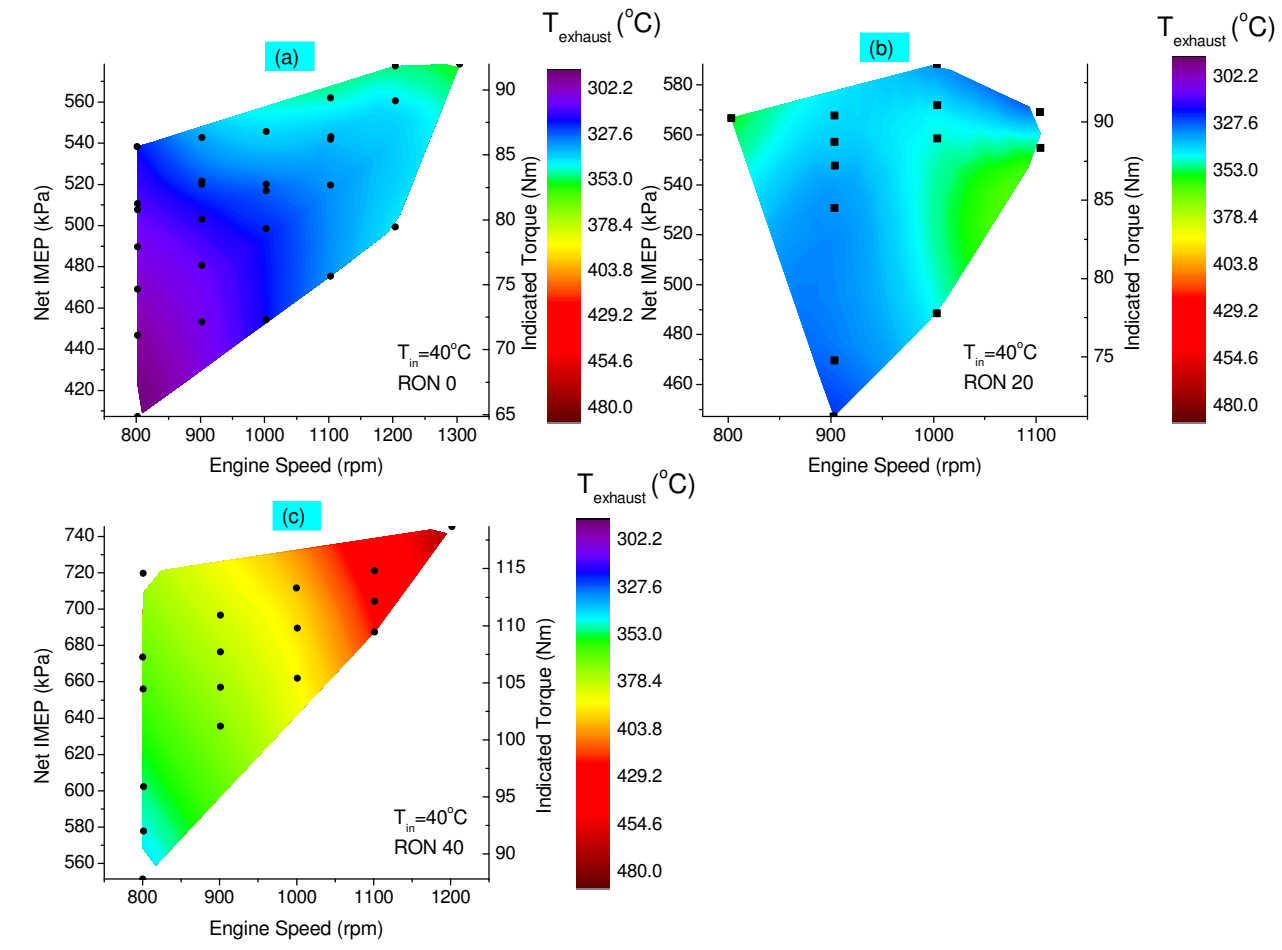

$\mathrm{T}_{\text {expaust }}\left({ }^{\circ} \mathrm{C}\right)$

Figure 5.7: PPCI exhaust gas temperature map for $40{ }^{\circ} \mathrm{C}$ intake air temperature at naturally aspirated conditions

\subsection{Optimized PPCI maps}

Experiments were performed for PPCI combustion mode at 650 different combinations of operating conditions such as $T_{\text {intake }}, P_{\text {intake }}, \mathrm{RON}$, equivalence ratio and engine speed. In order to generate the optimized map for PPCI combustion mode, the points with the best ISFC were chosen at every engine speed- load condition. The 
data points chosen are given in Appendix A.1. The best ISFC obtained was 200 $\mathrm{g} / \mathrm{kWh}$ at low engine loads. It has also been observed that up to $1400 \mathrm{rpm}$, the ISFC increases with an increase in engine load. The charge gets richer with an increase in load at these data points. However, at speeds higher than $1400 \mathrm{rpm}$, the ISFC values vary by a small amount at all loads. This is mainly because the equivalence ratio range is very narrow for higher engine speeds.

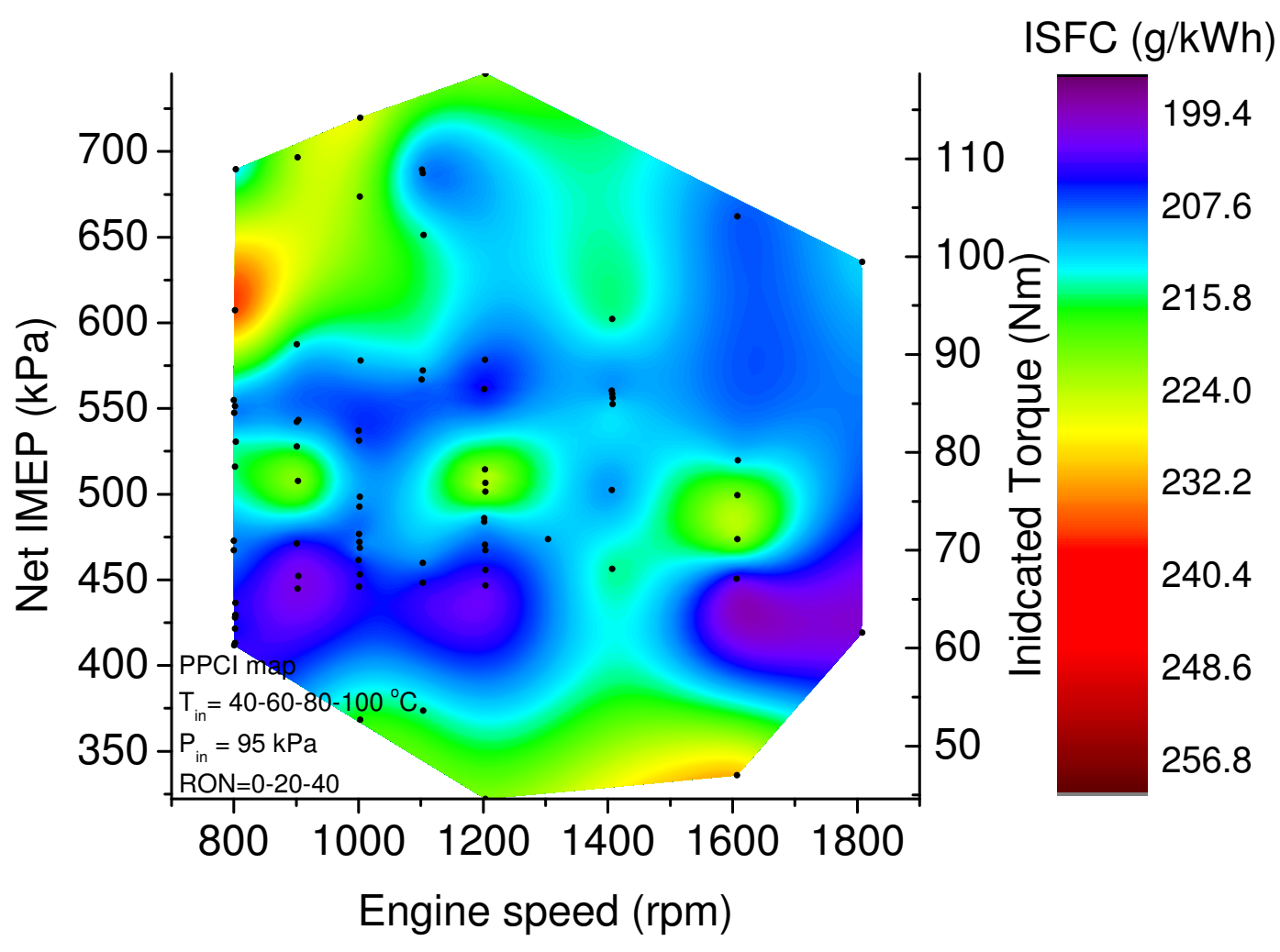

Figure 5.8: PPCI ISFC optimized map for all intake air temperatures and RONs at naturally aspirated conditions

Figure 5.9 illustrates the optimized BSFC map for three different fuel compositions 
RON 0, 20 and 40. Lowest BSFC of $250 \mathrm{~g} / \mathrm{kWh}$ is obtained at high loads and speeds. The friction losses are high at higher engine speeds and thereby have a significant effect on the BSFC values. The BSFC values are the highest at $1600 \mathrm{rpm}$ and low loads. This shows that it is not suitable to run the engine in PPCI mode at higher engine speeds and low loads.

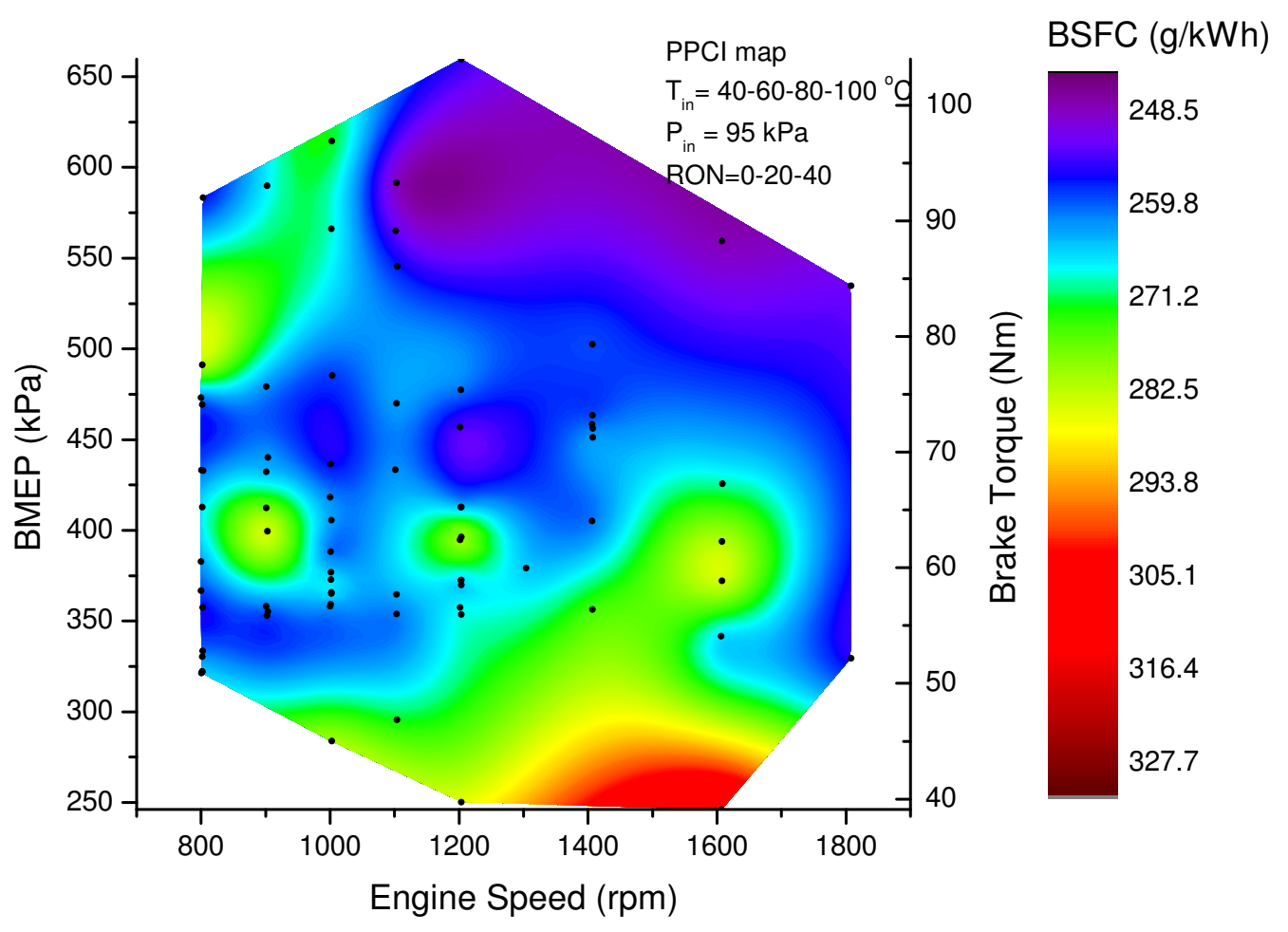

Figure 5.9: PPCI BSFC optimized map for all intake air temperatures and RONs at naturally aspirated

The indicated thermal efficiency maps are shown in Figure 5.10. The range of thermal efficiencies was 32- $42 \%$ over a load range of 45- $120 \mathrm{Nm}$. The best thermal efficiency 
points were obtained at an engine load of $450 \mathrm{kPa}$ IMEP for all speeds. Since the map was an optimized set of data points obtained from a combination of various parameters, the engine would run quite efficiently at most of the data points with the combinations used for the map. However, it can be seen that the thermal efficiency reduces to $35 \%$ at low speeds and higher loads, limiting the high load operation at low speeds for PPCI combustion mode.

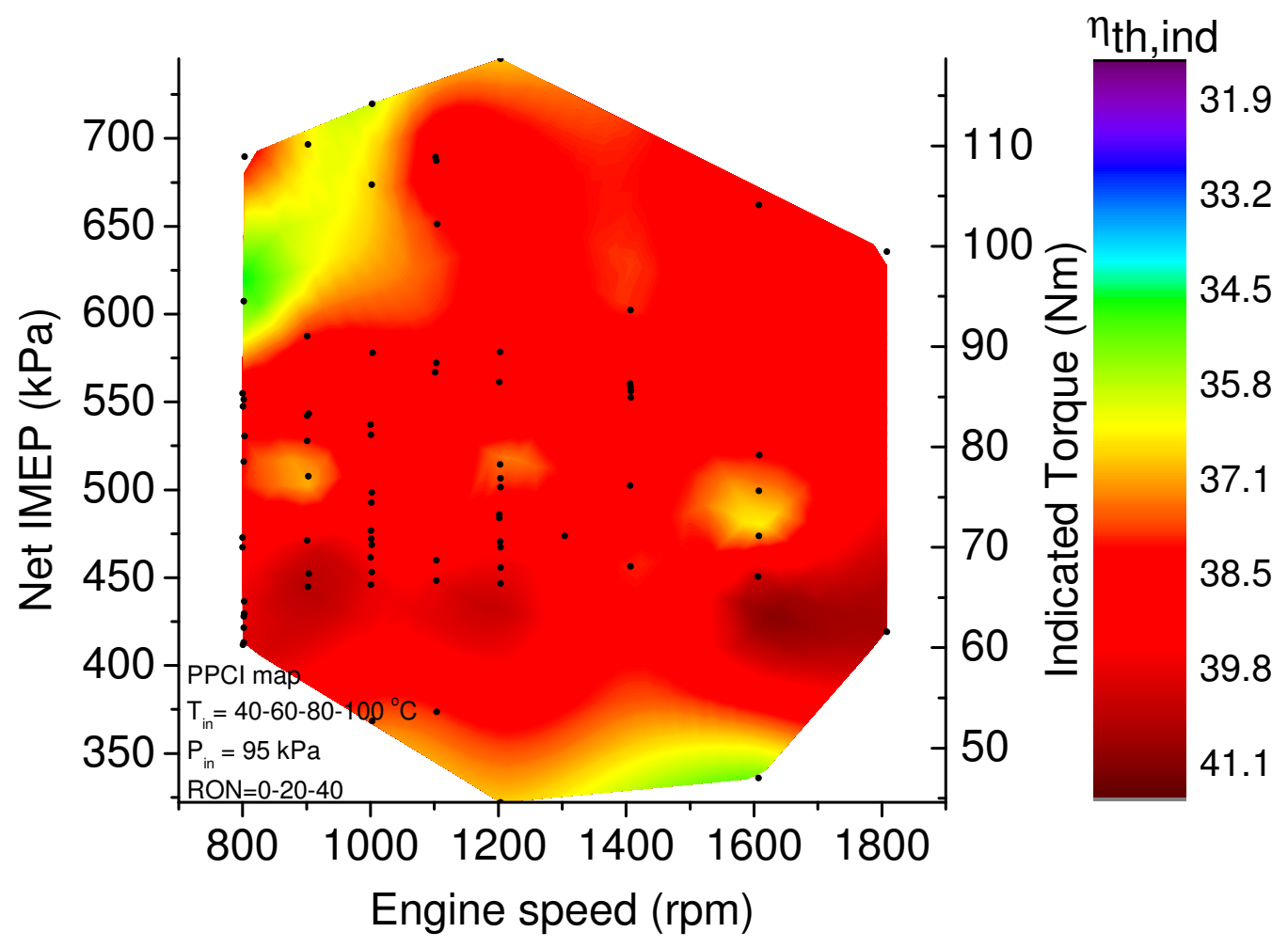

Figure 5.10: PPCI indicated thermal efficiency optimized map for all intake air temperatures and RONs at naturally aspirated conditions 
The optimized exhaust temperature map for PPCI combustion regime under naturally aspirated conditions is shown in Figure 5.11. It can be observed that $T_{\text {exhaust }}$ for almost all the data points lie above the catalyst light off temperature of 250 ${ }^{\circ} \mathrm{C}$. Moreover, the range of $T_{\text {exhaust }}$ lies in an acceptable region of $290-490{ }^{\circ} \mathrm{C}$. The range is a trade off between HCCI and RCCI combustion regime, in terms of exhaust temperature and $\mathrm{HC}$ emissions based on the findings in this thesis.

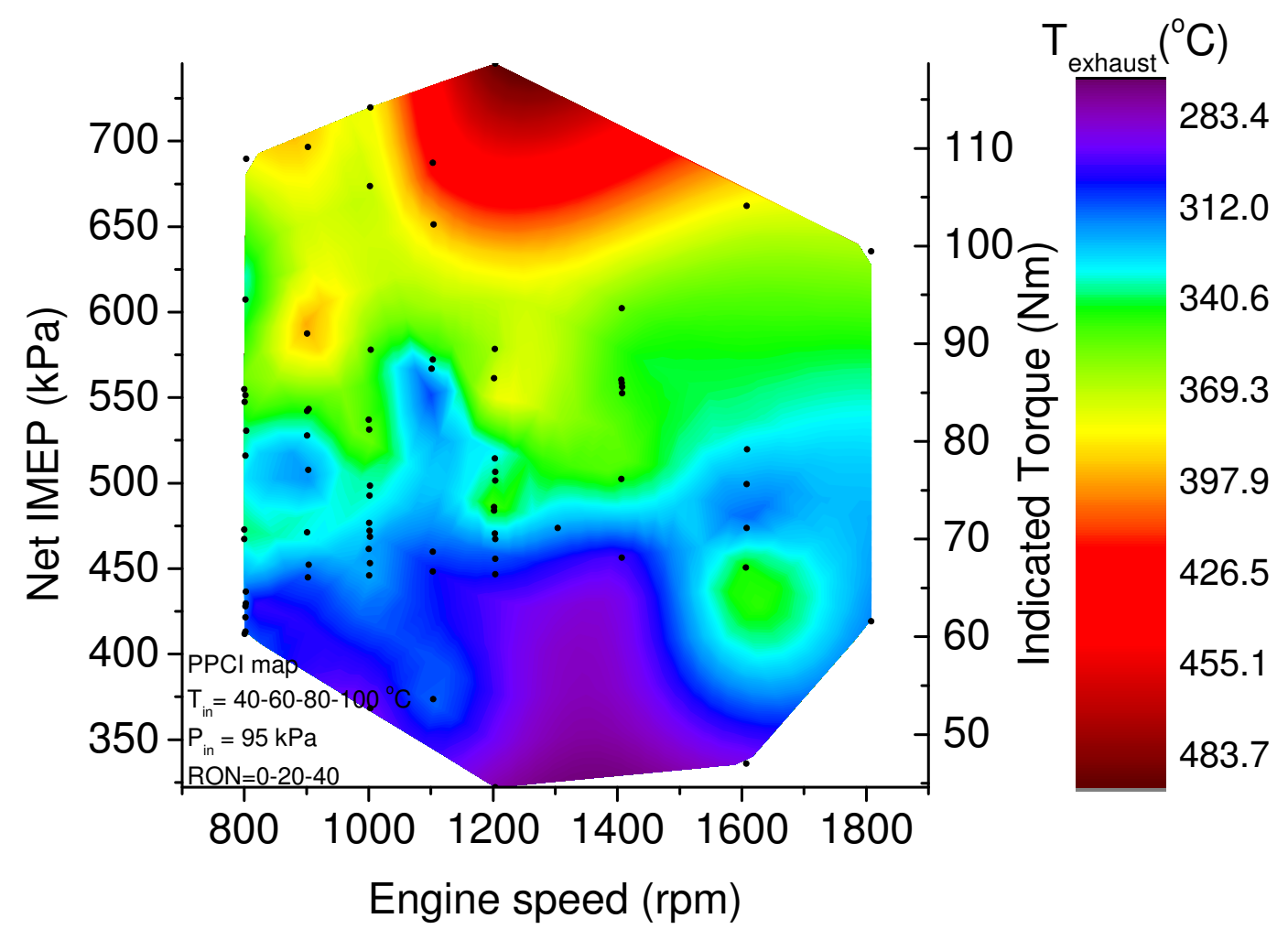

Figure 5.11: PPCI exhaust temperature optimized map for all intake air temperatures and RONs at naturally aspirated conditions 


\subsection{Effect of Intake Air Temperature on PPCI}

\section{Combustion}

Adjusting intake air temperature is one of the most common methods to control PPCI combustion [56]. For this reason, four different intake air temperatures are tested during experiment at a constant lambda and engine speed with RON20 fuel. Table 5.4 shows the test details for effects of increased intake air temperature.

Table 5.4

Operating conditions used for the experiments to study the effect of intake air temperature on PPCI combustion

\begin{tabular}{|l|l|}
\hline \multicolumn{1}{|c|}{ Test Parameters } & \multicolumn{1}{c|}{ Value/ Unit } \\
\hline Engine Speed & $1000(\mathrm{rpm})$ \\
\hline Injection Pressure & $100(\mathrm{bar})$ \\
\hline Injection Starting Angle & $100(\mathrm{deg}$ bTDC $)$ \\
\hline Fuel Type & RON 20 \\
\hline IVO & $25.5(\mathrm{deg}$ bTDC $)$ \\
\hline EVC & $22(\mathrm{deg}$ bTDC $)$ \\
\hline Throttle Body Position & $100(\%)$ \\
\hline Intake Air Temperature & $40,60,80,100\left({ }^{\circ} \mathrm{C}\right)$ \\
\hline Lambda & 2.0 \\
\hline Intake Pressure & $95(\mathrm{kPa})$ \\
\hline
\end{tabular}

The effects of increasing intake air temperature on in-cylinder pressure are shown in Figure 5.12. The maximum cylinder pressure increases with the increase of the intake air temperature. At the same time, the location of maximum cylinder pressure 
gradually approaches the TDC with an increase in intake air temperature. In addition, the maximum cylinder pressure occurred before TDC when the intake air temperature reached at $100{ }^{\circ} \mathrm{C}$, as shown in Figure 5.12 . Heating the air taken into the cylinder increases the reaction rate by providing faster movement of molecules. The start of combustion is advanced with increase of intake air temperature. During experiments, the knock was observed at high intake temperatures over $100{ }^{\circ} \mathrm{C}$ and misfire was observed at low intake temperatures below $40{ }^{\circ} \mathrm{C}$.

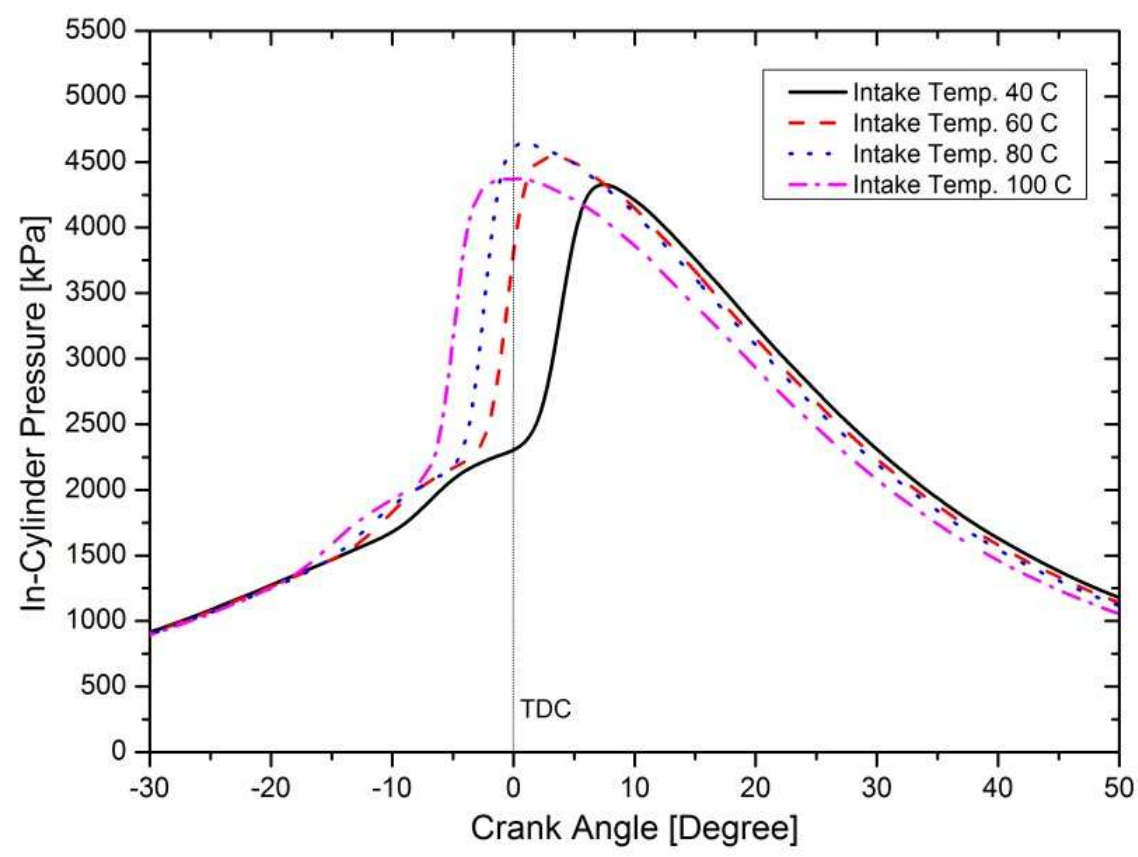

Figure 5.12: Effect of intake air temperature on PPCI in-cylinder pressure at a lambda of 2 


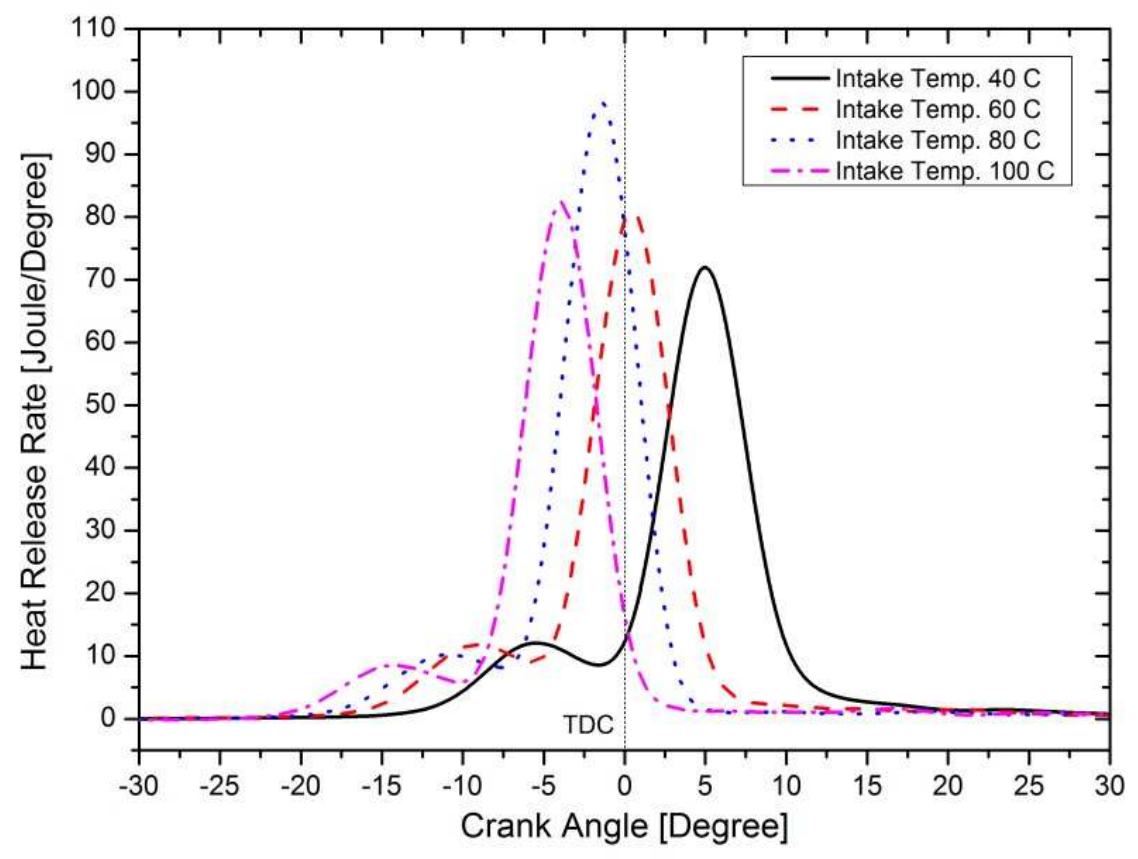

Figure 5.13: Effect of intake air temperature on the PPCI heat release rate at a lambda of 2

Figure 5.14 shows the effect of intake air temperature on IMEP and BMEP. It can be observed that the IMEP and BMEP reduce with an increase in $T_{\text {intake }}$. While maintaining a constant equivalence ratio, with an increase in intake temperature the air density decreases. The temperature of compression increases, thereby auto igniting the charge much earlier. With the combustion phasing being shifted away from the optimum value of 5-10 CAD aTDC, a drop in IMEP and BMEP is observed. 


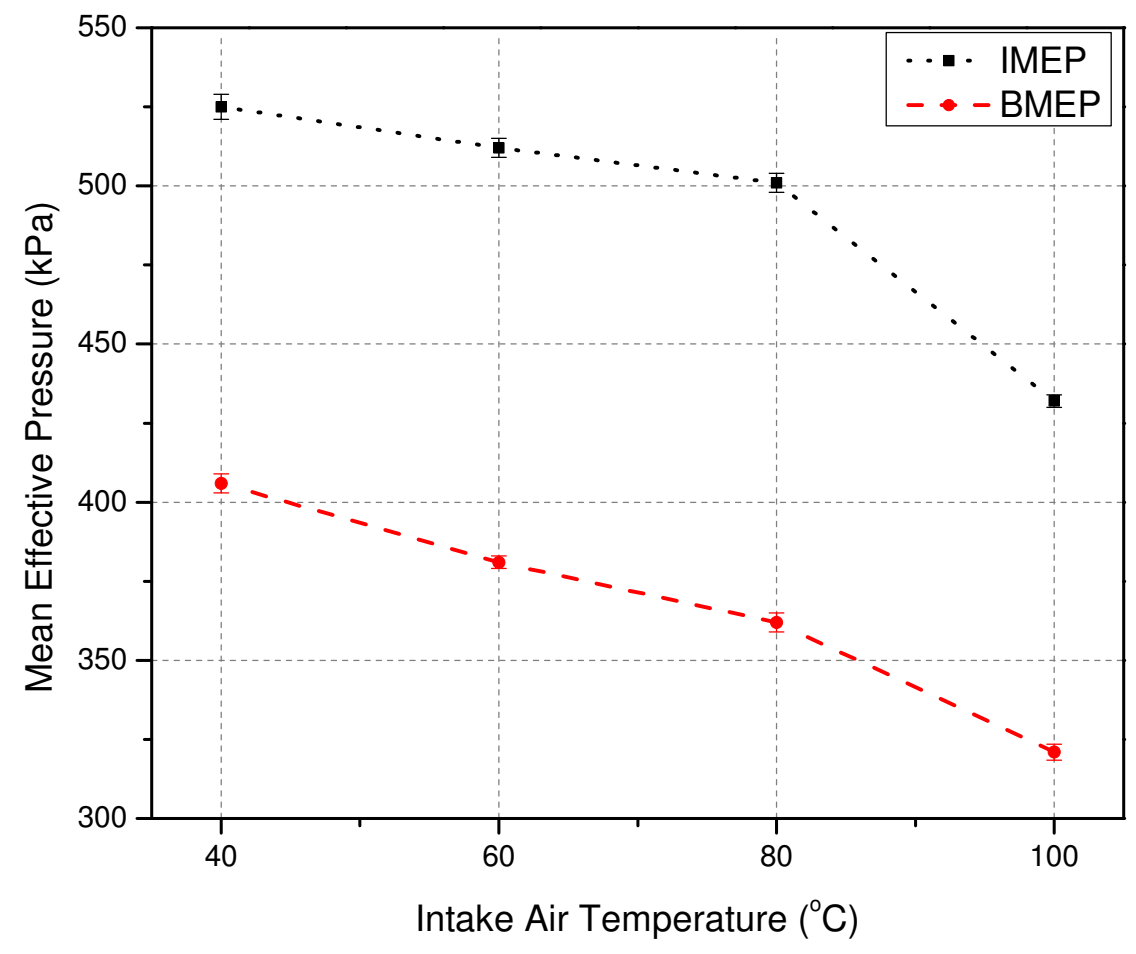

Figure 5.14: Effect of Intake temperature on IMEP and BMEP at a lambda of 2

The indicated thermal efficiency as a function of intake temperature is depicted in Figure 5.15. With an increase in intake air temperature, the thermal efficiency drops significantly. Due to the increase in compression and combustion temperature, the heat transfer losses increase. Moreover, the combustion efficiency is about $87 \%$ in case of $100{ }^{\circ} \mathrm{C}$ intake temperature. Due to the increase in fuel energy content and a drop in combustion efficiency, the thermal efficiency drops at higher intake temperatures. 


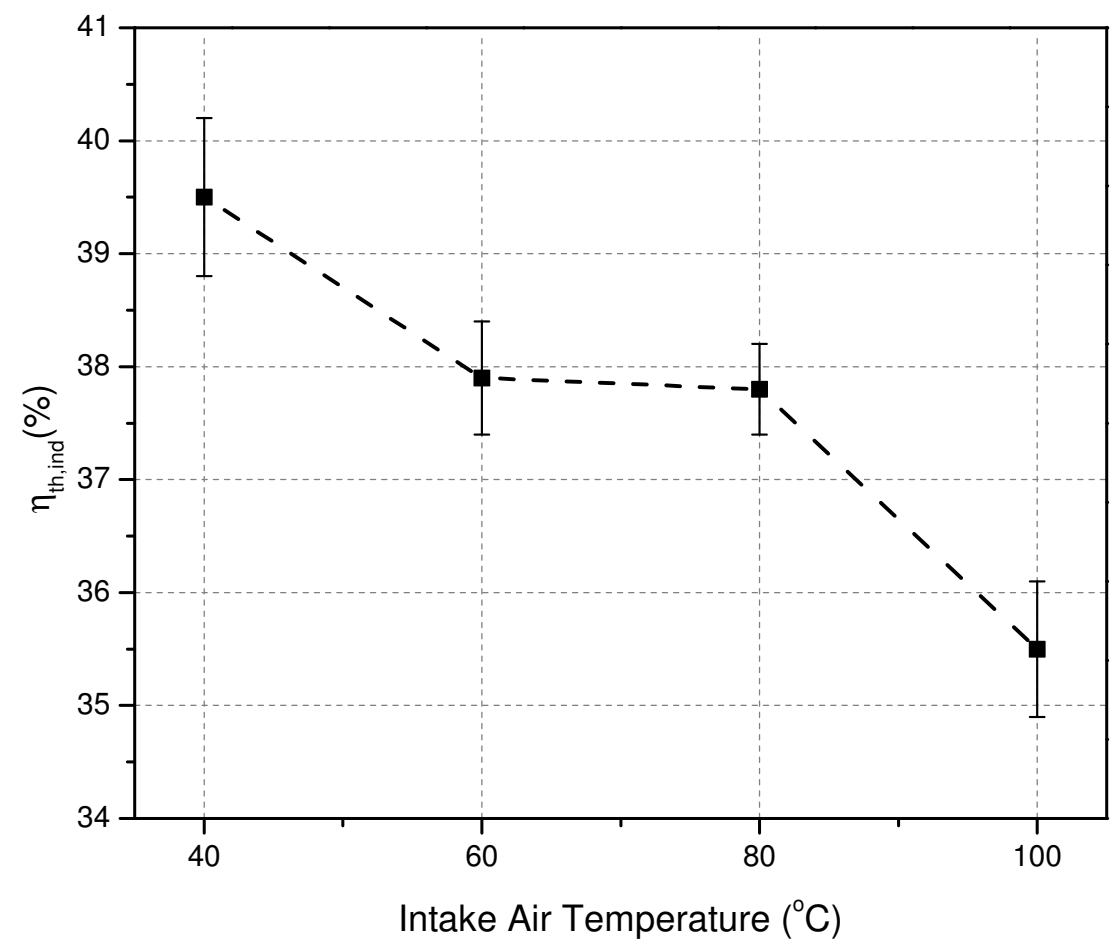

Figure 5.15: Effect of intake temperature on indicated thermal efficiency at a lambda of 2

The combustion characteristics at different intake temperatures are shown in Figure 5.16. It can be observed that the CA10, CA50 and CA90 get advanced with an increase in temperature. The start of injection for all the temperatures were held constant at $100 \mathrm{CAD}$ bTDC. With an increase in intake air temperature, the start of combustion gets advanced. This is due to the increase in the IVC temperature of the air-fuel mixture. Thereby, auto ignition of the mixture occurs much earlier, thereby 
advancing the combustion phasing. An interesting point to note is that the best indicated thermal efficiency of $39.5 \%$ was obtained when the combustion phasing was about 5 CAD aTDC. This supports the study in literature [40] that the optimal combustion phasing for the best thermal efficiency should be between 5-10 CAD aTDC. Since the SOI was held constant, the CA50 for the other temperatures got advanced. However, if the SOI was retarded with an increase in intake air temperature, the combustion phasing could be controlled to be in the range of 5-10 CAD aTDC.

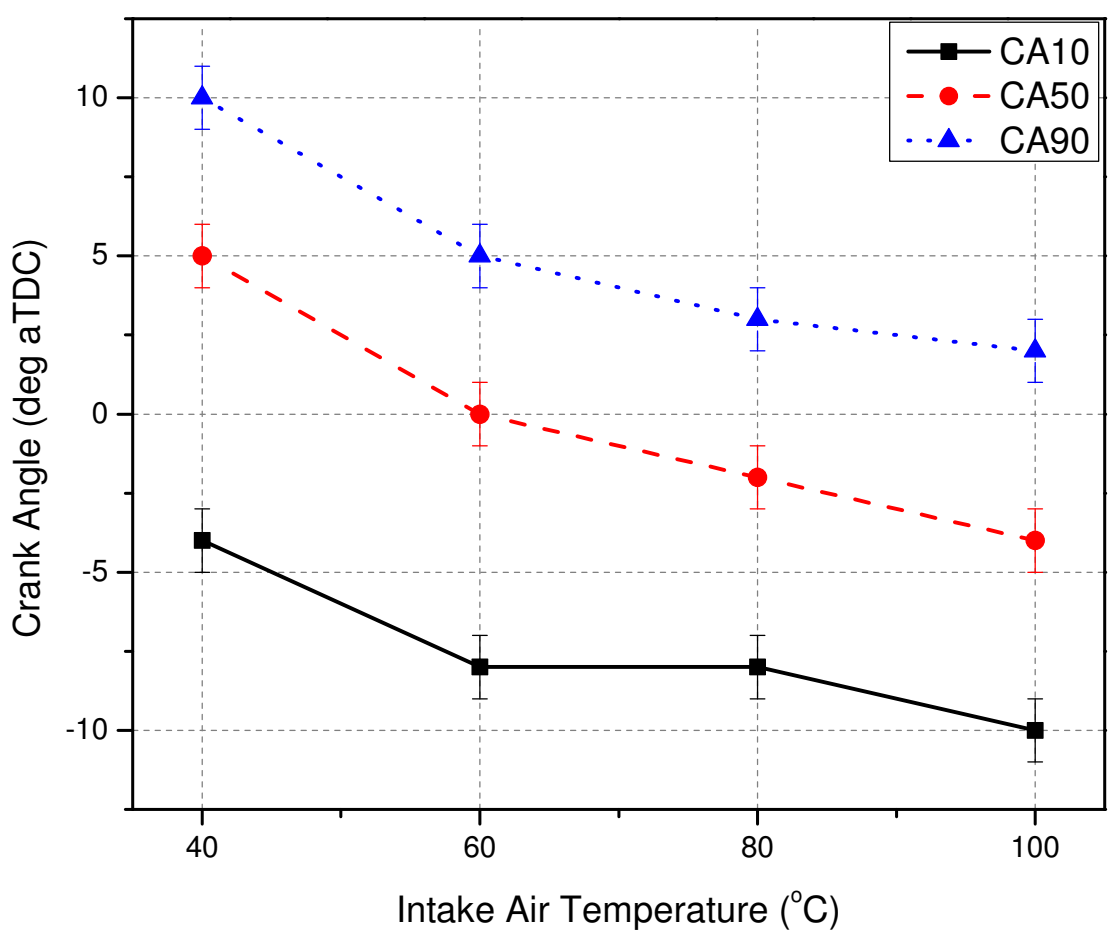

Figure 5.16: Effect of intake temperature on combustion phasing at a lambda of 2 


\subsection{Effects of Boost pressure on PPCI combustion}

An analysis of the experimental results was conducted to understand the effect of intake manifold pressure on PPCI combustion. All experiments were performed at seven different intake pressures from 1.0 bar to 1.6 bar with 0.1 bar intervals at different loads using n-heptane as the fuel. All tests were conducted at constant engine speed, intake temperature, injection timing and injection pressure conditions as given in Table 5.5 .

Table 5.5

Operating conditions used for the experiments to study the effect of intake pressure on PPCI combustion

\begin{tabular}{|l|l|}
\hline \multicolumn{1}{|c|}{ Test Parameters } & \multicolumn{1}{c|}{ Value/ Unit } \\
\hline Engine Speed & $1000(\mathrm{rpm})$ \\
\hline Injection Pressure & $100(\mathrm{bar})$ \\
\hline Injection Starting Angle & $100($ deg bTDC) \\
\hline Fuel Type & RON 0 \\
\hline IVO & $25.5($ deg bTDC $)$ \\
\hline EVC & $22($ deg bTDC $)$ \\
\hline Throttle Body Position & $100(\%)$ \\
\hline Intake Air Temperature & $60\left({ }^{\circ} \mathrm{C}\right)$ \\
\hline Lambda & $1.8-6.0$ \\
\hline Intake Pressure & $100: 10: 160(\mathrm{kPa})$ \\
\hline
\end{tabular}




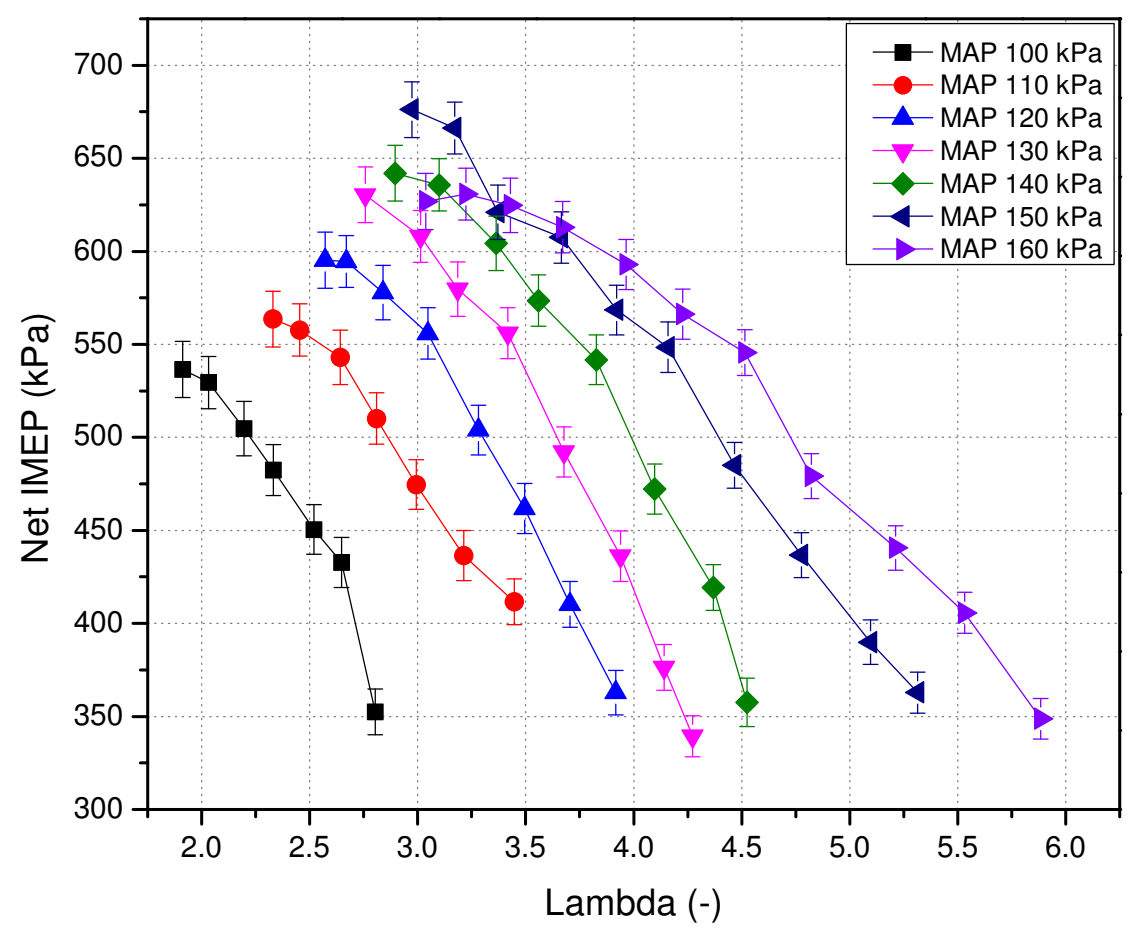

Figure 5.17: Effect of boost pressure on IMEP in the PPCI regime 


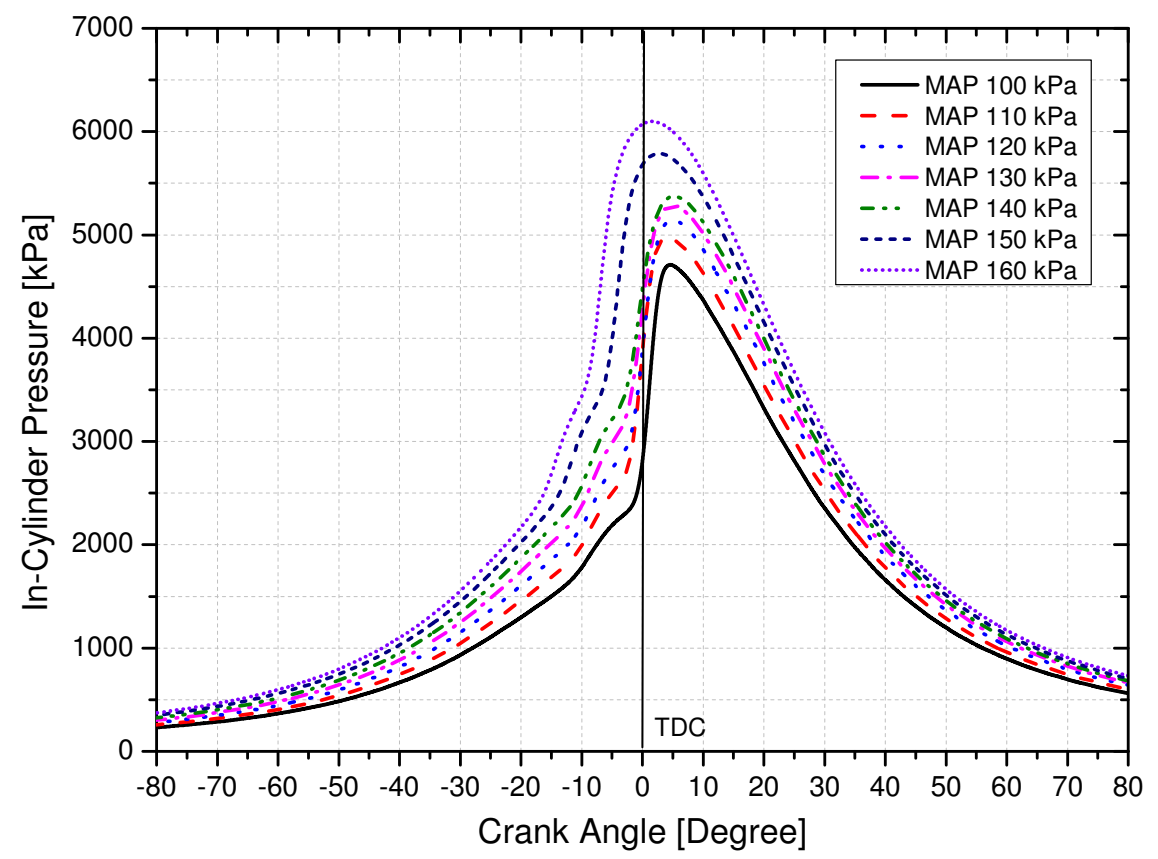

Figure 5.18: Variation of cylinder pressure versus crank angle at different intake manifold pressures at constant fuel energy $749 \mathrm{~J}$ in the PPCI regime

Figure 5.17 shows the effects of intake manifold pressure on IMEP. IMEP decreased with an increase in lambda. This is due to a decrease in input fuel energy quantity when moving towards lean air-fuel mixture (i.e., high lambda values). Figure 5.17 shows that PPCI combustion can be achieved at a larger range of lambda values with an increase in the intake manifold pressure. For a fixed lambda condition, as intake pressure increased, IMEP increased due to delivery of more air and fuel energy to the cylinder. But for a fixed intake pressure condition, IMEP has a decreasing trend with increase in lambda values. 
Figure 5.18 and 5.19 show the variations of cylinder pressure and heat release rate versus crank angle at different intake manifold pressures for a constant input fuel energy. In-cylinder pressure increased with the increase in intake manifold pressure. The compression pressure and temperature also increase at the end of compression stroke with an increase in intake manifold pressure. Higher in-cylinder pressure is obtained with the increase in intake manifold pressure as intake valve closing (IVC) pressure and IVC temperature will increase. This significantly affects PPCI combustion which is highly dependent on the temperature-pressure history during the compression stroke.

Maximum cylinder pressure was obtained near the TDC at higher intake manifold pressures especially at 150 and $160 \mathrm{kPa}$. Figure 5.19 shows the two stages of heat release in which increased intake manifold pressure resulted in earlier low temperature reactions. Also, main combustion was advanced with the increase of intake manifold pressure. 


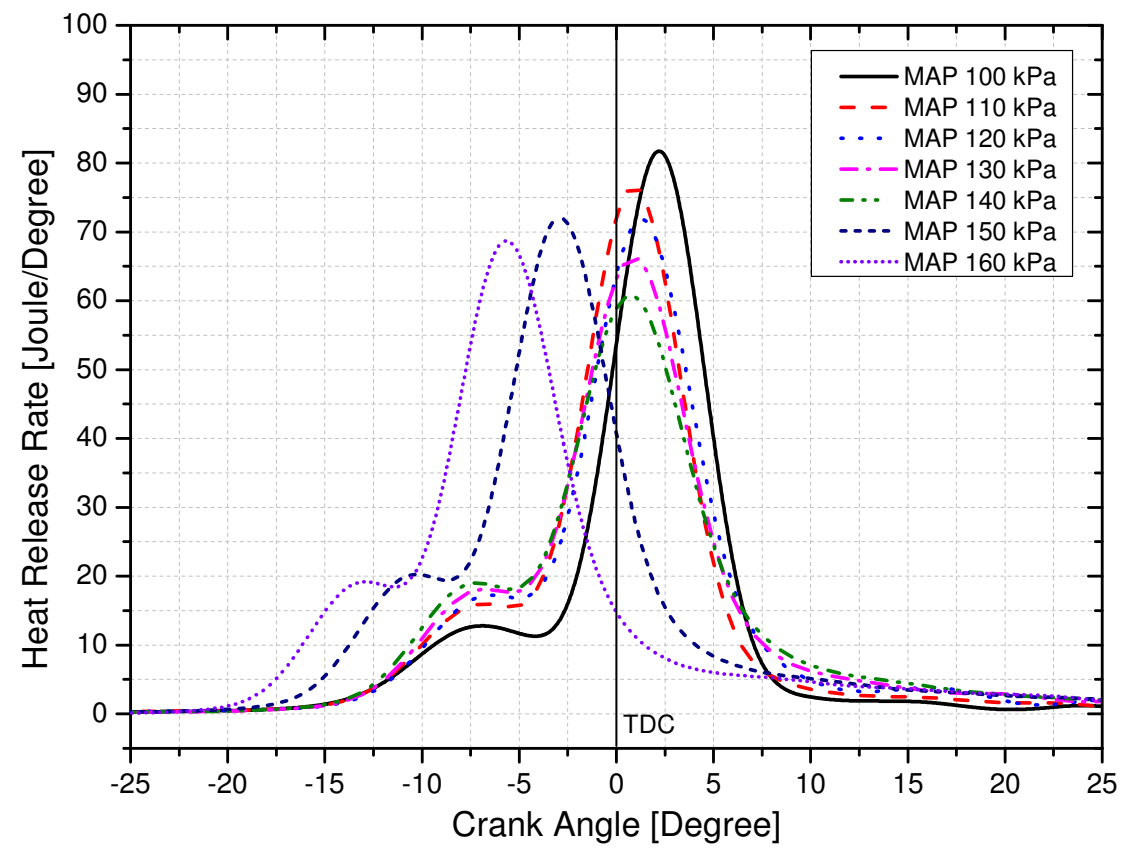

Figure 5.19: Variation of heat release rate versus crank angle at different intake manifold pressures at constant fuel energy $749 \mathrm{~J}$ in the PPCI combustion regime

Figure 5.20 shows the variation of indicated thermal efficiency as a function of lambda and intake manifold pressure. Indicated thermal efficiency increased until a certain lambda value and then started to decrease for all intake manifold pressures. Maximum thermal efficiency of $40 \%$ was observed at an intake manifold pressure of $100 \mathrm{kPa}$ and lambda 2.6, which is comparable to that of conventional diesel engines. As the intake manifold pressure increased, a small decrease in the indicated thermal efficiency was observed owing to leaner mixtures. 


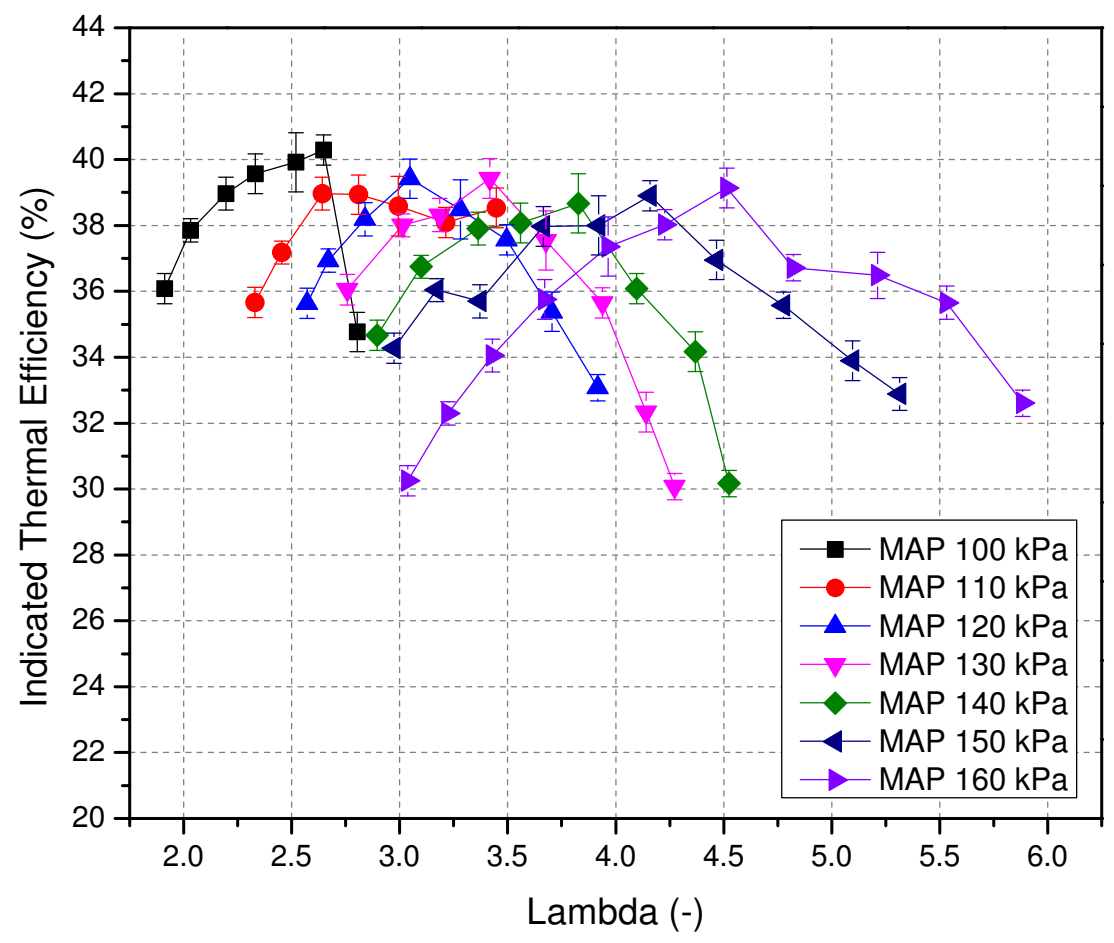

Figure 5.20: Variation of indicated thermal efficiency with lambda at different intake manifold pressures in PPCI combustion regime

Figure 5.21 depicts the effects of intake manifold pressure on CA50. It is apparent that combustion is advanced with an increase in intake manifold pressure. Therefore, CA50 is observed bTDC because of early auto-ignition at higher intake manifold pressures. Thermal efficiency is strongly affected by CA50. CA50 should be kept slightly after the TDC to obtain higher engine efficiency [40] [66]. An increase in thermal efficiency is observed when CA50 is slightly after TDC in Figure 5.21. CA50 was retarded after TDC at lower intake manifold pressure due to an increase of lambda. However, 
indicated thermal efficiency decreased because of very lean mixture at lambda value of 2.8 and intake manifold pressure of $100 \mathrm{kPa}$. At this point, the operating region is close to the misfiring zone with weak auto-ignition capability at very lean mixtures, leading to low indicated thermal efficiency. At $160 \mathrm{kPa}$, both the start of combustion (SOC) and CA50 were advanced especially with richer mixtures. Too early ignitions bTDC result in low indicated thermal efficiency.

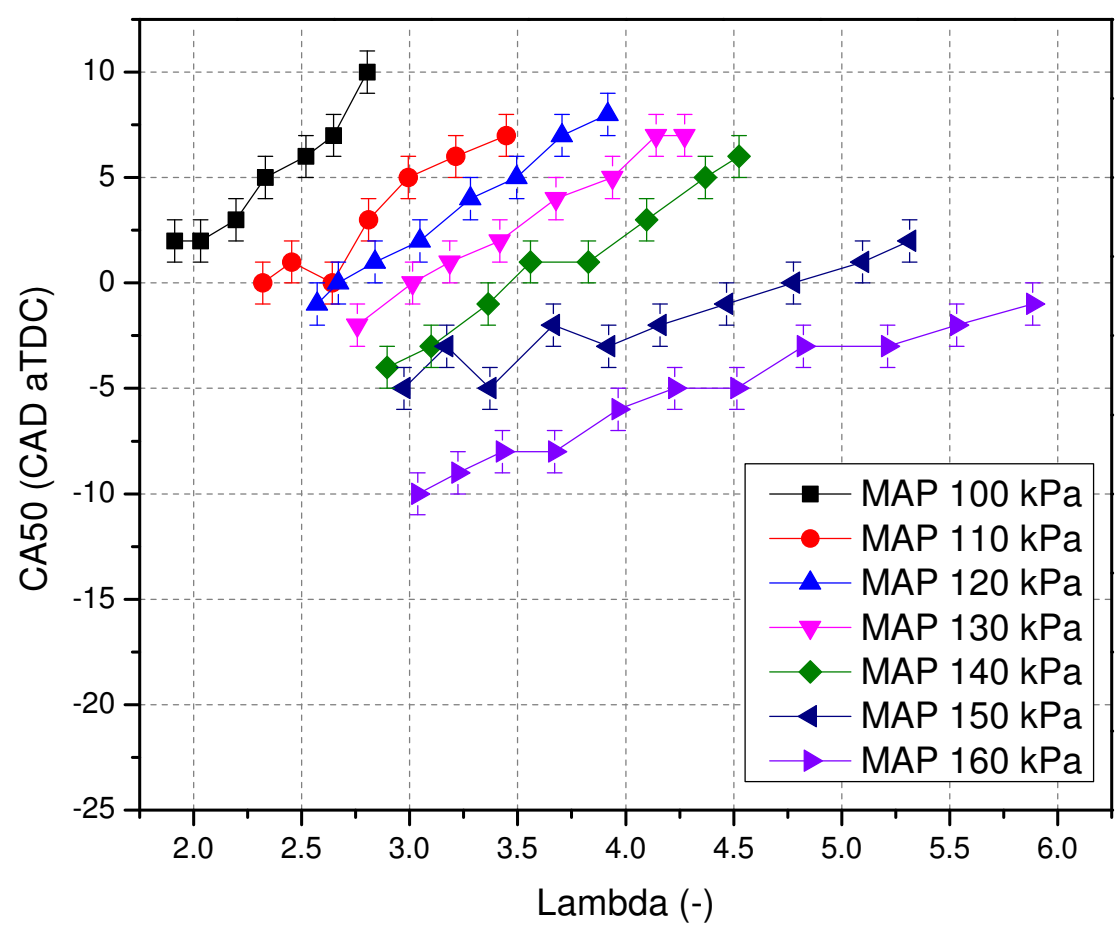

Figure 5.21: Effect of intake manifold pressure on CA50 at different lambda values in PPCI combustion regime 


\subsection{Effect of SOI on PPCI combustion}

PPCI combustion is strongly dependent on temperature of charge mixture and composition during the compression stroke. Injection timing is used commonly in order to control PPCI combustion, because injection timing alters the homogeneity of the charge mixture, start of combustion and combustion process. So, the effects of injection timing on PPCI combustion must be investigated in detail. The operating conditions for studying this effect is given in Table 5.6 .

Table 5.6

Operating conditions used for the experiments to study the effect of SOI on PPCI combustion

\begin{tabular}{|l|l|}
\hline \multicolumn{1}{|c|}{ Test Parameters } & \multicolumn{2}{c|}{ Value/ Unit } \\
\hline Engine Speed & $1000(\mathrm{rpm})$ \\
\hline Injection Pressure & $100(\mathrm{bar})$ \\
\hline SOI & $270,180,90,60,30,20(\mathrm{deg}$ bTDC $)$ \\
\hline Fuel Type & RON 0 \\
\hline IVO & $25.5(\mathrm{deg}$ bTDC $)$ \\
\hline EVC & $22(\mathrm{deg}$ bTDC $)$ \\
\hline Throttle Body Position & $100(\%)$ \\
\hline Intake Air Temperature & $80\left({ }^{\circ} \mathrm{C}\right)$ \\
\hline Lambda & 1.8 \\
\hline Boost Pressure & $95(\mathrm{kPa})$ \\
\hline
\end{tabular}

Figure 5.22 shows the variations of in-cylinder pressure at different SOI versus crank angle. Maximum in-cylinder pressure was obtained as $4733 \mathrm{kPa}$ at $2 \mathrm{CAD}$ bTDC when the fuel was injected at $270 \mathrm{CAD}$ bTDC whereas it was obtained $3368 \mathrm{kPa}$ at 
20 CAD bTDC when the fuel was injected 20 CAD bTDC. It was seen that maximum in-cylinder pressure increased and it was obtained earlier in case of early injection timing. Early fuel injection causes to obtain more homogeneous charge mixture. So, fuel molecules can meet with oxygen molecules more easily. In addition, the residence time for the fuel to vaporize increased and obtain stable combustion conditions as a result of early injection [40, 67]. Thus, fuel can be ignited earlier according to crank angle and maximum in-cylinder pressure was obtained earlier. In case of advancing SOI, the increase of maximum in-cylinder pressure can be explained by the fact that all fuel energy is released at a small interval of crank angle with more homogeneous charge mixture. SOC is retarded and large part of combustion occurred in expansion stroke when the fuel is injected towards to the TDC. This situation causes a decrease in the maximum in-cylinder pressure. 


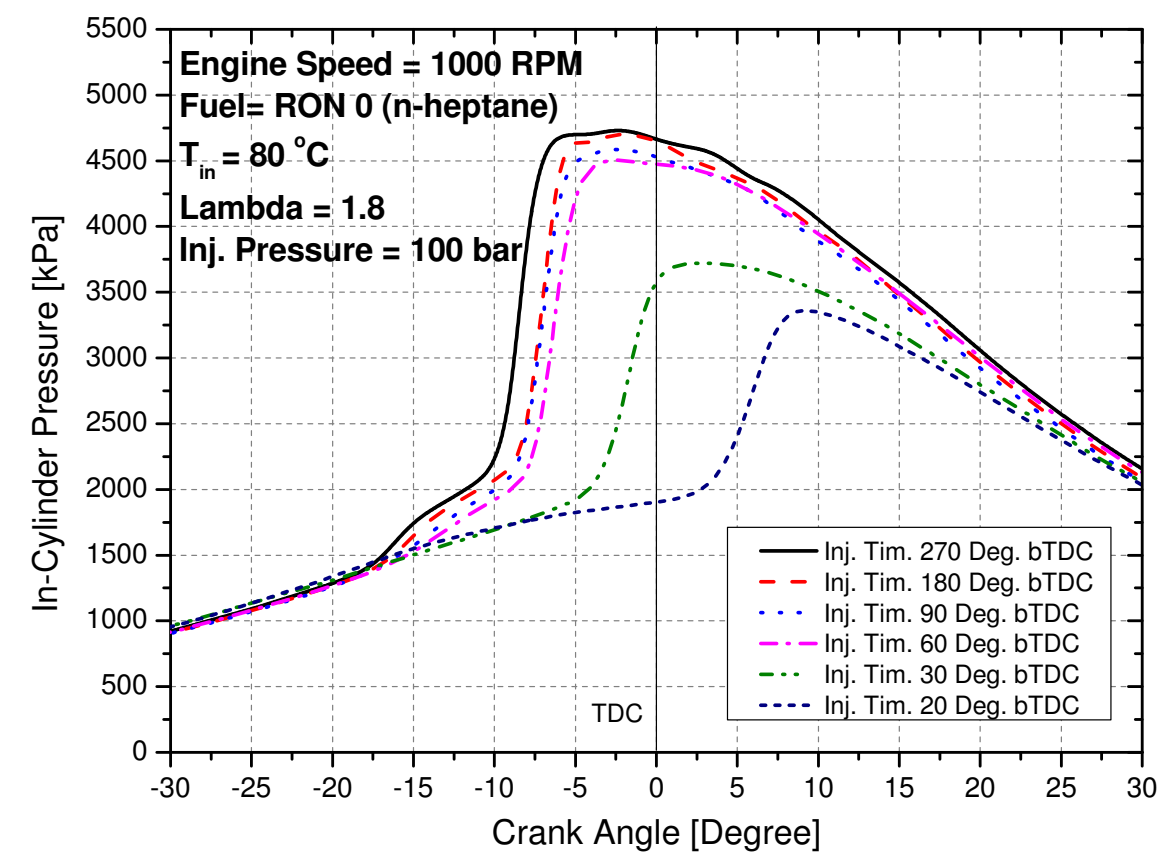

Figure 5.22: Effects of SOI on in-cylinder pressure in PPCI combustion regime

Figure 5.23 shows the heat release rates variation by injection timing. As seen in the figure there are two peak points in HRR for cases with SOI 180 and 270 CAD bTDC. The first peak indicates the insufficient in-cylinder temperature to vaporize of the fuel at the beginning of the injection. Retarded injection provides a higher incylinder temperature because of the single stage heat release. Advanced SOI caused early ignition as shown in Figure 5.23. Therefore the maximum heat release rate locations were shifted towards TDC except for SOI of 20 CAD bTDC. This may cause a reduction in thermal efficiency. Optimal CA50 is very critical in determining 
the best thermal efficiency of the engine at a given operating condition. Theoretically, an ideal CA50 lies close to TDC [68. However, when CA50 is located around 8-10 ${ }^{\circ}$ aTDC in a conventional CI or SI engine [40], net IMEP and thermal efficiency is the maximum. It is seen that the CA50s were obtained bTDC with advanced injection timings. This will reduce the thermal efficiency of the engine. CA50 was close to TDC when the SOI was $30 \mathrm{CAD}$ bTDC. N-heptane is a high reactivity fuel and therefore it should not be injected early as it leads to too early combustion.

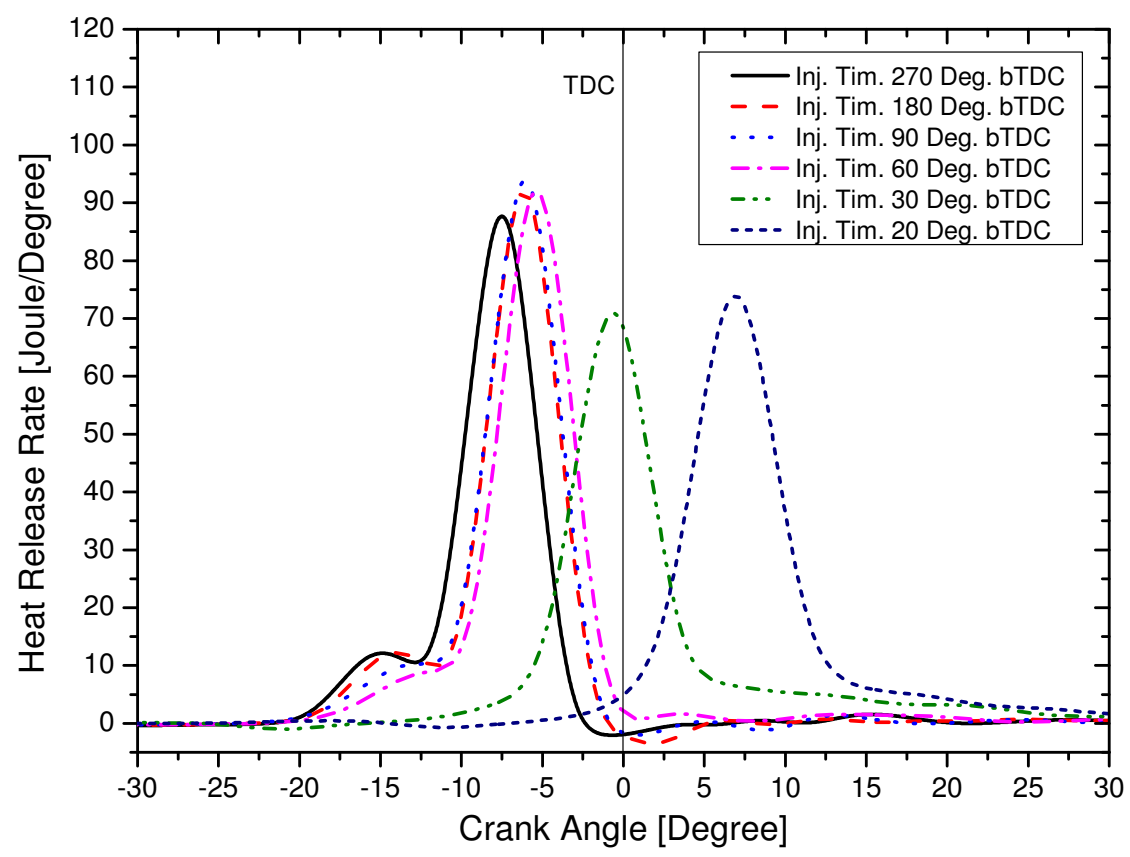

Figure 5.23: Effects of SOI on heat release rate in PPCI combustion regime

Figure 5.24 gives the CA10, CA50 and CA90 as a function of SOI. As seen in Figure 
5.24, there is no remarkable effect on CA10, CA50 and CA90 when SOI was fixed at interval of 270 and 90 CAD bTDC. But, CA10, CA50 and CA90 were obtained later if the injection timing was fixed under $90 \mathrm{CAD}$ bTDC. Combustion phasing was retarded towards TDC. So, CA10, CA50 and CA90 values were much retarded as calculated from the cumulative heat release rate.

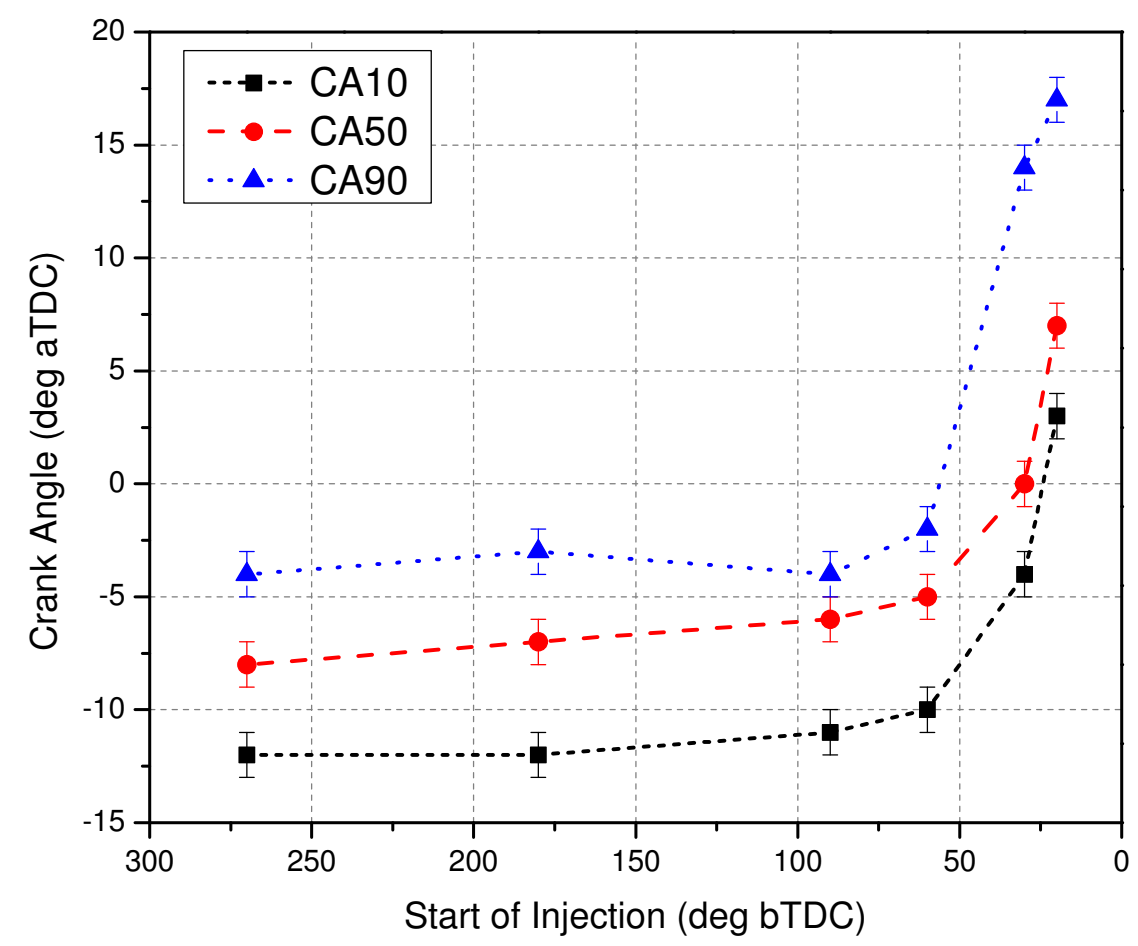

Figure 5.24: Effects of SOI on CA10, CA50 and CA90 in PPCI combustion regime 



\section{Chapter 6}

\section{Summary and Conclusions}

Experimental investigation has been carried out to determine the operating regions and performance maps for three different low temperature combustion regimes: HCCI, PPCI and RCCI. Different methods of operating range extension for load limit and lean limit have been studied. A parametric study has been conducted to study the effect of several operating conditions on the combustion and performance characteristics of the LTC modes. Major results and contributions from this thesis have been summarized and conclusions have been outlined. 


\subsection{Conclusions}

The results and the summary of the findings form this research have been described in the following sections:

\subsubsection{Operating range and performance maps}

- HCCI operation for naturally aspirated conditions in this study has a speed range of $800-1600 \mathrm{rpm}$ and load range of $250 \mathrm{kPa}$ to $580 \mathrm{kPa}$ IMEP for RON 0, 20 and 40. For boosted conditions the speed limit could be extended to $2000 \mathrm{rpm}$ and the load limits were between $440 \mathrm{kPa}$ to $800 \mathrm{kPa}$. The higher in-cylinder pressures and higher intake temperature with the assist of boost pressure enables extending the load limit and the speed limit for HCCI mode operation. Moreover, the control of combustion phasing was challenging for higher RON at lower $T_{\text {intake }}$. While very high loads result in pressure oscillations due to the rapid heat release rate, low loads result in unstable combustion due to the lower in-cylinder temperatures and dilution effect of the trapped exhaust gases. These two factors limit the HCCI operating range between the lean limit and the high load limit.

- The most efficient operating region for HCCI is found to be in the range of 
50-100 Nm brake torque. ISFC improved with engine load. The lowest ISFC of $205 \mathrm{~g} / \mathrm{kWh}$ was obtained for RON 40 and the best BSFC of $210 \mathrm{~g} / \mathrm{kWh}$ was obtained for RON 0. Fuels with higher reactivity tend to allow leaner HCCI operation. Moreover, a decrease in volumetric efficiency at increased $T_{\text {intake }}$ and higher boost pressures results in higher pumping losses thereby leading to higher BSFC values. Combustion phasing plays a crucial role in determining the optimal thermal efficiency at a given engine load and speed. The best thermal efficiencies were obtained at an optimal combustion phasing of 5-8 deg aTDC. A maximum indicated thermal efficiency of $40 \%$ was attained at mid load conditions for all three RONs. The exhaust gas temperatures are in the range of 230 to $410{ }^{\circ} \mathrm{C}$ which is close to typical catalyst light off temperatures. Thereby, the operating region for $\mathrm{HCCI}$ combustion regime falls in the acceptable range.

- The speed range for the RCCI mode operation gets narrower with an increase in PR. This is mainly due to the reduced reactivity of fuel at higher PR as a result of which the combustion becomes unstable at speeds higher than 1400 rpm for PR 60. Moreover, the lean limit for lower PR is much higher due to the combustion stability provided by the high reactive fuel dominance. At higher boost pressures, due to the increased charge temperature at IVC, the lean limit for all PRs could be further expanded. The engine load for the operating region is in the range of 300 to $1300 \mathrm{kPa}$ IMEP and speed range lies in the range of 800- $3200 \mathrm{rpm}$, which is considerably higher as compared to HCCI combustion 
regime.

- The best ISFC shifts towards higher load conditions at $1400 \mathrm{rpm}$ with an increase in the PR of the fuel. The best ISFC of $184 \mathrm{~g} / \mathrm{kWh}$ was obtained for PR 40 at $1800 \mathrm{rpm}$. At low loads and speeds, the lower combustion efficiencies lead to an increase in the ISFC. The range of BSFC obtained was $230-325 \mathrm{~g} / \mathrm{kWh}$ with th best BSFC occurring at high speeds and loads for all PRs. The compression ratio of the engine, pumping losses and specific heat ratio play a crucial role in determining the optimal thermal efficiency. Maximum indicated thermal efficiency of $45 \%$ was obtained at $1800 \mathrm{rpm}$ and $120 \mathrm{Nm}$ indicated torque for $\mathrm{PR}$ 40. Exhaust gas temperatures were in the range of $200{ }^{\circ} \mathrm{C}$ to $725{ }^{\circ} \mathrm{C}$. The exhaust gas temperatures are well below the catalyst light off temperatures at low loads. This region is not favorable due to the inability of the oxidation catalysts to function at these temperatures. However, about $90 \%$ of the data points lie in the favorable operating region with respect to the operating temperature of oxidation catalysts.

- For PPCI combustion mode, the engine could be run much leaner at higher intake temperatures, pushing the load limit towards much leaner operating conditions. The range of engine speeds is much larger for lower octane fuels RON 0 as compared to RON 40. RON 0 is more suitable to run the engine at low load conditions, whereas RON 40 is ideal for low-mid load conditions. The load range for operation was in the range of $320-750 \mathrm{kPa}$ IMEP, while the speed 
range was 800- $1800 \mathrm{rpm}$.

- The best ISFC was obtained at low loads for each engine speed. The best ISFC of $202 \mathrm{~g} / \mathrm{kWh}$ was attained at $800 \mathrm{rpm}$ and $65 \mathrm{Nm}$ indicated torque for RON 0. The sweet spot for BSFC (250 g/kWh) was obtained at a load of $72 \mathrm{Nm}$ and $1000 \mathrm{rpm}$ for RON 20. A maximum thermal efficiency of $42 \%$ is obtained at the point of the best ISFC. As a typical characteristic of PPCI combustion, the best efficiencies were obtained at low loads. The exhaust temperatures remained over $300{ }^{\circ} \mathrm{C}$ even at the lowest loads and speeds. This implies that the oxidation catalyst would function flawlessly over the entire operating region.

- As a baseline comparison with the SI map, it can be observed that RCCI combustion under naturally aspirated conditions had a much better ISFC at mid loads in the range of $600-800 \mathrm{kPa}$ IMEP and engine speed in the range of 1200 2000 rpm. Moreover, PPCI had a 5\% improvement in ISFC at $600 \mathrm{kPa}$ engine load and $1400 \mathrm{rpm}$ of engine speed. for low loads, HCCI combustion regime had an improvement of about $9 \%$ in ISFC values in the load range of 400-600 $\mathrm{kPa}$ and engine speed of 800-1600 rpm.

- Cost vs Efficiency Gain The Bosch 62251 port fuel injector costs about $\$ 95$ each. In order to install four port fuel injectors on the manifold, with the actuation linked to the control unit, the total cost to install the port fuel injection system could be roughly estimated to be $\$ 800$. As seen in this study, RCCI combustion regime can offer upto $14 \%$ improvement in fuel economy and upto 
$8 \%$ improvement in net indicated thermal efficiency over SI mode. Therefore, it is recommended that an SI-RCCI mode switch could be performed with one direct injection rail and one port fuel injection rail. With the cost incurred for the instrumentation of the PFI rail, a significant improvement in overall engine efficiency can be achieved.

\subsubsection{Parametric Study on Combustion and Performance characteristics}

- For HCCI combustion, the combustion phasing gets advanced with lower RON of the fuel. The higher reactivity of the fuel advances the start of combustion. At higher $T_{\text {intake }}$ and engine loads, the control of combustion pahsing becomes more challenging. The best thermal efficiency is attained at a combustion phasing of 8-10 CAD aTDC. With an increase in $T_{\text {intake, }}$, higher in-cylinder pressure and combustion temperatures result in knocking. However, higher $T_{\text {intake }}$ improves the auto ignition conditions in the combustion chamber. The SOC is advanced due to the higher compression temperatures. Higher boost pressure tends to decrease the thermal efficiency and the combustion efficiency. This is due to the fact that the CA50 is too advanced at these boost pressures.

- For RCCI combustion, there appears to be a two stage HTHR. The first stage 
heat release is mainly triggerred due to n-heptane being injected late into the cylinder. The first stage heat release triggers the remainder mixture to burn and thereby resulting in the second stage HTR. This two stage HTHR occurs due to the SOI for n-heptane being too retarded. The indicated thermal efficiency increased with an increase in PR. This is because of the reduced in-cylinder temperatures and pressures due to the two stage HTHR for PR 60. Moreover, the combustion efficiency improves with PR because of the higher completeness of combustion with the two stage HTHR for the conditions studied. With an increase in $T_{\text {intake, }}$, the SOC tends to get advanced due to the higher charge temperatures. However, the CA50 does not get advanced drastically and remains around 8-10 CAD aTDC. With an increase in boost pressure, the CA10 gets advanced significantly. But the thermal efficiency and net IMEP do not change much since the combustion phasing lies in the range of 8-12 CAD aTDC.

- For PPCI combustion, the IMEP and BMEP tend to reduce with an increase in $T_{\text {intake }}$ since the temperature of compression increases and thereby reducing the amount of fuel being injected. The CA10, CA50 and CA90 tend to get advanced with an increase in $T_{\text {intake }}$. Due to the increased manifold temperature of air-fuel mixture, auto ignition occurs much earlier and thereby advancing the combustion phasing. Thermal efficiencies are strongly affected by combustion phasing. The best thermal efficiencies are obtained when the combustion phasing are in the range of 5-10 CAD aTDC. PPCI combustion could be achieved 
at a larger range of lambda values with an increase in boost pressure. The two stage heat release (LTR and HTR) result in reduced in-cylinder temperatures, thereby resulting in earlier low temperature reactions with increase in boost pressure. Therefore, the combustion phasing was advanced with increase in boost pressure. Maximum thermal efficiency of $40 \%$ was observed at $100 \mathrm{kPa}$ boost pressure and lambda of 2.6, which is comparable to that of conventional diesel engines. Advancing the SOI results in more homogeneous mixture and provides sufficient time for the fuel to vaporize. Thereby the fuel is ignited early and maximum in-cylinder pressure is obtained. It was observed that the maximum in-cylinder pressures and temperatures reduced when SOI approached 20 CAD bTDC. The combustion phasing does not change significantly when the SOI is retarded from 270 to 90 CAD bTDC. However, when further retarded, the combustion phasing gets advanced significantly due to the insufficient time for the mixing of air-fuel mixture, thereby resulting in a heterogeneous mixture. Moreover, the combustion duration is much larger at retarded SOI.

\subsection{Major Contribution towards the thesis}

The major contribution towards the thesis are as mentioned below: 
- Instrumentation and calibration of Port Fuel Injection system and Direct Injection system

- Developed control blocks and control strategies for port fuel injectors and supercharger control

- Conducted experiments for three different LTC combustion regimes: HCCI, RCCI and PPCI over 2500 data points with operating conditions including intake air temperature, boost pressure, RON, fuel-air equivalence ratio, injection pressure and engine speed.

- Developed an in-house MATLAB post processing script to calculate over 50 different parameters to understand the engine characteristics and behavior at each operating condition.

- Investigated the effect of each parameter on the combustion (CA10, CA50, CA90 and BD) and performance (IMEP, indicated thermal efficiency, combustion efficiency) characteristics of the engine for each of the LTC regime.

- Developed operating region maps to determine the upper and lower limits of LTC operation

- Developed and studied the performance maps for ISFC, BSFC, indicated thermal efficiency and exhaust temperature) for each of the LTC modes 


\subsection{Future Work}

- With respect to engine experimentation, several tasks need to be carried out in order to utilize the maximum capability of the engine in terms of performance and operating range. One of the major tasks would be to change the compression ratio of the engine to $12.1: 1$ by using newly designed pistons [37]. With this, the load range of the engine is expected to become much more wider. Moreover, even the overall engine efficiency should improve significantly. It would also be feasible to run the engine with higher RON fuels.

- One of the shortcomings of this research is that the emissions analyzer was not at our disposal. Further improvisations to the experimental setup could be pursued in terms of emission analysis. A detailed emissions study on the engine could provide more information and corroborate the findings, leading to more conclusive inferences.

- The homogeneity and mixing characteristics of the fuel should be studied through detailed analytical models and simulation studies. Ensuring optimal spray angle and a detailed study of split injection strategies for RCCI could provide improvements in terms of combustion and overall engine efficiency.

- Development of an LTC-electric hybrid powertrain [54] would be the next step in terms of improvising the overall system efficiency particularly during engine 
transients. With the assist of torque blending, the engine maps for different combustion modes could be used to decide the favorable regions of operation for the LTC engine when working in conjunction with an e-motor.

- A potential area of improvement would be the implementation of model based predictive controller on the engine. A real time feedback of CA50 and model parameterization of RCCI combustion is currently being pursued by the students in the EML team. Implementing the controller on the engine, by studying and understanding the engine LTC maps would be a task worth pursuing.

- The noise level of the engine is one of the factors that has a significant impact on the operating region maps. A thorough noise analysis could be performed in order to determine the combustion noise level which would help researchers to develop desirable operating region maps.

- In the current setup of the LTC engine, the supercharger is externally run by an e-motor. Given that the engine is already equipped with the stock turbocharger, it would be worthwhile to analyze the extent to which the turbocharger could be utilized to provide the necessary boost pressure.

- The low efficiency islands observed in the ISFC optimized maps for RCCI combustion regime could be improved by optimizing the cam phasing, introducing EGR or by varying the direct injection pressure. This could be potential research that would improve the areas of low ISFC. 



\section{References}

[1] A. Paykani, A. Kakaee, P. Rahnama, and R. D. Reitz. "Progress and recent trends in reactivity-controlled compression ignition engines". International Journal of Engine Research, 17(5):481-524, 2016.

[2] A. B. Dempsey, S. J. Curran, and R. M. Wagner. "A perspective on the range of gasoline compression ignition combustion strategies for high engine efficiency and low NOx and soot emissions: Effects of in-cylinder fuel stratification". International Journal of Engine Research, 2016. doi: 10.1177/1468087415621805.

[3] Eaton M62 supercharger efficiency map. http://www.eaton.com/ecm/groups/ public/@pub/@eaton/@per/documents/content/ct_128484.gif, 2016. Accessed on: 2016-07-27.

[4] B. Bahri, M. Shahbakhti, K. Kannan, and A. A. Aziz. "Identification of ringing operation for low temperature combustion engines". Applied Energy, 171:142152,2016 . 
[5] S. Polat, K. Kannan, M. Shahbakhti, A. Uyumaz, and H. S. Yucesu. "Study of high speed gasoline direct injection compression ignition (GDICI) engine operation in the LTC regime". Int. Research Conference on Engineering, Science and Management (IRCESM), June 3-4, 2015.

[6] C. Cinar, O. Can, F. Sahin, and H. S. Yucesu. "Effects of premixed diethyl ether (DEE) on combustion and exhaust emissions in a HCCI-DI diesel engine". Applied Thermal Engineering, 30(4):360-365, 2010.

[7] O. Can. "An investigation of the effects of partial HCCI application with premixed ethanol on combustion and emissions in a DI diesel engine". PhD thesis, University of Gazi, Graduate School of Natural and Applied Sciences , Ankara, 2012.

[8] J. Ma, X. Lü, L. Ji, and Z. Huang. "An experimental study of HCCI-DI combustion and emissions in a diesel engine with dual fuel". International Journal of Thermal Sciences, 47(9):1235-1242, 2008.

[9] S. Kokjohn, R. Hanson, D. Splitter, J. Kaddatz, and R. D. Reitz. "Fuel reactivity controlled compression ignition (RCCI) combustion in light-and heavy-duty engines". SAE International Journal of Engines, 4(1):360-374, 2011.

[10] G. Haraldsson, P. Tunestal, B. Johansson, and J. Hyvonen. "HCCI closedloop combustion control using fast thermal management". SAE Technical Paper 2004-01-0943, 2004. 
[11] K. Hamada, S. Niijima, K. Yoshida, K. Yoshida, H. Shoji, K. Shimada, and K. Shibano. "The effects of the compression ratio, equivalence ratio, and intake air temperature on ignition timing in an HCCI engine using DME fuel". SAE Technical Paper 2005-32-0002, 2005.

[12] G. Haraldsson, P. Tunestal, B. Johansson, and J. Hyvonen. "HCCI combustion phasing in a multi cylinder engine using variable compression ratio". SAE Technical Paper 2002-01-2858, 2002.

[13] J. Hyvonen, G. Haraldsson, and B. Johansson. "Operating range in a multi cylinder HCCI engine using variable compression ratio". SAE Technical Paper 2003-01-1829, 2003.

[14] F. Agrell. "Control of HCCI by aid of Variable Valve Timings with Specialization in Usage of a Non-Linear Quasi-Static Compensation”. PhD thesis, KTH, School of Industrial Engineering and Management (ITM), Machine Design (Dept.), Machine Design (Div.)., 2006.

[15] G. M. Shaver, M. Roelle, and J. C. Gerdes. "Modeling cycle-to-cycle coupling in HCCI engines utilizing variable valve actuation". In Proceedings of the IFAC Symposium on Advances in Automotive Control, 2004.

[16] X. Lü, W. Chen, and Z. Huang. "A fundamental study on the control of the HCCI combustion and emissions by fuel design concept combined with controllable 
EGR. Part 1. The basic characteristics of HCCI combustion". Fuel, 84(9):10741083, 2005.

[17] X. Lü, W. Chen, and Z. Huang. "A fundamental study on the control of the HCCI combustion and emissions by fuel design concept combined with controllable EGR. Part 2. Effect of operating conditions and EGR on HCCI combustion". Fuel, 84(9):1084-1092, 2005.

[18] S.M. Aceves, D. Flowers, F. Martinez-Frias, J.and Espinosa-Loza, W.J. Pitz, and R Dibble. "Fuel and Additive Characterization for HCCI Combustion". SAE Technical Paper 2003-01-1814, 2003.

[19] D. S. Kim and C. S. Lee. "Improved emission characteristics of HCCI engine by various premixed fuels and cooled EGR". Fuel, 85(5):695-704, 2006.

[20] G. M. Shaver, M. J. Roelle, and J. C. Gerdes. "Modeling cycle-to-cycle dynamics and mode transition in HCCI engines with variable valve actuation". Control Engineering Practice, 14(3):213-222, 2006.

[21] Y. Peng, M. Tan, L. Guo, F. Liu, H. Li, and Y. Guo. "Study the ethanol SI/HCCI combustion mode transition by using the fast thermal management system". Chinese Science Bulletin, 52(19):2731-2736, 2007.

[22] G. T. Kalghatgi. "Auto-ignition quality of practical fuels and implications for fuel requirements of future SI and HCCI engines". SAE Technical Paper 200501-0239, 2005. 
[23] B. Johansson. "High-load partially premixed combustion in a heavy-duty diesel engine". In Diesel engine emissions reduction (DEER) Conference. Chicago, Illinois, pages 21-25, 2005.

[24] Y. Ra, P. Loeper, R. Reitz, M. Andrie, R. Krieger, D. Foster, R. Durrett, V. Gopalakrishnan, A. Plazas, and R. Peterson. "Study of high speed gasoline direct injection compression ignition (GDICI) engine operation in the LTC regime". SAE International Journal of Engines, 4(1):1412-1430, 2011.

[25] M. Sjöberg and J. E. Dec. "Smoothing HCCI heat-release rates using partial fuel stratification with two-stage ignition fuels". SAE Technical Paper 2006-01-0629, 2006.

[26] Y. Yang, J. Dec, N. Dronniou, M. Sjöberg, and W. Cannella. "Partial fuel stratification to control HCCI heat release rates: fuel composition and other factors affecting pre-ignition reactions of two-stage ignition fuels". SAE International Journal of Engines, 4(1):1903-1920, 2011.

[27] J. E. Dec, Y. Yang, and N. Dronniou. "Boosted HCCI-controlling pressurerise rates for performance improvements using partial fuel stratification with conventional gasoline". SAE International Journal of Engines, 4(1):1169-1189, 2011.

[28] S. L. Kokjohn and R. D. Reitz. "Characterization of dual-fuel PCCI combustion 
in a light-duty engine". In Proceedings of the International Multi-Dimensional Engine Modeling UserâĂŹs Group Meeting, 2010.

[29] D. A. Splitter, M. L. Wissink, T. L. Hendricks, J. B. Ghandhi, and R. D. Reitz. "Comparison of RCCI, HCCI, and CDC operation from low to full load". In THIESEL 2012 conference on thermo-and fluid dynamic processes in direct injection engines, 2012.

[30] D. Splitter, M. Wissink, D. DelVescovo, and R. D." Reitz. "RCCI engine operation towards 60\% thermal efficiency. SAE Technical Paper 2013-01-0279, 2013.

[31] X. Lu, D. Han, and Z. Huang. "Fuel design and management for the control of advanced compression-ignition combustion modes". Progress in Energy and Combustion Science, 37(6):741-783, 2011.

[32] H. Zhao. "HCCI and CAI engines for the automotive industry". Chapter 2,9,11,17, Woodhead Publishing Abington, Cambridge, 2007.

[33] Z. Wang, Z. Zhao, D. Wang, M. Tan, Y. Han, Z. Liu, and H. Dou. "Impact of pilot diesel ignition mode on combustion and emissions characteristics of a diesel/natural gas dual fuel heavy-duty engine". Fuel, 167:248-256, 2016.

[34] M. A. Amin and A. A. Azhar. "Homogenous charge compression ignition (HCCI) technique: a review for application in two-stroke gasoline engines". In Applied Mechanics and Materials, volume 165, pages 53-57. Trans Tech Publ, 2012. 
[35] S. L. Kokjohn and R. D. Reitz. "Reactivity controlled compression ignition and conventional diesel combustion: a comparison of methods to meet lightduty NOx and fuel economy targets". International Journal of Engine Research, 14(5):452-468, 2013.

[36] D. Splitter, M. Wissink, S. Kokjohn, and R. D. Reitz. "Effect of compression ratio and piston geometry on RCCI load limits and efficiency". SAE Technical Paper 2012-01-0383, 2012.

[37] H. A. Saigaonkar. "An Investigation Of Variable Valve Timing Effects On HCCI Engine Performance", MS Thesis, Michigan Technological University, 2014.

[38] V. S. Thakkar. "Modeling and Experimental Setup Of An HCCI Engine", MS Thesis, Michigan Technological University, 2014.

[39] D. Kothari. "Experimental Setup And Controller Design For An HCCI Engine”, MS Thesis, Michigan Technological University, 2014.

[40] J. B. Heywood. "Internal Combustion Engine Fundamentals". Chapters 2,4,5,6,7,9,10,12,15 ,McGraw-hill New York, 1988.

[41] A. Simi. "Hydrogen Direct Injection In Reciprocating Engines Using Commercial Injectors". PhD thesis, UNIVERSITA DI PISA, 2011. 
[42] H. Li, W. Neill, and W. Chippior. "Cycle-to-cycle variation of a HCCI engine operated with n-heptane". In Proceeding of Combustion Institute/Canadian Section (CI/CS) Spring Technical Conference, 2007.

[43] B. Challen and R. Baranescu. "Diesel Engine Reference Book. 2nd Edition". Chaper 6, Butterworth-Heinemann Ltd. Pp, 1999.

[44] J. Chang, O. Güralp, Z. Filipi, D. Assanis, T. Kuo, P. Najt, and R. Rask. "New heat transfer correlation for an HCCI engine derived from measurements of instantaneous surface heat flux". SAE Technical Paper 2004-01-2996.

[45] F. Payri, P. Olmeda, C. Guardiola, and J. Martín. Adaptive determination of cutoff frequencies for filtering the in-cylinder pressure in diesel engines combustion analysis. Applied Thermal Engineering, 31(14):2869-2876, 2011.

[46] G. Lavoie, E. Ortiz-Soto, A. Babajimopoulos, J. B. Martz, and D. N. Assanis. "Thermodynamic sweet spot for high-efficiency, dilute, boosted gasoline engines". International Journal of Engine Research.

[47] C. Kavuri and S. Kokjohn. "Investigating Air Handling Requirements of High Load Low Speed Reactivity Controlled Compression Ignition (RCCI) Combustion". SAE Technical Paper 2016-01-0782, 2016.

[48] T. Aroonsrisopon, V. Sohm, P. Werner, D. E. Foster, T. Morikawa, and M. Iida. "An investigation into the effect of fuel composition on HCCI combustion characteristics". SAE Technical Paper 2002-01-2830, 2002. 
[49] G. Shibata, K. Oyama, T. Urushihara, and T. Nakano. "correlation of low temperature heat release with fuel composition and hcci engine combustion". SAE Technical Paper 2005-01-0138, 2005.

[50] C. Cinar, A. Uyumaz, H. Solmaz, and T. Topgul. "Effects of valve lift on the combustion and emissions of a HCCI gasoline engine". Energy Conversion and Management, 94:159-168, 2015.

[51] X. Han, M. Zheng, J. S. Tjong, and T. Li. "Suitability Study of n-Butanol for Enabling PCCI and HCCI and RCCI Combustion on a High Compression-ratio Diesel Engine”. SAE Technical Paper 2015-01-1816, 2015.

[52] B. G. Bunting. "Fuel effects on spark assisted HCCI combustion in a gasoline engine". Prepr. Pap.-Am. Chem. Soc., Div. Fuel Chem, 49(2):736, 2004.

[53] S. L. Kokjohn and R. D. Reitz. "A modeling study of charge preparation and combustion in an HCCI engine using a variable pressure pulse (VPP) injection system and optimized PRF blends". In International Multidimensional Engine Modeling User's Group Meeting, Detroit, MI, 2009.

[54] A. Solouk, M. Shakiba, K. Kannan, H. Solmaz, M. Bidarvatan, N. T. Kondipati, P. Dice, and M. Shahbakhti. "Fuel Economy Benefits of Integrating a MultiMode Low Temperature Combustion (LTC) Engine in a Series Extended Range Electric Powertrain". SAE 2016 International Powertrains, Fuels and Lubricants 
Meeting, Baltimore, Maryland, USA. 16FFL-0277, 13 pages, 2016 (Accepted for publication in June 2016).

[55] S. Pischinger, V. K. Rajamani, and Y. Jeihouni. "Impact of Fuel Properties on the Performance of a Direct Injection Diesel Engine under Part Homogeneous Operating Conditions". SAE Technical Paper 2011-01-1358, 2011.

[56] J. E. Dec, Y. Yang, and N. Dronniou. "Improving Efficiency and Using E10 for Higher Loads in Boosted HCCI Engines". SAE International Journal of Engines, 5(3):1009-1032, 2012.

[57] M. Shahbakhti, A. Ghazimirsaied, and C. R. Koch. "The effect of operating conditions on HCCI exhaust gas temperature". In Proceeding of Combustion Institute-Canadian Section (CICS) Spring Technical Conference, Paper No. CICS-A02, volume 6, pages 10-13, 2009.

[58] R. J. Wanker, J. C. Wurzenberger, and H. A. Schuemie. "Three-way catalyst light-off during the NEDC test cycle: fully coupled 0D/1D simulation of gasoline combustion, pollutant formation and aftertreatment systems". SAE International Journal of Fuels and Lubricants, 1(1):1373-1385, 2008.

[59] K. Tanikawa, T. Hirota, T. Yamada, M. Komori, G. Zhang, and H. Muraki. "Development of advanced three-way catalyst technology". SAE Technical Paper 2008-01-1645, 2008. 
[60] B. Walter and B. Gatellier. "Development of the high power NADIâĎć concept using dual mode diesel combustion to achieve zero NOx and particulate emissions". SAE Technical Paper 2002-01-1744, 2002.

[61] C. Cinar, A. Uyumaz, H. Solmaz, F. Sahin, S. Polat, and E. Yilmaz. "Effects of intake air temperature on combustion, performance and emission characteristics of a HCCI engine fueled with the blends of $20 \%$ n-heptane and $80 \%$ isooctane fuels". Fuel Processing Technology, 130:275-281, 2015.

[62] S. Curran, R. Hanson, R. Wagner, and R. D. Reitz. "Efficiency and emissions mapping of RCCI in a light-duty diesel engine". SAE Technical Paper 2013-010289, 2013.

[63] H. Liu, X. Wang, Z. Zheng, J. Gu, H. Wang, and M. Yao. "Experimental and simulation investigation of the combustion characteristics and emissions using n-butanol/biodiesel dual-fuel injection on a diesel engine". Energy, 74:741-752, 2014 .

[64] L. Zhu, Y. Qian, X. Wang, and X. Lu. "Effects of direct injection timing and premixed ratio on combustion and emissions characteristics of RCCI (Reactivity Controlled Compression Ignition) with N-heptane/gasoline-like fuels". Energy, 93:383-392, 2015.

[65] C.A.J. Leermakers, C.C.M. Luijten, L.M.T. Somers, G.T. Kalghatgi, and B.A. 
Albrecht. "Experimental study of fuel composition impact on PCCI combustion in a heavy-duty diesel engine". SAE Technical Paper 2011-01-1351.

[66] T. Tsurushima. "A new skeletal PRF kinetic model for HCCI combustion". Proceedings of the Combustion Institute, 32(2):2835-2841, 2009.

[67] C. Baumgarten. "Mixture formation in internal combustion engines". Chapter 6, Springer Science \& Business Media, 2006.

[68] H. Solmaz. "Combustion, performance and emission characteristics of fusel oil in a spark ignition engine". Fuel Processing Technology, 133:20-28, 2015. 
Appendix A

Table of Data points for

\title{
Experiments
}

\author{
A.1 PPCI
}




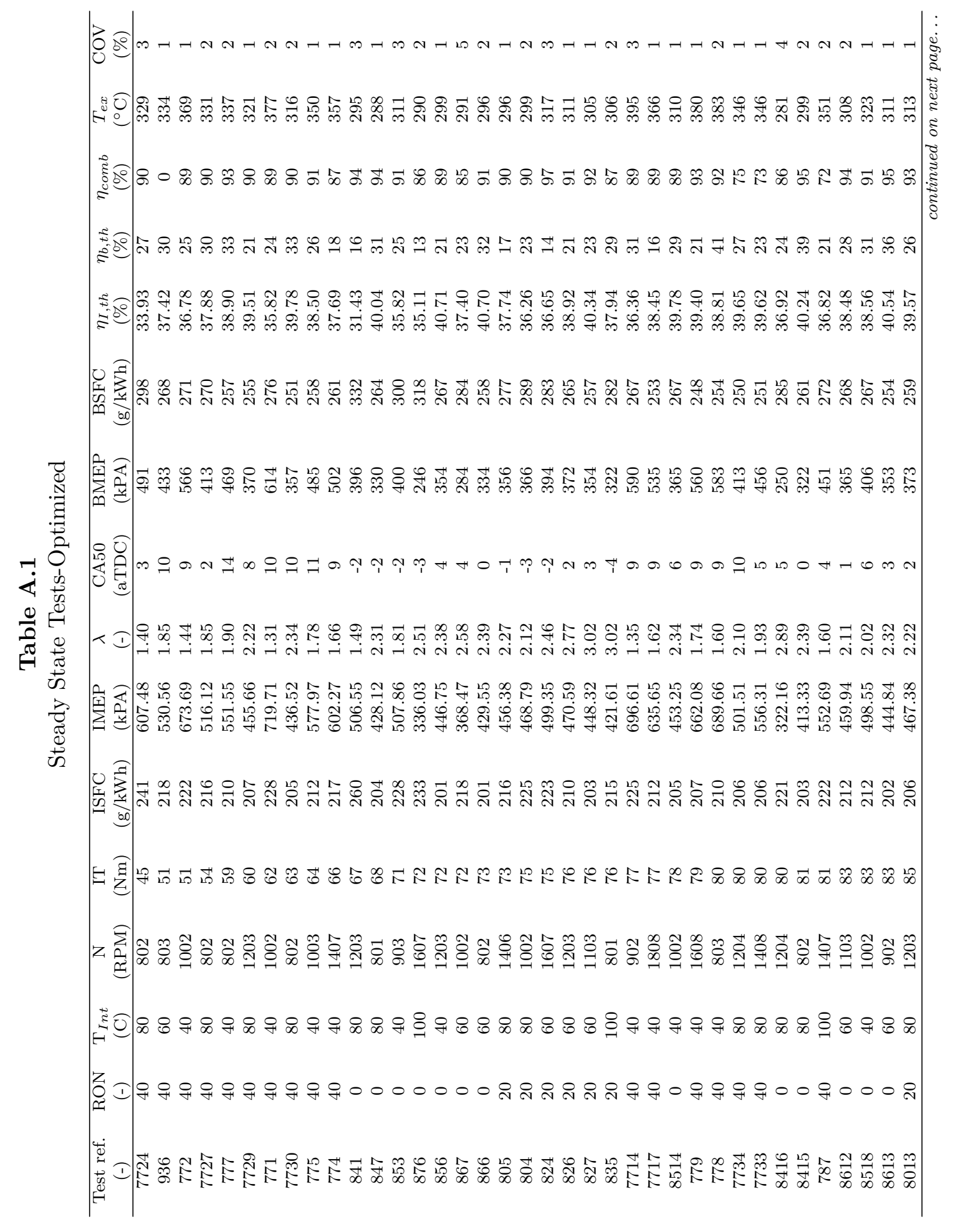




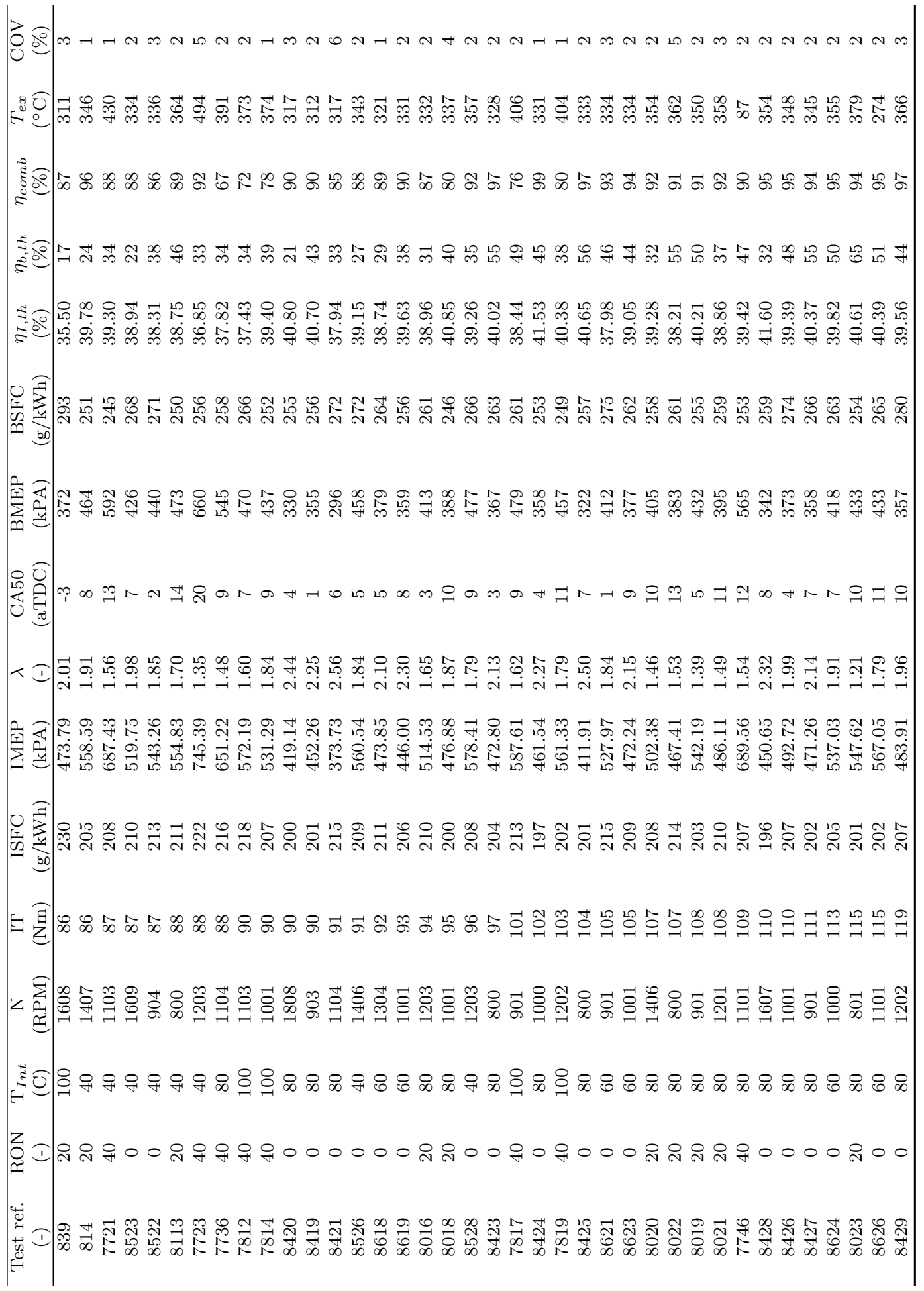




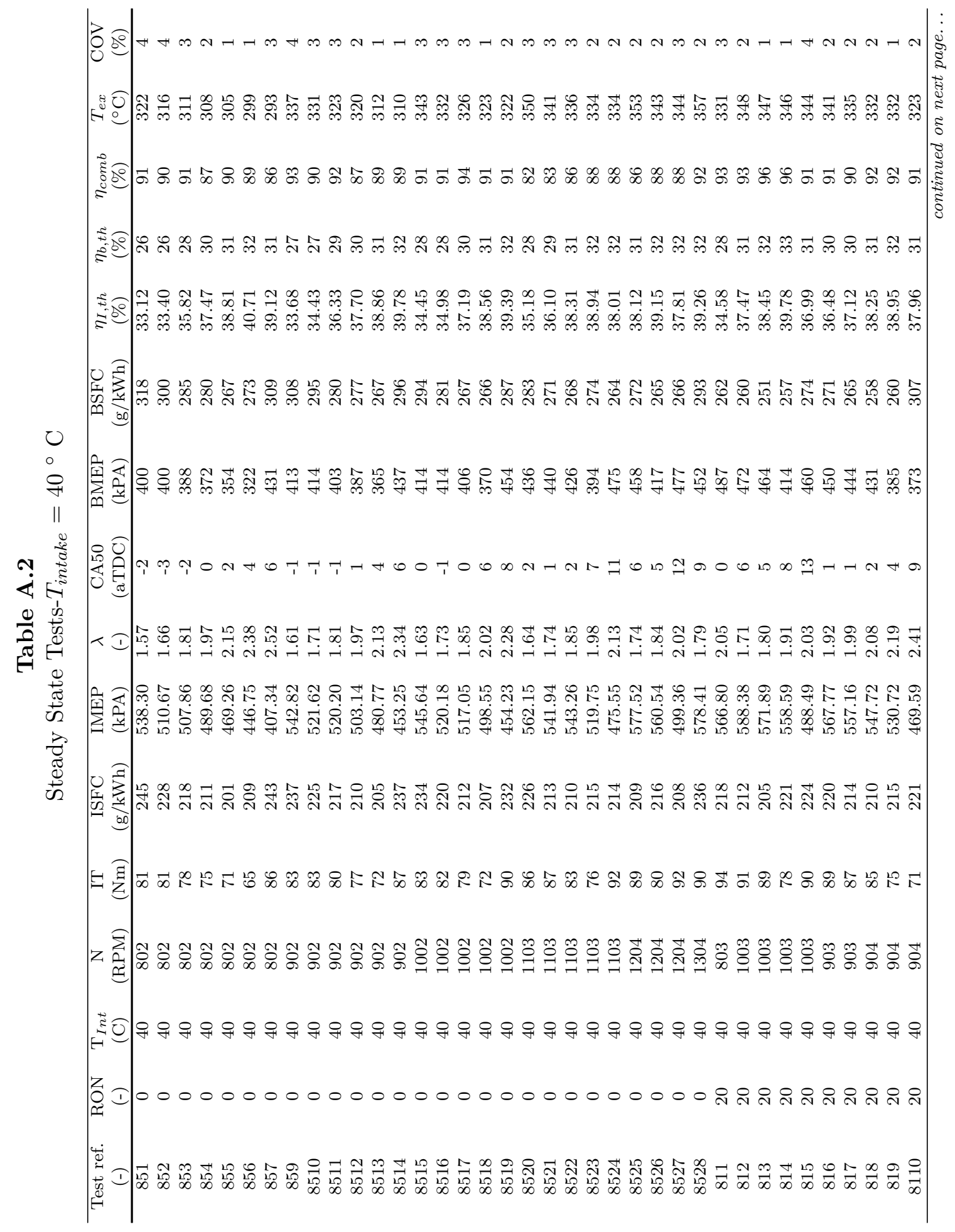




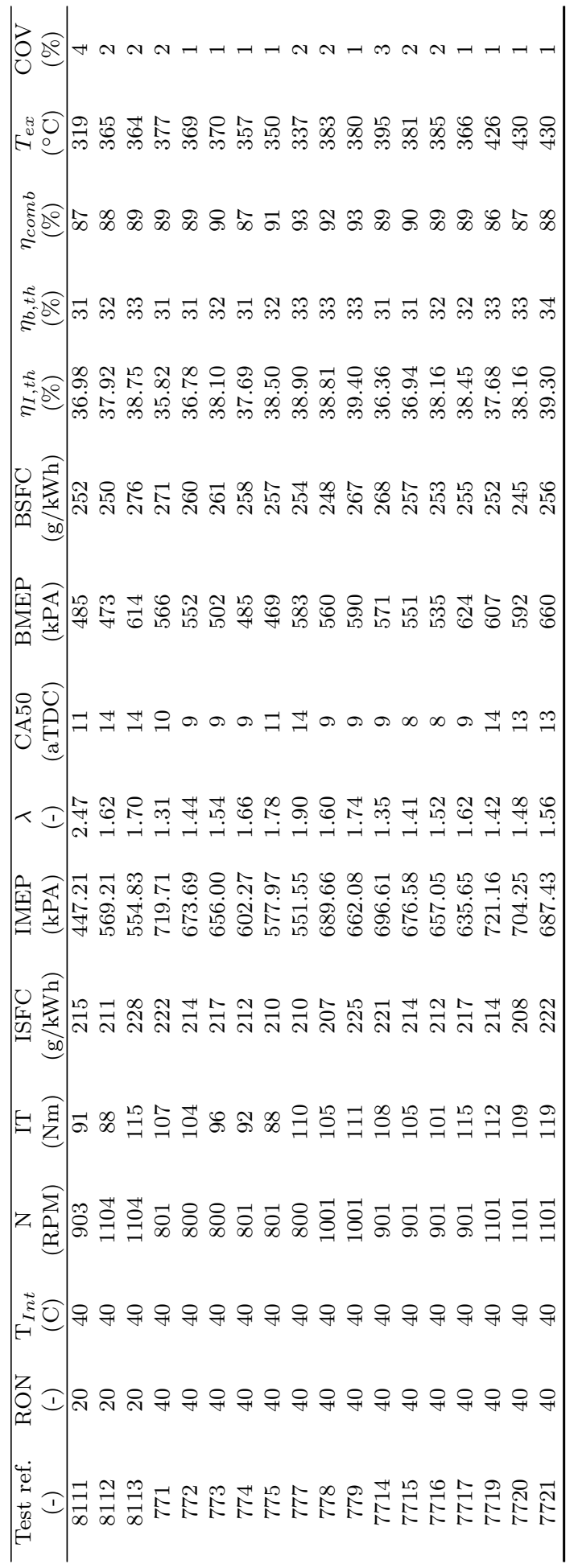




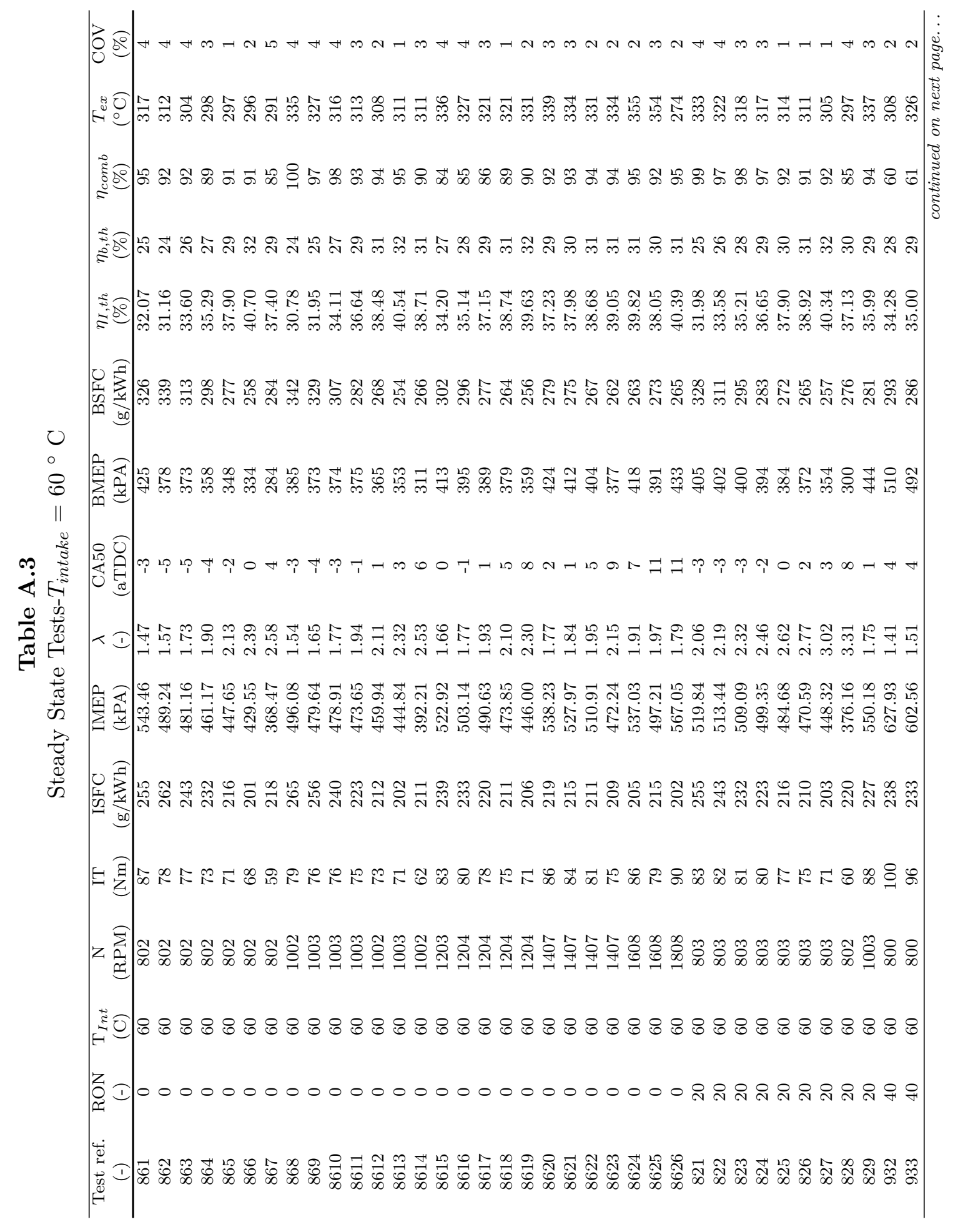




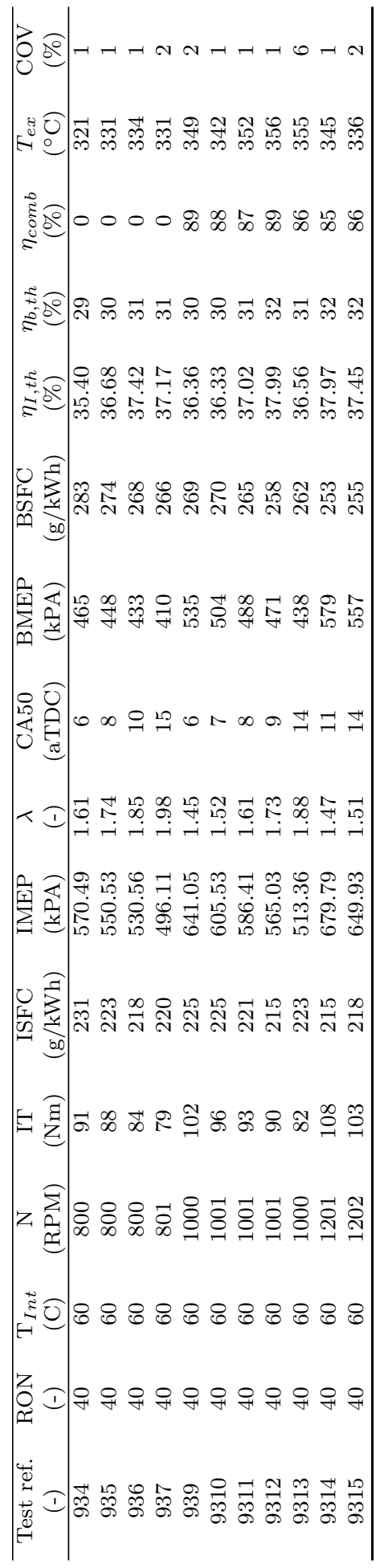




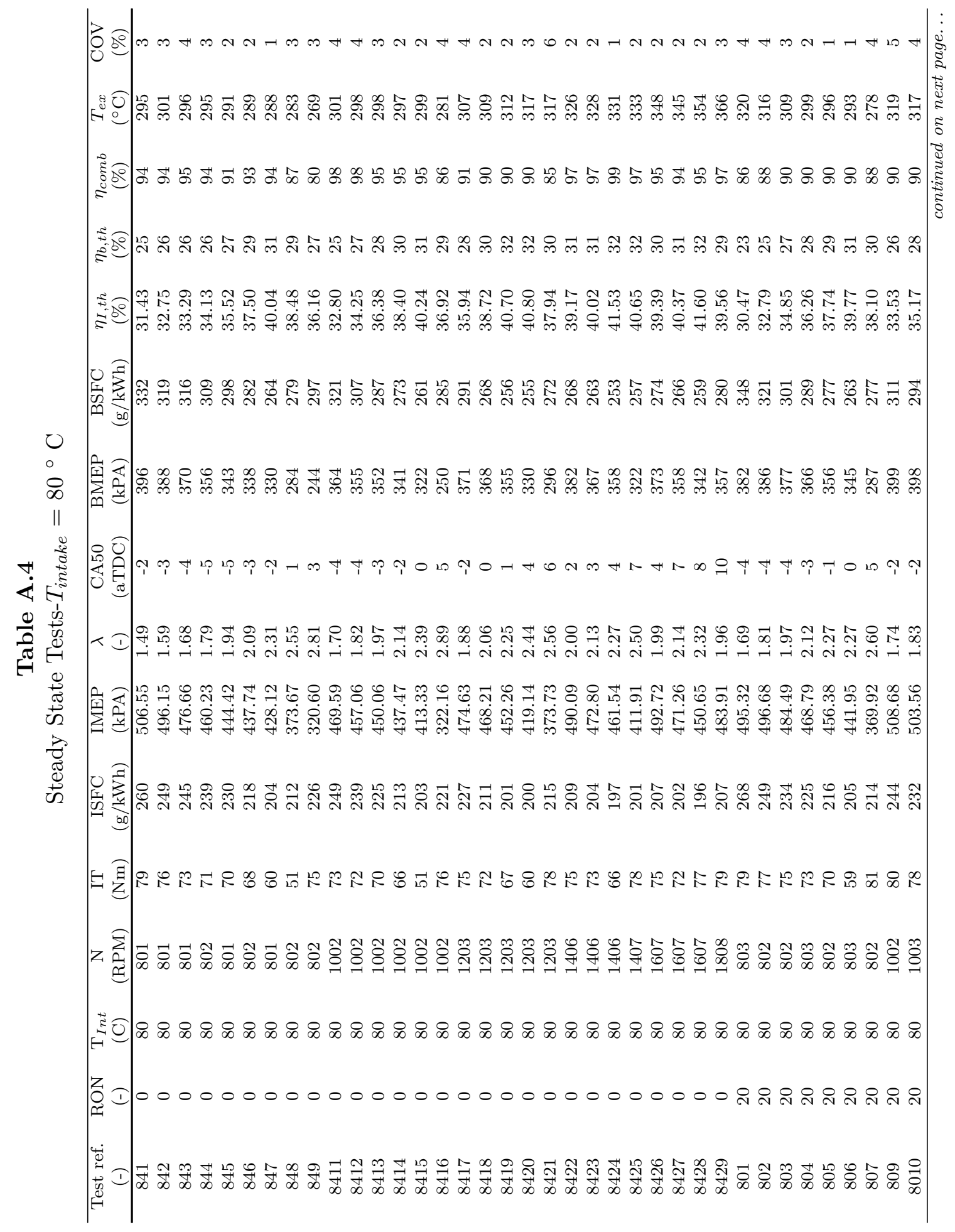




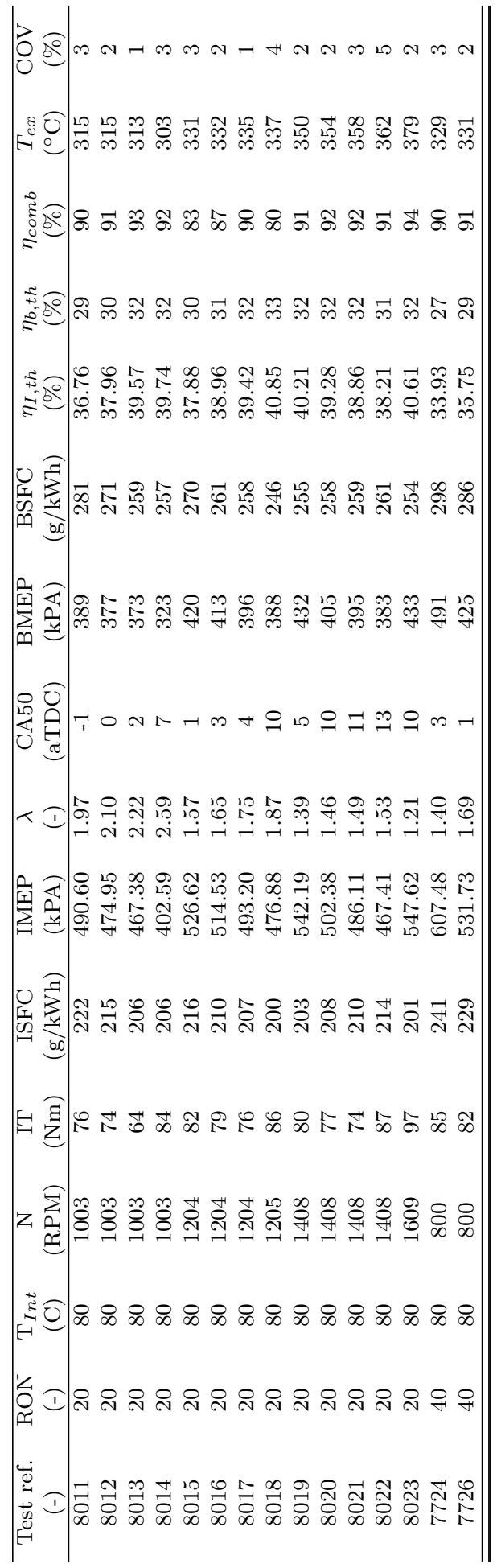




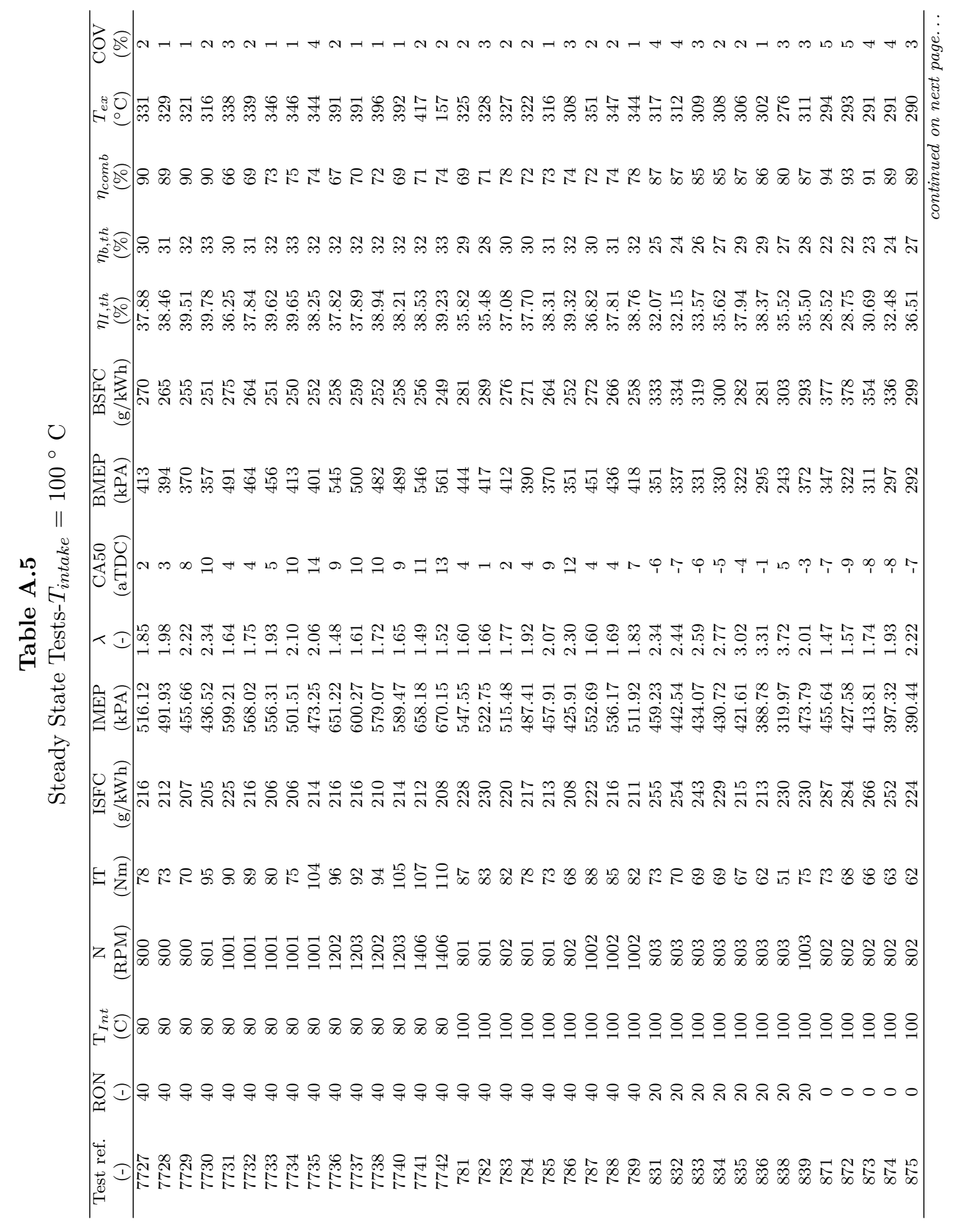




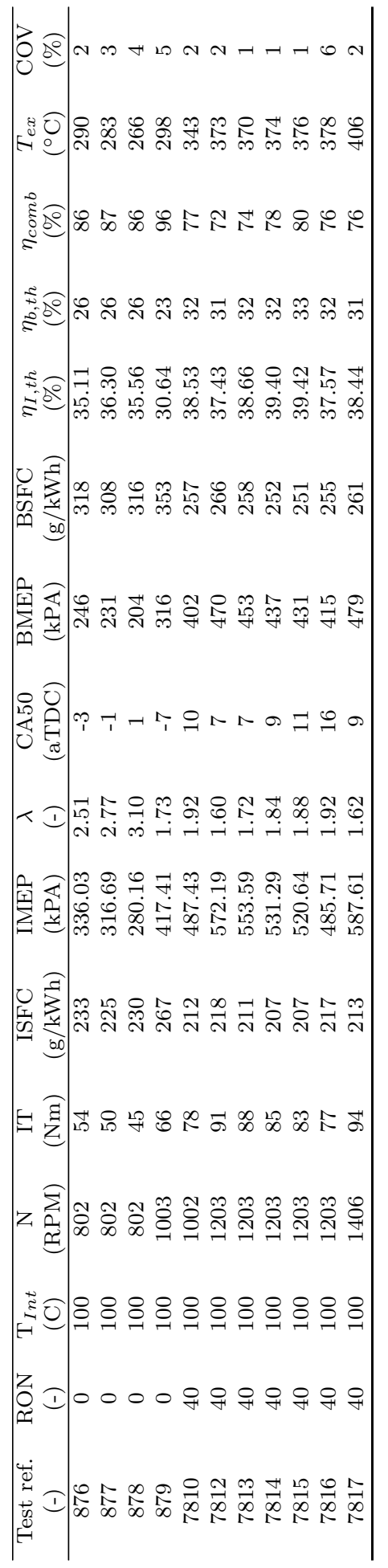


A.2 HCCI 


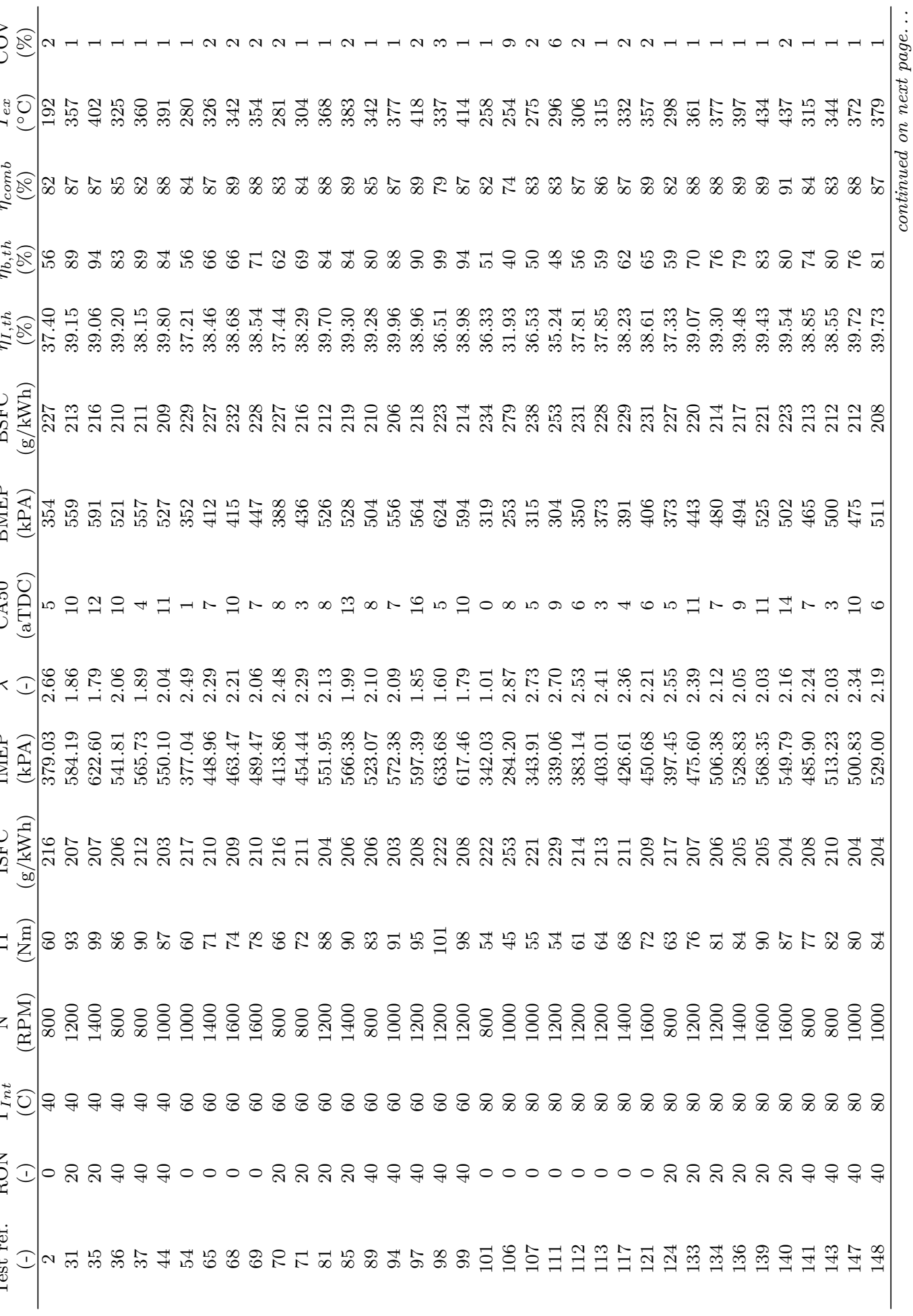




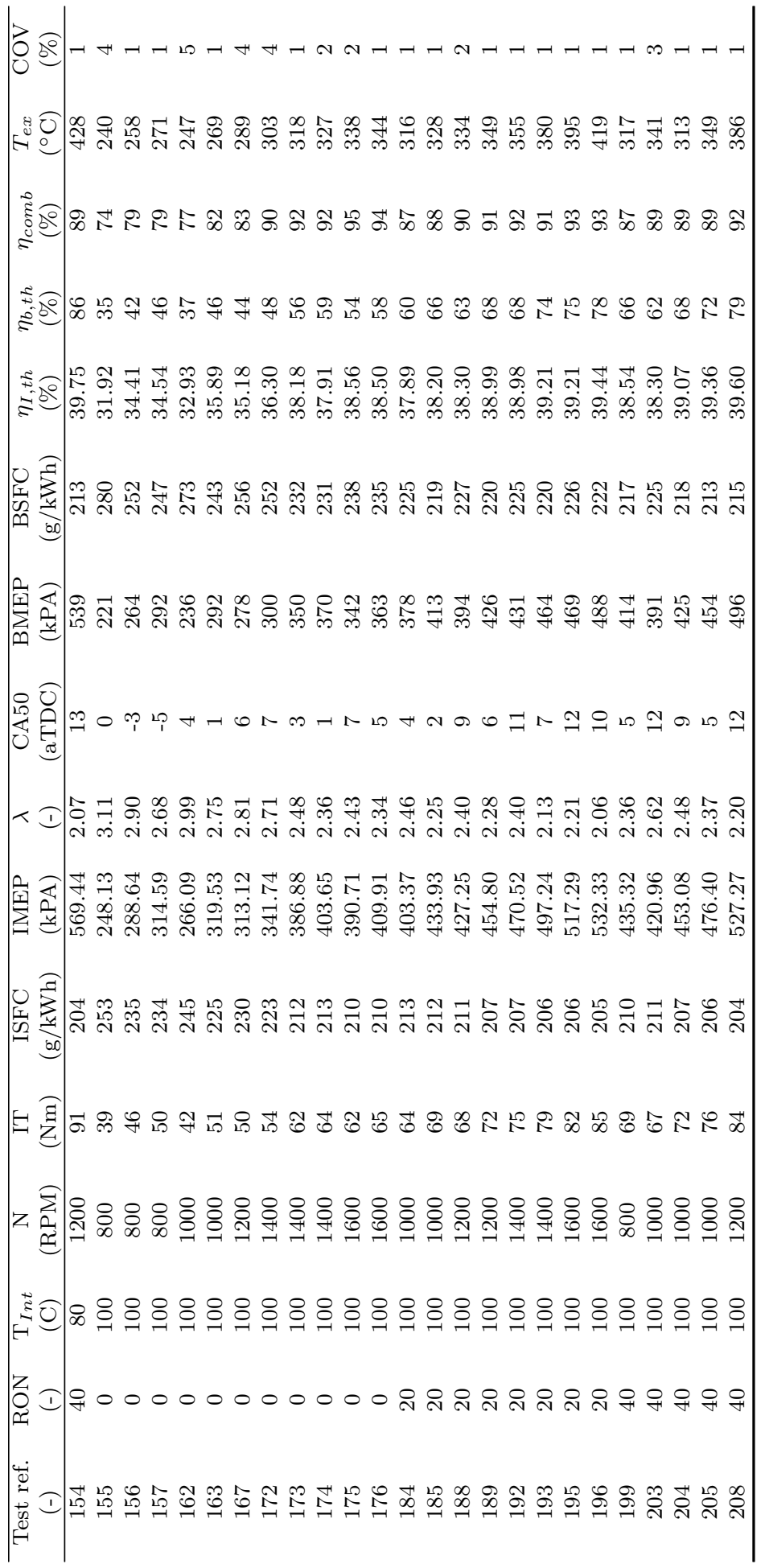




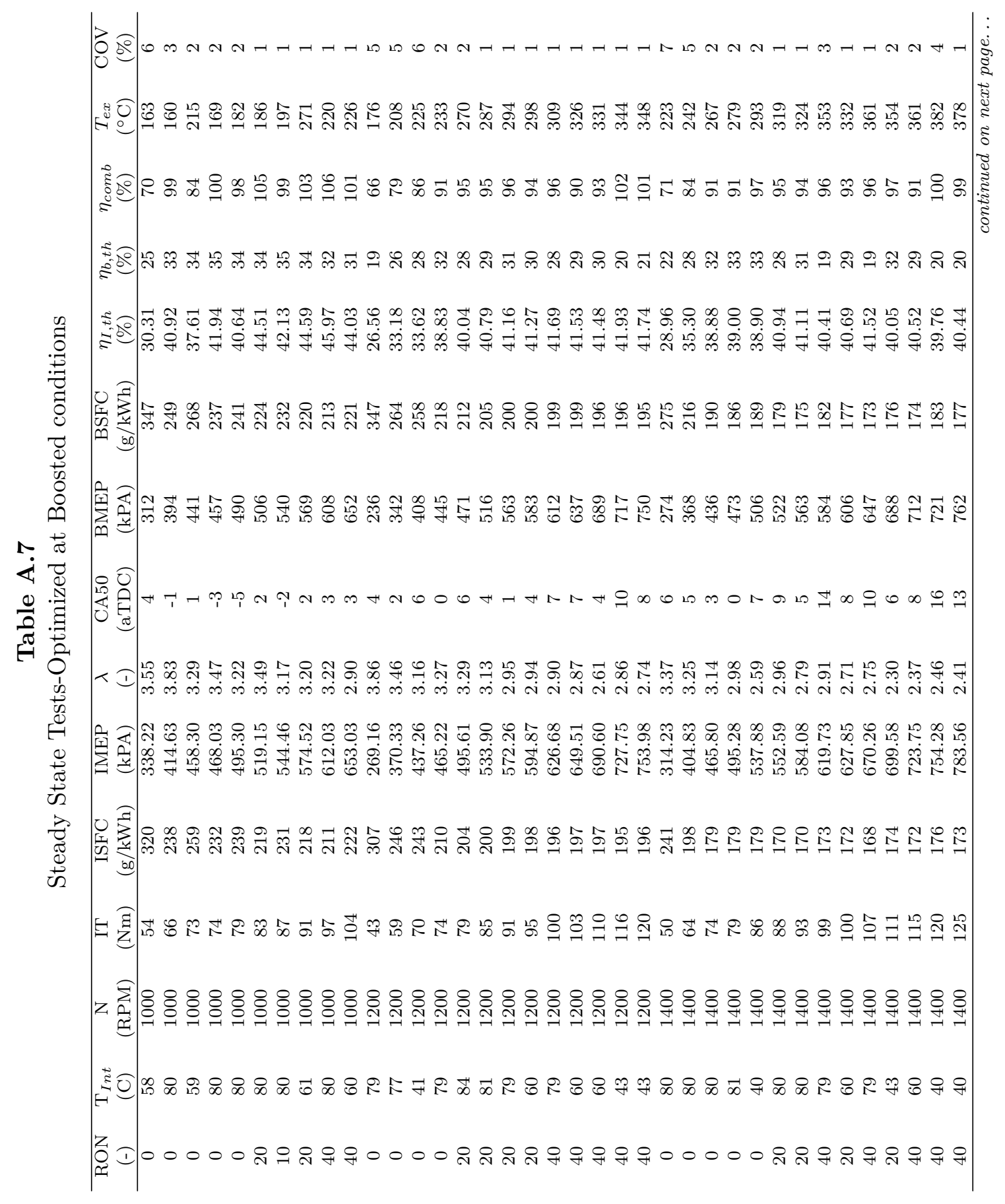




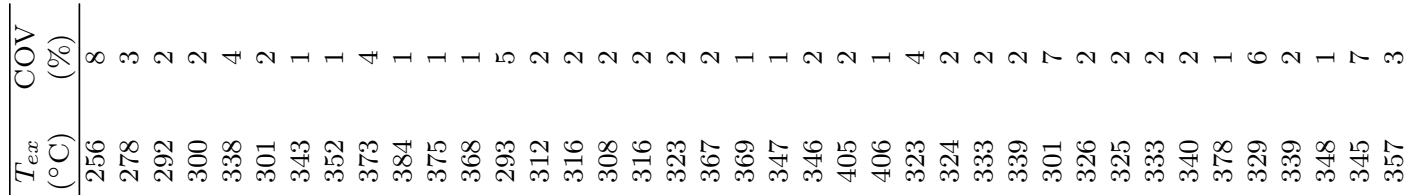

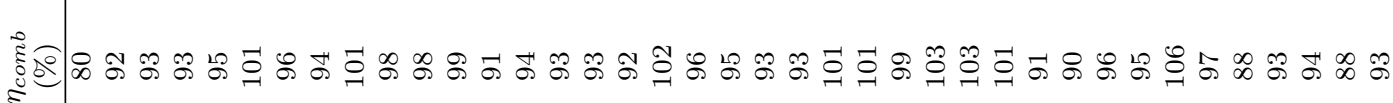

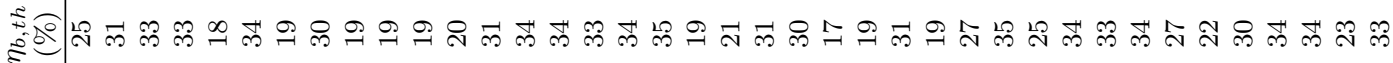

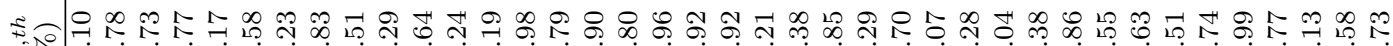

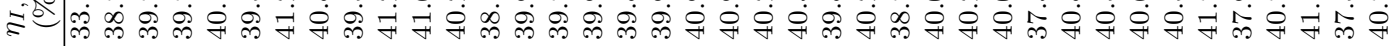

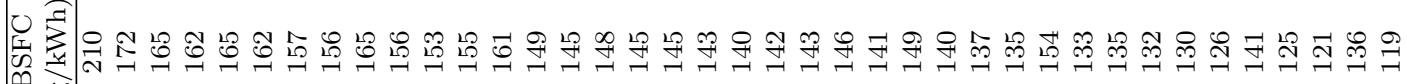

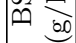

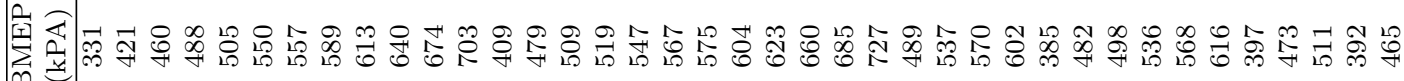

选贯

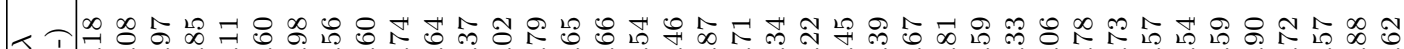
m

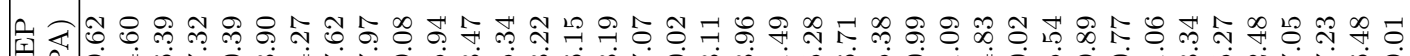

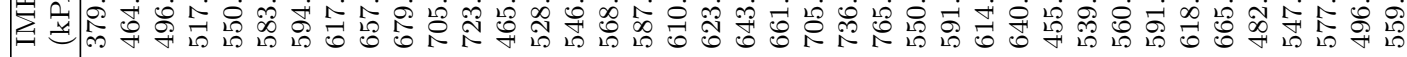

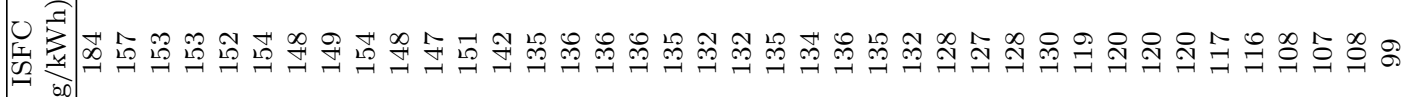

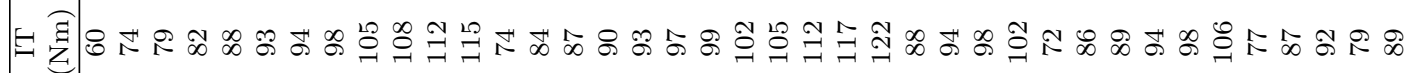

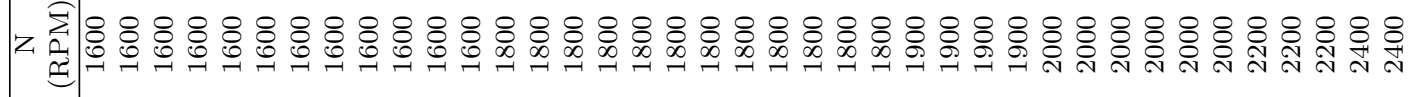

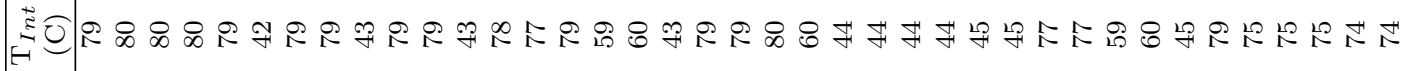
| 
A.3 RCCI 


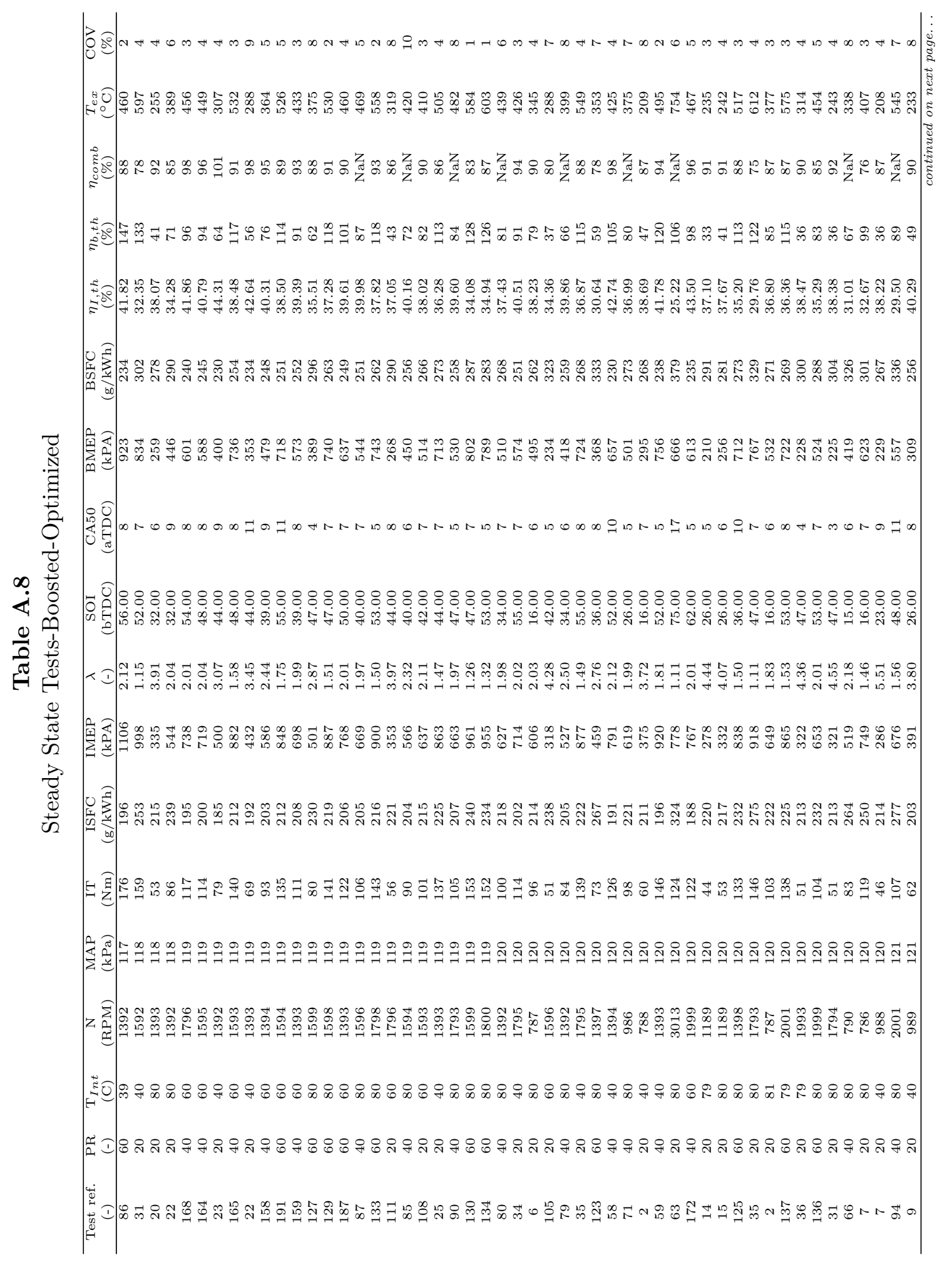




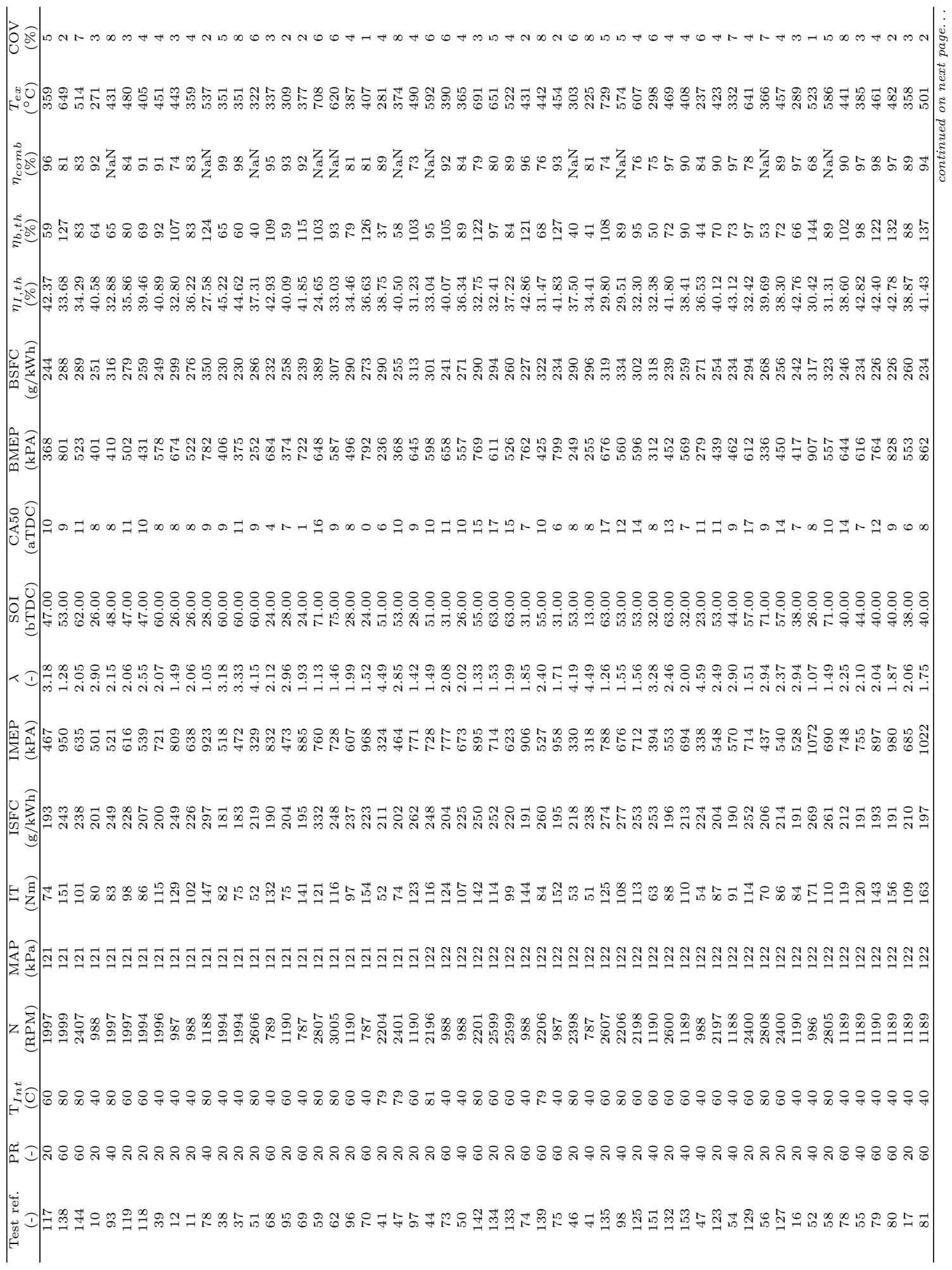




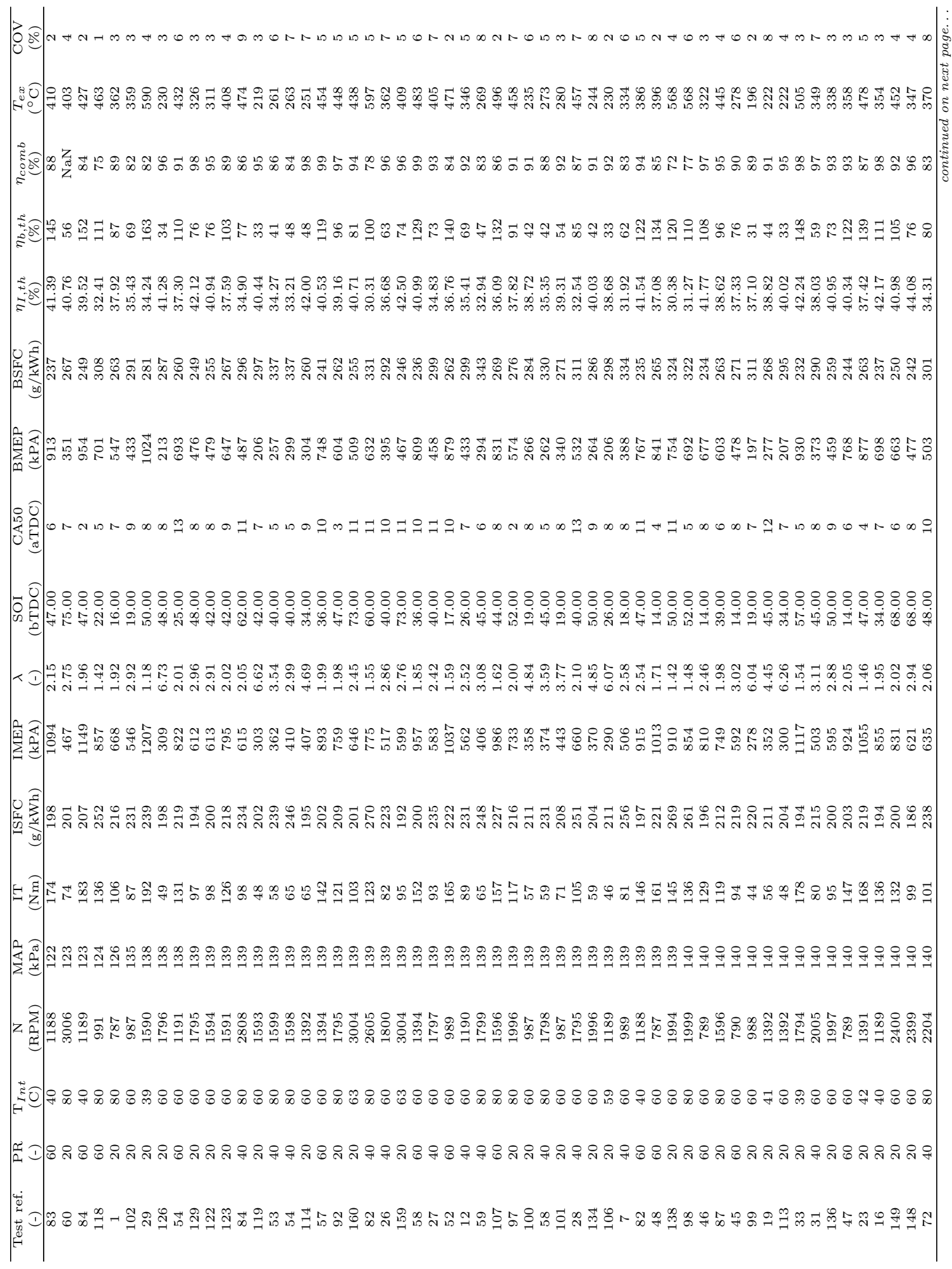




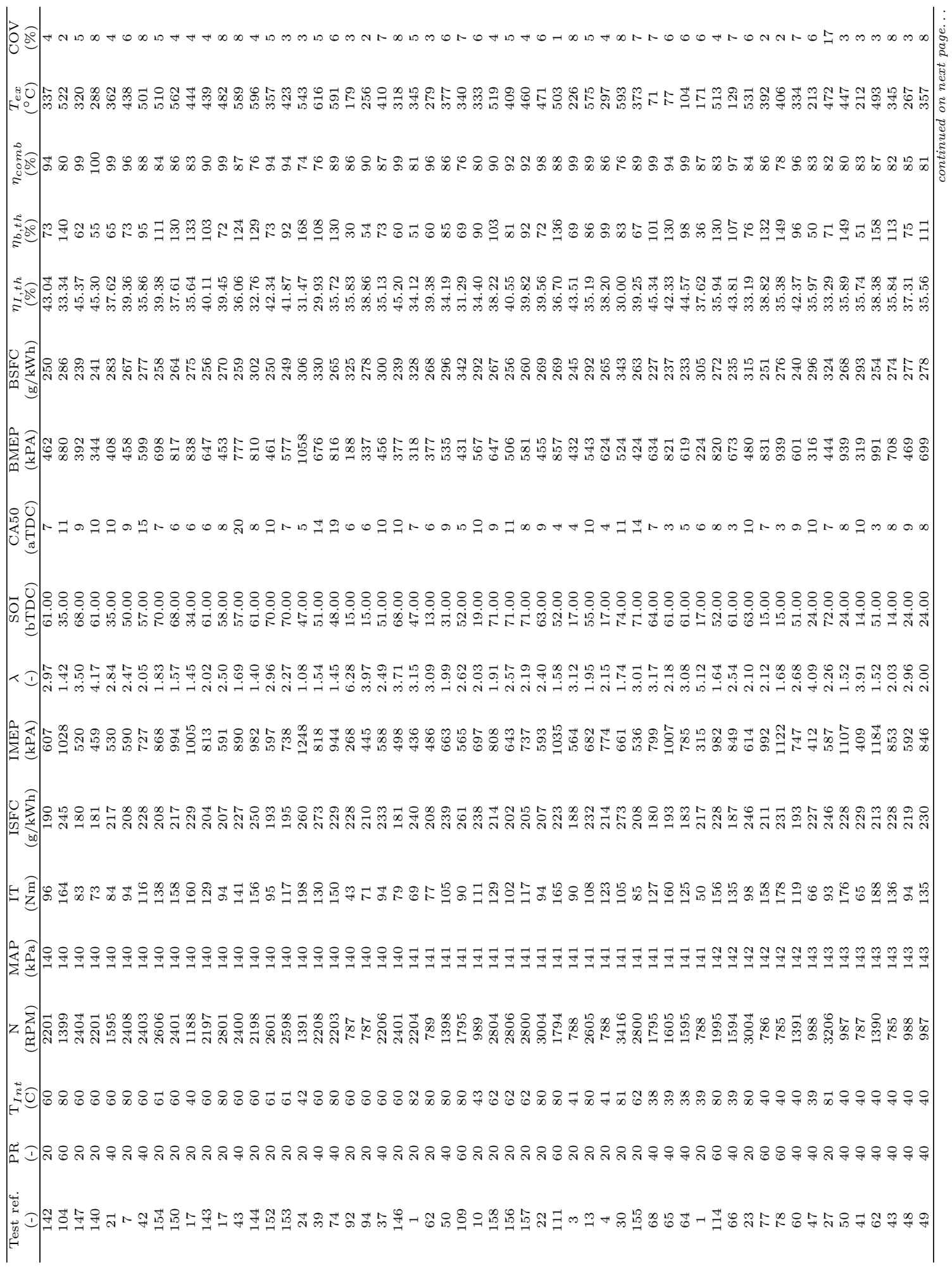




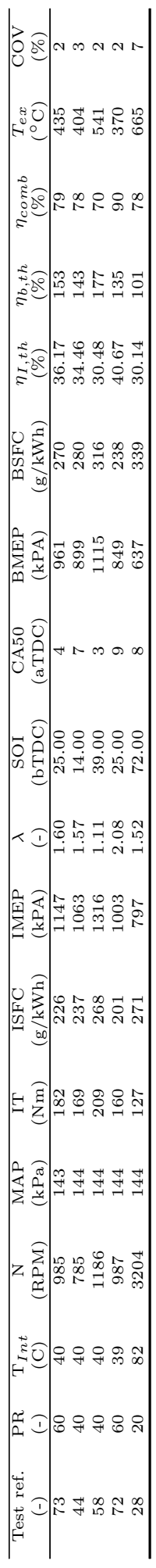




\section{Appendix B}

\section{MSc Publications}

\section{B.1 Conference Papers}

$\dagger$ A. Solouk, M. Shakiba, K. Kannan, H. Solmaz, M. Bidarvatan, N. T. Kondipati, P. Dice, M. Shahbakhti, "Fuel Economy Benefits of Integrating a MultiMode Low Temperature Combustion (LTC) Engine in a Series Extended Range Electric Powertrain", SAE 2016 International Powertrains, Fuels and Lubricants Meeting, Baltimore, Maryland, USA, Paper No. 16FFL-0277, 13 pages, 2016. (Accepted for publication in June 2016) 
The following paper was automatically selected by IRCESM 2015 conference for journal publication.

† S. Polat, K. Kannan, M. Shahbakhti, A. Uyumaz, "An experimental study for the effects of supercharging on performance and combustion of an early direct injection HCCI engine", International Journal of Advanced Research in Engineering Vol 1 (1) Apr-Jun 2015.

\section{B.2 Journal Paper}

$\dagger$ B. Bahri , M. Shahbakhti, K. Kannan, A. A. Aziz, "Identification of Ringing operation for Low Temperature Combustion engine", Applied Energy, 171:142$152,2016$. 


\section{Appendix $\mathrm{C}$}

\section{Program and Data File Summary}

The following lists describe the data files and the post processing code that is used for experiments used for this thesis.

Table C.1

Experimental data files

\begin{tabular}{|l|l|}
\hline File Name & File Description \\
\hline \hline HCCI_NA.mat & $\begin{array}{l}340 \text { data points for HCCI naturally aspirated tests for } \\
\text { all intake temperatures, RON and engine speed }\end{array}$ \\
\hline HCCI_boosted.mat & $\begin{array}{l}435 \text { data points for HCCI boosted tests for all intake } \\
\text { temperatures, RON and engine speed }\end{array}$ \\
\hline PPCI_NA.mat & $\begin{array}{l}387 \text { data points for PPCI Naturally aspirated tests for } \\
\text { all intake temperatures, RON and engine speed }\end{array}$ \\
\hline RCCI_NA.mat & $\begin{array}{l}453 \text { data points for RCCI Naturally aspirated tests for } \\
\text { all intake temperatures, RON and engine speed }\end{array}$ \\
\hline RCCI_boosted.mat & $\begin{array}{l}453 \text { data points for RCCI boosted tests for all intake } \\
\text { temperatures, RON and engine speed }\end{array}$ \\
\hline
\end{tabular}


Table C.2

Experimental data files organized in excel

\begin{tabular}{|l|l|}
\hline File Name & File Description \\
\hline \hline $\begin{array}{l}\text { Combined data for HCCI natu- } \\
\text { rally aspirated.xlsx }\end{array}$ & $\begin{array}{l}\text { Data points for HCCI naturally aspirated } \\
\text { tests for all intake temperatures, RON and } \\
\text { engine speed }\end{array}$ \\
\hline $\begin{array}{l}\text { HCCI_boosted_optimized } \\
\text { sheet.xlsx }\end{array}$ & $\begin{array}{l}\text { Data points for HCCI boosted tests for all } \\
\text { intake temperatures, RON and engine speed }\end{array}$ \\
\hline Test_Summary_PPCI.xlsx & $\begin{array}{l}\text { Data points for PPCI Naturally aspirated } \\
\text { tests for all intake temperatures, RON and } \\
\text { engine speed }\end{array}$ \\
\hline $\begin{array}{l}\text { LTC Engine-PCCI Mode-All Ex- } \\
\text { periments.xlsx }\end{array}$ & $\begin{array}{l}\text { Test number and operating conditions for all } \\
\text { PPCI tests summarized }\end{array}$ \\
\hline RCCI_NA_Optimized_All.xlsx & $\begin{array}{l}\text { Data points for RCCI Naturally aspirated } \\
\text { tests for all intake temperatures, RON and } \\
\text { engine speed }\end{array}$ \\
\hline $\begin{array}{l}\text { RCCI boosted_all tests with } \\
\text { BSFC paramterized.xlsx }\end{array}$ & $\begin{array}{l}\text { Data points for RCCI boosted tests for all } \\
\text { intake temperatures, RON and engine speed }\end{array}$ \\
\hline RCCI data points effect.xlsx & $\begin{array}{l}\text { Data points for the parametric study on } \\
\text { RCCI combustion }\end{array}$ \\
\hline HCCI data points effect.xlsx & $\begin{array}{l}\text { Data points for the parametric study on } \\
\text { HCCI combustion }\end{array}$ \\
\hline
\end{tabular}

Table C.3

Origin Project files

\begin{tabular}{|l|l|}
\hline File Name & File Description \\
\hline \hline HCCI all tests_1-27- & $\begin{array}{l}\text { All plots and data for all HCCI tests (natu- } \\
\text { rally aspirated+Boosted) }\end{array}$ \\
\hline LTC PPCI maps.opj & All plots and data for PPCI tests \\
\hline RCCI_NA_COV10.opj & $\begin{array}{l}\text { All plots and data for all RCCI tests (natu- } \\
\text { rally aspirated+Boosted) }\end{array}$ \\
\hline
\end{tabular}


Table C.4

DSPACE Raw Data for all experiments

\begin{tabular}{|l|l|}
\hline Folder Name & File Description \\
\hline \hline dspace_exp5 & $\begin{array}{l}\text { 335 Data files for HCCI steady state tests (natu- } \\
\text { rally aspirated) }\end{array}$ \\
\hline dspace_exp7 & 213 Data files for HCCI tests (naturally aspirated) \\
\hline dspace_exp9 & 229 Data files for HCCI tests (Boosted) \\
\hline dspace_exp10 & 107 Data files for HCCI tests (Boosted) \\
\hline dspace_exp14 & 39 Data files for HCCI tests (Boosted) \\
\hline dspace_exp19 & 184 Data files for RCCI tests (naturally aspirated) \\
\hline dspace_exp21 & 191 Data files for RCCI tests (Boosted) \\
\hline dspace_exp21 & 191 Data files for RCCI tests (Boosted) \\
\hline dspace_exp22 & 160 Data files for RCCI tests (Boosted) \\
\hline dspace_exp23 & 144 Data files for RCCI tests (Boosted) \\
\hline dspace_exp24 & 99 Data files for RCCI tests (Boosted) \\
\hline dspace_exp25 & 114 Data files for HCCI tests (Boosted) \\
\hline $\begin{array}{l}\text { PPCI_All_DSPACE } \\
\text { files (77-test dspace to }\end{array}$ & 625 Data files for PPCI tests (naturally aspirated) \\
106-test dspace) & \\
\hline
\end{tabular}


Table C.5

Labview Raw Data for all experiments

\begin{tabular}{|l|l|}
\hline Folder Name & File Description \\
\hline \hline labview_exp5 & $\begin{array}{l}\text { 335 Data files for HCCI steady state tests (natu- } \\
\text { rally aspirated) }\end{array}$ \\
\hline labview_exp7 & 213 Data files for HCCI tests (naturally aspirated) \\
\hline labview_exp9 & 229 Data files for HCCI tests (Boosted) \\
\hline labview_exp10 & 107 Data files for HCCI tests (Boosted) \\
\hline labview_exp14 & 39 Data files for HCCI tests (Boosted) \\
\hline labview_exp19 & 184 Data files for RCCI tests (naturally aspirated) \\
\hline labview_exp21 & 191 Data files for RCCI tests (Boosted) \\
\hline labview_exp21 & 191 Data files for RCCI tests (Boosted) \\
\hline labview_exp22 & 160 Data files for RCCI tests (Boosted) \\
\hline labview_exp23 & 144 Data files for RCCI tests (Boosted) \\
\hline labview_exp24 & 99 Data files for RCCI tests (Boosted) \\
\hline labview_exp25 & 114 Data files for HCCI tests (Boosted) \\
\hline $\begin{array}{l}\text { PPCI_All_labview files } \\
\text { (77-test labview to } \\
\text { 106-test labview) }\end{array}$ & D25 Data files for PPCI tests (naturally aspirated) \\
\hline
\end{tabular}


Table C.6

ACAP Raw Data for all experiments

\begin{tabular}{|l|l|}
\hline Folder Name & File Description \\
\hline \hline ACAP_exp5 & $\begin{array}{l}\text { 335 Data files for HCCI steady state tests (natu- } \\
\text { rally aspirated) }\end{array}$ \\
\hline ACAP_exp7 & 213 Data files for HCCI tests (naturally aspirated) \\
\hline ACAP_exp9 & 229 Data files for HCCI tests (Boosted) \\
\hline ACAP_exp10 & 107 Data files for HCCI tests (Boosted) \\
\hline ACAP_exp14 & 39 Data files for HCCI tests (Boosted) \\
\hline ACAP_exp19 & 184 Data files for RCCI tests (naturally aspirated) \\
\hline ACAP_exp21 & 191 Data files for RCCI tests (Boosted) \\
\hline ACAP_exp21 & 191 Data files for RCCI tests (Boosted) \\
\hline ACAP_exp22 & 160 Data files for RCCI tests (Boosted) \\
\hline ACAP_exp23 & 144 Data files for RCCI tests (Boosted) \\
\hline ACAP_exp24 & 99 Data files for RCCI tests (Boosted) \\
\hline ACAP_exp25 & 114 Data files for HCCI tests (Boosted) \\
\hline $\begin{array}{l}\text { PPCI_All_ACAP files } \\
\text { (77-test ACAP to 106- } \\
\text { test ACAP) }\end{array}$ & \\
\hline
\end{tabular}


Table C.7

Matlab Scripts for post processing the data

\begin{tabular}{|l|l|}
\hline File Name & File Description \\
\hline Engine_data_analysis_steadystate.m & Updated post pro- \\
& cessing script used \\
& for data analysis for \\
& all three combustion \\
& regimes \\
\hline
\end{tabular}


Table C.8

Figure files included in this thesis

\begin{tabular}{|c|c|}
\hline File Name & File Descrip \\
\hline LTC.png & Figure 1.1 \\
\hline Fig1.png & Figure 1.2 \\
\hline ThesisOrganization.png & Figure 1.3 \\
\hline ExperimentalTestSetup_12-9-2015.png & Figure 2.1 \\
\hline experimental_setup.png & Figure 2.2 \\
\hline portfuelinjectorassembly.png & Figure 2.3 \\
\hline TriggeredSubsystem_PFI_control.png & Figure 2.4 \\
\hline Monitoring_panel_PFi_dspace.png & Figure 2.5 \\
\hline verification_DI_injectors.png & Figure 2.6 \\
\hline calibration_PFI_IsoOctane.png & Figure 2.7 \\
\hline Verification_PFI_IsoOctane.png & Figure 2.7 \\
\hline calibration_PFI_nHeptane.png & Figure 2.8 \\
\hline Verification_PFI_nHeptane.png & Figure 2.8 \\
\hline supercharger_Test_VFD_schematic.png & Figure 2.9 \\
\hline supercharger_frequencyMap24-5IVO.png & \begin{tabular}{l|l|} 
Figure & 2.10
\end{tabular} \\
\hline supercharger_frequencyMap25-5IVO.png & Figure 2.10 \\
\hline simulinkModel_superchargerControl.png & Figure 2.11 \\
\hline SusperchargerControlPanel_controlDesk.png & Figure 2.12 \\
\hline FMEP_parameterized.png & Figure 3.1 \\
\hline OperatingRegion_40_NA.png & Figure 3.2 \\
\hline OperatingRegion_100_NA.png & Figure 3.2 \\
\hline OperatingRegion_40_boosted120.png & Figure 3.3 \\
\hline ISFC_40deg_NA.png & Figure 3.4 \\
\hline ISFC_40deg_boost120.png & Figure 3.5 \\
\hline BSFC_40deg_NA.png & Figure 3.6 \\
\hline BSFC_40deg_boost120.png & Figure 3.7 \\
\hline ITE_40deg_NA.png & Figure 3.8 \\
\hline ITE_40deg_boost120.png & Figure 3.9 \\
\hline Texh_40deg_NA.png & Figure 3.10 \\
\hline Texh_40deg_boost120.png & Figure 3.11 \\
\hline $\begin{array}{l}\text { IMEP-IT-Speed-ISFCcombinedforalltemparaturesand } \\
\text { fuels HCCI.png }\end{array}$ & Figure 3.12 \\
\hline CombinedISFCmap.png & Figure 3.13 \\
\hline CombinedBSFCmap_HCCI.png & Figure 3.14 \\
\hline CombinedBSFCmap.png & Figure 3.15 \\
\hline $\begin{array}{l}\text { IT-IMEP-Speed-ITEcombinedforalltemparatures and } \\
\text { fuels.png }\end{array}$ & Figure 3.16 \\
\hline
\end{tabular}


Table C.9

Figure files included in this thesis (Contd.)

\begin{tabular}{|c|c|}
\hline File Name & File Descript \\
\hline combinedITEmap.png & Figure 3.17 \\
\hline Combinedexhaustmap.png & Figure 3.18 \\
\hline Combinedexhausttempmap.png & Figure 3.19 \\
\hline ROneffect_combustion.png & Figure 3.20 \\
\hline RON_IMEP_TEF_CEF.png & Figure 3.21 \\
\hline tempeffect_IMEP_CEF_TEF.png & Figure 3.22 \\
\hline tempeffect_combustion.png & Figure 3.23 \\
\hline Boostpressureeffect_Pressure_heatrelease.png & Figure 3.24 \\
\hline Boostpressureeffect_Combustiongraphs.png & Figure 3.25 \\
\hline Boostpressureeffect_IMEP_TEF_CEF.png & Figure 3.26 \\
\hline Experimental FMEP vs Parameterized FMEP.png & Figure 4.1 \\
\hline P140T40.png & Figure 4.2 \\
\hline P140T60.png & Figure 4.3 \\
\hline mergeP140T40_ISFC.png & Figure 4.4 \\
\hline MergeP140T40_BSFC.png & Figure 4.5 \\
\hline MergeP140T40_indeffciency.png & Figure 4.6 \\
\hline MergeP140T40_Exhausttemp.png & Figure 4.7 \\
\hline ISFC_NA_RCCI.png & Figure 4.8 \\
\hline ISFC.png & Figure 4.9 \\
\hline BSFC_COV10_NA_RCCI.png & Figure 4.10 \\
\hline BSFC.png & Figure 4.11 \\
\hline ITE_NA_RCCI.png & Figure 4.12 \\
\hline ITE.png & Figure 4.13 \\
\hline Exhausttemp_NA_RCCI.png & Figure 4.14 \\
\hline Exhausttemp.png & Figure 4.15 \\
\hline ISFC_superchargerLossesaccounted.png & Figure 4.16 \\
\hline ITE_superchargerLossesaccounted.png & Figure 4.17 \\
\hline rcciRONeffect_pressuretrace_constantfuelenergy.png & Figure 4.22 \\
\hline Graph94.png & Figure 4.23 \\
\hline RONeffect_combustion_constantfuelenergy1.png & Figure 4.24 \\
\hline RONeffect_indicated_constantfuelenergy.png & Figure 4.25 \\
\hline rccitempEffect_pressuretrace.png & Figure 4.26 \\
\hline rccitempeffect_combustion.png & Figure 4.27 \\
\hline rccitempeffect_performance.png & Figure 4.28 \\
\hline boost_pressure_pressuretrace.png & Figure 4.29 \\
\hline rcciboost_pressure_combustionGraphs.png & Figure 4.30 \\
\hline rcciboost_pressure_performace.png & Figure 4.31 \\
\hline
\end{tabular}


Table C.10

Figure files included in this thesis (Contd.)

\begin{tabular}{|c|c|c|}
\hline File Name & File Descrip & ption \\
\hline $\begin{array}{llll}\text { Experimental } & \text { FMEP } & \text { vs } & \text { Parameterized } \\
\text { FMEP.png } & & & \end{array}$ & Figure 5.1 & \\
\hline T40_PPCI.png & Figure 5.2 & \\
\hline T80_EPS.png & Figure 5.3 & \\
\hline MergeISFCT40.png & Figure 5.4 & \\
\hline MergeBSFCT40.png & Figure 5.5 & \\
\hline MergeITET40.png & Figure 5.6 & \\
\hline MergeexhausttempT40.png & Figure 5.7 & \\
\hline ISFCoptimized.png & Figure 5.8 & \\
\hline BSFCoptimized.png & Figure 5.9 & \\
\hline ITEoptimized.png & Figure 5.10 & \\
\hline Texhaustoptimized.png & Figure 5.11 & \\
\hline pressuretrace.png & Figure 5.12 & \\
\hline heatresleaserate.png & Figure 5.13 & \\
\hline MEP_temperatureeffect.png & Figure 5.14 & \\
\hline ITE_temperatureeffect.png & Figure 5.15 & \\
\hline combustionGraphs_temperatureeffect.png & Figure 5.16 & \\
\hline IMEP_superchargereffect.png & Figure 5.17 & \\
\hline 4-In-cylinder_pressure.png & Figure 5.18 & \\
\hline 5-heatreleaserate.png & Figure 5.19 & \\
\hline thermaleff_superchargereffecr.png & Figure 5.20 & \\
\hline CA50_superchargereffect.png & Figure 5.21 & \\
\hline 1-pressure.png & Figure 5.22 & \\
\hline 2-heatrelease.png & Figure 5.23 & \\
\hline combustionGraphs_injectiontiming.png & Figure 5.24 & \\
\hline
\end{tabular}


Table C.11

Visio Figure files in this thesis

\begin{tabular}{|l|l|l|}
\hline File Name & File Description \\
\hline \hline ThesisOrganization.vsx & Figure & 1.3 \\
\hline ExperimentalTestSetup_12-9-2015.vsx & Figure & 2.1 \\
\hline supercharger_Test_VFD_schematic.vsx & Figure & 2.9 \\
\hline
\end{tabular}


Table C.12

Project files for testing and data acquisition

\begin{tabular}{|l|l|}
\hline File Name & File Description \\
\hline \hline Allengine68.slx & $\begin{array}{l}\text { Dspace project file for } \\
\text { the Engine Control } \\
\text { Model }\end{array}$ \\
\hline Reader20.vi & $\begin{array}{l}\text { Labview Visual inter- } \\
\text { face for online moni- } \\
\text { toring and control }\end{array}$ \\
\hline kaushik_configfile_7-16- 2015.nce & $\begin{array}{l}\text { Labview configuration } \\
\text { file for EML team }\end{array}$ \\
\hline
\end{tabular}





\section{Appendix D}

\section{Letters of Permission}

$\dagger$ This permission is for Figure 1.1.

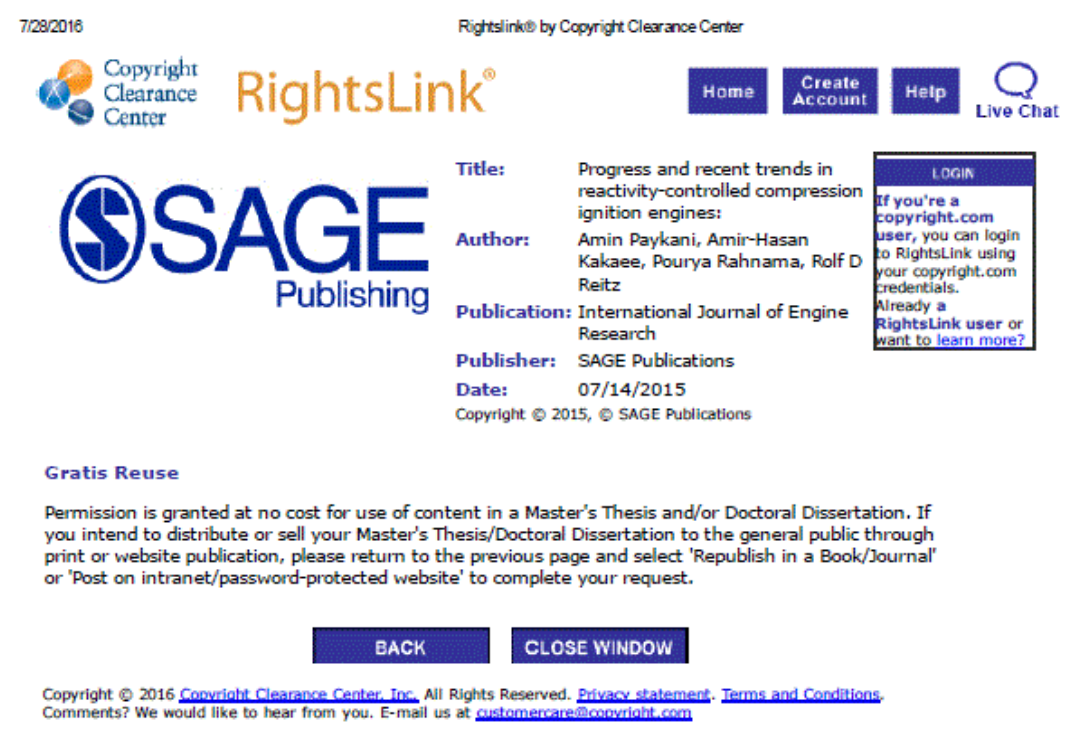

Figure D.1: Copyright permission for the Figure 1.1 
$\dagger$ This permission is for Figure 1.2

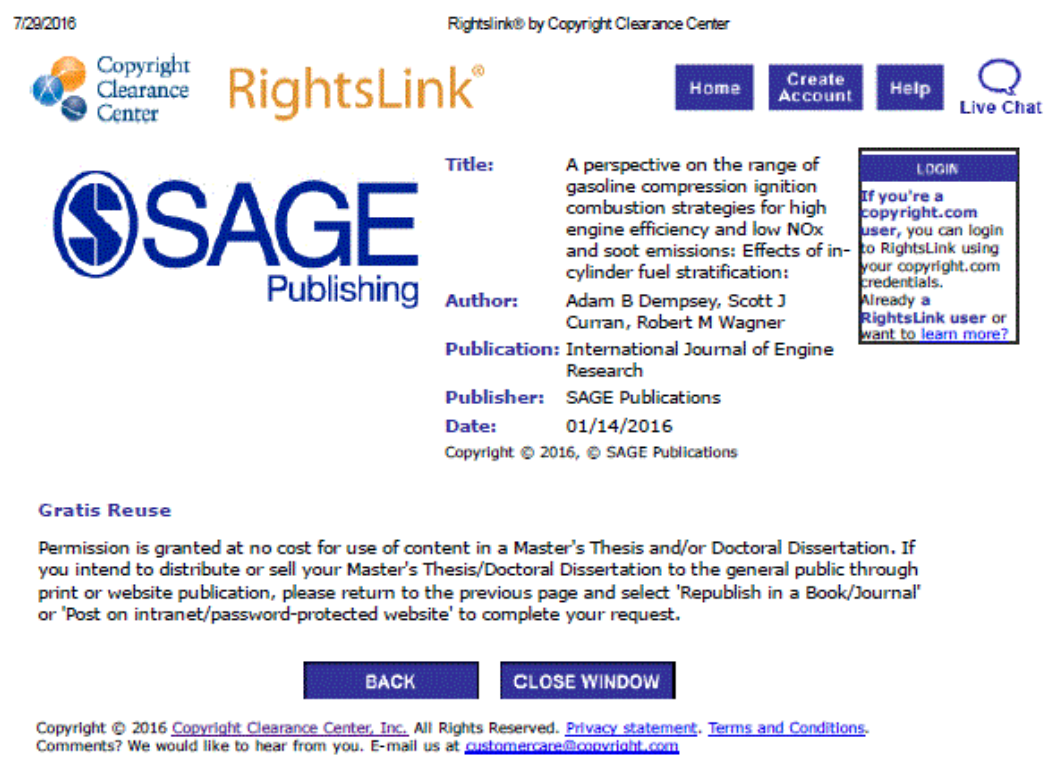

Figure D.2: Copyright permission for the Figure 1.2 